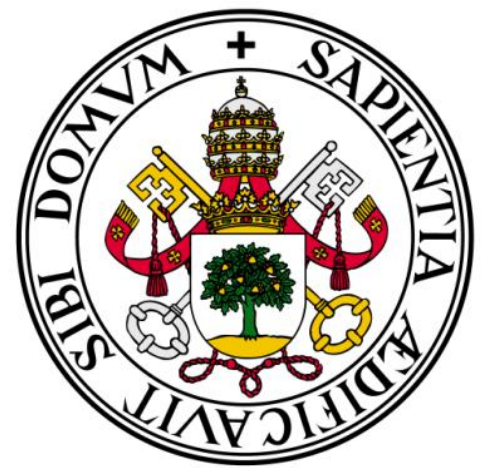

Universidad de Valladolid

Facultad de Medicina

Dpto. de Bioquímica y Biología Molecular y Fisiología

\title{
Estudio lipidómico de la movilización de ácido araquidónico asociada a la respuesta inmune innata
}

TESIS DOCTORAL

Luis Gil de Gómez Sesma

Directores: Jesús Balsinde

Ma Ángeles Balboa 


\section{N D ÍCE G E NERA L}

\section{CONTENIDOS PREVIOS}

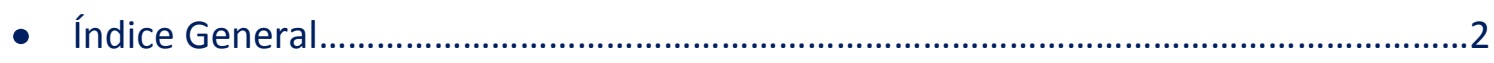

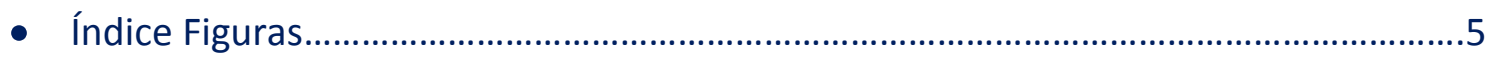

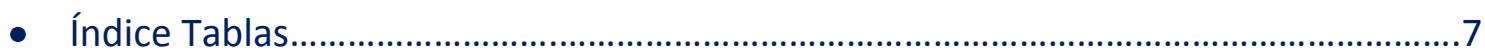

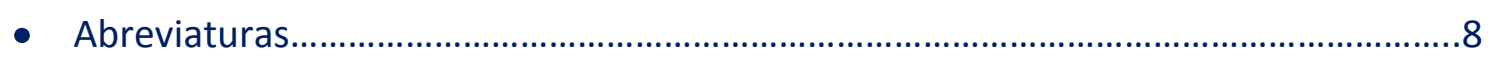

A.- INTRODUCCIÓN......................................................................... 12

A.1El sistema inmune. La respuesta a patógenos ....................................................13

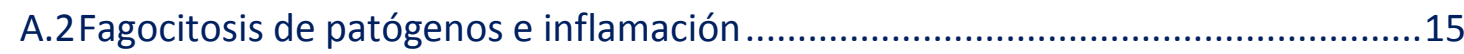

A.2.1 Reconocimiento del zimosán en macrófagos ......................................................... 15

A.2.1.1 Receptores de reconocimiento de patógenos ........................................... 16

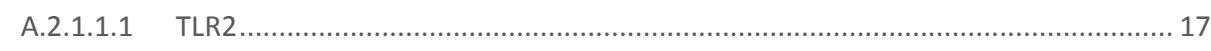

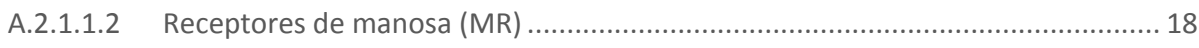

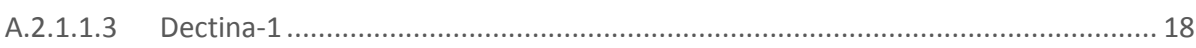

A.2.1.2 Receptores de reconocimiento de no patógenos .......................................... 19

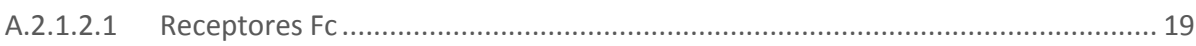

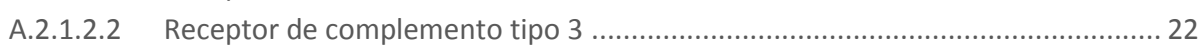

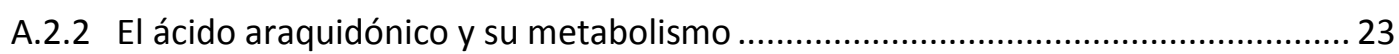

A.2.2.1 Los glicerofosfolípidos, principales depósitos de ácido araquidónico ................ 25

A.2.2.2 Movilización del ácido araquidónico ........................................................... 28

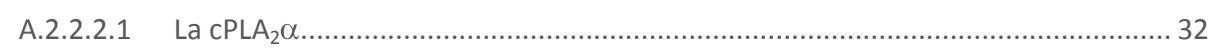

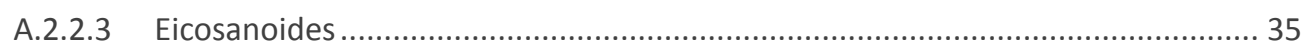

A.3La espectrometría de masas como herramienta de análisis ................................37

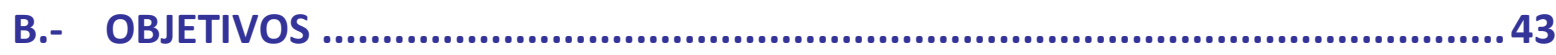

C.- MATERIALES Y MÉTODOS ............................................................ 45

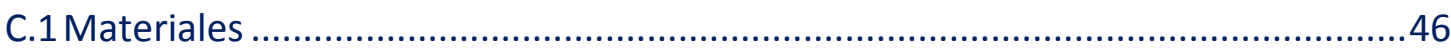

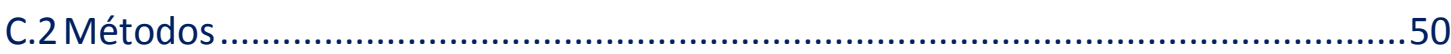

C.2.1 Extracción de macrófagos peritoneales de ratón.................................................50 50

C.2.2 Extracción y aislamiento de células polimorfonucleares de sangre periférica humana 50

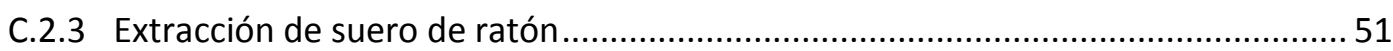

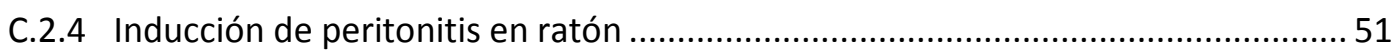

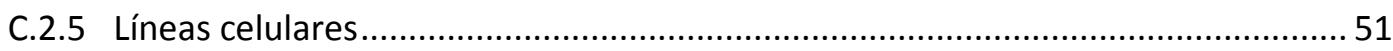

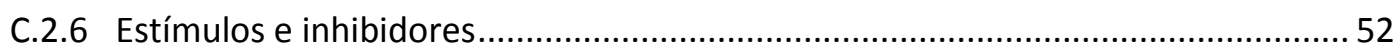

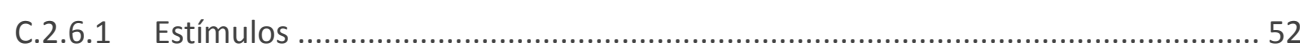

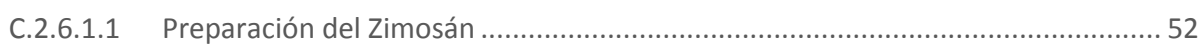

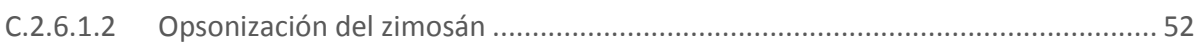

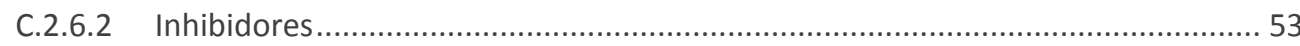

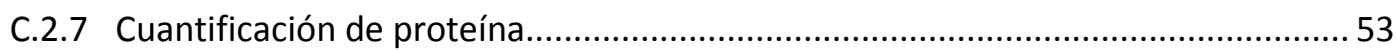


C.2.8 Liberación de AA en condiciones de estimulación .............................................. 53

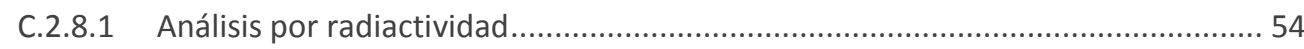

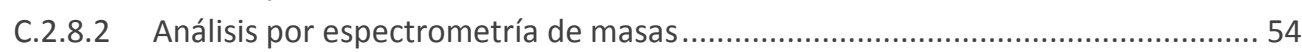

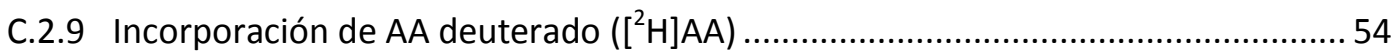

C.2.10 Introducción de las especies 1- $\left[{ }^{2} \mathrm{H}\right]$ araquidonoil-2-araquidonoil-sn-glicero-2fosfatidilinositol y 1-araquidonoil-2-[ $\left[{ }^{2} \mathrm{H}\right]$ araquidonoil-sn-glicero-2-fosfatidilinositol ........ 55

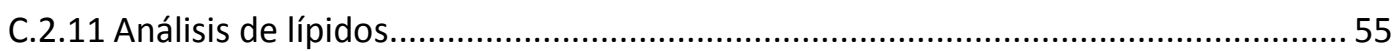

C.2.11.1 Extracción de lípidos.................................................................................... 55

C.2.11.2 Análisis de ácidos grasos mediante cromatografía de gases acoplada a espectrometría de masas (GC/MS) ............................................................................ 56

C.2.11.2.1 Derivatización de ácidos grasos...................................................................... 56

C.2.11.2.2 Análisis de ésteres metílicos............................................................................56

C.2.11.3 Análisis de especies de fosfolípidos mediante cromatografía de líquidos acoplada a espectrometría de masas (HPLC-MS) ......................................................... 57

C.2.11.3.1 Acoplamiento HPLC/ESI/MS ........................................................................ 57

C.2.11.3.2 Análisis de especies moleculares de PC, PE PI y PS............................................ 57

C.2.11.4 Cromatografía de líquidos en fase normal acoplada a ESI-MS en la detección de

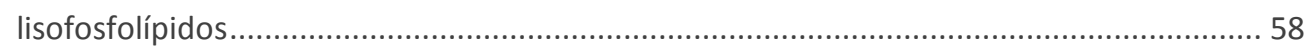

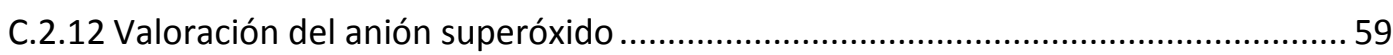

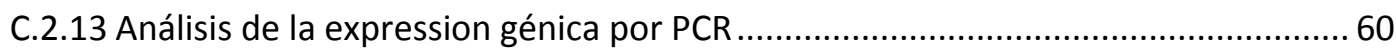

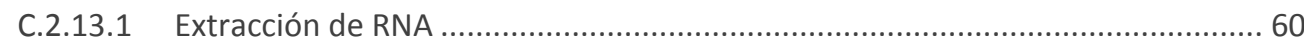

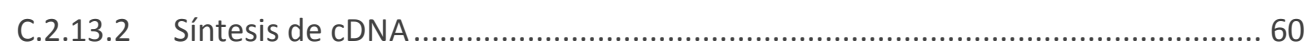

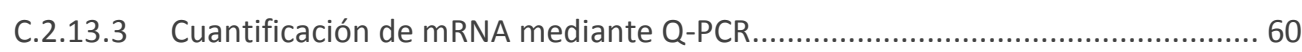

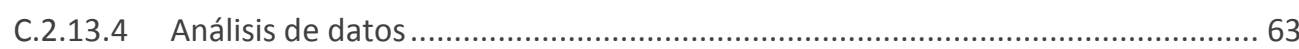

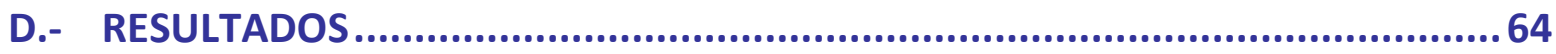

D.1Estimulación de macrófagos peritoneales de ratón mediante zimosán .................65

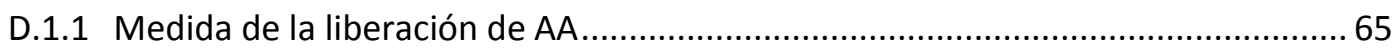

D.1.2 Estudio de las especies de glicerofosfolípidos implicados en la liberación de AA . 66

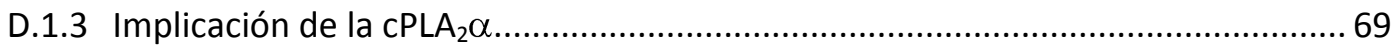

D.2Efecto sinérgico de la estimulación mediante LPS y zimosán ................................76

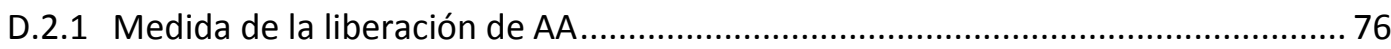

D.2.2 Estudio de las especies de glicerofosfolípidos implicadas en la liberación de AA.. 78

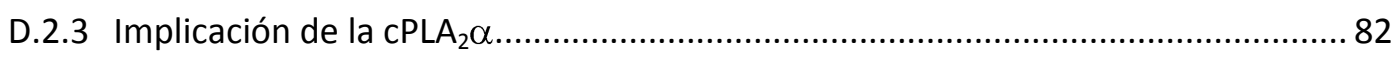

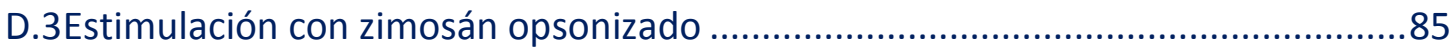

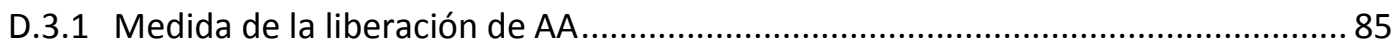

D.3.2 Análisis de las especies de glicerofosfolípidos implicadas en la liberación de AA . 88

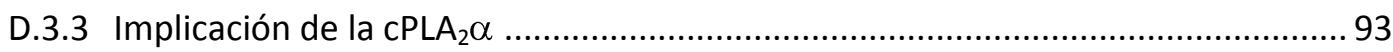

D.41,2-Diaraquidonoil-glicero-sn-3-fosfatidilinositol...........................................100

D.4.1 Factores que regulan la producción de PI(20:4/20:4) ...................................... 101

D.4.2 Formación de $\mathrm{PI}(20: 4 / 20: 4)$ durante la peritonitis en ratón ................................. 102

D.4.3 PI $\left(\left[{ }^{2} \mathrm{H}\right] \mathrm{AA} /\left[{ }^{2} \mathrm{H}\right] \mathrm{AA}\right)$ como aceptor de AA exógeno en especies de $\mathrm{PI}$.................... 103

D.4.4 Introducción del PI(20:4/20:4) en las células y su seguimiento ............................ 105

D.4.4.1 Relación de $\mathrm{PI}(20: 4 / 20: 4)$ con la expresión de diferentes genes implicados en

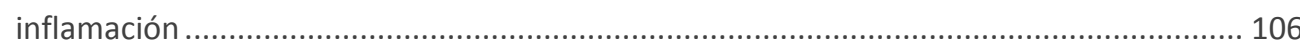

D.4.4.2 Relación del PI(20:4/20:4) con el aumento de los niveles de $\mathrm{O}_{2}{ }^{-}$celular ........... 108 


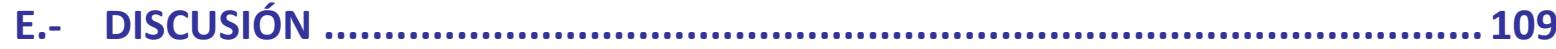

E.1 Efecto sinérgico de la estimulación por LPS y zimosán en la liberación de AA ....110

E.2 Liberación de AA desde las especies plasmalógenas de PE por la estimulación de zimosán opsonizado

E.3 El PI(20:4/20:4) en la respuesta inmune innata ..................................................115

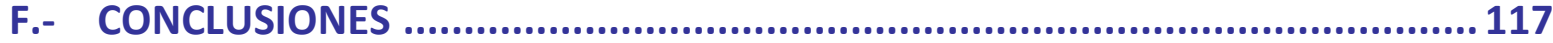

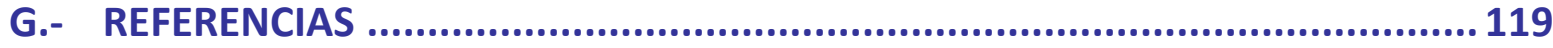




\section{N D ÍCE FI G URAS}

Figura 1. Esquema del sistema fagocítico mononuclear........................................................................ 14

Figura 2 Receptores implicados en el reconocimiento del zimosán y el zimosán opsonizado........................ 23

Figura 3 Comparativa de diferentes ácidos grasos con su respectiva nomenclatura...................................... 24

Figura 4. Esquema de un glicerofosfolípido y su correspondiente nomenclatura. ....................................... 26

Figura 5 Esquema de la síntesis celular de diferentes especies plasmalógenas de glicerofosfolípidos. ...........27

Figura 6 Esquema de las dos rutas de incorporación de AA libre a los glicerofosfolípidos ..............................29

Figura 7 Esquema del intercambio de AA entre las especies de glicerofosfolípidos por transacilación ............ 30

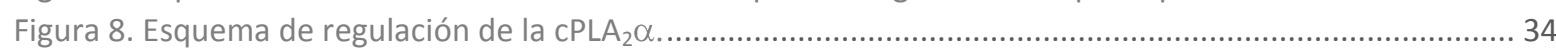

Figura 9 Esquema de las diferentes rutas de síntesis de los diversos eicosanoides a partir de AA................... 36

Figura 10. Figura del funcionamiento del MS-triple cuadrupolo. Se detalla el método precursor ion scanning.

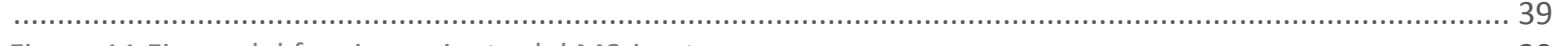

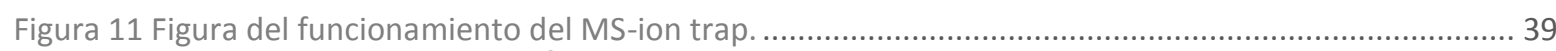

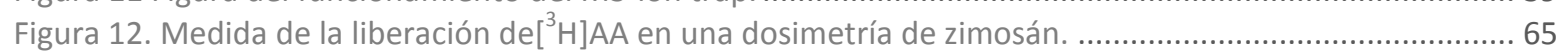

Figura 13. Medida de la liberación de $\left[{ }^{3} \mathrm{H}\right] \mathrm{AA}$ por la estimulacióncon zimosán a diferentes tiempos ...............66 66

Figura 14. Análisis de los glicerofosfolípidos implicados en la liberación de AA por zmosán ..........................67

Figura 15. Análisis del total de glicerofosfolípidos implicados en la liberación de AA por zmosán .................. 68

Figura 16. Análisis de PI(20:4/20:4) y PC(20:4/20:4) en la estimulación por zimosán ...................................69

Figura 17 Análisis del efecto de inhibidores de $\mathrm{CPLA}_{2} \alpha$ en especies de lisoPI .............................................. 70

Figura 18. Análisis del efecto de diferentes inhibidores de $\mathrm{PLA}_{2}$ en la liberación de [ $\left.{ }^{3} \mathrm{H}\right] \mathrm{AA}$ por la estimulación

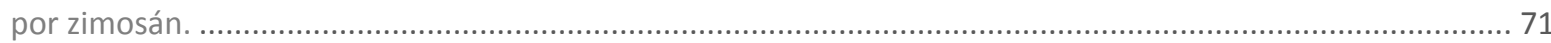

Figura 19. Análisis de la liberación de $\left[{ }^{3} \mathrm{H}\right] \mathrm{AA}$ en ratones $\mathrm{KO}$ de la $\mathrm{cPLA} \mathrm{A}_{2} \alpha$ estimulados con zimosán............ 72 Figura 20. Análisis del efecto de la pirrofenona en la liberación de de AA desde los glicerofosfolípidos por la

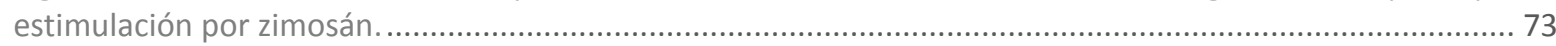

Figura 21. Análisis del efecto de la pirrofenona en la liberación de de AA desde total de glicerofosfolípidos por la estimulación por zimosán. ............................................................................................................... 74 Figura 22. Análisis del efecto de la pirrofenona sobre los niveles de $\operatorname{PI}(20: 4 / 20: 4)$ y $\operatorname{PC}(20: 4 / 20: 4)$ ante la

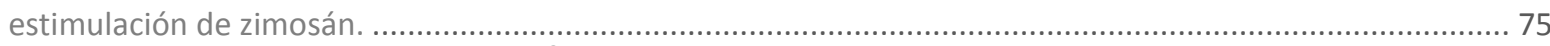
Figura 23. Medida de la liberación de $\left[{ }^{3} \mathrm{H}\right] \mathrm{AA}$ por la estimulación con LPS y zimosán. .................................. 76

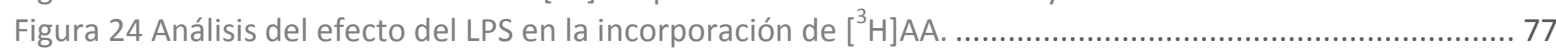
Figura 25 Análisis del efecto del LPS sobre los glicerofosfolípidos con AA .............................................. 78 Figura 26. Análisis del efecto sinérgico del LPS y el zimosán sobre las especies de glicerofosfolípidos con AA 80 Figura 27. Análisis del efecto sinérgico del LPS y el zimosán sobre el total de glicerofosfolípidos con AA ....... 81 Figura 28. Análisis del efecto del LPS y zimosán sobre los niveles de las especies PI(20:4/20:4) y PC(20:4/20:4).

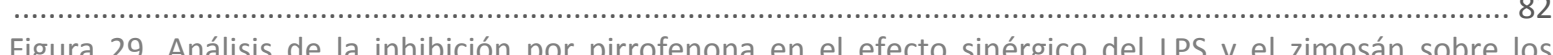

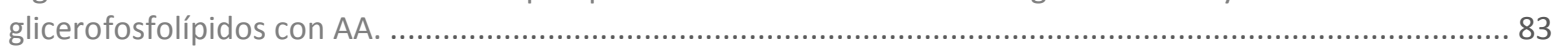
Figura 30. Análisis de la inhibición por pirrofenona en el efecto sinérgico del LPS y el zimosán sobre el total de

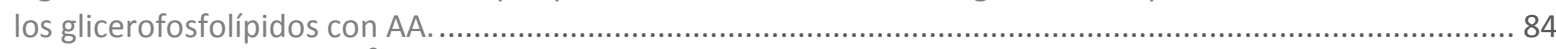

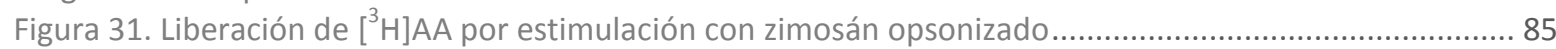

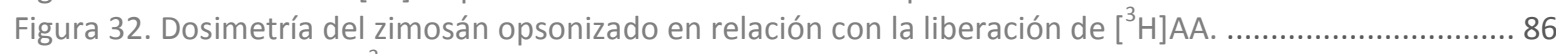

Figura 33. Liberación de $\left[{ }^{3}\right]$ AA tras una doble estimulación con zimosán y zimosán opsonizado.....................87

Figura 34. Análisis del efecto del zimsán opsonizado sobre las especies de PE con AA. ...............................88

Figura 35. Análisis del efecto del zimsán opsonizado sobre las especies de lisoPE .......................................89

Figura 36. Análisis del efecto del zimsán opsonizado sobre las especies de PC, PI y PS con AA. ....................90

Figura 37. Análisis del efecto del zimsán opsonizado sobre el total de glicerofosfolípidos con AA. ................ 91

Figura 38. Análisis del efecto del zimsán opsonizado sobre las especies PI(20:4/20:4) y PC(20:4/20:4) .........92

Figura 39. Análisis del efecto de diferentes inhibidores de $\mathrm{PLA}_{2}$ en la liberación de $\left[{ }^{3} \mathrm{H}\right] \mathrm{AA}$ por la estimulación

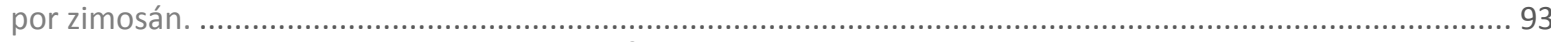
Figura 40. Análisis de la liberación de $\left[{ }^{3} \mathrm{H}\right] \mathrm{AA}$ en ratones $\mathrm{KO}$ de la $\mathrm{CPLA}_{2} \alpha$ estimulados con zimosán

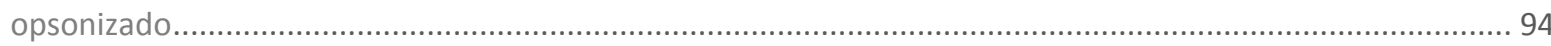


Figura 41. Análisis de la inhibición por pirrofenona del efecto del zimosán opsonizado sobre especies de PE

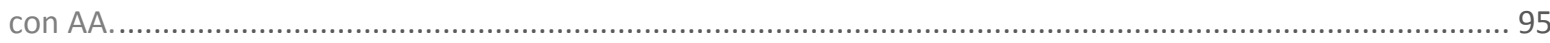
Figura 42. Análisis de la inhibición por pirrofenona del efecto del zimosán opsonizado especies de lisoPE. ...96 Figura 43. Análisis de la inhibición por pirrofenona del efecto del zimosán opsonizado sobre

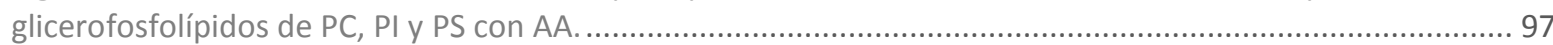
Figura 44. Análisis de la inhibición por pirrofenona del efecto del zimosán opsonizado sobre el total de glicerofosfolípidos con AA.

Figura 45. Análisis de la inhibición por pirrofenona del efecto de la estimulación con zimosán opsonizado sobre $\mathrm{PI}(20: 4 / 20: 4)$ y $\mathrm{PC}(20: 4 / 20: 4)$ 99

Figura 46. Niveles de PI(20:4/20:4) a diferentes tiempos de exposición a zimosán. .................................... 100

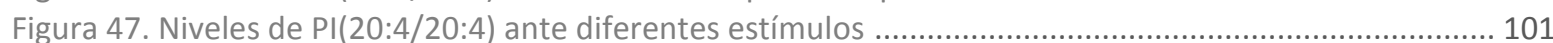

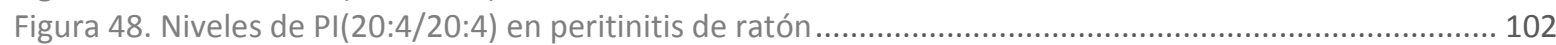

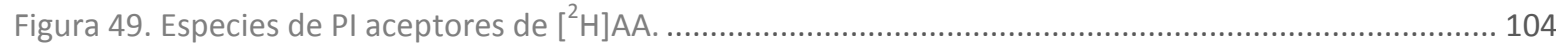

Figura 50. Expresión de genes implicados en inflamación en presencia de PI(20:4/20:4) ........................... 107

Figura 51. Media de anión superóxido y su relación con la presencia de $\mathrm{PI}(20: 4 / 20: 4)$.............................. 108 


\section{N DíCE TABLAS}

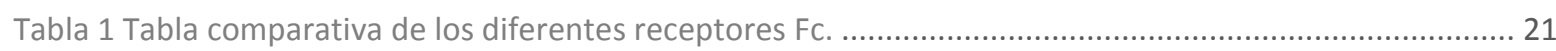

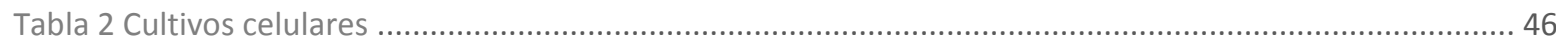

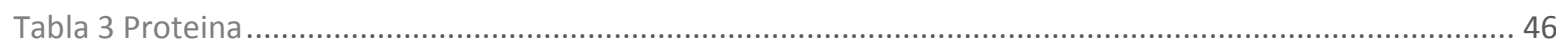

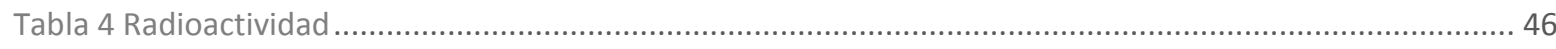

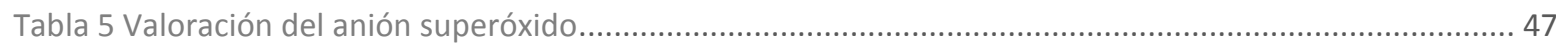

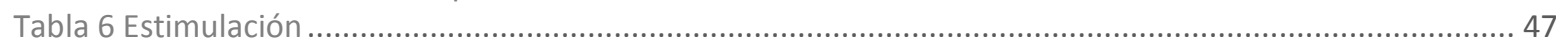

Tabla 7 Análisis por Cromatografía/Espectrometría de masas ...................................................................48

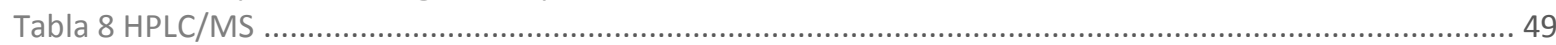

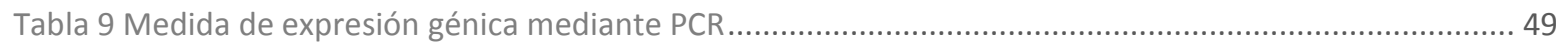

Tabla 10 Gradiente de eluyentes para el análisis de glicerofosfolípidos por HPLC/MS ................................ 58

Tabla 11 Oligonucleótidos utilizados en los ensayos de Q-PCR ............................................................62

Tabla 12 Genes estudiados por la posible implicación de la especie PI(20:4/20:4) .................................. 106 


\section{A B RE V I A T URAS}

- $\mathrm{AA}$

- ACSL

- $\quad$ AA-DHAP-R

- ADHAP-S

- AAG3P-AT

- $\mathrm{APCl}$

- ATP

- BEL

- cDNA

- CDP

- $\mathrm{CHO}$

- CID

- CoA

- CoA-IT

- cOX-2

- cPLA $_{2}$

- $\quad \mathrm{CPLA}_{2} \alpha$.

- CR3

- CYP

- $\quad$ DAG

- DGAT

- DC-SIGN

- DHAP-AT

- DHAP

- DHAP-AT

- DHET

- DMSO

- DTT

- dNTPs

- eDTA

- ELISA

- ESI

- $\quad$ eET

- $\mathrm{FAB}$

- $\mathrm{FC}$

- FCR

- FBS

- GAPDH
Ácido araquidónico (20:4n-6)

Acil coenzima A sintetasa de cadena larga

Acil/alquil-dihidroxiacetona reductasa

Alquil-DHAP sintetasa

Alquil/acil-glicero-3-fosfato aciltransferasa

Ionización química a presión atmosférica

Adenosina trifosfato

Bromoenol lactona

Ácido desoxirribonucleico complementario

Citidina difosfato

Células de cáncer de ovario de hamster

Disociación inducida por colisión

Coenzima A

Transacilasa independiente de CoA

Ciclooxigenasa 2

Fosfolipasa $\mathrm{A}_{2}$ citosólica dependiente de $\mathrm{Ca}^{+2}$

Fosfolipasa citosólica dependiente de $\mathrm{Ca}^{+2}$ de grupo IVA

Receptores del complemento 3

Citocromo

Diacilglicerol

Diacilglicerol aciltransferasa

Dendritic cell- specific ICAM-3-grabbing nonintegrin

Dihidroxiacetona fosfato aciltransferasa

Dihidroxiacetona fosfato

Dihidroxiacetona fosfato aciltransferasa

Ácido dihidroxieicosatetraenoico

Dimetil sulfóxido

1,4-Ditiotreitol

Mezcla de deoxinucleótidos trifosfato

Ácido etilendiaminotetraacético

Ensayos de inmunoabsorción ligado a enzima

Ionización por electrospray

Áciso epoxieicosatetraenoico

Bombardeo de átomos rápidos

Fragmento cristalizable

Receptores Fc

Suero fetal bovino

Glirealdehído -3-fosfato deshidrogenasa 
- $\mathrm{GC} / \mathrm{MS}$

- GPAT

- G3P

- $\mathrm{H}_{2} \mathrm{O}$ DEPC

- HETE

- HPETES

- HPLC/MS

- Ig

- $\lg G$

- IL

- $\quad \mathrm{iPLA}_{2}$

- KO

- LC

- Lisopa

- LisoPC

- LisoPE

- LisoPI

- LisoPL

- LOX

- $\quad$ LPLATs

- LPA

- $\quad$ lPAAT

- $\quad$ LPCAT

- $\quad$ LPIAT

- LPS

- LT

- LRR

- Lys

- $\mathrm{m} / \mathrm{z}$

- MALDI

- MAPK

- MBOAT

- MS

- NADPH

- NFKB

- NIST

- NL

- NP

- NK

- OxoETE

- PA
Cromatografía de gases acoplada a espectrometría de masas

Glicerol-3-fosfato aciltransferasa

Glicerol-3-fosfato

Agua tratada con dietilpirocarbonato

Ácido hidroxieicosatetraenoico

Ácidos hidroperoxieicosatetranoicos

Cromatografía de líquidos de alta resolución acoplada a espectrometría de masas

Inmunoglobulina

Inmunoglobulina G

Interleuquina

Fosfolipasa $\mathrm{A}_{2}$ citosólica independiente de $\mathrm{Ca}^{+2}$

Knockout (carente de gen)

Cromatografía de líquidos

Ácido lisofosfatídico

Lisoglicerofosfolípidos de colina

Lisoglicerofosfolípidos de etanolamina

Lisofosfatidilinositol

Lisoglicerofosfolípido

Lipoxigenasa

Llisofosfolípido aciltransferasas dependientes de CoA

Ácido lisofosfatídico

LisoPA : acilCoa aciltransferasa

LisoPC : acilCoa aciltransferasa dependiente de CoA

LisoPI : acilCoa aciltransferasa dependiente de CoA

Lipopolisacárido

Leucotrieno

Repeticiones ricas en leucina

Lisina

Relación masa carga

Desorción/ionización láser asistida por matriz

Proteína kinasa activada por mitógenos

Aciltransferasas unidas a membrana

Espectrometría de masas

Nicotinamida adenina dinucleótido fosfato

Factor de transcripción nuclear KB

Instituto Nacional de Estándares y Tecnología (USA)

Pérdida neutra

Fase normal

Células natural killer

Ácido oxoeicosatetraenoico

Ácido fosfatídico 
- $\quad$ PAF

- PAP

- Pam

- $\mathrm{PBS}$

- $P C$

- $\quad P E$

- $\quad P G$

- $\mathrm{PH}$

- PI

- PIP

- $\mathrm{PIP}_{2}$

- Pir

- PL

- $\mathrm{PLA}_{1}$

- $\mathrm{PLA}_{2}$

- PLC

- $\mathrm{pNPP}$

- PMA

- $\mathrm{PMN}$

- PMSF

- PS

- Q-PCR

- $\mathrm{R}_{1}$

- $\mathrm{R}_{2}$

- $\mathrm{RE}$

- RP

- mRNA

- ROS

- PAMP

- PIP

- PRR

- PTFBA

- RNA

- rpm

- RM

- $\quad$ RT

- SE

- Ser

- SIGNR1

- sn

- $\mathrm{sPLA}_{2}$

- $\quad$ SOD
Factor activador de plaquetas

fosfatidato fosfohidrolasas

Ácido palmítico (16:0)

Tampón fosfato salino

Glicerofosfolípido de colina

Glicerofosfolípido de etanolamina

Prostaglandina

Fosfohidrolasa

Fosfatidilinositol

Fosfatidilinositol fosfato

Fosfatidilinositol, 4,5-bifosfato

Pirrofenona

Glicerofosfolípido

Fosfolipasa $A_{1}$

Fosfolipasa $A_{2}$

Fosfolipasa C

Fosfato de paranitrofenilo

Forbol 12-miristato-13-acetato

Polimorfonucleares

Fluoruro de fenilmetilsulfonilo

Glicerofosfolípido de serina

PCR cuantitativa

Resto hidrocarbonado en la posición sn-1 del glicerol

Resto hidrocarbonado en la posición sn-2 del glicerol

Retículo endoplasmático

Fase reversa

Ácido ribonucleico mensajero

Especies reactivas de oxígeno

Patrones moleculares asociados a patógenos

Fosfoinosítido

Receptores de reconocimiento de patógenos

Perfluorotributilamina

Ácido ribonucleico

Revoluciones por minuto

Receptor de manosa

Transcriptasa reversa

Error estándar

Serina

Specific ICAM-3-grabbing nonintegrin-related 1

Estereo específica

Fosfolipasa $A_{2}$ secretada

Superóxido dismutasa 
- $\quad T \underline{a}$

- TAG

- tIR

- TLC

- TNF- $\alpha$

- TLR

- TX

- U

- UPLC

- UV

- V

- WT
Temperatura

Triacilglicerol

Receptor Toll-interleuquina-1

Cromatografia en capa fina

Factor de necrosis tumoral $\alpha$

receptor Toll like

Tromboxano

Unidad

Cromatografía de líquidos de ultra presión

Luz ultravioleta

Volumen

Wild type (control) 


\section{A.- INTRODUCCIÓN}




\section{A.1 El sistema inmune. La respuesta a patógenos}

Microorganismos y patógenos en general son capaces de invadir organismos vivos, infectarlos $y$, en último lugar, provocar su muerte. Con el fin de eliminar estos patógenos, la evolución ha llevado a desarrollar y perfeccionar un mecanismo de defensa llamado sistema inmune.

En mamíferos, la protección se lleva a cabo mediante dos estrategias diferenciadas: la inmunidad innata, una primera línea de defensa no específica con receptores altamente conservados evolutivamente desde las plantas o las moscas del vinagre; y la inmunidad adaptativa, un sistema especializado que comprende células diferenciadas con capacidad de reconocimiento de patógenos y que se encarga tanto de la eliminación de patógenos en una segunda fase de la infección como de generar memoria inmunológica. Esta capacidad se debe a un desarrollo basado en una selección clonal a partir de un vasto repertorio de linfocitos que contienen una gran variedad de receptores específicos generados por reordenación genética [1].

La inmunidad adaptativa se desencadena tras ser activada por la inmunidad innata, la cual actúa en la primera fase de la infección. La inmunidad innata, constituida como una formidable defensa contra amenazas externas, comprende a las células dendríticas, las células polimorfonucleares (PMN) y al denominado "sistema fagocítico mononuclear". Este sistema incluye a los promonocitos y sus precursores en la médula ósea, los monocitos distribuidos en la sangre periférica y los macrófagos, localizados en los tejidos

Los macrófagos son células fagocíticas residentes en los tejidos linfoides y no linfoides [2] descritos por primera vez a finales del siglo XIX por Élie Metchnikoff, premio Nobel de Fisiología y Medicina en 1908. En las décadas siguientes se conseguirían definir los mecanismos que permiten la activación de los macrófagos. No fue hasta un siglo después cuando se empezaron a documentar los innumerables papeles que juegan estas células fagocíticas [3].

En la actualidad se sabe que los macrófagos están ampliamente distribuidos por todo el cuerpo, incluidas las vías de acceso de microorganismos, y que su actividad incluye la participación en la captura inicial y procesamiento de los antígenos potenciales (inmunidad innata) que a su vez implica la activación de la maquinaria de acción de los linfocitos T y B (inmunidad adaptativa).

Los macrófagos están implicados, además de en la eliminación de patógenos gracias a su eficiente actividad endocítica y fagocítica, en la homeostasis tisular [4] y en la regulación local y sistémica de la respuesta inflamatoria e inmune a través de su capacidad capacidad para inducir la producción de citoquinas inflamatorias o ácido araquidónico $(\mathrm{AA})[5,6]$. 


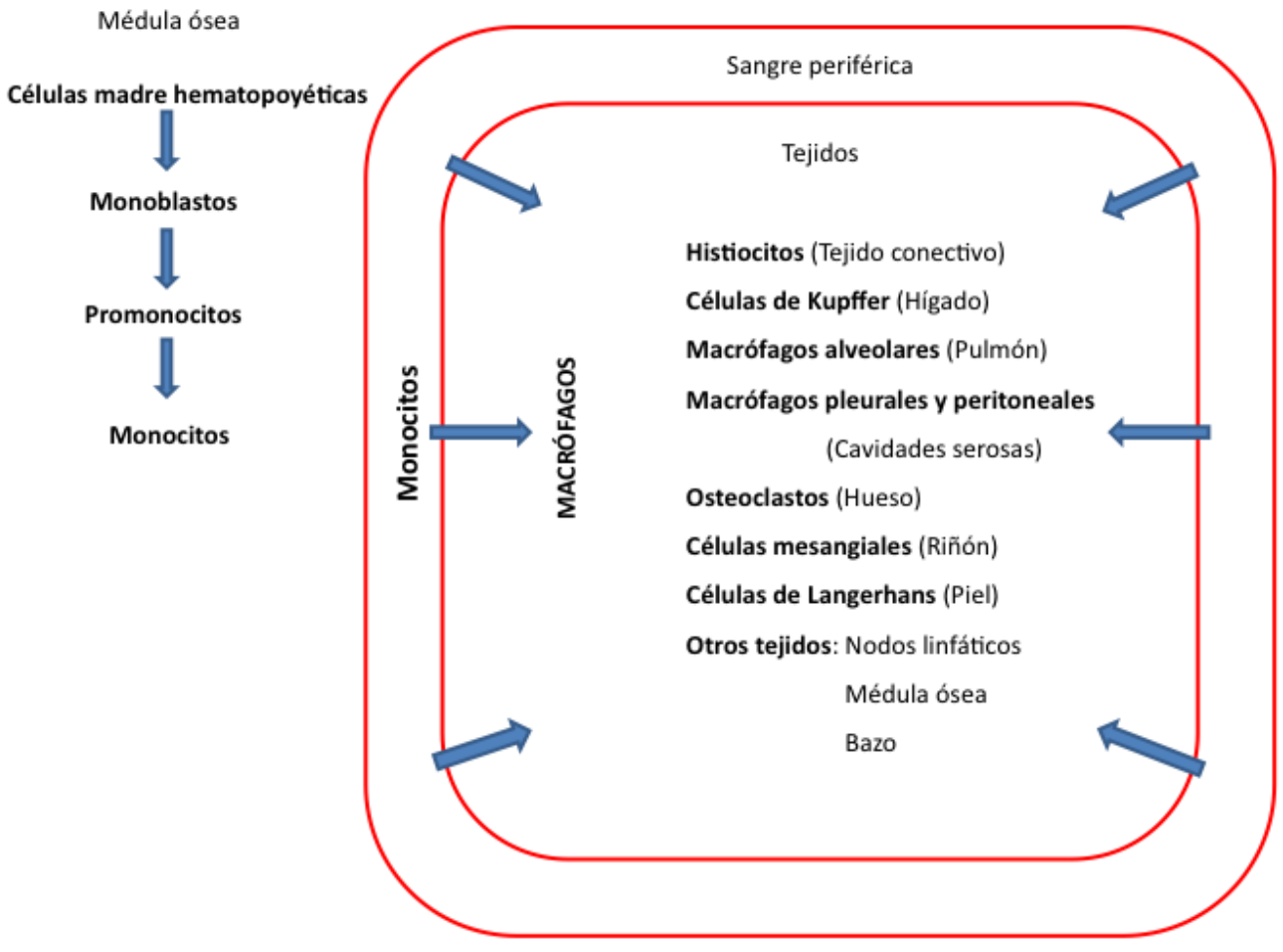

Figura 1. Esquema del sistema fagocítico mononuclear 


\section{A.2 Fagocitosis de patógenos e inflamación}

La palabra fagocitosis deriva de la palabra griega phageinkytos que significa literalmente "comer células". La fagocitosis es un tipo de endocitosis por la cual, una vez reconocido el patógeno, las células especializadas como los macrófagos o los neutrófilos, pertenecientes a la familia de las células PMN, lo rodean y lo introducen al interior para su eliminación. En organismos pluricelulares esta actividad tiene como función tanto el reciclaje de células y tejidos muertos como la defensa ante agentes foráneos que al ser reconocidos por receptores de la superficie de células fagocíticas son capaces de iniciar cascadas metabólicas que derivan en el desarrollo de reacciones inflamatorias [2].

La inflamación es una parte de la respuesta inmediata de un organismo a infecciones, traumatismos y enfermedades post-isquémicas, tóxicas o autoinmunes [7]. La inflamación comprende un conjunto complejo de interacciones de factores solubles y células que pueden tener lugar en cualquier tejido y está tipificado por síntomas como el enrojecimiento, el calor, el dolor y el tumor o hinchazón. Estos síntomas aparecen como resultado de un incremento tanto en flujo sanguíneo como en el movimiento de leucocitos además de un aumento en la permeabilidad de los capilares sanguíneos que permite extravasación, es decir, el abandono del torrente sanguíneo atravesando la pared endotelial de diferentes moléculas como factores del complemento, anticuerpos y citoquinas [8].

El proceso normalmente permite la recuperación tisular. Sin embargo, si la destrucción dirigida y la reparación asistida no están totalmente coordinadas, la inflamación puede ocasionar daños tisulares persistentes por leucocitos o linfocitos. La inflamación cuenta con sus propios puntos de control, incluyendo señales moleculares que pueden favorecer la supresión de la inflamación dependiendo del momento y la situación. Así, el estado de no inflamación no se presenta de forma pasiva por la ausencia de estímulos inflamatorios [7] sino que requiere la secreción de citoquinas antiinflamatorias, la inhibición de cascadas de señalización proinflamatorias, la redistribución de receptores de mediadores inflamatorios y la activación de células reguladoras [9].

\section{A.2.1 Reconocimiento del zimosán en macrófagos}

El zimosán es una preparación de la pared celular de la levadura S. cerevisiae compuesta principalmente por $\beta$-glucanos, manosas, manoproteínas y quitinas, todas ellas implicadas en el reconocimiento de levaduras por parte de sistema inmune [10]. Esta preparación se ha utilizado durante más de 50 años como modelo de estímulo de la fagocitosis y la inflamación tanto en ensayos in vivo como in vitro [11]. Además, el zimosán, al igual que otros agentes patógenos, tiene la capacidad de opsonizarse, es decir, de ser cubiertos por una serie de moléculas presentes en el suero denominadas opsoninas, que incluyen las inmunoglobulinas $G$ (IgG) y los factores de 
complemento. Dichas moléculas, al igual que el zimosán, pueden ser reconocidos por receptores de membrana.

En la superficie macrofágica, al igual que en el resto de tipos celulares que componen el sistema fagocítico, los receptores se dividen dependiendo de si reconocen patógenos o moléculas no patógenas, denominándose receptores de reconocimiento de patógenos (PRR) o receptores de reconocimiento de no patógenos, respectivamente.

En macrófagos, la fagocitosis del zimosán comienza con su reconocimiento por diferentes PRR. El zimosán se une preferentemente al receptor dectina-1 y al complejo TLR2/TLR6. Además, también se ha determinado la implicación del receptor de manosa [12].

Por su parte, los receptores que reconocen el zimosán son también capaces de unir el zimosán opsonizado. Esto se debe a que, aunque cubierto por diversas partículas, el zimosán opsonizado presenta los mismos motivos moleculares que se unen a los PRR que reconocen el zimosán. Pero además, el zimosán opsonizado posee la capacidad de ser reconocido por otros receptores de no patógenos de la superficie macrofágica. Así, el zimosán opsonizado se une principalmente, por una parte, a los receptores $\mathrm{Fc}(\mathrm{FcR})$ que reconocen partículas cubiertas con IgG $y$, por otra, a los receptores de complemento 3 (CR3) que reconocen partículas opsonizadas con el complemento C3b y, en concreto, con su fragmento C3bi [13].

Además de inducir la liberación de AA asociada a una posterior formación de eicosanoides, el reconocimiento del zimosán, opsonizado o no, está implicado en la formación de citoquinas proinflamatorias [14], la activación mediante fosforilación de la fosfolipasa C (PLC) [15] que deriva en la formación de inositol trisfosfato y diacilglicerol (DAG) [16] y en un incremento del calcio intracelular [14].

\section{A.2.1.1 Receptores de reconocimiento de patógenos}

Los PRR forman un grupo diverso y heterogéneo, aunque todos ellos poseen características comunes. La primera es que reconocen componentes microbianos conocidos como patrones moleculares asociados a patógenos (PAMP). Estos patrones pueden constar de azúcares, proteínas, lípidos o diferentes motivos de ácidos nucleicos los cuales son esenciales para la supervivencia del microorganismo. Segundo, los PRR se expresan constitutivamente en el huésped y detectan los patógenos sea cual sea el estado en que se encuentre en su ciclo de vida. Tercero, los PRRs son codificados en línea germinal, no clonados, expresados en todas las células de un tipo dado e independientes de la memoria inmunológica. Diferentes PRR reaccionan con PAMP específicos, mostrando diferentes patrones de expresión activando rutas de señalización específicas y promoviendo diferentes respuestas antipatogénicas [1].

Hay más de cien de estos receptores PRR que directamente activan las células inmunes, seguido de una cascada de señales que permiten la expresión de una variedad de genes implicados en las respuestas inflamatoria e inmune. Estos receptores incluyen a los receptores Toll-like (TLR), 
los PRR mejor caracterizados, y otros receptores como los receptores lectinas tipo-C que incluten los receptores de manosa y el receptor de $\beta$-glucanos, dectina- 1 , entre otros.

\section{A.2.1.1.1 TLR2}

Los receptores Toll-like se han identificado como la principal clase de PPR [17]. Inicialmente se describieron con un importante papel en el desarrollo dorso-ventral de Drosophila [18]. A posteriori se los implicó en la respuesta inmune innata de las moscas de la fruta y otros insectos [19].

Los TLR son proteínas de membrana de tipo I, es decir, que contienen un dominio Nterminal extracelular, compuesto por repeticiones ricas en leucina (LRR) que media en el reconocimiento de PAMP, además de un dominio transmembrana y un dominio homólogo intracelular receptor tipo Toll-interleuquina-1 (TIR) que es requerido para el inicio de la señalización intracelular [17]. Esta señalización permitirá la producción de diferentes citoquinas inflamatorias, IFN tipo I y quimioquinas.

El reconocimiento de PAMP por TLR, sólo o formando heterodímeros con otros TLR o no TLR, induce señales responsables de la activación de genes importantes en una defensa efectiva contra el huésped, especialmente citoquinas proinflamatorias.

Además de la activación de la respuesta inmune innata, el reconocimiento mediado por TLR representa una unión entre los sistemas de inmunidad innata y adquirida induciendo la maduración de las células dendríticas y la proliferación y activación de las células T [20].

Hasta la actualidad, se han llegado a describir trece TLRs en ratones y humanos, TLR10 se expresa exclusivamente en humanos y TLR11-13 en ratones [21]. En ratones, TLR11, 12 y 13 componen otra subfamilia adicional [22]. De todos ellos, es necesario resaltar TLR2 por reconocer zimosán [23].

La familia de los TLR2 incluye a TLR1, TLR2 TLR6 y TLR10, éste último exclusivo de humanos. Además de zimosán, TLR2 reconoce lípidos de una variedad de microorganismos [24]. Puede interaccionar con sus ligandos en forma de heterodímeros, con TLR1 (TLR2/TLR1) o TLR6 (TLR2/TLR6), o incluso con no TLRs como CD36 y CD14. El dímero TLR1/TLR2 une lipopéptidos triacilados y lipoproteínas de micobacterias y se ha sugerido que TLR10 interacciona con TLR1 o TLR2, aunque el ligando de estos heterodímeros es aún desconocido.

Por su parte el reconocimiento de partículas de zimosán por parte del dímero TLR2/TLR6 se requiere para la activación del factor de transcripición nuclear (NFKB) y la producción de citoquinas proinflamatorias como TNF- $\alpha$ [10]. Sin embargo, la activación de los TLR no es suficiente para comenzar la fagocitosis ya que su expresión en células no fagocíticas no confiere a estas céluas la capacidad de internalizar el zimosán [23]. Además, se ha demostrado que no se requiere la activación de los TLR para el reclutamiento de fagosomas. De hecho, se ha descrito que son los propios TLR los que son reclutados para los fagosomas durante la internalización de patógenos [25], donde pueden reconocer diferentes ligandos. 
Sin embargo, se ha demostrado mediante el uso de ratones KO de TLR2 que la liberación de $A A$ y la producción de eicosanoides como el leucotrieno $C_{4}$ son independientes de este receptor en respuesta a zimosán [12].

\section{A.2.1.1.2 Receptores de manosa (MR)}

Descrito por primera vez por Stahl en 1978 [26], el receptor de manosa (MR o CD206) es una lectina tipo $C$ que pertenece a toda una la familia de receptores de manosa que comprende MR, Endo180, DEC205, y el receptor de fosfolipasas $A_{2}$ de bajo peso molecular. MR une moléculas glicosiladas con una manosa terminal de un amplio rango de bacterias Gram-negativas y Grampositivas, hongos, protozoos, levaduras y micobacterias. Se expresa principalmente en macrófagos [27] y células dendríticas inmaduras, aunque también ha sido detectado en compartimentos de células endoteliales, células de riñón, células del músculo liso traqueal y epitelio pigmentado de la retina [28].

El MR ha sido asociado al reconocimiento de las moléculas de manosa presentes en el zimosán. Así, se ha definido la implicación en el reconocimiento de zimosán de SIGNR1 (specific ICAM-3-grabbing nonintegrin-related 1), un receptor homólogo de DC-SIGN (dendritic cell- specific ICAM-3-grabbing nonintegrin) considerado como el mayor receptor de manosa en macrófagos peritoneales de ratón [27].

\section{A.2.1.1.3 Dectina-1}

La dectina-1 es un receptor tipo II transmembrana expresado en células mieloides, principalmente macrófagos, células dendríticas y neutrófilos [29]. Este receptor puede reconocer patógenos fúngicos vivos y comúnmente se ha descrito como el principal receptor en macrófagos responsable de la fagocitosis de levaduras, principalmente por el reconocimiento del $\beta$-1,3-glucano central en la pared celular de levaduras y la pared celular fúngica [30].

En macrófagos y células dendríticas, dectina-1 es el receptor principal pero no exclusivo de la fagocitosis de zimosán [31]. Junto con los TLRs reconocen componentes de las paredes celulares fúngicas y de levaduras sugiriendo que estos receptores pueden estar colaborando en la generación de la respuesta inflamatoria. En este sentido, se ha descrito la colaboración de TLR2 y dectina-1 en la respuesta inflamatoria mediada por el reconocimiento de zimosán en macrófagos [10].

Mediante el uso de anticuerpos monoclonales [30]y policlonales [32] de dectina-1 se ha demostrado la implicación de este receptor en la fagocitosis de zimosán por parte de los macrófagos. Además, ratones deficientes en dectina-1 son incapaces de fagocitar el zimosán y presentan más susceptibilidad a infecciones fúngicas [33,34]. También se ha comprobado que la reducción de expresión de dectina-1 mediante microRNA en macrófagos de ratón suprime la estimulación de la producción de ROS producido por zimosán [31,35] corroborando la importancia de este receptor en la defensa innata. 
El reconocimiento de zimosán por dectina-1 parece ser clave en la activación de la cascada metabólica implicada en la inflamación. Así, en células RAW que sobreexpresan dectina-1 se ha comprobado un aumento en la liberación de AA, la expresión de COX-2 y la producción de prostaglandinas [12].

\section{A.2.1.2 Receptores de reconocimiento de no patógenos}

Los receptotes de no patógenos reconocen a partículas que cubren a los patógenos. Este reconocimiento es específico, cada partícula se une a un receptor concreto e inicia un determinado tipo de fagocitosis. Dependiendo del receptor implicado, se han definido dos tipos diferentes de fagocitosis de partículas opsonizadas: la fagocitosis tipo I mediada por los receptores Fc (FcR) que une partículas cubiertas por IgG y la fagocitosis tipo II en el que los receptores de complemento tipo 3 (CR3) reconocen partículas cubiertas con complemento [36]. De este modo, los FcR y los CR3 se convierten en receptores clave en el reconocimiento de no patógenos y en el inicio de los procesos fagocíticos.

\section{A.2.1.2.1 Receptores Fc}

Los FcR unen regiones Fc de anticuerpos que son atacados por células infectadas o patógenos invasores y son expresadas en muchos tipos celulares del sistema inmune. Son consideradas como el punto de unión entre la inmunidad adaptativa y la inmunidad innata. Hay muchas clases de receptores Fc basados en el tipo de región Fc que reconocen. Receptores Fc gamma ( $F C \gamma R s)$, receptores $F c$ epsilon (FceRs), receptores $F c$ alfa (FcaRs) y receptores Fc delta (FcठRs) [37]. Este último subgrupo está implicado en la respuesta de las células B [38].

Fc $\gamma R s[39,40]$ son proteínas integrales de membrana que unen específicamente la parte Fc de la molécula IgG en la superficie de varias células incluyendo macrófagos, monocitos, neutrófilos, células natural killer (NK) y células B y T. Tres clases de moléculas Fc $\gamma R$ han sido descritas, FC $\gamma \mathrm{RI}$ (CD64), FcyRII (CD32) y FcyRIII (CD16), que difieren en sus afinidades, siendo FC $\gamma$ RI el receptor de alta afinidad. Tres genes diferentes codifican $F C \gamma R I$ y $F c \gamma R I I(A, B$ y $C$ ) y dos (A y B), FcyRIII.

FceRs consiste en un receptor de alta afinidad (FcERI) y un receptor de baja afinidad (FceRII o CD23). FcERI pertenece a la superfamilia de las inmunoglobulinas y se presenta en las células de Langerhans, mastocitos, basófilos y neutrófilos, mientras que FceRIl es una lectina tipo-C expresada en células $B$, eosinófilos y mastocitos. Los mastocitos reconocen alérgenos cubiertos por IgE principalmente por $F C \varepsilon R I$ que lleva a la activación de las quinasas Scr y Syk. En mastocitos de ratón se ha demostrado que sus receptores interaccionan sinérgicamente con TLR2 y TLR4 [41].

Solo un miembro pertenece al subgrupo de FcaR, el FcaRI o CD89 [42]. Está presente en las células del linaje mieloide como macrófagos, monocitos, eosinófilos y neutrófilos e interacciona con las partículas opsonizadas con IgA. Hay otro FcR que reconoce IgA, llamado receptor Fcalfa/mu $(F c \alpha / \mu R)$ por su capacidad para también reconocer IgM [43]. Este receptor es una proteína 
transmembrana tipo I que une tanto IgA como IgM con una afinidad intermedia, y que se expresa en lifocitos maduros $B$, células dendríticas foliculares y macrófagos.

Los FcR juegan un papel muy importante en los procesos inflamatorios causados por la presencia de patógenos cubiertos. Así, se ha demostrado que el reconocimiento de IgG por parte de esta familia de FcR implica la liberación de AA en macrófagos peritoneales de ratón cuando estos se estimulan con zimosán opsonizado [44]. 


\begin{tabular}{|c|c|c|c|c|}
\hline Receptor & $\begin{array}{c}\text { Principal } \\
\text { anticuerpo que } \\
\text { reconoce } \\
\end{array}$ & $\begin{array}{l}\text { Afinidad por el } \\
\text { anticuerpo }\end{array}$ & Distribución celular & Funciones \\
\hline $\begin{array}{l}\text { FcyRI } \\
\text { (CD64) }\end{array}$ & IgG1 e IgG3 & $\begin{array}{c}\text { Alta } \\
\left(\mathrm{Kd} \sim 10^{-9} \mathrm{M}\right)\end{array}$ & $\begin{array}{l}\text { Macrófagos } \\
\text { Neutrófilos } \\
\text { Eosinófilos } \\
\text { Células dendríticas }\end{array}$ & $\begin{array}{l}\text { Fagocitosis } \\
\text { Estallido } \\
\text { respiratorio } \\
\text { Inducción de } \\
\text { muerte } \\
\text { microbiana }\end{array}$ \\
\hline $\begin{array}{l}\text { Fc } \gamma \text { RIIA } \\
\text { (CD32) }\end{array}$ & IgG1 & $\begin{array}{c}\text { Ваја } \\
\left(\mathrm{Kd}>10^{-7} \mathrm{M}\right)\end{array}$ & $\begin{array}{c}\text { Macrófagos } \\
\text { Neutrófilos } \\
\text { Células cebadas } \\
\text { Eosinófilos } \\
\text { Plaquetas } \\
\text { Células dendríticas }\end{array}$ & $\begin{array}{l}\text { Fagocitosis } \\
\text { Degranulación } \\
\text { (eosinófilos) }\end{array}$ \\
\hline $\begin{array}{l}\text { FcyRIIB } \\
\text { (CD32) }\end{array}$ & $\operatorname{IgG1}$ & $\begin{array}{c}\text { Ваја } \\
\left(\mathrm{Kd}>10^{-7} \mathrm{M}\right)\end{array}$ & $\begin{array}{c}\text { Macrófagos } \\
\text { Neutrófilos } \\
\text { Células cebadas } \\
\text { Eosinófilos } \\
\text { Células dendríticas } \\
\text { Células B }\end{array}$ & $\begin{array}{l}\text { No Fagocitosis } \\
\text { Inhibición de } \\
\text { actividad celular }\end{array}$ \\
\hline $\begin{array}{l}\text { Fc } \gamma \text { RIIIA } \\
\text { (CD16A) }\end{array}$ & IgG1 e IgG3 & $\begin{array}{c}\text { Ваја } \\
\left(\mathrm{Kd}>10^{-6} \mathrm{M}\right)\end{array}$ & $\begin{array}{c}\text { Macrófagos } \\
\text { Células cebadas } \\
\text { Basófilos } \\
\text { Células NK } \\
\text { Células dendríticas }\end{array}$ & $\begin{array}{l}\text { Inducción de } \\
\text { citotoxicidad } \\
\text { mediada por } \\
\text { anticuerpos }\end{array}$ \\
\hline $\begin{array}{l}\text { Fc } \gamma \text { RIIIB } \\
\text { (CD16B) }\end{array}$ & IgG e IgG3 & $\begin{array}{c}\text { Вaja } \\
\left(\mathrm{Kd}>10^{-6} \mathrm{M}\right)\end{array}$ & Neutrófilos & $\begin{array}{l}\text { Inducción de } \\
\text { muerte } \\
\text { microbiana } \\
\text { Activación de } \\
\text { genes }\end{array}$ \\
\hline Fc $\gamma \varepsilon R I$ & $\operatorname{IgE}$ & $\begin{array}{c}\text { Alta } \\
\left(\mathrm{Kd} \sim 10^{-10} \mathrm{M}\right)\end{array}$ & $\begin{array}{c}\text { Células cebadas } \\
\text { Eosinófilos } \\
\text { Basófilos } \\
\text { Células de Langerhans }\end{array}$ & Degranulación \\
\hline $\begin{array}{l}\text { FceRII } \\
\text { (CD23) } \\
\end{array}$ & $\operatorname{IgE}$ & $\begin{array}{c}\text { Baja } \\
\left(\mathrm{Kd}>10^{-7} \mathrm{M}\right)\end{array}$ & $\begin{array}{c}\text { Células B } \\
\text { Eosinófilos } \\
\text { Células de Langerhans } \\
\end{array}$ & $\begin{array}{l}\text { Posible molécula } \\
\text { de adhesión }\end{array}$ \\
\hline $\begin{array}{l}\text { Fc } \alpha \text { RI } \\
\text { (CD89) }\end{array}$ & $\operatorname{Ig} A$ & $\begin{array}{c}\text { Ваја } \\
\left(\mathrm{Kd}>10^{-6} \mathrm{M}\right)\end{array}$ & $\begin{array}{c}\text { Macrófagos } \\
\text { Neutrófilos osinófilos } \\
\text { Células de Kupffer }\end{array}$ & $\begin{array}{l}\text { Fagocitosis } \\
\text { Inducción de } \\
\text { muerte } \\
\text { microbiana }\end{array}$ \\
\hline $\mathrm{F} c \alpha / \mu \mathrm{R}$ & $\operatorname{IgA}$ e IgM & $\begin{array}{c}\text { Alta para IgM, } \\
\text { Media para IgA }\end{array}$ & $\begin{array}{l}\text { Células B } \\
\text { Macrófagos }\end{array}$ & $\begin{array}{l}\text { Inducción de } \\
\text { muerte } \\
\text { microbiana }\end{array}$ \\
\hline
\end{tabular}




\section{A.2.1.2.2 Receptor de complemento tipo 3}

El receptor de complemento tipo 3 (CR3, mac-1, integrina $\left.\alpha_{M} \beta_{2} \circ \mathrm{CD} 11 \mathrm{~b} / \mathrm{CD} 18\right)$ es un glicoproteína heterodimérica transmembrana perteneciente a la familia de las integrinas $\beta 2$, constituida por una subunidad CD11b asociada no covalentemente con CD18 [45].

CR3 está presente en leucocitos, monocitos, macrófagos y neutrófilos y es muy importante para la adhesión celular y citotoxicidad mediada por la célula. Principalmente, CR3 actúa como receptor para una variedad de ligandos endógenos y organismos infecciosos. Así, es el principal receptor para el fragmento C3bi de la proteína complementaria, implicándolo en el reconocimiento de zimosán opsonizado.

Sin embargo, también puede ser considerada como una PRR ya que induce la captación, a través de las uniones a diferentes sitios, de una amplia variedad de patógenos no cubiertos por inmunoglobulinas o complementos incluyendo la fagocitosis de zimosán no opsonizado [36].

Se ha descrito que CR3 como un receptor complejo capaz de reconocer tanto el zimosán no opsonizado como el opsonizado. La opsonización provoca que el zimosán se una a diferentes sitios de CR3 [46] Dependiendo del sitio de unión implicado, CR3 puede promover tanto la fagocitosis de tipo I como la de tipo II. Se ha descrito que ambos tipos de fagocitosis presentan diferencias tanto en la formación de la invaginación de la membrana como en la implicación de diferentes proteínas GTPasas o tirosinas quinasas [36].

Entre los efectos del reconocimiento de partículas cubiertas por complemento, se ha observado que, en monocitos humanos, CR3 contribuye junto a dectina-1 a la liberación de $\mathrm{O}^{-}$a través de la activación de la NADPH oxidasa por zimosán opsonizado [47]. Sin embargo, se ha demostrado que la unión de zimosán opsonizado a CR3 no promueve la liberación de AA en macrófagos peritoneales de ratón [44]. 


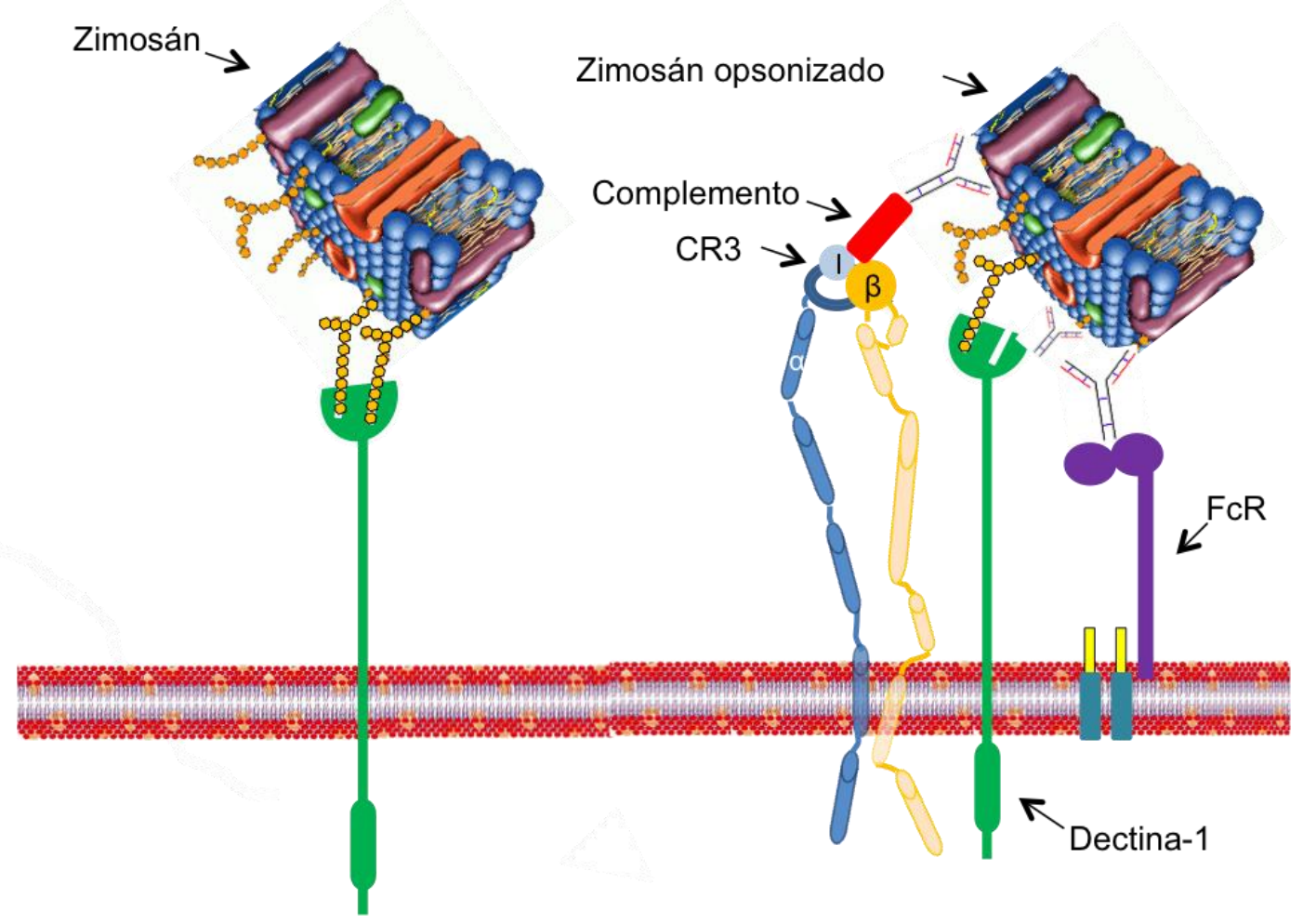

Figura 2 Receptores implicados en el reconocimiento del zimosán y el zimosán opsonizado.

\section{A.2.2 El ácido araquidónico y su metabolismo}

Entre los principales mediadores que desenadenan la respuestra inflamatoria se incluye a los eicosanoides, compuestos lipídicos que se consideran claves en fisiopatología $[48,49]$ a través de su reconocido papel en la inflamación y en la regulación de la inmunidad [50, 51]. Los eicosanoides se producen por la oxigenación de ácidos grasos poliinsaturados esenciales de 20 átomos de carbono, principalmente el ácido araquidónico (AA).

El ácido araquidónico (AA) o ácido 5,8,11,14-eicosatetranoico es un ácido graso poliinsaturado de veinte átomos de carbono (20:4) del tipo omega-6 (n-6) por presentar un doble enlace entre los carbonos situados en posición seis y siete contando desde metilo terminal de la molécula. 

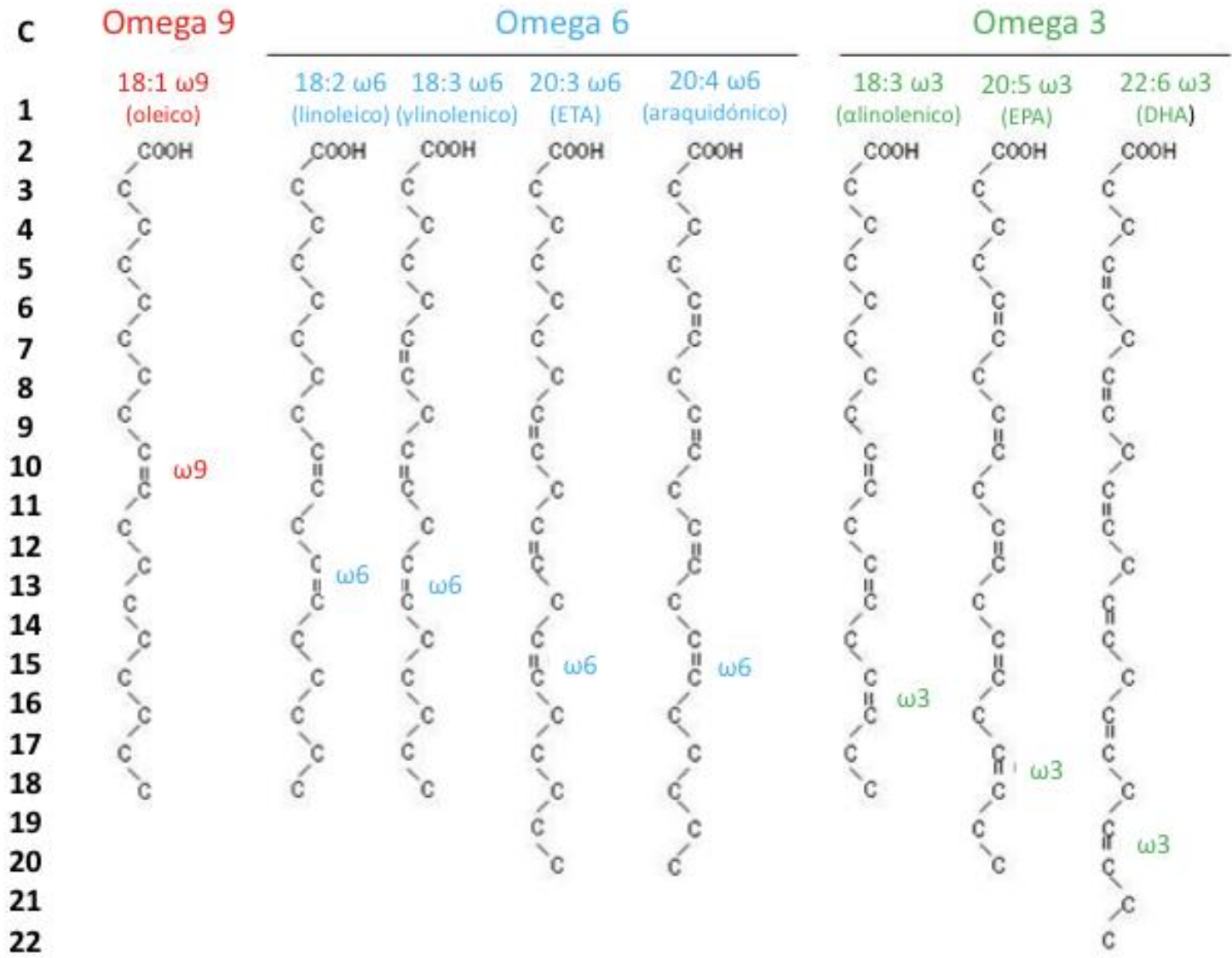

Figura 3 Comparativa de diferentes ácidos grasos con su respectiva nomenclatura

En mamíferos se han descrito dos fuentes de AA [52]. En la primera de ellas, la síntesis de AA a partir de un ácido graso esencial, el ácido linoleico, 18:2(n-6), que es absorbido de la dieta a través del intestino [53]. En esta síntesis están involucradas una enzima desaturasa $\Delta 6$, una enzima elongasa y una enzima desaturasa $\Delta 5$, de modo que en esta ruta biosintética también se forman, además del $\mathrm{AA}$, otros ácidos grasos poliinsaturados [54]. La síntesis del AA a partir de ácido linoleico ocurre principalmente en el hígado, aunque también puede producirse en otros tejidos. Desde el hígado, el AA se libera al torrente sanguíneo, desde donde se distribuye a los diferentes tejidos, quedando así accesible a los macrófagos.

La otra fuente de $A A$ es su asimilación directa de la dieta, especialmente de la carne y huevos. En los seres humanos, la mayor parte del AA proviene de la síntesis a partir del ácido linoleico ingerido (10-20 g por día) frente a la ingesta directa de AA que supone alrededor de 0,25 g por día [52]. Por su parte, en mamíferos herbívoros la totalidad del AA proviene del ácido linoleico.

Independientemente de su origen, el AA no se encuentra distribuido uniformemente entre los tejidos. De ello se encargan una serie de mecanismos basados en reacciones específicas de acilación, la asociación a lipoproteínas y la regulación de la producción a partir del ácido linoleico. Desde el hígado, el AA se incorpora a la sangre esterificado en los lípidos de diversas lipoproteínas 
(VLDL, HDL, LDL) o como 1-liso-2-araquidonoil-sn-glicero-3-fosfocolina, lisoglicerofosfolípido que se asocia a albúmina $[52,55]$ y que se sintetiza por la acción de una enzima fosfolipasa $A_{1}\left(P L A_{1}\right)$. El significado de este segundo mecanismo sería el transporte del AA a tejidos a los que las lipoproteínas tienen un difícil acceso sin la necesidad de que se encuentre libre en el torrente sanguíneo. Tomando tanto la forma libre como la asociada, el AA representa entre un 10 y un $11 \%$ de los ácidos grasos en los glicerofosfolípidos del plasma, llegando a suponer un $13 \%$ en el hígado [56].

Además de su implicación en la inflamación y la respuesta inmune innata, el AA por si mismo puede presentar alguna otra función biológica importante como apoptosis [57-59]. Además, bajo la presencia de elevadas concentraciones, el AA puede dar lugar a cantidades significativas de ácido adrénico (22:4n-6), producto resultante de la elongación de dos carbonos [60]. Este ácido graso es el precursor de las prostaglandinas de veintidós carbonos (dihomoprostaglandinas), homólogas a las derivadas del AA [61-64].

Aunque el AA y sus metabolitos se consideren protectores en caso de enfermedad [65, 66], cuando se producen en exceso pueden llegar a ser tóxicos o provocar disfunciones metabólicas [67, 68]. La gran actividad biológica de los eicosanoides obliga a las células a tener un control exhaustivo de los niveles de AA libre. Con ese fin, una continua movilización desde los glicerofosfolípidos regula la disponibilidad de AA libre lo que, frecuentemente, representa un paso limitante en la generación de eicosanoides. [69, 70].

\section{A.2.2.1 Los glicerofosfolípidos, principales depósitos de ácido araquidónico}

Los glicerofosfolípidos son componentes principales de las membranas celulares. [71]. Su estructura comprende un esqueleto de glicerol fosfato unido a una cabeza polar. Las posiciones del glicerol están numeradas de manera estereo-específica ( $s n)$, de tal forma que en todos los casos el grupo fosfato se halla en la posición sn-3 del glicerol. Según la cabeza polar que está unida a ese grupo fosfato se dividen en diferentes clases: glicerofosfolípidos de colina (PC), etanolamina (PE), inositol (PI), glicerol (PG), serina (PS) y, cuando no hay unida ninguna cabeza polar, ácido fosfatídico (PA). Mientras que en la posición sn-2 las cadenas laterales están unidas mediante enlace éster, en la posición sn-1 puede haber diferentes tipos de enlaces: éter vinílico, éter o éster, que se corresponden con las subclases plasmenil, plasmanil y fosfatidil, respectivamente. En la posición sn-2 de los glicerofosfolípidos hay esterificado un ácido graso que habitualmente es insaturado. En células inflamatorias, el AA se encuentra esterificado casi exclusivamente en la posición sn-2 [69]. 


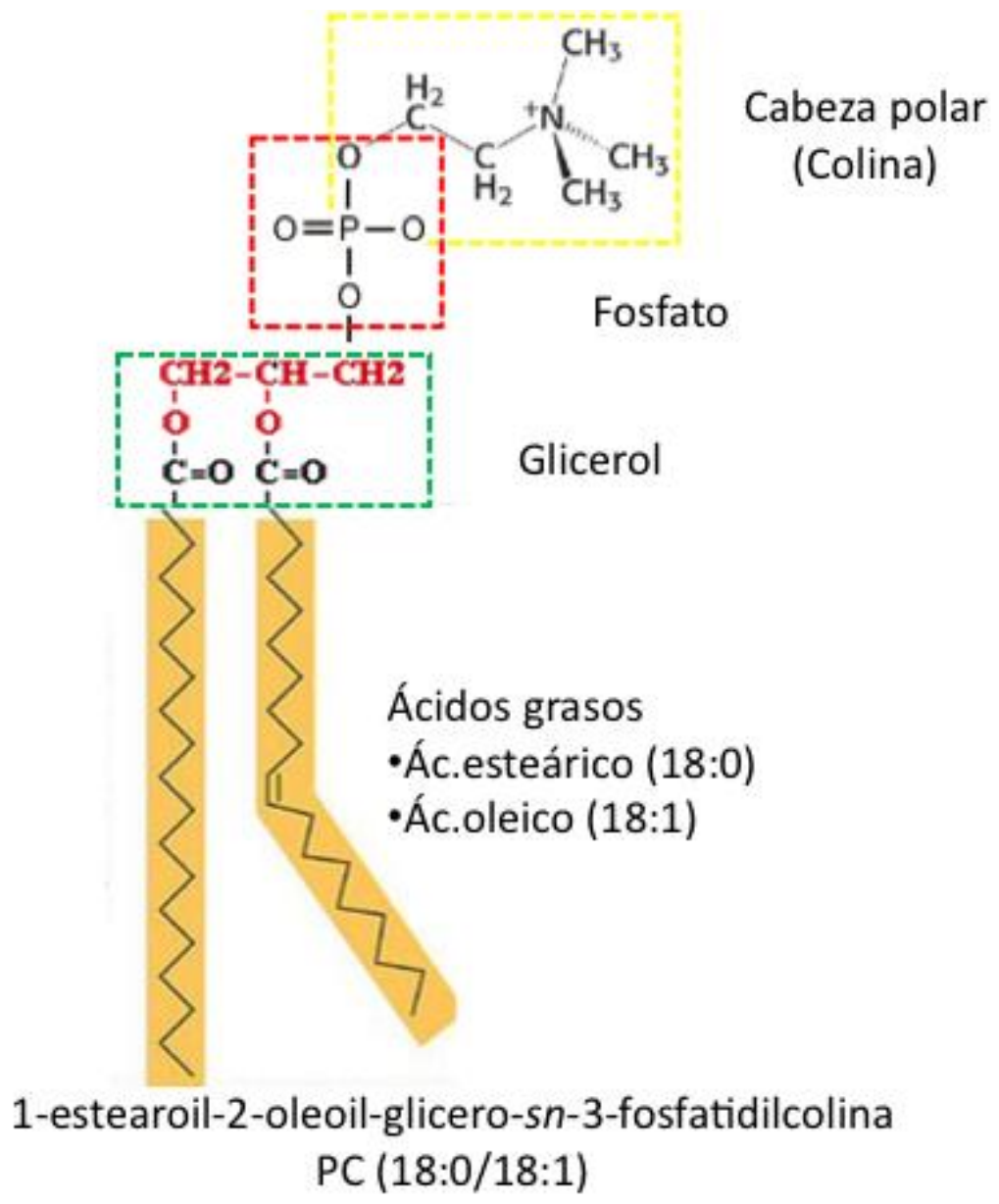

Figura 4. Esquema de un glicerofosfolípido y su correspondiente nomenclatura.

En las células implicadas en reacciones inflamatorias, los fosfolípidos con enlace éter en posición sn-1 representan un grupo importante. Dentro de este grupo, las especies que presentan enlace vinil éter, denominadas plasmalógenas, fueron descritas por primera vez por Feulgen y Volt en 1924 y contienen tanto etanolamina como colina como cabeza polar del esqueleto de glicerol [72]. La biosíntesis de los plasmalógenos se inicia en los peroxisomas. A través de la actividad de la enzima DHAP-AT (dihidroxiacetona fosfato aciltransferasa) se produce la unión de DHAP (dihidroxiacetona fosfato) con un ácido graso esterificado con CoA. Posteriormente, el enlace éter en la posición sn-1 se introduce por la ADHAP-S (alquil-DHAP sintetasa) mediante la sustitución del ácido graso en posición sn-1 por un alcohol. El siguiente paso es la reducción del grupo cetona de la posición sn-2 del alquil-DHAP dando como resultado la formación de 1-alquil-2-acil-sn-glicero-3fosfato (1-alquil-G3P).Esta reacción se cataliza por la acción de la acil/alquil-dihidroxiacetona reductasa (AA-DHAP-R), enzima que se ha encontrado tanto en peroxisomas como en retículo endoplasmático. En el retículo endoplasmático se completa la síntesis de las especies de plasmalógenos. Para ello, la alquil/acil-glicero-3-fosfato aciltransferasa (AAG3P-AT) lleva a cabo una acilación dando lugar a 1-alquil-2-acil-sn-glicero-3-fosfato, donde mediante la acción de una fosfohidrolasa $(\mathrm{PH})$ y la etanolamina-fosfotransferasa sustituye el grupo fosfato incorporando citidina-difosfato-etanolamina (CDP-etanolamina) para formar, en presencia de magnesio, 1-alquil- 
2-acil-sn-glicero-3-fosfoetanolamina (alquilacil-GPE) [73]. Con la desaturación, donde participan el citocromo b5 dependiente del transporte de electrones y la desaturasa $\Delta 1$-alquil, se finaliza la síntesis de los plasmalógenos de PE [74]. Mediante sucesivas metilaciones de la cabeza polar se pueden sintetizar plasmalógenos de PC a partir de los plasmalógenoss de PE [75].

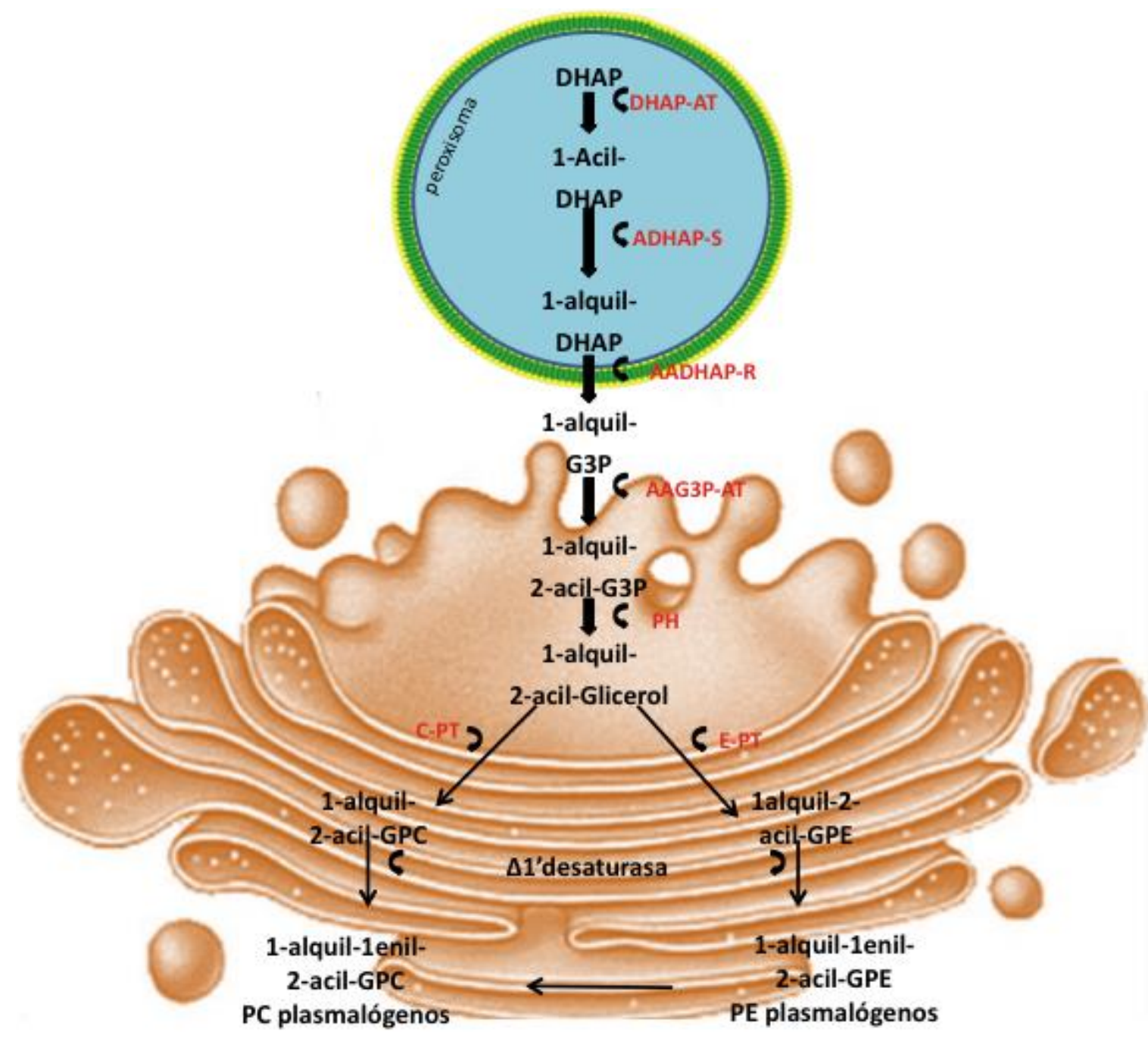

Figura 5 Esquema de la síntesis celular de diferentes especies plasmalógenas de glicerofosfolípidos.

La estructura y composición de los plasmalógenos y, en particular, el enlace vinil éter situado en la posición sn-1, dicta su papel en las membranas celulares. Los plasmalógenos han sido descritos como antioxidantes endógenos ya que el enlace vinil éter es propenso a ser atacado por oxidantes; como mediadores en la estructura y dinámica de la membrana debido a que exhiben una tendencia a no formar bicapas lipídicas reduciendo así la tensión superficial y la viscosidad; y como almacenes de ácidos grasos poliinsaturados y mediadores lipídicos dado que la posición sn-2 generalmente contiene AA o ácido docosahexaenoico [76]. 


\section{A.2.2.2 Movilización del ácido araquidónico}

El continuo tráfico de AA que participa en el control de los niveles de AA libre en las células [77] da lugar a un gran número de especies diferentes de glicerofosfolípidos con AA [78].

Dos reacciones contrarias controlan los niveles celulares de AA libre: por un lado, las fosfolipasas $A_{2}\left(P L A_{2}\right)$, que liberan $A A$ de la posición $s n-2$ de los fosfolípidos y, por otra parte, las lisofosfolípido aciltransferasas dependientes de CoA (LPLATS) que modulan las reacciones de acilación que reincorporan ese ácido graso en los fosfolípidos [79, 80].

El primer paso de la incorporación de AA en los lípidos celulares es la activación del grupo carboxilo del ácido graso por tioesterificación con CoA. Esta reacción es catalizada por acil-CoA sintetasas (ACSL) presentes en las células [80]. Por su implicación en el metabolismo de AA, cabe destacar las ACSL3, 4 y 6 , acil-CoA sintetasas de cadena larga, que muestran cierta selectividad por este ácido graso $[81,82]$.

El siguiente paso en la incorporación de $A A$ es la esterificación del ácido graso, predominantemente en la posición $s n-2$ de los glicerofosfolípidos, una reacción llevada a cabo por las LPLATs, en particular la familia de las denominadas aciltransferasas unidas a membrana (membrane-bound O-acyltransferase, MBOAT) [83]. Por su alta afinidad por el AA es necesario resaltar a la Liso-PC:acil-CoA aciltranferasa 2 (LPCAT2)[84], la lisoPC:acil-CoA aciltransferasa 3 (LPCAT3)[85], la lisoPI:acil-CoA aciltransferasa 1 (LPIAT1 o MBOAT7) [86, 87] y la ácido lisofosfatídico:acil-CoA aciltransferasa 3 (LPAAT3) [88].

Siguiendo este esquema de incorporación, en función de la concentración de AA libre en las células, el proceso se realiza a través de dos rutas diferenciadas: la ruta de novo, descrita por Kennedy y Weiss en 1956 [89], que es de alta capacidad y baja afinidad, y el ciclo de Lands, de alta afinidad y baja capacidad [90] que funciona principalmente cuando el AA está presente en concentraciones bajas.

En la ruta de novo, las moléculas de AA-CoA pueden esterificarse tanto en el glicerol-3fosfato (G3P) por la acción de la glicerol-3-fosfato aciltransferasa (GPAT) dando lugar a ácido lisofosfatídico (LPA), como en LPA por la acción del ácido de la LPAAT generando, en último lugar, PA [84]. El metabolismo de este PA puede generar dos derivados diferenciados: DAG mediante la activación de la fosfatidato fosfohidrolasas (PAP) que puede dar lugar a TAG a través de la acción de la diacilglicerol aciltransferasa (DGAT) o diversas clases de PL como PC, PE o PS; por otro lado, el otro derivado del metabolismo del PA es la citidina difosfato-DAG(CDP-DAG) que puede metabolizarse y formar PI, PS, PG y cardiolipinas (CL) [91].

Sin embargo, esta ruta de alta capacidad y baja afinidad no puede llegar a explicar la gran diversidad y asimetría que presentan los fosfolípidos. En 1958, Lands describió un rápido intercambio en posición sn-2 de los fosfolípidos regulado coordinadamente por las actividades de

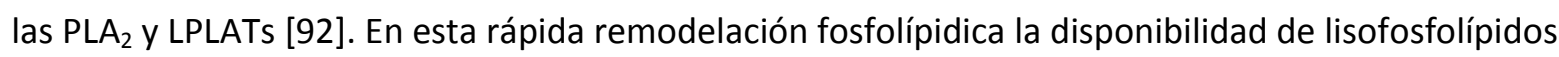
(lisoPL), que actúan como aceptores de AA, constituye un factor limitante [93]. 


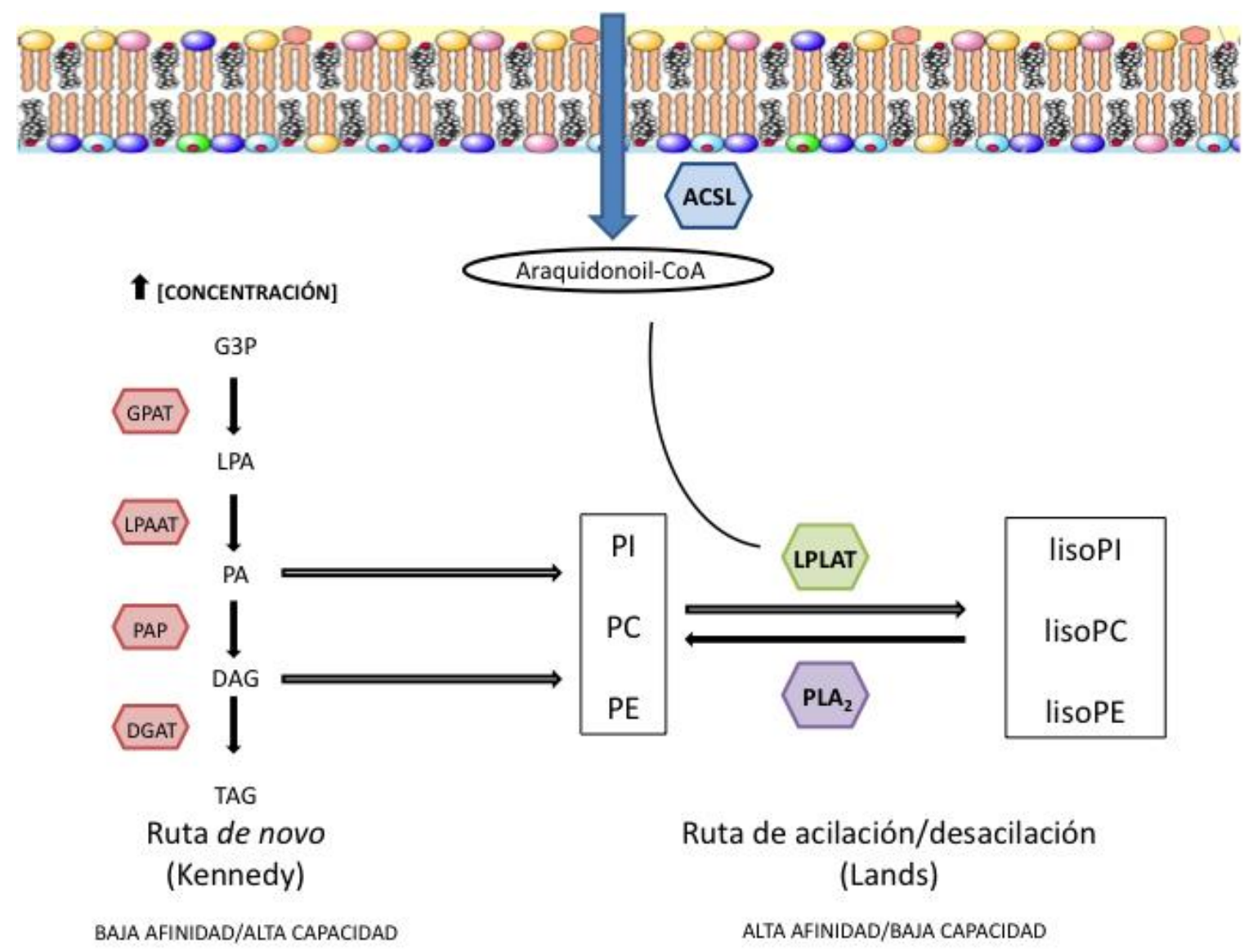

Figura 6 Esquema de las dos rutas de incorporación de AA libre a los glicerofosfolípidos

La unión del AA a los glicerofosfolípidos se encuentra sujeta también a sucesivas reacciones de intercambio directo entre especies, denominadas transacilaciones $[79,80]$. Estas reacciones son catalizadas por la transacilasa independiente de CoA (CoA-IT), una enzima que transfiere parte de ese AA preferentemente de especies de PC a especies plasmalógenas de PE [79]. Este hecho no sólo contribuye a la distribución final del ácido graso dentro de los diferentes grupos celulares de lípidos sino que también está implicado en la homeostasis de la membrana celular y en el control de las respuestas celulares durante la activación tanto fisiológica como fisiopatológica [58, 94]. Dado que la secuencia de la CoA-IT no ha sido aún descrita, actualmente los estudios de la regulación celular de la CoA-IT se realizan siguiendo la actividad de la enzima [95, 96]. 


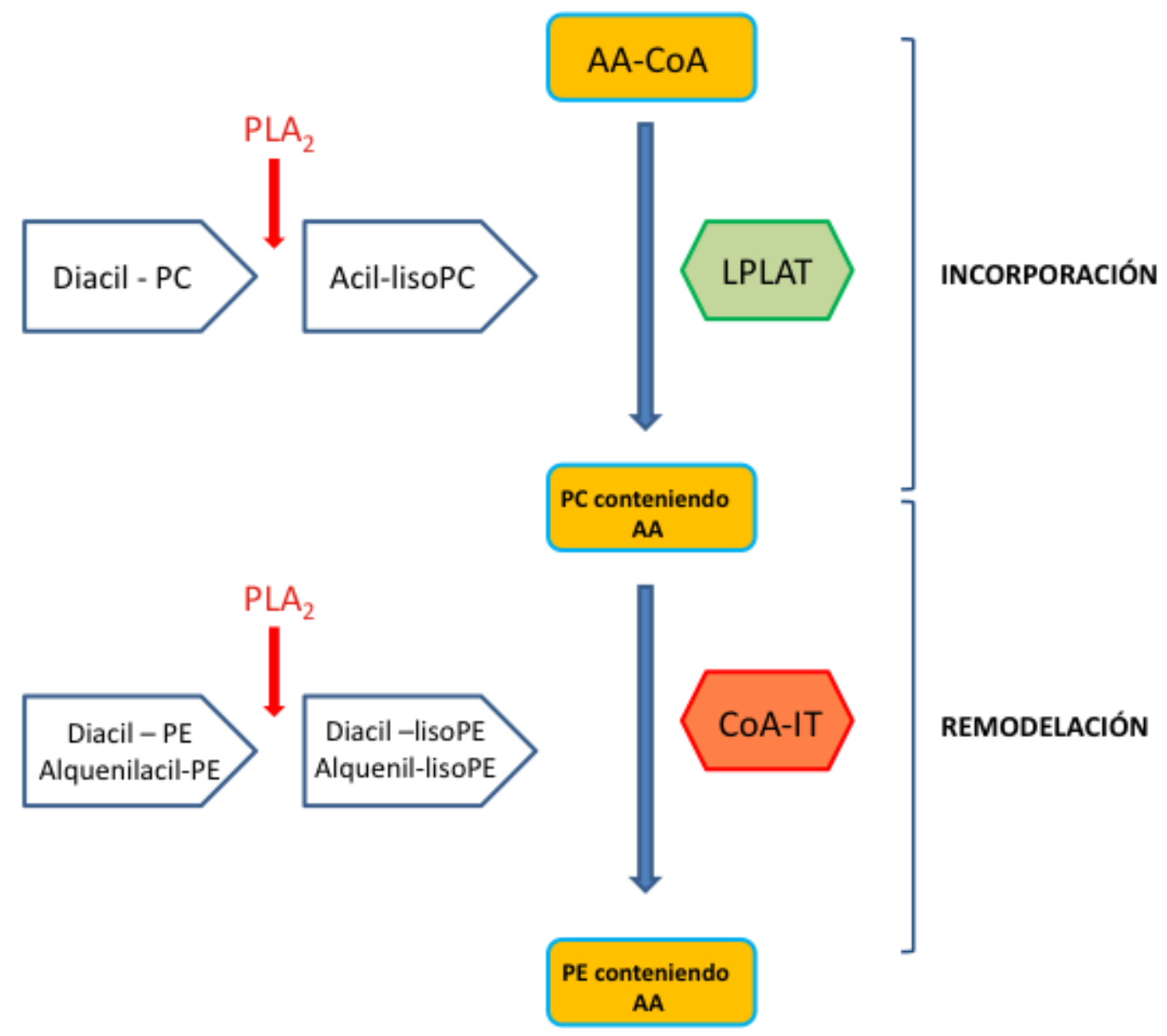

Figura 7 Esquema del intercambio de AA entre las especies de glicerofosfolípidos por transacilación

Una vez que el AA ha sido efectivamente incorporado en los fosfolípidos, el ácido graso puede ser liberado bajo condiciones de estimulación, por distintas enzimas PLA . Las PLA $_{2}$ hidrolizan el resto acilo de la posición sn-2 del glicerol, generando un ácido graso libre y un 2lisofosfolípido. El hecho de que, los ácidos grasos poliinsaturados como el AA se encuentren principalmente en la posición $s n-2$ del glicerofosfolípido, hace que las $\mathrm{PLA}_{2}$ jueguen un papel muy importante en la liberación de AA y la posterior generación de eicosanoides.

Además, los lisofosfolípidos producidos por la acción de las $\mathrm{PLA}_{2}$ pueden ser transformados en ácido lisofosfatídico o ser acetilados y formar PAF. Estos productos juegan diversos e importantes papeles fisiológicos y patológicos $[97,98]$

En condiciones basales, los niveles de AA libre son muy bajos debido a que las reacciones de reacilación dominan sobre las reacciones de desacilación. Diversos agonistas pueden producir la estimulación de las células fagocíticas al ser reconocidos por receptores de membrana. Esto implica la activación intracelular de las $\operatorname{PLA}_{2}[77,99,100]$ provocando que la velocidad de liberación en fosfolípidos exceda a la de reincorporación, lo que da lugar a la acumulación de AA libre seguida de su conversión en diversos eicosanoides. No obstante, bajo estas condiciones de estimulación, las reacciones de reacilación de AA siguen siendo muy significativas. Así, se ha descrito que solo una 
parte del AA producida por $\mathrm{PLA}_{2}$ es convertido en eicosanoides y el resto es reacilado de nuevo en fosfolípidos [101-103].

En mamíferos se han descrito más de 30 enzimas con actividad PLA ${ }_{2}$, [104, 105]. Atendiendo a un criterio de homología de secuencia, las fosfolipasas $A_{2}$ se han clasificado en 16 grupos $[104,106,107]$ aunque basados en propiedades bioquímicas pueden ser agrupadas en 5 familias principales, denominadas fosfolipasas secretadas dependientes de calcio $\left(\mathrm{SPLA}_{2}\right)$, fosfolipasas citosólicas dependientes de calcio $\left(\mathrm{CPLA}_{2}\right)$, fosfolipasas citosólicas independientes de calcio ( (PLA $_{2}$ ), acetilhidrolasas de los factores de activación plaquetaria (PAF) y fosfolipasas lisosomales.

Desde hace más de tres décadas, diferentes publicaciones han ido describiendo la activación de las $\mathrm{PLA}_{2}$ y la movilización de AA en células estimuladas con zimosán [108] y, en concreto, la liberación de AA en macrófagos peritoneales de ratón durante la fagocitosis de zimosán [103]. Los macrófagos estimulados con zimosán muestran un aumento de la liberación de $A A$, el cual es revertido en la presencia de inhibidores de $\mathrm{PLA}_{2}$, involucrando directamente a estas enzimas en la liberación de AA.

Posteriormente, se asignó a la fosfolipasa citosólica dependiente de calcio de grupo IVA $\left(\mathrm{CPLA}_{2} \alpha\right)$ un papel central e indspensable en la liberación de AA desde las diferentes clases de glicerofosfolípidos en macrófagos peritoneales de ratón [101]. En concreto, el zimosán induce un incremento en la actividad enzimática de la $\mathrm{CPLA}_{2} \alpha$ y el subsecuente aumento de la liberación de AA en macrófagos peritoneales de ratón mediante la elevación transitoria de los niveles de calcio intracelulares y la fosforilación de esta fosfolipasa [109].

Por otra parte, también se ha descrito la implicación de la $\mathrm{PLA}_{2}$ secretada de grupo $\mathrm{V}$ en la amplificación de la señal generada por la cPLA 2 . Así, los macrófagos peritoneales de ratones que no expresan esta $S P L A_{2}$ producen menos cantidades de eicosanoides como el leucotrieno $C_{4}\left(L_{T C}\right)$ y la prostaglandina $E_{2}$ en respuesta a zimosán, comparando con las células de ratones de la cepa salvaje [110]. En concreto la $\mathrm{SPLA}_{2}$ de grupo $\mathrm{V}$ se transloca a los fagosomas durante la fagocitosis del zimosán, coincidiendo con el máximo pico de producción de $\mathrm{LTC}_{4}$, cuya síntesis se ha demostrado localizada en el fagosoma gracias la tinción de este eicosanoide durante la fagocitosis [111]. Sin embargo, este papel amplificador de la $\mathrm{SPLA}_{2}$ de grupo $\mathrm{V}$ parece ser altamente dependiente de la cepa de ratón considerada [112]. 


\section{A.2.2.2.1 La CPLA $2 \alpha$}

La enzima que hoy conocemos como $\mathrm{CPLA}_{2} \alpha$ se describió por primera vez en 1986 por Leslie y Kramer en plaquetas y neutrófilos humanos, respectivamente [113, 114]. En 1991 Clark y Kramer purificaron, secuenciaron y clonaron la cPLA $\alpha$ de células U937 [115, 116]. El gen de esta $\mathrm{PLA}_{2}$ ha sido mapeado en el cromosoma 1q25 [117]. La enzima, que es se considera un enzima ubicua en tejidos de mamíferos [118], contiene 749 aminoácidos y un peso molecular de 85kDa $[115,116]$.

Mediante el uso de ratones deficientes en $\mathrm{CPLA}_{2} \alpha$ se ha demostrado que esta enzima es esencial para la liberación de AA y la posterior producción de eicosanoides en respuesta a zimosán [119]. Muchos fosfolípidos como PC, PE y PI son sustratos de la $\mathrm{CPLA}_{2} \alpha$ [120]. Aunque la enzima parece no presentar preferencia por ninguno de estos fosfolípidos [120], PC es relativamente un buen sustrato y se ha utilizado con asiduidad para determinar la actividad de esta $\operatorname{PLA}_{2}[115,116]$.

Diversos agonistas que actúan por diferentes mecanismos pueden inducir la liberación de $A A$, lo que sugiere que diferentes rutas pueden promover la activación de la $\operatorname{CPLA}_{2} \alpha$ [121]. Así, además del zimosán, el LPS (componentes de la pared bacteriana) el éster de forbol (PMA), ácido okadaico, fosfatidilinositol, 4,5-bifosfato ( $\mathrm{PIP}_{2}$ ), factor de activación plaquetaria (PAF) o ionónofos se han descrito como estímulos de la liberación de AA en macrófagos [101, 122-126]. Experimentos con ratones knockout del gen que codifica para esta fosfolipasa han observado una reducción significativa en los efectos de los procesos inflamatorios provocados por estos estímulos [97]. En la actualidad, se considera que es necesaria la implicación de la $\mathrm{CPLA}_{2} \alpha$ en la liberación de $\mathrm{AA}$ y posterior producción de eicosanoides en respuesta a diferentes estímulos lo que la define a la $\mathrm{CPLA}_{2} \alpha$ como una enzima central en la inflamación y la respuesta inmune innata.

Además de la actividad fosfolipasa, la cPLA $\alpha$ también posee actividad lisofosfolipasa y transacilasa [127]. A diferencia de la dependencia de calcio de la actividad fosfolipasa, se ha demostrado usando micelas como sustrato que la actividad lisofosfolipasa es independiente de calcio [127]. Gracias a esta actividad lisofosfolipasa, la $\mathrm{CPLA}_{2} \alpha$ es capaz de remover los dos ácidos grasos presentes en un diacil fosfolípido [107]. Nótese sin embargo que una gran proporción del AA presente en células fagocíticas se halla en fosfolípidos con énlaces éter o vinil éter en posición sn-1, no atacables por tanto por una lisofosfolipasa.

\section{A.2.2.2.1.1 Regulación de la cPLA $2 \alpha$}

La $\mathrm{CPLA}_{2} \alpha$ se regula fundamentalmente a nivel postranscripcional y esta regulación es mediada por calcio y por fosforilación [121]. La estructura tridimensional de esta enzima, observada mediante rayos $X$ [128] ha servido para una mejor comprensión de su actividad $y$ regulación. La $\mathrm{CPLA}_{2} \alpha$ presenta un dominio $\mathrm{C} 2$ de unión lipídica dependiente de calcio y un dominio catalítico $\alpha-\beta$ hidrolasa. Ambos dominios se requieren para su total actividad. La unión dependiende de calcio al dominio $\mathrm{C} 2$ puede activar la $\mathrm{CPLA}_{2} \alpha$, provocando el desplazamiento de la enzima a la membrana fosfolipídica $[115,129]$ y a las vesículas que contienen fosfolípidos. [130]. 
Además, los agonistas de la movilización de calcio inducen la liberación de AA promoviendo la translocación de la cPLA $2 \alpha$ desde el citosol a la envoltura nuclear y el retículo endoplasmático [66, 131-133]. Ciclooxigenasas y 5-lipoxigenasas, enzimas implicadas en la generación de eicosanoides a partir de $A A$, están también localizadas en estos sitios, sugiriendo un papel en la producción de eicosanoides en el núcleo [66, 134].

Después de la localización en la membrana, el sitio activo formado por serina-228/ácido áspártico-549 localizado en el dominio $\alpha / \beta$ hidrolasa se encarga de catalizar la hidrólisis $[121,135]$. El sitio catalítico está compuesto por una región central $\alpha-\beta$ hidrolasa conservada a lo largo de muchas lipasas diferentes y una región en forma de caperuza encontrada solo en esta enzima. Dentro de esta caperuza, existe una región que actúa como tapa y previene el modelado de los sustratos fosfolipídicos en el sitio activo. Se ha propuesto que esta enzima debe experimentar un cambio conformacional en la presencia de sustrato permitiendo, de este modo, abrir la región que hace de tapa. De hecho, algunos estudios usando sustratos lipídicos e inhibidores específicos que se unen al sitio activo han mostrado un cambio conformacional en la región que corresponde a la tapa en presencia de sustrato [136].

Se ha demostrado también la activación de la $\operatorname{CPLA}_{2} \alpha$ mediada por la fosforilación de residuos de Serina $\left(\operatorname{Ser}^{505}, \operatorname{Ser}^{515}\right.$ y Ser ${ }^{727}$ ) de la secuencia de aminoácidos que compone la proteína. Así, la sobreexpresión del gen de la $\mathrm{CPLA}_{2} \alpha$ en células $\mathrm{CHO}$ con una mutación en la $\operatorname{Ser}^{505}$ ha mostrado una menor liberación de AA que la sobreexpresión de la $\operatorname{cPLA}_{2} \alpha$ en la cepa salvaje [137][Lin 1993]. Dicha fosforilación es llevada a cabo por diferentes quinasas como la MAP quinasa (MAPK) $[122,137]$. En el caso de la fagocitosis del zimosán se ha descrito que la fosforilación de la $\mathrm{CPLA}_{2} \alpha$ en la $\mathrm{Ser}^{505}$ es mediada por ERK y p38 MAPK, aunque otros mecanismos de regulación dependientes de MAPK se han propuesto como promotores de la liberación de AA por el desplazamiento de la $\mathrm{CPLA}_{2} \alpha$ a la membrana plasmática. Así, se ha demostrado que la $\mathrm{CPLA}_{2} \alpha$ se trasloca a fagosoma durante la fagocitosis de las partículas de zimosán en macrófagos peritoneales de ratón [138]. Por su parte, en macrófagos humanos derivados de monocitos tratados con zimosán opsonizado, esta traslocación es mediada por la activación de JNK, el cual es responsable de la fosforilación de $\mathrm{CPLA}_{2} \alpha$ en la $\operatorname{Ser}^{505}$ [139].

Sin embargo, en algunos modelos celulares el papel de la fosforilación de $\operatorname{Ser}^{505}$ ha sido cuestionado. En plaquetas humanas, la trombina promueve la fosforilación de la $\operatorname{cPLA}_{2} \alpha$ en $\operatorname{Ser}^{505}$ por el homólogo de MAPK, p38. A pesar de ello, la inhibición de la activación de la p38 por el inhibidor SB203580, previene la fosforilación de $\mathrm{CPLA}_{2} \alpha$ en la $\operatorname{Ser}^{505}$ pero no afecta a la liberación de AA [140].

Además del papel del calcio y la fosforilación de $\operatorname{Ser}^{505}$ en la regulación de $\operatorname{cPLA}_{2} \alpha$, se han descrito otros mecanismos que pueden jugar un papel importante en la regulación de la actividad de la cPLA $\alpha$. Así, se ha demostrado que la $\mathrm{CPLA}_{2} \alpha$ puede ser activada por los mediadores lipídicos ceramida-1-fosfato $[141,142]$ y la unión de alta afinidad a $\mathrm{PIP}_{2}[143]$ promueve la traslocación de la $\mathrm{CPLA}_{2} \alpha$ del citosol a membrana perinuclear con niveles basales de calcio intracelular [144]. La 
$\mathrm{CPLA}_{2} \alpha$ presenta un grupo catiónico de lisinas (Lys ${ }^{488} / \mathrm{Lys}^{541} / \mathrm{Lys}^{543} / \mathrm{Lys}^{544}$ ) que une fosfolípidos aniónicos como PIP 2 [145]. La mutación en dicho grupo de lisinas $\operatorname{CPLA}_{2} \alpha$ impide que la enzima pueda traslocarse a las membranas de los fagosomas [146].

Especies de PC, la anexina y el $\mathrm{O}_{2}^{-}$generado por la acción de la NADPH oxidasa también se han descrito como reguladores de la actividad de la $\mathrm{CPLA}_{2} \alpha$ [147-149]. En este último caso, la producción de $\mathrm{O}_{2}{ }_{2}$, aparte de estar implicada en la activación de la $\operatorname{cPLA}_{2} \alpha$ a través de un incremento intracelular de calcio [149], es también crítica en la muerte de patógenos y en el mantenimiento de una defensa eficiente contra posibles huéspedes [47]. Esto lleva a sugerir en una acción coordinada de la liberación de AA mediante la regulación de la $\operatorname{CPLA}_{2} \alpha$ y la producción de $\mathrm{O}_{2}{ }^{-}$durante la fagocitosis de patógenos como el zimosán.

Además de la regulación postranscipcional, la $\mathrm{CPLA}_{2} \alpha$ presenta otra regulación que se lleva a cabo a nivel transcripcional $[150,151]$. Las citoquinas y los factores de crecimiento pueden incrementar el RNA mensajero y los niveles de proteína de la $\mathrm{CPLA}_{2} \alpha$ en diversos tipos celulares [121]. El incremento de la expresión se relaciona con el aumento de la producción de prostaglandinas, lo cual puede ser prevenido por glucocorticoides [152].

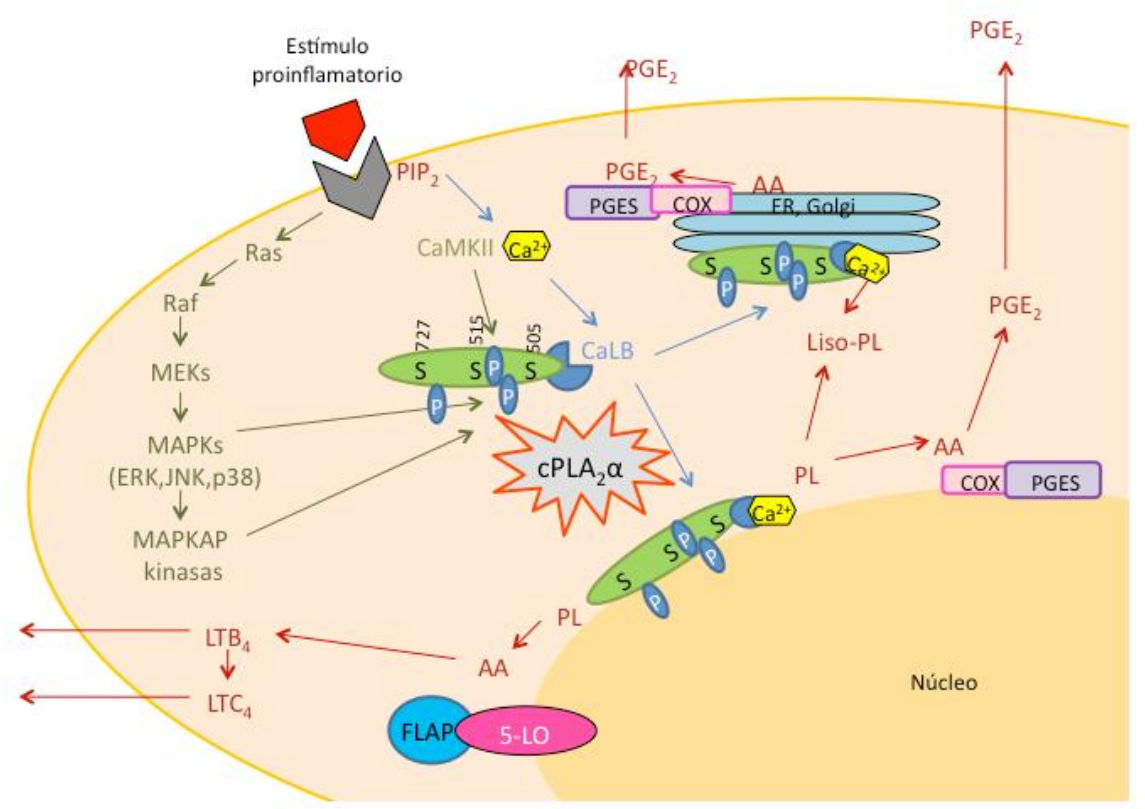

Figura 8. Esquema de regulación de la $\mathrm{cPLA}_{2} \alpha$. 


\section{A.2.2.3 Eicosanoides}

Una variedad de mediadores desencadenan la respuestra inflamatoria, entre los que se incluyen los eicosanoides, [48, 49]. Los eicosanoides son compuestos lipídicos que se producen por la oxigenación de ácidos grasos poliinsaturados esenciales de 20 átomos de carbono, principalmente el AA.

La formación de eicosanoides tras la liberación del AA de los fosfolípidos bajo condiciones de estimulación es realizada a través de la ciclooxigenasa (COX), la lipoxigenasa (LOX), el citocromoP450 y otras reacciones no enzimáticas de oxidación de AA. Estas cuatro rutas dan lugar a multitud de compuestos como prostaglandinas (PG), isoprostanos, tromboxanos (TX), leucotrienos (LT), lipoxinas y ácidos epoxieicosatrienoicos. Todos ellos actúan de forma paracrina/autocrina a través de receptores específicos de la membrana plasmática [95].

Para la biosíntesis de PG y TX a partir de AA, la síntesis de la prostaglandina $\mathrm{H}_{2}\left(\mathrm{PGH}_{2}\right)$ vía COX es el primer paso. La COX incorpora $\mathrm{O}_{2}$ molecular y forma $\mathrm{PGG}_{2}$ que se reduce a continuación para formar $\mathrm{PGH}_{2}$ por la acción del sitio activo de la peroxidasa. $\mathrm{PGH}_{2}$ es el sustrato de diferentes $P G$ y $T X$ sintasas que se expresan en tejidos y células de una manera selectiva y sintetizan $P G_{2}$, $\mathrm{PGD}_{2}, \mathrm{PGI}_{2}, \mathrm{PGF}_{2}$ y $\mathrm{TXA}_{2}$ [153]. Estos compuestos pueden cumplir importantes funciones biológicas como la modulación del tono muscular, permeabilidad vascular, hiperalgesia, fiebre y agregación plaquetaria [Stables 2010].

$\mathrm{LT}$, eoxinas, lipoxinas y ácidos hidroperoxieicosatetranoicos (HPETEs) son sintetizados a partir de AA por las enzimas LOX (5-, 12- y 15-LOX) que añaden $\mathrm{O}_{2}$ molecular en el AA estéreoespecíficamente. La 5-LOX forma ácido 5-hidroperoxieicosatetranoico (5-HPETE) que se metaboliza a $\mathrm{LTA}_{4}$ en un segundo paso. El $\mathrm{LTA}_{4}$ es inestable y puede convertirse rápidamente en $\mathrm{LTB}_{4}$, un potente quimioatrayente para leucocitos polimorfonucleares. Adicionalmente, el $\mathrm{LTA}_{4}$ se puede convertir en $\mathrm{LTC}_{4}$ el cual es precursor de $\mathrm{LTD}_{4}$ y $\mathrm{LTE}_{4}$. Estos tres leucotrienos actúan en la respuesta alérgica [154]. Por su parte, las eoxinas se producen de una manera similar a los leucotrienos pero por la acción de la 15-LOX y son casi tan potentes como los leukotrienos derivados de la 5lipoxigenasa [155]. Finalmente, las lipoxinas son generadas por síntesis transcelular a través de la 15-LOX y, además de estar implicadas en la respuesta antiinflamatoria [156], también se les ha asignado propiedades anticancerígenas y neuroprotectoras $[157,158]$.

Otros metabolitos como los ácidos eicosatrienoicos (EET) y sus productos derivados de la hidrólisis del grupo epóxido, los ácidos dihidroxieicosatrienoicos (DHET) son generados por la acción de las enzimas citocromo-P450 [159]. Los EET se han asociado con propiedades antiinflamatorias en enfermedades cardiovasculares [160] y sus niveles bajos parecen estar implicados en el desarrollo de enfermedades como la obesidad y la diabetes [161].

La cuarta y última ruta de formación de eicosanoides es la reacción de AA con especies oxigenadas para formar un grupo de compuestos conocido como isoprostanos. Debido a que las reacciones no son estereoselectivas, generan diferentes isómeros con estructuras similares a sus 
respectivas prostaglandinas. Debido a sus orígenes, los isoprostanos se han usado como marcadores de estrés oxidativo [162].

Los eicosanoides influyen en la activación, migración y diferenciación de las células del sistema inmune y generalmente se asume que son pro-inflamatorios. Sin embargo, algunos eicosanoides son capaces de controlar la síntesis de citoquinas, pudiendo jugar de este modo, papeles pro- y anti-inflamatorios [163]. Así, PGE 2 puede inducir la COX-2 en fibroblastos que, a la vez que puede estimular su propia producción, tiene la capacidad tanto de inducir la producción de citoquinas como la interleuquina 6 (IL-6) en macrófagos como de inhibir la 5-LOX y, de este modo, disminuir la producción de los LT de serie 4 e inducir la 15-LOX, promoviendo así la formación de lipoxinas [8].

Esta actividad de los eicosanoides como reguladores en los procesos inmunopatológicos incluye, además, remodelación tisular crónica, cancer, asma, artritis reumatoide y desordenes autoinmunes. También se les reconoce la capacidad para regular respuestas fisiológicas como la homeostasis vascular, la protección de la mucosa gástrica y la agregación plaquetaria [164].

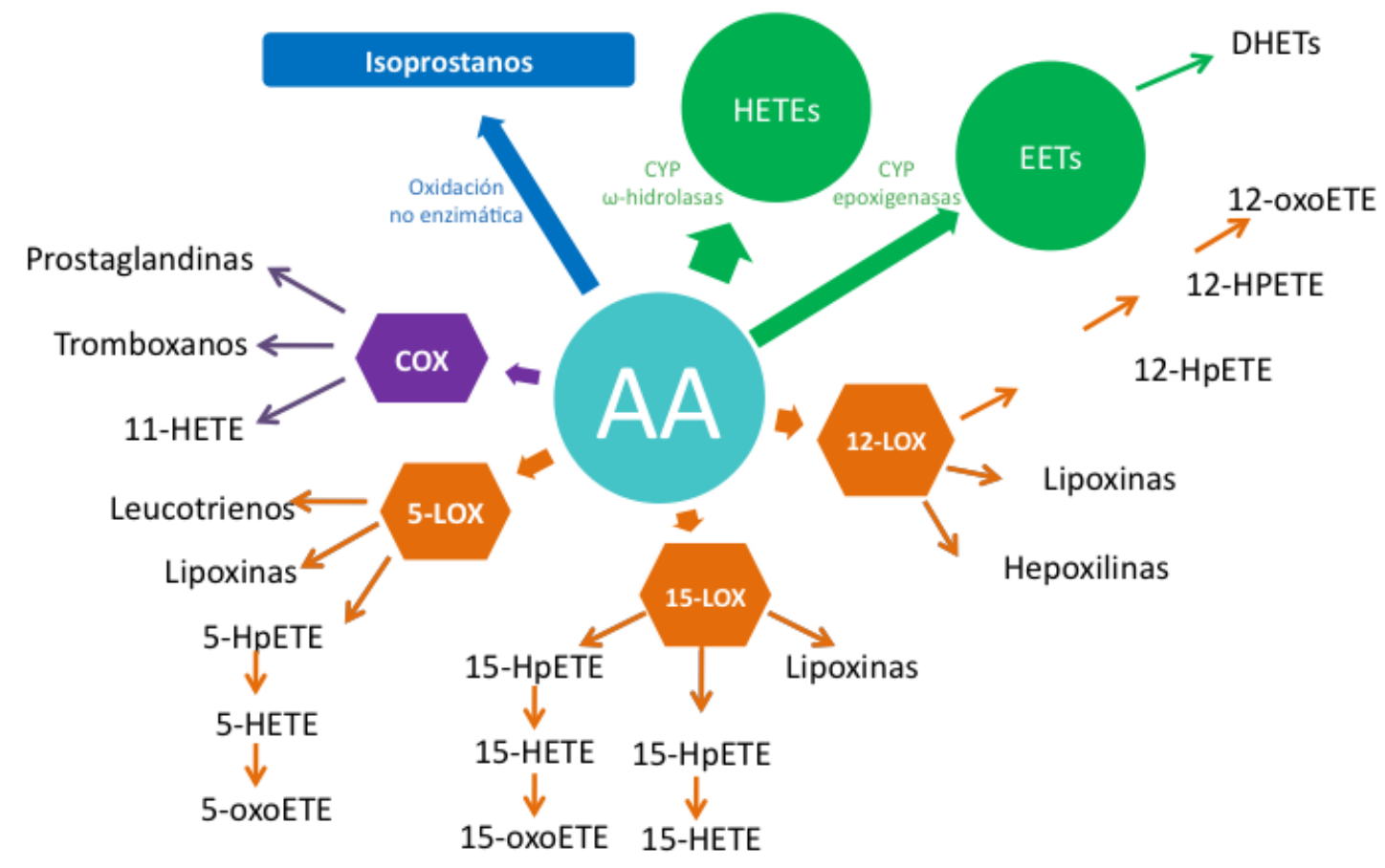

Figura 9 Esquema de las diferentes rutas de síntesis de los diversos eicosanoides a partir de AA. 


\section{A.3 La espectrometría de masas como herramienta de análisis}

Tradicionalmente, los estudios de liberación e incorporación celular de AA de los fosfolípidos han hecho uso de ácidos grasos marcados radiactivamente. Después de la extracción lipídica y la separación cromatográfica, la cuantificación se llevaba a cabo mediante contaje de centelleo líquido [58, 71, 94, 165]. Sin embargo, usando esta metodología no es posible discernir la composición molecular exacta de los fosfolípidos que contienen dicho AA. Este problema se ha resuelto mediante el análisis por espectrometría de masas (MS).

Las moléculas se definen, entre muchos otros aspectos, por su masa molecular y por su polaridad. Además pueden presentar carga eléctrica, ya sea de forma natural o por haber sido estimulados en un campo eléctrico. A la relación entre la masa molecular y la carga eléctrica de cualquier analito se denomina relación masa carga o $\mathrm{m} / \mathrm{z}$.

La MS es una técnica basada en la detección de moléculas por dicha relación $\mathrm{m} / \mathrm{z}$ lo cual proporciona a esta técnica una gran capacidad de identificación de diferentes moléculas, aspecto sumamente útil en diferentes campos como la proteómica o la metabolómica.

El espectrómetro de masas se caracteriza por el tipo de ionización que emplea para que los analitos adquieran carga (fuente de ionización) y por el proceso que utiliza para separar esos iones (analizador). En el proceso de ionización de las moléculas, la energía suministrada puede fragmentar el analito. Según su capacidad de fragmentación, las fuentes de ionización se clasifican en fuertes y suaves. Debido a que la volatilización de la muestra no es necesaria, la ionización suave ha sido ampliamente utilizada en la detección de glicerofosfolípidos. Dentro de los métodos suaves, se encuentran el bombardeo con átomos rápidos (FAB), la desorción/ionización láser asistida por matriz (MALDI), la ionización mediante electrospray (ESI) y la ionización química a presión atmosférica (APCI) [166].

La ESI-MS no requiere reacciones de derivatización, se caracteriza por una alta sensibilidad y una moderada complejidad experimental y produce resultados reproducibles [167] En esta técnica, el disolvente en el que está la muestra adquiere carga y, mediante la evaporación de éste, la carga es transferida a los analitos, generalmente como ganancia o pérdida de un protón. ESI consigue la ionización de compuestos de polaridad media y media-alta con relación $\mathrm{m} / \mathrm{z}$ desde 100 hasta más allá de 10000 unidades. Además, ESI permite que la ionización se pueda llevar a cabo tanto en modo positivo como en negativo, proporcionando una variable más a la hora de la optimización de la detección de los analitos. Otra de las ventajas de ESI es su capacidad de acoplamiento a HPLC.

Las características de ionización de los glicerofosfolípidos dependen de su estructura. Un glicerofosfolípido está caracterizado por la cabeza polar (que define su clase), por la longitud de las cadenas laterales de las posiciones $s n-1$ y $s n-2$ y por la regioisomería, es decir, la posición relativa de las cadenas laterales en el esqueleto de glicerol (especies). Esta estructura los hace aptos para el 
análisis mediante MS, y en especial, mediante ESI ya que adquieren carga negativa o positiva fácilmente gracias al fosfato o la cabeza polar unida a él. Aunque dadas sus características, el análisis de los glicerofosfolípidos se ha llevado a cabo principalmente mediante ESI, también hay estudios realizados mediante APCI [168].

En cuanto a los analizadores, diferentes tipos se han utilizado en el análisis de glicerofosfolípidos, entre los que destacan el de tiempo de vuelo (ToF) [169], el triple cuadrupolo [170], la trampa de iones [171], el q-trap [172], el basado en la transformada de Fourier (FTICR) [173] y el orbitrap [174, 175]. Los analizadores de iones más utilizados en análisis de glicerofosfolípidos por la MS son el analizador de triple cuadrupolo y la trampa iónica.

En el análisis mediante triple cuadrupolo, un método de trabajo es el basado en el precursor ion scanning. En el aparato, el primer cuadrupolo escanea el rango de $\mathrm{m} / \mathrm{z}$ que se programe, en este caso el de los glicerofosfolípidos; en el segundo, la cámara de colisión, los iones seleccionados anteriormente son fragmentados por disociación inducida por colisión (CID), y el tercer cuadrupolo transmite un fragmento con una $\mathrm{m} / \mathrm{z}$ específica, de tal modo que sólo se detectan los iones separados en el primer cuadrupolo que poseen un fragmento característico $[176,177]$. Así, la infusión directa junto con el precursor ion scanning son capaces de analizar familias de compuestos con $\mathrm{m} / \mathrm{z}$ diferentes pero que comparten fragmentos característicos comunes que corresponden a los valores de $\mathrm{m} / \mathrm{z}$ del ión precursor. De este modo, todas las especies de $\mathrm{Pl}$, con $\mathrm{m} / \mathrm{z}$ distintas debido a la variedad del número de carbonos y dobles enlaces de las cadenas de los ácidos grasos, serán detectadas en el tercer cuadrupolo si en el primer cuadrupolo se ha seleccionado el fragmento característico de la cabeza polar de inositol correspondiente a una $\mathrm{m} / \mathrm{z}$ de 241 en modo negativo. De forma similar, familias de compuestos pueden ser caracterizados por CID por una específica perdida neutra (NL de sus siglas en inglés Neutral Loss). En este análisis, el primer cuadrupolo y el tercer cuadrupolo pueden estar en modo scan pero acoplados con la diferencia de $\mathrm{m} / \mathrm{z}$ de NL. Sin embargo, el mayor problema es que, en la medida de que la información de la masa obtenida corresponde a la suma de carbonos y dobles enlaces de los dos ácidos grasos presentes, no es posible identificar inequívocamente los ácidos grasos presentes en el glicerofosfolípido ni su posición en el esqueleto de glicerol. Otro inconveniente de este procedimiento es que los complejos efectos matriz puede producir supresión iónica y la señal de las especies presentes a bajas concentraciones en la muestra pueden perderse. 
Q1

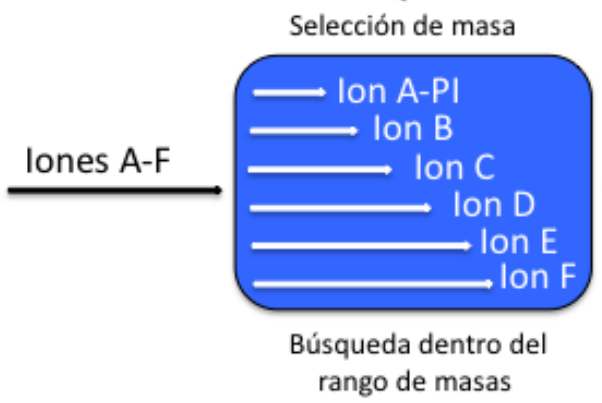

Q2

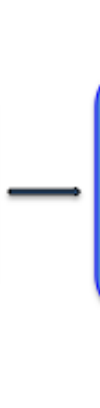

Celda de colisión

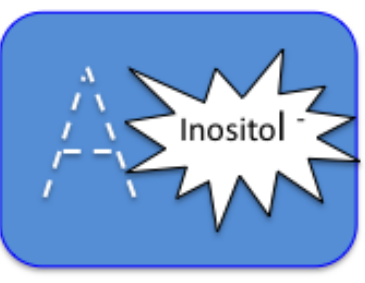

Fragmentación del ión seleccionado (ión A)
Q3

Filtrado sólo el fragmento 241

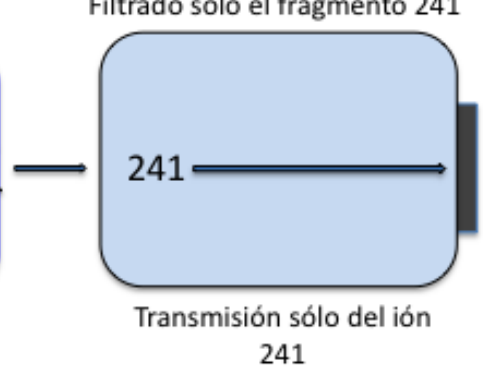

Figura 10. Figura del funcionamiento del MS-triple cuadrupolo. Se detalla el método precursor ion scanning.

Por su parte, en la trampa de iones la fragmentación se produce por transmisión de energía cinética al ión que se pretende fragmentar. El choque con el gas de colisión (Helio o Argón) aumenta la energía interna del analito y produce la fragmentación que es dependiente de su estructura. Aunque en la trampa de iones el proceso de aislamiento y fragmentación de iones es fuertemente dependiente del tiempo, esta técnica otorga la posibilidad de realizar más de un ciclo de aislamiento y fragmentación $\left(\mathrm{MS}^{\mathrm{n}}\right)$, de modo que se puede conseguir una mayor caracterización estructural de los analitos [178, 179].

Sin embargo, el hecho de que las trampas iónicas no son válidas para los análisis de cuantificación durante la fragmentación (método MS/MS) provoca que la única manera de cuantificar sea mediante el análisis de los iones producidos en la fuente de ionización (MS) lo que podría hacer muy complicada la caracterización de todos las clases de glicerofosfolípidos debido a que la gran diversidad estructural que éstos presentan. Por otra parte, la supresión iónica en el análisis por el uso de la infusión directa puede llegar incluso eliminar señales menores de glicerofosfolípidos.

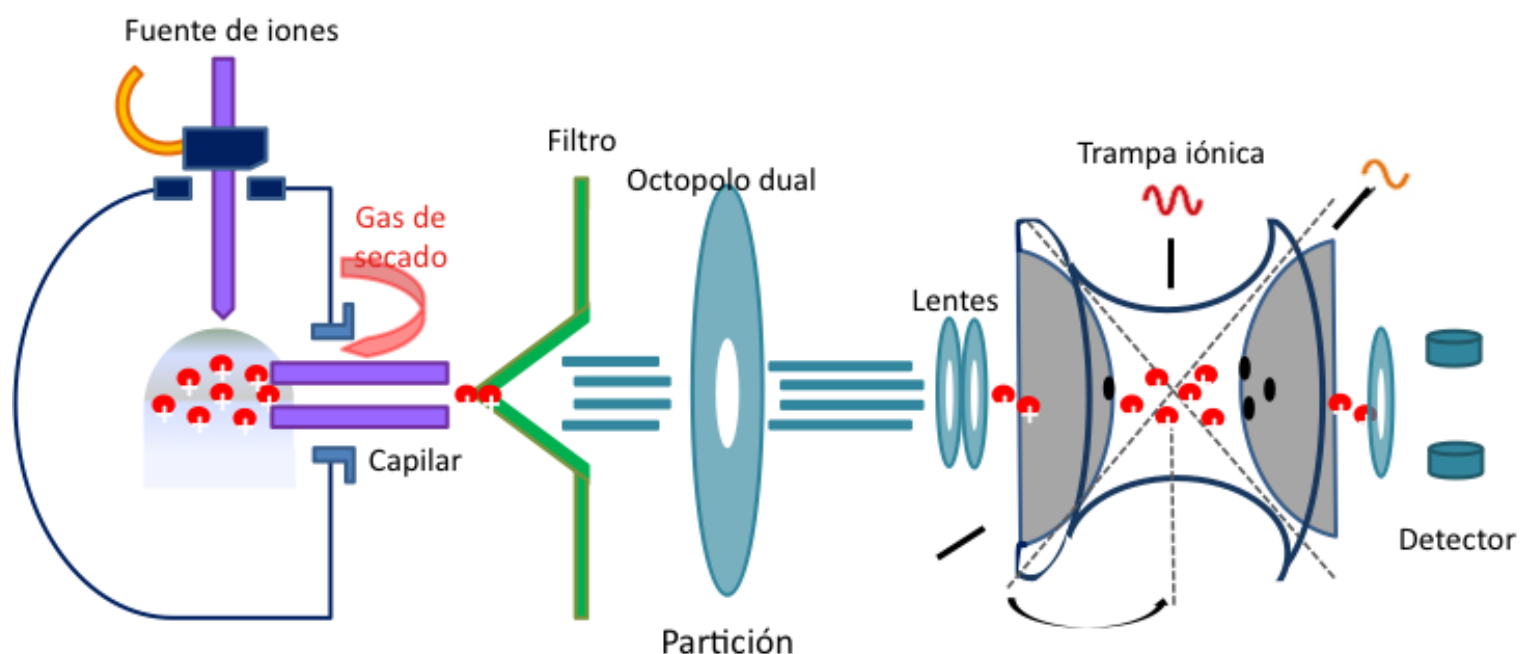

Figura 11 Figura del funcionamiento del MS-ion trap. 
Surge entonces la necesidad de separar de forma previa los analitos presentes en la muestra para minimizar los efectos de matriz y mejorar así la obtención de información estructural. La técnica analítica de separación por excelencia es la cromatografía, de la que existen diferentes modalidades: cromatografía en capa fina (TLC), cromatografía de gases (GC) o cromatografía de líquidos (LC) entre la que destaca por su gran capacidad de análisis, la cromatografía de líquidos de alta resolución (HPLC).

La cromatografía de líquidos ofrece rapidez, resolución, alta especificidad y alta sensibilidad. Además, a diferencia de la TLC, al no exponer la muestra a la atmósfera evita la oxidación de los analitos los cuales además al ser separados se pueden recoger automáticamente en fracciones para su posterior purificación o análisis. En este tipo de separación, los analitos se reparten entre una fase estacionaria sólida y una fase móvil líquida.

En 1975 se empezó a utilizar la técnica HPLC en el análisis de glicerofosfolípidos [180], y ya en 1994 se aplicó el acoplamiento a la MS con ionización por ESI [181]. A partir de entonces, el acoplamiento del HPLC con la MS ha sido con frecuencia mediante ESI y, teniendo en cuenta la separación iónica, se han usado diferentes analizadores [182]. Las trampas iónicas se ha usado en modo escaneo completo (HPLC-ESI-MS) [181, 183, 184]. Es este tipo de análisis por MS, los problemas de saturación del analizador se han evitado por la separación previa por cromatografía.

La separación de glicerofosfolípidos por HPLC puede llevarse a cabo por el uso de dos fases estacionarias distintas, denominadas fase normal (NP) y fase reversa (RP) [182].

En la modalidad de fase normal (NP-HPLC), la fase móvil es no polar y la fase estacionaria polar, de modo que las moléculas diluidas en la fase móvil interactúan con una fase estacionaria polar, generalmente silica gel [185] o columnas modificadas diol [186]. Los glicerofosfolípidos son separados fundamentalmente por la polaridad de sus cabezas polares, primero eluyen aquellos con cabeza más apolar y finalmente los que tienen la cabeza más polar. Los eluyentes más utilizados para la separación de glicerofosfolípidos mediante NP-HPLC han sido cloroformo, metanol, isopropanol, hexano, etanol, agua y acetonitrilo.

Por su parte, la cromatografía en fase reversa (RP-HPLC) presenta una fase estacionaria apolar compuesta de sílice recubierta con cadenas hidrocarbonadas, comúnmente octadecil y octil [181, 183, 184]. En esta modalidad los glicerofosfolípidos se separan fundamentalmente según las características de las cadenas laterales (longitud y dobles enlaces) unidas en las posiciones sn-1 y sn-2 del esqueleto de glicerol, eluyendo primero aquellas que presentan un menor número de carbonos y un mayor número de dobles enlaces [187]. Esto implica que los glicerfosfolípidos pertenecientes a la misma clase (la misma cabeza polar) y presentando la misma masa/carga pero conteniendo diferentes cadenas acil, pueden ser separados por este procedimiento.

Tanto la NP como la RP-HPLC ofrecen una buena separación que evita interferencias en el análisis. Sin embargo, el hecho de que los glicerfosfolípidos coeluyan por la cabeza polar en NPHPLC, limita su capacidad analítica. Cuando se requiere el análisis de compuestos minoritarios y/o especies concretas, la RP-HPLC es la técnica de separación más usada. No obstante, mientras que 
es posible una buena separación de PE, PC y PI por la RP-HPLC, PA muestra frecuentemente la formación de colas en los picos cromatográficos que a menudo dificultan su cuantificación. Aunque se han mejorado los métodos [188], en el análisis de PA se utiliza preferentemente la NP-HPLC. Esta modalidad también se usa en al análisis de especies de lisofosfolípidos debido a que la única presencia de una cadena acil hace fácil la identificación una vez separados por su cabeza polar.

El uso de la HPLC acoplado a MS (HPLC/MS) o la infusión directa a MS ha permitido alcanzar la información estructural favoreciendo de este modo un mayor conocimiento de la dinámica celular del AA $[189,190]$ y del perfil lipidómico de especies fosfolipídicas que contienen AA [78]. De este modo, Astudillo et. al. al comparar la distribución de fosfolípidos que contienen AA en monocitos de sangre periférica humana [191], macrófagos derivados de monocitos humanos [192] y macrófagos peritoneales de ratón [95] pudo definir diferencias en las especies fosfolipídicas concretas en estos tipos celulares, incluyendo especies plasmalógenas de gran importancia biológica.

Además, para una aproximación metabolipidómica, la combinación de la MS con el uso de isótopos estables como el AA marcado con deuterios puede proporcionar información acerca de la movilización del AA bajo diferentes condiciones de estimulación. De este modo se puede profundizar en un estudio comparativo de la remodelación lipídica entre las condiciones de estimulación y las condiciones de equilibrio que presenta el estado basal.

Aunque estos estudios centran la atención en el análisis de los fosfolípidos con el AA, otros estudios han ampliado el abanico en la comprensión de los glicerofosfolípidos que pueden actuar como biomarcadores, de productos lipídicos relacionadas con los procesos inflamatorios o la localización subcelular de especies lipídicas.

Así, se ha llegado a la identificación en macrófagos de glicerofosfolípidos inusuales como especies de PI con enlaces éter, especies de PE que contienen cadenas de ácidos grasos muy largas o fosfolípidos que contienen treonina como cabeza polar [193] que pueden actuar como biomarcadores. Además, recientemente mediante el uso combinando de la HPLC-ion trap MS y la HPLC-triple cuadrupolo MS se han descrito, en respuesta a diferentes niveles de estrés oxidativo por $\mathrm{H}_{2} \mathrm{O}_{2}$ en células EA.hy926, siete lisofosfolípidos relacionados con la activación de $C P L A_{2} \alpha$, los cuales podrían ser potencialmente considerados como biomarcadores en condiciones de estrés [194].

Otros análisis lipidómicos se han dirigido a establecer la dinámica del metabolismo lipídico y la regulación durante la estimulación inflamatoria. Análisis cuantitativos por la MS en los que se han llegado a identificar cuatrocientas especies lipídicas incluyendo ácidos grasos, acil-CoAs, eicosanoides, glicerofosfolípidos, esfingolípidos, esteroles y glicerolípidos [195].

La aplicación de las técnicas de MS para la cuantificación de eicosanoides ha supuesto un importante avance en este campo de investigación ya que permite el análisis a gran escala en contraposición de los tradicionales análisis basados en los ensayos de inmunoabsorción ligado a enzima (ELISA) que sólo permiten el análisis de un único eicosanoide por ensayo. El uso de la MS 
ha permitido la realización de perfiles de eicosanoides con más de 140 especies detectadas [196] incluyendo metabolitos derivados de AA generados por las rutas COX, LOX y CYP450 y aquellos derivados de rutas no enzimáticas. Además, han podido ser detectados dihomoprostaglandinas derivadas de ácido adrénico $[61,64]$ en todos los tipos de macrófagos, sugiriendo que estos compuestos pueden poseer significado biológico.

Por otra parte, análisis en macrófagos de las especies lipídicas de los diferentes orgánulos subcelulares como el retículo endoplasmático, la mitocondria, el núcleo y el citoplasma han descrito que la activación celular puede conllevar una remodelación de las especies de lípidos específica en estos compartimentos subcelulares [197].

Todas estas aplicaciones hacen de la MS una técnica muy útil para la investigación de lípidos y otras moléculas fundamentales en la señalización y metabolismo celular. Junto a la HPLC y al desarrollo de la UPLC (cromatografía de líquidos de ultra presión) forman una herramienta básica en el desarrollo de los campos de la metabolómica en general y la lipidómica en particular. 
B.- OBJETIVOS 
Los objetvos de esta tesis son:

- Estudio de la liberación de AA en macrófagos peritoneales de ratón estimulados por zimosán, incluyendo el análisis mediante HPLC/MS de las especies de glicerofosfolípidos con contenido en AA implicadas con el fin de obtener un punto de comparación ante otras condiciones de estimulación.

- Análisis mediante HPLC/MS de los glicerofosfolípidos con contenido en AA implicados en el efecto sinérgico en la liberación de AA observado por la exposición previa a LPS de macrófagos estimulados con zimosán.

- Estudio en macrófagos peritoneales de ratón del efecto de la opsonización del zimosán en la liberación de AA y la identificación mediante el uso de HPLC/MS de las especies de glicerofosfolípdos implicadas en dicha movilización.

- Estudio de la implicación de la cPLA2 $\alpha$ en la liberación de AA observada en las diferentes condiciones de estimulación.

- Una aproximación a la especie $\mathrm{PI}(20: 4 / 20: 4)$ a través del estudio de su formación en diferentes escenarios tanto celulares como in vivo, su respuesta a diferentes estímulos y la identificación de posibles productos resultantes de su metabolismo.

- Estudio de la relación de $\mathrm{PI}(20: 4 / 20: 4)$ con la regulación de procesos asociados a la respuesta inmune innata. 


\section{C.- MATERIALES Y MÉTODOS}




\section{C.1 Materiales}

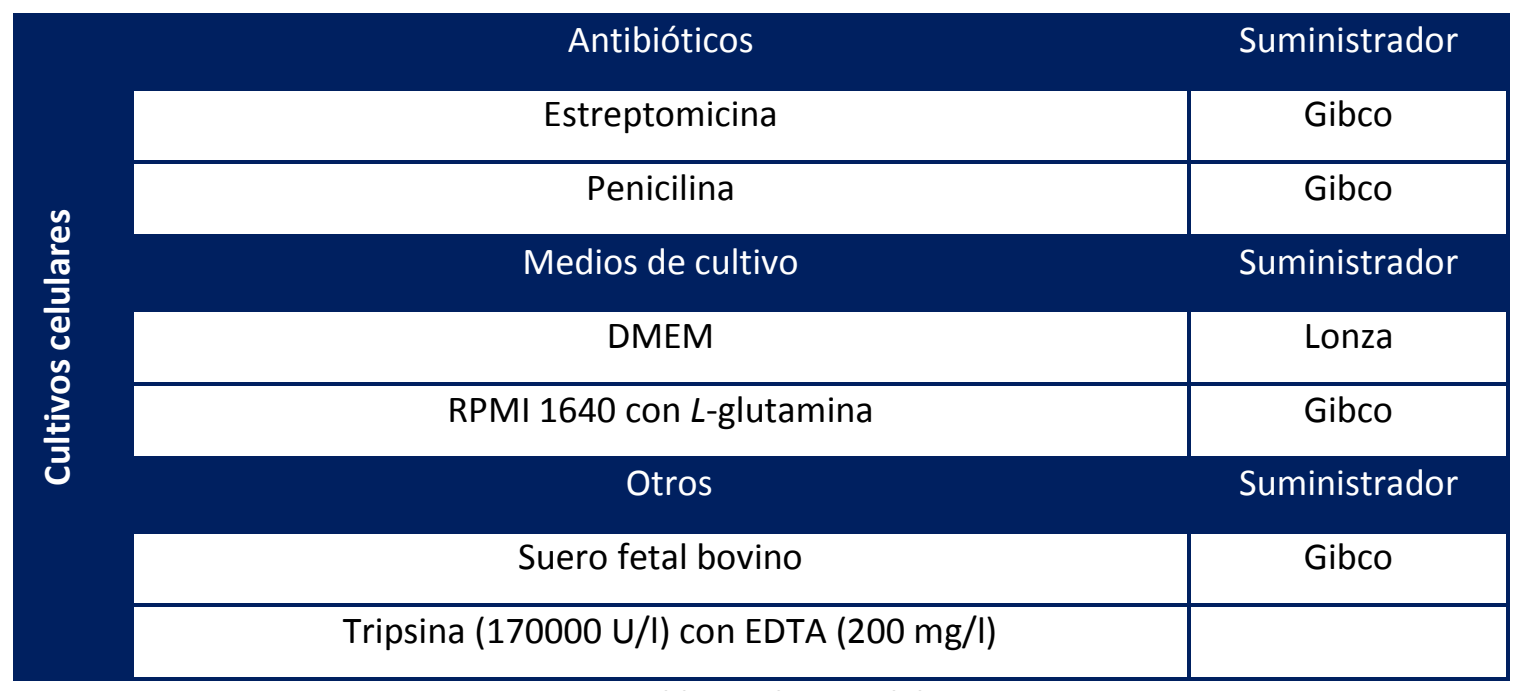

Tabla 2 Cultivos celulares

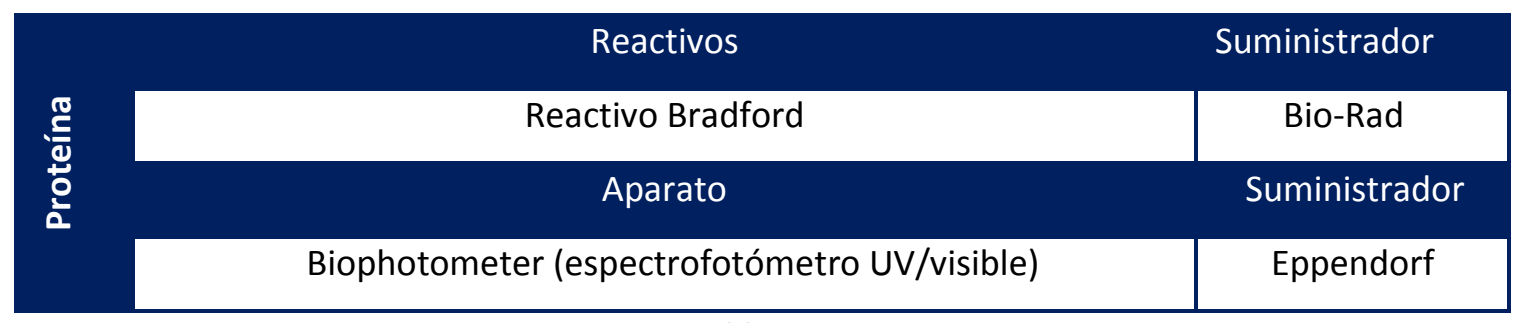

Tabla 3 Proteina

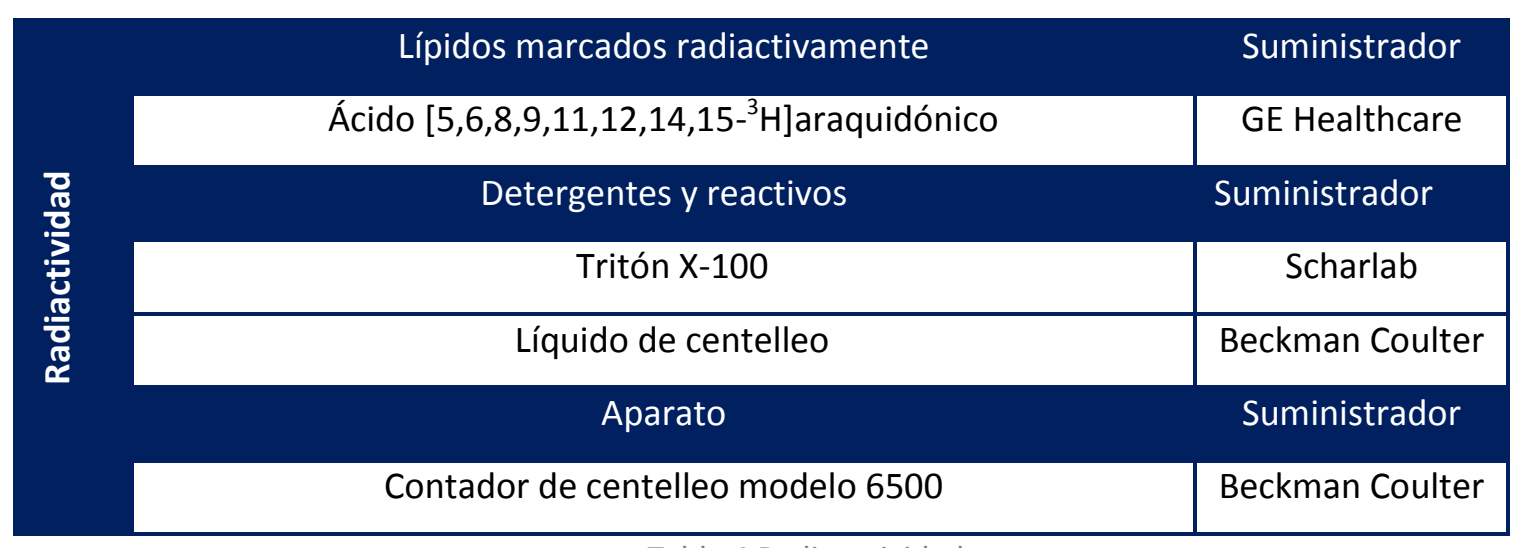

Tabla 4 Radioactividad 


\begin{tabular}{|c|c|c|}
\hline & Reactivos & Suministrador \\
\hline - & Citocromo C & Sigma-Aldrich \\
\hline & Citocalasina B & Sigma-Aldrich \\
\hline & Superóxido dismutasa (SOD) & Sigma-Aldrich \\
\hline & Aparato & Suministrador \\
\hline & Biophotometer (espectrofotómetro UV/visible) & Eppendorf \\
\hline & Otros & Suministrador \\
\hline 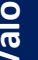 & Histona H1 & Tebu-bio \\
\hline & Mix PI (extracto de hígado bovino) & Sigma-Aldrich \\
\hline
\end{tabular}

Tabla 5 Valoración del anión superóxido

\begin{tabular}{|c|c|c|}
\hline \multirow{7}{*}{ :응 } & Estímulo & Suministrador \\
\hline & Zimosán & Sigma-Aldrich \\
\hline & LPS & Sigma-Aldrich \\
\hline & Forbol 12-miristato-13-acetato (PMA) & Sigma-Aldrich \\
\hline & PAF & Biomol \\
\hline & A23187 & \\
\hline & ATP & Sigma-Aldrich \\
\hline
\end{tabular}

Tabla 6 Estimulación 


\begin{tabular}{|c|c|}
\hline Eluyentes & Suministrador \\
\hline Cloroformo & Fisher \\
\hline Hexano & Fisher \\
\hline Metanol & Fisher \\
\hline Hidróxido de amonio $30 \%$ & Fisher \\
\hline $\mathrm{H}_{2} \mathrm{O}$ MillliQ & Millipore \\
\hline Estándares & Suministrador \\
\hline 1,2-didodecanoil-sn-glicero-3-fosfatidiletanolamina & Sigma-Aldrich \\
\hline 1,2-diheptadecanoil-sn-glicero-3-fosfatidilcolina & Larodan \\
\hline 1,2-dipentadecanoil-sn-glicero-3-fosfatidilcolina & Larodan \\
\hline 1,2-dihexadecanoil-sn-glicero-3-fosfatidilinositol & Sigma-Aldrich \\
\hline 1,2-dilaurioil-sn-glicero-3-fosfatidilserina & Larodan \\
\hline 1-tridecanoil-2-hidroxi-sn-glicero-3-fosfatidilcolina & Avanti \\
\hline 1-miristoil-2-hidroxi-sn-glicero-3-fosfatidiletanolamina & Avanti \\
\hline 1-palmitoil-2-hydroxi-sn-glicero-3-fosfatidilinositol & Avanti \\
\hline Mezcla de 37 ésteres metílicos de ácidos grasos (FAME) & Supelco \\
\hline Lípidos deuterados & Suministrador \\
\hline Ácido $\left[5,6,8,9,11,12,14,15-d_{8}\right]$ araquidónico & Sigma-Aldrich \\
\hline 1- $\left[{ }^{2} \mathrm{H}\right]$ araquidonoil-2-araquidonoil-sn-glicero-2-fosfatidilinositol & Cayman \\
\hline 1-araquidonoil-2-[2H]araquidonoil-sn-glicero-2-fosfatidilinositol & Cayman \\
\hline Columnas y precolumnas & Suministrador \\
\hline Supelcosil LC-18 de $5 \mathrm{~mm} \times 250 \times 2,1 \mathrm{~mm}$ & Sigma-Aldrich \\
\hline Supelguard LC-18 de $20 \times 2,1 \mathrm{~mm}$ & Sigma-Aldrich \\
\hline Supelcosil LC-Si de $3 \mu \mathrm{m} \times 150 \times 3 \mathrm{~mm}$ & Sigma-Aldrich \\
\hline Supelguard LC-Si de $20 \times 2,1 \mathrm{~mm}$ & Sigma-Aldrich \\
\hline DB-23 de $60 \mathrm{~m} \times 250 \mathrm{~mm}$ D.I. $\times 0,15 \mathrm{~mm}$ (GC-MS) & Agilent \\
\hline
\end{tabular}

Tabla 7 Análisis por Cromatografía/Espectrometría de masas 


\begin{tabular}{|c|c|c|}
\hline \multirow{4}{*}{} & Aparatos & Suministrador \\
\cline { 2 - 3 } & Hitachi LaChrom Elite L-2130 & Merck \\
\cline { 2 - 3 } & Hitachi Autosampler L-2200 & Merck \\
\cline { 2 - 3 } & Trampa iónica Bruker Esquire 6000 & Bruker Daltonics \\
\cline { 2 - 3 } & Agilent 5975 (espectrómetro de masas) & Agilent \\
\hline Agilent 7693 con inyector automático & Agilent \\
\hline Agilent 7890A (cromatógrafo de gases) & Agilent \\
\hline
\end{tabular}

Tabla $8 \mathrm{HPLC} / \mathrm{MS}$

\begin{tabular}{|c|c|c|}
\hline & Disolventes & Suministrador \\
\hline & Cloroformo & Scharlab \\
\hline & 2-propanol & Scharlab \\
\hline & Etanol & Scharlab \\
\hline & $\mathrm{H}_{2} \mathrm{O}$ DEPC & Sigma-Aldrich \\
\hline & Reactivos & Suministrador \\
\hline 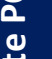 & Cebadores decámeros aleatorios (50 mM) & Ambion \\
\hline స్ & Cebadores oligo (dT) (50 mM) & Ambion \\
\hline$\varepsilon$ & DNA polimerasa $(1 \mathrm{U} / \mathrm{ml})$ & Biotools \\
\hline 竞 & $\mathrm{H}_{2} \mathrm{O}$ DEPC & Sigma-Aldrich \\
\hline :ơ & Inhibidor de RNAsa $(20 \mathrm{U} / \mathrm{ml})$ & Ambion \\
\hline 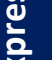 & Mezcla de dNTPs (25 mM cada uno) & Biotools \\
\hline נِ & Transcriptasa reversa M-MLV (100 U/ml) & Ambion \\
\hline$\frac{\pi}{80}$ & Brilliant III Ultra-Fast SYBR ${ }^{\circledR}$ Green QPCR Master Mix & Agilent \\
\hline$\sum$ & Otros & Suministrador \\
\hline & TrayCell (cubeta de espectrofotómetro) & Helma Analytics \\
\hline & FrameStar ${ }^{\circledR} 96$ A12 con Clear Adhesiv Seal (placas) & Mettler Toledo \\
\hline & Aparatos & Suministrador \\
\hline & BioPhotometer (espectrofotómetro UV/visible) & Beckman Coulter \\
\hline & 7500 Real-Time PCR System & Applied Biosystem \\
\hline
\end{tabular}




\section{C.2 Métodos}

\section{C.2.1 Extracción de macrófagos peritoneales de ratón}

Los macrófagos peritoneales de ratón de la cepa Swiss Webster (CFW ${ }^{\circledR}$ ) se extrajeron mediante una modificación del protocolo descrito por Cohn y Benson [198]. Los ratones Swiss se sacrificaron mediante exposición a $\mathrm{CO}_{2}$. Posteriormente se abrió la piel abdominal y se les inyectó 5 $\mathrm{ml}$ de PBS frío. Tras una agitación suave, se recogió el fluido intraperitoneal, haciendo en total dos extracciones. El contenido intraperitoneal se centrifugó durante 10 minutos a $1200 \mathrm{rpm}(290 \mathrm{~g})$ y las células se cultivaron en placas de 6 pocillos con medio RPMI 1640 con glutamina 2 mM, penicilina $(100 \mathrm{U} / \mathrm{ml})$, estreptomicina $(100 \mu \mathrm{g} / \mathrm{ml})$ y $10 \%$ de $\mathrm{FBS}$, a $37^{\circ} \mathrm{C}$ en atmósfera humidificada con $5 \%$ de $\mathrm{CO}_{2}$, permitiendo la adherencia de los macrófagos durante toda la noche antes de proceder al ensayo.

\section{C.2.2 Extracción y aislamiento de células polimorfonucleares de sangre periférica humana}

La extracción y aislamiento de neutrófilos pertenecientes a la familia de las PMN a partir de sangre periférica humana comenzó con la dilución de la bolsa de leucoféresis en una proporción 1:1 con PBS ( $\mathrm{pH} 7,4)$. Tras verter dicha solución sobre una fase de Ficoll en una proporción de 3:1 $\mathrm{v} / \mathrm{v}$, se procedió a centrifugar durante 30 minutos a $1900 \mathrm{rpm}(726 \mathrm{~g})$ para obtener una capa inferior donde se sitúan las células PMN. Después de retirar la parte superior, las células se resuspendieron en medio HBSS en proporción $1: 1 \mathrm{v} / \mathrm{v}$ con dextrano $(3 \%, 0,9 \% \mathrm{de} \mathrm{NaCl})$ autoclavado y se dejó sedimentar las células durante 30 minutos a temperatura ambiente. Se retiró la fase superior donde se encuentran las células PMN y se llevaron a cabo tres choques osmóticos usando concentraciones progresivas de $\mathrm{NaCl}$, de $0,2 \%$ a $1,6 \%$, con el fin de eliminar los eritrocitos existentes, con centrifugaciones intermedias para eliminar el sobrenadante a $1500 \mathrm{rpm}$ durante 10 minutos. Las células fueron contadas en PBS y resuspendidas posteriormente a una concentración de $1 \times 10^{6}$ células $/ \mathrm{ml}$ en medio RPMI suplementado con glutamina $2 \mathrm{mM}$, penicilina $(100 \mathrm{U} / \mathrm{ml})$, estreptomicina $(100 \mu \mathrm{g} / \mathrm{ml})$ y HEPES $10 \mathrm{mM}$. Las células se mantuvieron en agitación en un agotador orbital hasta su utilización no más tarde de 6 horas tras la extracción. 


\section{C.2.3 Extracción de suero de ratón}

Tras anestesiar los animales con ketamina (Imalgene 1000- Merial) y xylacina (Rompun 2\%Bayer) a dosis $100 \mathrm{mg} / \mathrm{kg}$ y $10 \mathrm{mg} / \mathrm{kg}$ respectivamente se buscó el punto de latido cardíaco y una vez encontrado, se pinchó con una jeringa de $1 \mathrm{ml}$ y aguja de $25 \mathrm{G}$ a la que previamente se le había introducido un mínimo volumen de aire. Una vez que se observó el borboteo de la sangre en la jeringa, se empezó a subir el émbolo de la jeringa hasta perder el latido del animal. Se pasó la sangre a un tubo específico para separación de suero (microvette ${ }^{\circledR}$ CB 300) y se centrifugó 10 minutos a $10.000 \mathrm{~g}$ y temperatura ambiente. Por último, se recogió el sobrenadante, se añadió a un eppendorf nuevo y se guardó a $-80^{\circ} \mathrm{C}$ hasta su uso.

\section{C.2.4 Inducción de peritonitis en ratón}

La peritonitis se indujo mediante una inyección intraperitoneal de $1 \mathrm{mg}$ de partículas de zimosán en un volumen de $500 \mu \mathrm{l}$ de PBS estéril en ratones Swiss. A los ratones control se les inyectó sólo PBS. Los ratones se mantuvieron durante diferentes tiempos de estimulación (entre 30 minutos y 3 horas) antes de sacrificarlos en la cámara de $\mathrm{CO}_{2}$. El contenido intraperitoneal se extrajo siguiendo el protocolo descrito en el apartado C.2.1 [199].

\section{C.2.5 Líneas celulares}

La línea celular U937 (promonocitos humanos) se cultivó en atmósfera humedecida con 5\% de $\mathrm{CO}_{2}$ en medio RPMI-1640 suplementado con $10 \%(\mathrm{v} / \mathrm{v})$ de suero fetal bovino, $100 \mathrm{U} / \mathrm{ml}$ de penicilina y $100 \mu \mathrm{g} / \mathrm{ml}$ de estreptomicina.

La línea celular HL-60 (neutrófilos humanos) se cultivó de igual manera que las células U937. Las células RAW 264.7, células adherentes, se cultivaron en medio DMEM con las mismas proporciones de suero y antibióticos que U937 y HL-60.

En todos los experimentos llevados a cabo, una hora antes de cualquier tratamiento, se retiró el medio de cultivo y se añadió el mismo medio suplementado con las mismas cantidades de antibióticos pero con la ausencia de suero (medio incompleto). 


\section{C.2.6 Estímulos e inhibidores}

\section{C.2.6.1 Estímulos}

Numerosas publicaciones han descrito la liberación de AA a concentraciones de $1 \mathrm{mg} / \mathrm{ml}$ de zimosán, donde dicha liberación es máxima [78]. Otras publicaciones han expresado la concentración de zimosán en número de partículas por número de células [200], considerando que

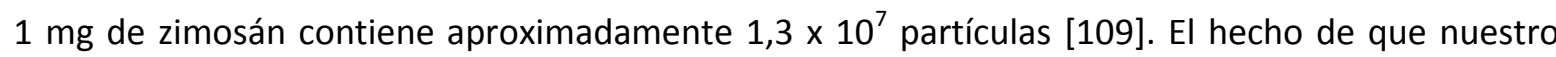
proyecto de investigación incluya numerosas técnicas y que cada una de las cuales presenten un límite de detección diferente, provoca que se presente una diversidad de diseños experimentales con diferente número de células en cada caso. Para permitir una mejor y más adecuada comparativa, las concentraciones de zimosán se calcularon como cantidad de zimosán (mg) en referencia al número de células.

Además, se han utilizado otros estímulos como LPS, PAF, iónoforo A23187, PMA y ATP. EI LPS se usó a una concentración de $100 \mathrm{ng} / \mathrm{ml}$, PAF ,100nM; A23187 ,10 $\mu \mathrm{M}$; ATP, $500 \mu \mathrm{M}$; y se añadió PMA a una concentración de 100 nM.

\section{C.2.6.1.1 Preparación del Zimosán}

El zimosán se resuspendió en PBS, se calentó durante 60 min a $100 \stackrel{\circ}{\circ}$, se centrifugó durante $30 \mathrm{~min}$ a $4000 \mathrm{rpm}$ (3220 g), y se lavó tres veces con PBS, centrifugando en cada caso a 4000 rpm (3220 g) durante 5 min. El precipitado final se resuspendió en PBS a una concentración final de $20 \mathrm{mg} / \mathrm{ml}$ y se guardó a $-20^{\circ} \mathrm{C}$ hasta su uso. Antes de cada experimento, el zimosán se sonicó en un sonicador de tip (Fisher Bioblock Scientific Vibra-Cell 75115) 2 veces durante 20 segundos $[101,201]$.

\section{C.2.6.1.2 Opsonización del zimosán}

El zimosán, tras ser centrifugado un minuto a $12000 \mathrm{rpm}$, se incubó con suero de la especie de que provengan los macrófagos, en este caso ratones, a una concentración de $10 \mathrm{mg} / \mathrm{ml}$ de suero a $37{ }^{\circ} \mathrm{C}$ durante 20 minutos. Posteriormente, se volvió a centrifugar en las mismas condiciones y se lavó con PBS $1 \mathrm{X}$. Tras una tercera centrifugación, se resuspendió en medio incompleto donde se sonicó del mismo modo que se hace para el zimosán no opsonizado. 


\section{C.2.6.2 Inhibidores}

Durante el desarrollo de este trabajo se utilizaron tres inhibidores químicos de $\mathrm{PLA}_{2}$ [202][Dennis 2011]: la pirrofenona, inhibidor de la cPLA2 $\alpha$, a una concentración de $1 \mu \mathrm{M}$, la bromoenol lactona (BEL), inhibidor de la $\mathrm{PPLA}_{2}$, a una concentración de $10 \mu \mathrm{M}$. Además se utilizaron dos inhibidores específicos de la iPLA ${ }_{2}$ descritos recientemente, FKGK11 (1,1,1,2,2-pentafluoro-7fenilheptano-3-uno) y FKGK18 (1,1,1-trifluoro-6-(naftaleno-2-il)hexano-2-uno) [202, 203] que fueron suministrados por el Doctor Kokotos de la Universidad de Atenas. En referencia a estos dos últimos inhibidores, las concentraciones a usar se determinaron mediante un ensayo dosisrespuesta, probando su efectividad en la inhibición de la formación de lisofosfolípidos a partir de la pérdida de un ácido graso de los glicerofosfolípidos, actividad descrita en el caso de la $\mathrm{PPLA}_{2}$. Se determinó una concentración óptima de $1 \mu \mathrm{M}$.

En ensayos de actividad realizados in vitro con anterioridad se demostró que, para concentraciones usadas en este estudio, las actividades de la $\operatorname{cPLA}_{2} \alpha$ y la $\mathrm{iPLA}_{2}$ se inhiben cuantitativamente con pirrofenona $[204,205]$ y $\operatorname{BEL}[206,207]$, respectivamente. Además, a las concentraciones utilizadas la pirrofenona no afecta a la actividad de la $\mathrm{iPLA}_{2}$, así como tampoco el BEL tiene efecto alguno en la actividad de la $\mathrm{CPLA}_{2} \alpha$. Los inhibidores se añadieron 30 minutos a las células antes del estímulo.

\section{C.2.7 Cuantificación de proteína}

La proteína se cuantificó usando el método de Bradford [Bradford 1976]. Es un método colorimétrico que se basa en el cambio del máximo de absorbancia que sufre el azul de Coomassie G-250 cuando en medio ácido interacciona de forma no covalente con las proteínas, de 465 a 595 $\mathrm{nm}$. Con la absorbancia medida, se determina la concentración de proteínas utilizando la Ley de Lambert-Beer. Para dicho cálculo se realizó una curva patrón con distintas cantidades de BSA, disueltas en $\mathrm{H}_{2} \mathrm{O}$ MilliQ, cubriendo un rango de 1 a $10 \mu \mathrm{g} / \mathrm{ml}$.

\section{C.2.8 Liberación de AA en condiciones de estimulación}

Dependiendo de si el motivo del experimento es medir liberación total o liberación por especies de fosfolípidos se utiliza el análisis por radiactividad o por espectrometría de masas respectivamente. El protocolo, según sea un caso u otro, difiere en algunos puntos concretos que se detallan a continuación. 


\section{C.2.8.1 Análisis por radiactividad}

Los macrófagos peritoneales, una vez extraídos de los ratones, se plaquearon a razón de 2 $\times 10^{5}$ células por pocillo en placas de 12 pocillos. Se dejaron adherir a los pocillos durante 4 horas aproximadamente, se lavaron con PBS y se volvieron a dejar en medio completo durante toda la noche. Después de ese tiempo, los macrófagos se lavaron con PBS dos veces y se dejaron en medio completo con $\left[{ }^{3} \mathrm{H}\right] \mathrm{AA}$, a una concentración de $0,25 \mu \mathrm{Ci} / \mathrm{ml}$. Estas condiciones permiten la incorporación de este AA marcado pero no supone ninguna estimulación ni activación celular. Pasadas 12 horas, las células se lavaron tres veces con medio incompleto conteniendo albúmina a una concentración de $0,5 \mathrm{mg} / \mathrm{ml}$ con el fin de eliminar el exceso de ácido graso radiactivo. Tras los lavados, las células se dejaron en medio incompleto durante una hora y se añadieron los diferentes estímulos a diferentes concentraciones incubando durante distintos tiempos. Pasado el tiempo establecido en cada experimento se recogieron los sobrenadantes. Éstos se centrifugaron a 12000 rpm durante 2 minutos con el fin de descartar restos celulares y células no adheridas y se recogió una fracción $(400 \mu \mathrm{l})$ para medir la radioactividad, se mezcló con $3 \mathrm{ml}$ de líquido de centelleo y se midió en un contador de centelleo. Por otra parte, los macrófagos se lisaron con $400 \mu l$ de Tritón $0,1 \%$ y, al igual que con el sobrenadante, se les añadió el líquido de centelleo y se contó la radiactividad, medida en dpm (desintegraciones por minuto). Los datos se expresan en $\%$ de $\left[{ }^{3} \mathrm{H}\right] \mathrm{AA}$ liberado respecto al total de $\left[{ }^{3} \mathrm{H}\right] \mathrm{AA}\left(\left[{ }^{3} \mathrm{H}\right] \mathrm{AA}\right.$ liberado $+\left[{ }^{3} \mathrm{H}\right] \mathrm{AA}$ presente en las células).

\section{C.2.8.2 Análisis por espectrometría de masas}

El protocolo es idéntico al del análisis por radiactividad con la excepción de que a las células no se le añade $\left[{ }^{3} \mathrm{H}\right] \mathrm{AA}$ lo que provoca a su vez que, después de las 12 horas, no sea necesario un lavado exhaustivo con BSA. Las células, como en el caso anterior, son dejadas en medio incompleto durante 1 hora y después se añaden los estímulos, ya sea LPS y/o zimosán. Tras la estimulación, se lavan los macrófagos con PBS y, tras retirarlo, se raspan en $150 \mu \mathrm{l}$ de agua MilliQ para la posterior extracción lipídica.

\section{C.2.9 Incorporación de AA deuterado $\left(\left[{ }^{2} \mathrm{H}\right] \mathrm{AA}\right)$}

Para evaluar la incorporación del ácido $\left[{ }^{2} \mathrm{H}\right] \mathrm{AA}, 2 \times 10^{6}$ células se lavaron cuidadosamente tres veces con medio incompleto. A continuación, se incubaron 1 hora en $2 \mathrm{ml}$ de dicho medio a 37 ${ }^{\circ} \mathrm{C}$ en atmósfera humedecida y con $5 \%$ de $\mathrm{CO}_{2}$. Para evaluar la incorporación del ácido araquidónico, las células se expusieron a $\left[{ }^{2} \mathrm{H}\right] \mathrm{AA}$ disuelto en etanol a la concentración y tiempo indicados.

Dado que las células RAW 264.7 son adherentes, se lavaron cuidadosamente en las placas donde se desarrolló el experimento con medio incompleto evitando que se despegasen de la placa. Tras la incorporación, se eliminó el medio de los pocillos y se rasparon las placas con agua MilliQ 
para recoger las células.

En el caso de las células HL-60, al tratarse de células en suspensión, se centrifugaron para resuspenderlas en medio incompleto una hora antes de añadir el $\left[{ }^{2} \mathrm{H}\right] \mathrm{AA}$ y se volvieron a centrifugar tras el tratamiento para terminar resuspendiéndolas en $150 \mu \mathrm{l}$ de agua MilliQ.

Para evaluar la incorporación del AA exógeno tanto en estos tipos celulares como en macrófagos de ratón o neutrófilos humanos, las células se expusieron a $\left[{ }^{2} \mathrm{H}\right] \mathrm{AA}$ disuelto en etanol $(0,1 \%(v / v))$.

\section{C.2.10 Introducción de las especies 1-[ $\left[{ }^{2} \mathrm{H}\right]$ araquidonoil-2- araquidonoil-sn-glicero-2-fosfatidilinositol y $\quad$ 1- araquidonoil-2-[ $\left.{ }^{2} \mathrm{H}\right]$ araquidonoil-sn-glicero-2- fosfatidilinositol}

Para llevar a cabo la introducción de las especies 1-[ $\left.{ }^{2} \mathrm{H}\right]$ araquidonoil-2-araquidonoil-snglicero-2-fosfatidilinositol y 1-araquidonoil-2-[ $\left.{ }^{2} \mathrm{H}\right]$ araquidonoil-sn-glicero-2-fosfatidilinositol dentro de la célula, en medio incompleto se añadieron $5 \mathrm{nmol}$ de Histona H1 y $10 \mathrm{nmol}$ del fosfolípido. Para el control en ausencia de $\mathrm{PI}$, se añadió la misma cantidad de Histona H1. Después de sonicar durante 2 minutos, ambas mezclas con y sin PI se incubaron durante 30 minutos a $37^{\circ} \mathrm{C}$ antes de ser añadidas a las células a las que previamente se las había retirado el medio de cultivo completo y se habían mantenido durante 1 hora en medio incompleto.

\section{C.2.11 Análisis de lípidos}

\section{C.2.11.1 Extracción de lípidos}

En el caso de células en suspensión, las células se resuspendieron en $\mathrm{H}_{2} \mathrm{O}$. En el caso de células adherentes, éstas se despegaron mediante un raspado en $\mathrm{H}_{2} \mathrm{O}$ MilliQ. A partir de aquí, se añadieron los correspondientes estándares internos y se procedió a la extracción de los lípidos celulares siguiendo el protocolo descrito por Bligh \& Dyer [208]: se añadieron 3,75 volúmenes (en relación al volumen de la fase acuosa) de cloroformo/metanol 1:2 v/v, se agitó fuertemente con vórtex, se añadieron 1,25 volúmenes de $\mathrm{H}_{2} \mathrm{O}$ y 1,25 volúmenes de cloroformo, se agitó de nuevo y se centrifugó a $3000 \mathrm{rpm}$ (800 g) durante 5 minutos a 4 으 con el fin de separar las fases. Tras retirar a otro tubo la fase orgánica que se sitúa en la parte inferior, se añadieron 2 volúmenes de cloroformo sobre la fase acuosa para una segunda extracción. Ésta se llevo a cabo después de agitar y centrifugar de similar forma a la primera extracción. Las dos extracciones se juntaron en un mismo tubo y se evaporaron totalmente. 


\section{C.2.11.2 Análisis de ácidos grasos mediante cromatografía de gases acoplada a espectrometría de masas (GC/MS)}

\section{C.2.11.2.1 Derivatización de ácidos grasos}

Tras la extracción lipídica se procedió a la transmetilación de los ácidos grasos. Para ello se disolvió la muestra en $50 \mu \mathrm{l}$ de cloroformo/metanol 2:1 v/v, pasándolo después a un tubo de vidrio roscado. Se añadieron $500 \mu \mathrm{l}$ de $\mathrm{KOH} 0,5 \mathrm{M}$ en metanol y se incubó a $37^{\circ} \mathrm{C}$ durante 30 minutos en agitación generando ésteres metílicos de los ácidos grasos (FAMEs). Transcurrida dicha incubación, la reacción se neutralizó añadiendo un volumen de $\mathrm{HCl}$ 0,5 $\mathrm{M}$ y los ácidos grasos transmetilados se extrajeron dos veces con un volumen de hexano. Esta fase orgánica se guardó a $-80{ }^{\circ} \mathrm{C}$ en atmósfera de $\mathrm{N}_{2}$ hasta su análisis.

\section{C.2.11.2.2 Análisis de ésteres metílicos}

La cuantificación se llevó a cabo mediante el uso de un estándar interno (lípido análogo al lípido problema del cual se quiere conocer la composición de ácidos grasos pero con cadenas de un número impar de átomos de carbono, que son despreciables en la naturaleza) y mediante una curva de calibración externa para cada FAME.

Para llevar a cabo el análisis de los ésteres metílicos obtenidos se utilizó un espectrómetro de masas (Agilent $5975 \mathrm{MS}$ ) en modo de impacto electrónico (EI, $70 \mathrm{eV}$ ), equipado con un inyector automático y acoplado a un cromatógrafo de gases con una columna capilar [(50\%-cianopropil)metilpolisiloxano]. El programa de temperatura utilizado es una modificación del descrito por Abu et al. [232]. La temperatura del inlet se mantuvo a $250^{\circ} \mathrm{C}$. La temperatura del horno se programó a $50^{\circ} \mathrm{C}$ durante 1 minuto, se incrementó hasta $175^{\circ} \mathrm{C}$ a $25^{\circ} \mathrm{C} /$ minuto, y posteriormente hasta $230^{\circ} \mathrm{C}$ a $2,75^{\circ} \mathrm{C} / \mathrm{min}$ para finalizar con una rampa de $10^{\circ} \mathrm{C} / \mathrm{min}$ hasta alcanzar los $235^{\circ} \mathrm{C}$ donde se mantiene durante 5 minutos. La temperatura final se mantuvo 5 minutos, siendo el tiempo total de la carrera 39,8 min. La temperatura de la línea de transferencia del espectrómetro de masas se sitúo a $250^{\circ} \mathrm{C}$, y la del cuadrupolo a $150^{\circ} \mathrm{C}$ y la fuente del MS a $230^{\circ} \mathrm{C}$. El He fue usado como gas portador a una presión constante de 26,1 psi. En cada caso se inyectó $1 \mathrm{ml}$ de muestra en modo splitless (sin división de la muestra). La adquisición de datos se realizó en modo scan para la identificación de compuestos, y en modo SIM (monitorización de iones seleccionados) para la cuantificación.

La identificación de compuestos se realizó usando tres referencias: el tiempo de retención de cada FAME establecido tras pasar una mezcla de 37 FAMEs, la librería de espectros NIST (Instituto Nacional de Estándares y Tecnología) y, por último, los fragmentos característicos obtenidos en modo SIM: 74 y 87 para FAMES saturados, 83 para monoinsaturados, 67 y 81 para diinsaturados, y 79 y 91 para poliinsaturados [209].

El espectrómetro de masas fue calibrado usando PTFBA (perfluorotributilamina) suministrado con el aparato y usando el protocolo del equipo. El software utilizado fue MSD 
Productivity Chemstation, G1701EA, revisión E.02.00 SP2 (G1701-64553).

\section{C.2.11.3 Análisis de especies de fosfolípidos mediante cromatografía de líquidos acoplada a espectrometría de masas (HPLC-MS)}

\section{C.2.11.3.1 Acoplamiento HPLC/ESI/MS}

La separación cromatográfica de los glicerofosfolípidos se realizó en un sistema de HPLC compuesto por un sistema de bombas binaria con desgasificador en línea y régimen de gradiente Hitachi LaChrom Elite L-2130 y un inyector Hitachi Autosampler L-2200 acoplado a un espectrómetro de masas de trampa iónica Bruker Esquire $6000^{\circ}$. El efluente procedente del HPLC entra a la cámara de electronebulización (ESI) del espectrómetro de masas pasando antes por un separador de caudal. La presión del gas de nebulización se ajustó a 30 psi, el caudal del gas de secado a $4 \mathrm{l} / \mathrm{min}$ y la temperatura del gas de secado a $350^{\circ} \mathrm{C}$. La calibración de la trampa iónica se realizó mediante el protocolo del propio equipo con la solución Tunning Mix (Agilent).

\section{C.2.11.3.2 Análisis de especies moleculares de PC, PE PI y PS.}

El análisis se lleva a cabo siguiendo el protocolo descrito por Balgoma et al. [ Balgoma 2008] con ligeras modificaciones. Los lípidos totales extraídos por el método de Bligh \& Dyer fueron disueltos en metanol/agua $(9: 1 \mathrm{v} / \mathrm{v})$. Para la separación cromatográfica se usó la columna Supelcosil LC-18 protegida con una precolumna Supelguard LC-18. Las condiciones cromatográficas utilizadas se basaron en las descritas por Igbavboa et al. [Igbavboa 2002] con algunas modificaciones. La fase móvil que se utilizó fue un gradiente del eluyente $A$ (metanol/agua/hexano/hidróxido de amonio al 30\%, 87,5:10,5:1,5:0,5 v/v/v/v), eluyente B (metanol/hexano/hidróxido de amonio al 30\%, 87,5:12:0,5 v/v/v/), y eluyente $C$ (metanol/agua, 9:1 $\mathrm{v} / \mathrm{v})$.

El volumen de inyección fue de $80 \mu \mathrm{l}$ y la velocidad de flujo fue $0,5 \mathrm{ml} / \mathrm{min}$ que fue dividido antes de entrar al espectrómetro de masas, dejando pasar un flujo de $0,2 \mathrm{ml} / \mathrm{min}$. Las especies de $\mathrm{PI}$, PE y PS se detectaron en modo negativo como $[\mathrm{M}-\mathrm{H}]^{-}$con corriente de capilar $+3500 \mathrm{~V}$ a lo largo de los primeros 23 minutos. Las especies de $\mathrm{PC}$ se detectaron como $[\mathrm{M}+\mathrm{H}]^{+}$desde el minuto 23 al 40 con corriente de capilar -4000 V. La identificación de las especies de PC se realizó en modo negativo mediante la adición de ácido acético después de la columna con un flujo de $100 \mu \mathrm{l} / \mathrm{h}$, condiciones en las que se produce el aducto $\left[\mathrm{M}+\mathrm{CH}_{3} \mathrm{CO}_{2}\right]^{2}$. El rango de $\mathrm{m} / \mathrm{z}$ rastreado para los experimentos de identificación fue m/z 150-1000 y para los experimentos de detección 450-1000. Para la identificación de cada especie se usaron las bases de datos RCM lipidcalculator (http://pharmacology.ucdenver.edu/lipidcalc) y de Lipid Maps (www.lipidmaps.org). Además se llevaron a cabo sucesivas fragmentaciones en modo MRM para la caracterización exacta de cada especie, concretamente los fragmentos correspondientes a las cadenas $R_{1}$ y $R_{2}$ de los fosfolípidos, y del fragmento correspondiente a la pérdida neutra de $R_{2}$. Como estándares internos así como para curvas de calibrado se usaron 1, 2-dipentadecanoil-sn-glicero-3-fosfatidilcolina con $\mathrm{m} / \mathrm{z}=706,5$ 
para especies de PC, 1,2-didodecanoil-sn-glicero-3-fosfatidiletanolamina con $\mathrm{m} / \mathrm{z}=578,5$ para especies de $\mathrm{PE}, 1$,2-dihexadecanoil-sn-glicero-3-fosfatidilinositol con $\mathrm{m} / \mathrm{z}=809,5$ para especies de $\mathrm{PI}$ y 1,2-dilaurioil-sn-glicero-3-fosfatidilserina con $\mathrm{m} / \mathrm{z}=$ para especies de PS.

\begin{tabular}{|cccc|}
\hline Tiempo $(\mathrm{min})$ & Eluyente A & Eluyente B & Eluyente C \\
\hline $\mathbf{0}$ & 100 & 0 & 0 \\
17,5 & 50 & 50 & 0 \\
30 & 0 & 100 & 0 \\
35 & 0 & 100 & 0 \\
38 & 0 & 0 & 100 \\
47 & 0 & 0 & 100 \\
50 & 0 & 100 & 0 \\
\hline
\end{tabular}

Tabla 10 Gradiente de eluyentes para el análisis de glicerofosfolípidos por HPLC/MS

En los experimentos de incorporación de $\left.{ }^{2} \mathrm{H}\right] \mathrm{AA}$ a los fosfolípidos celulares, dos criterios han servido para la identificación de los glicerofosfolípidos que incorporan $\left[{ }^{2} \mathrm{H}\right] \mathrm{AA}$ respecto a los glicerofosfolípidos que se encuentran de forma natural en las células: la distribución isotópica y la fragmentación [90].

La presencia de deuterios provoca la modificación de la distribución isotópica ya que aumenta la $\mathrm{m} / \mathrm{z}$ del glicerofosfolípido en 8 unidades y modifica su apariencia presentando una forma acampanada en contraposición a la forma de media campana las de moléculas no deuteradas. Así $\mathrm{PI}(20: 4 / 20: 4)$ presenta una $\mathrm{m} / \mathrm{z}$ de 905 mientras que el la $\mathrm{m} / \mathrm{z}$ de $\left.\mathrm{PI}\left({ }^{2} \mathrm{H}\right] \mathrm{AA} / 20: 4\right)$ es de 913 con forma de campana debido a la presencia del $\left[{ }^{2} \mathrm{H}\right] \mathrm{AA}$.

El segundo criterio se basa en la aparición de fragmentos característicos de las cadenas laterales deuteradas. En este caso, se detecta un pico de $\mathrm{m} / \mathrm{z} 311$ que corresponde a $\left[{ }^{2} \mathrm{H}\right] \mathrm{AA}$ mientras que con AA nativo su $\mathrm{m} / \mathrm{z}$ sería de 303 .

\section{C.2.11.4 Cromatografía de líquidos en fase normal acoplada a ESI-MS en la detección de lisofosfolípidos}

La muestra se homogeneizó por agitación en $0,5 \mathrm{ml}$ de agua MilliQ. Para evitar la hidrólisis de los lisofosfolídos, en especial, de lisoPI, es común acidificar el medio añadiendo ácido clorhídrico $(\mathrm{HCl})$. Sin embargo, este paso no se llevó a cabo en el caso de los análisis de lisoPE con el propósito de conservar las especies con enlaces plasmenilo que son atacados por la acidificación producida por el $\mathrm{HCl}$. Antes de comenzar la extracción, se añadieron los estándares correspondientes. Los lípidos se extrajeron dos veces con 1 volumen de $n$-butanol saturado en agua [103, 210]. Las fases orgánicas reunidas (fase superior) se evaporaron al vacío, los lípidos se volvieron a disolver en cloroformo y se guardaron bajo nitrógeno a $-80{ }^{\circ} \mathrm{C}$ hasta su análisis. Para la separación 
cromatográfica se utilizó una columna Supelcosil LC-Si protegida con una precolumna Supelguard LC-Si. El flujo de elución fue $0,5 \mathrm{ml} /$ minuto, dejando entrar $0,2 \mathrm{ml} /$ minuto al espectrómetro de masas. Se utilizó un método en gradiente con los eluyentes cloroformo/metanol/hidróxido de amonio $30 \%(75: 24,5: 0,5, \mathrm{v} / \mathrm{v})$ (A) y cloroformo/metanol/agua/hidróxido de amonio $30 \%$ $(55: 39: 5,5: 0,5, v / v)$ (B). El gradiente empezó con el $100 \%$ de $A$ para disminuir hasta el $50 \%$ de $A$ en 2 minutos. Este porcentaje se mantuvo durante 8 minutos y en los 2 minutos siguientes cambió linealmente al $0 \%$. Se introdujeron $0,2 \mathrm{ml} /$ minuto en la cámara de nebulización cuyos parámetros fueron: presión del gas de nebulización $30 \mathrm{psi}$, caudal del gas de secado $8 \mathrm{l} /$ minuto, y temperatura de secado $365{ }^{\circ} \mathrm{C}$. Las especies de lisoPE y lisoPI fueron detectados en modo negativo como [M-H]con una corriente de capilar $+3500 \mathrm{~V}$, mientras que las especies de lisoPC fueron detectados en modo positivo con una corriente de capilar de $-4000 \mathrm{~V}$. El rango de $\mathrm{m} / \mathrm{z}$ para la detección de fue de 450-700. Se usaron 1-tridecanoil-2-hidroxi-sn-glicero-3-fosfocolina con $\mathrm{m} / \mathrm{z}=454$ para lisoPC y 1miristoil-2-hidroxi-sn-glicero-3-fosfoetanolamina con $\mathrm{m} / \mathrm{z}=424$ para lisoPE como estándares internos para la cuantificación. Para la cuantficación de lisoPI se realizó un recta de calibrado externa con el estándar 1-palmitoyl-2-hydroxi-sn-glicero-3-fosfoinositol ya que esta especie se encuentra de forma endógena en las células.

\section{C.2.12 Valoración del anión superóxido}

El ensayo se realizó en un volumen final de $1 \mathrm{ml}$ en placas de 6 pocillos donde el día anterior se habían plaqueado $2 \times 10^{6}$ macrófagos peritoneales de ratón. Para ello, la reacción se Ilevó a cabo en un buffer al que incluye 10mM HEPES a pH 7,5, $150 \mathrm{mM} \mathrm{NaCl}, 1,2 \mathrm{mM} \mathrm{MgCl}$, 1,3 $\mathrm{mM} \mathrm{CaCl}_{2}$ al que se había añadido previamente glucosa con una concentración de 5,5 mM, además de citocromo $\mathrm{C}$ a una concentración final de $75 \mathrm{nmol} / \mathrm{ml}$, cuya reducción se utiliza para cuantificar la producción de anión superóxido. A las células, a las que se les retiró el medio y se lavó con PBS estéril, se les añadió la mezcla con y sin superóxido dismutasa (SOD) a una concentración de 10 $\mathrm{mg} / \mathrm{ml}$ con el fin excluir la reducción del citocromo $\mathrm{C}$ no evitable por SOD [47]. 5 minutos antes de ser estimuladas las células, se añadió citocalasina B a una concentración $5 \mathrm{mg} / \mathrm{ml}$, un compuesto capaz de promover la generación de anión superóxido [211] debido a su capacidad para inhibir de la polimerización de la actina y con ello la organización citoesquelética [212, 213]. Posteriormente, los macrófagos peritoneales de ratón fueron estimulados con PMA (100 nM), zimosán y zimosán opsonizado ( $1 \mathrm{mg} / \mathrm{ml}$ ). Tras 1 hora de incubación, se retiró el medio de los pocillos y se centrifugó a $1500 \mathrm{rpm}$ durante 5 minutos a $4^{\circ} \mathrm{C}$. La absorbancia se leyó en un espectrofotómetro a una absorbancia de $550 \mathrm{~nm}$ (A550). Para representar los datos, la diferencia de absorbancia de las muestras sin SOD y con SOD fue dividida por el diferencial de reducción del citocromo $C$ obtenido al añadir a sobrenadantes de células disulfito potásico $\left(R_{\text {red }}\right)$ y ferrocianuro potásico $\left(R_{o x}\right)$. El resultado fue multiplicado por 75 que corresponde a los nmoles de citocromo $C$ añadidos a la reacción y dividido por 2 ya que se utilizaron $2 \times 10^{6}$ células y los resultados se muestran en nmol de Citocromo $\mathrm{C}$ reducidos $/ \mathrm{h} / 10^{6}$ células. La siguiente ecuación determina los $\mathrm{nmol}$ de citocromo $\mathrm{C}$ reducido/h/10 ${ }^{6}$ células= [(A550 en ausencia de SOD-A550 en presencia de SOD)/(Rred-Rox)]x75/2. 


\section{C.2.13 Análisis de la expression génica por PCR}

\section{C.2.13.1 Extracción de RNA}

El RNA de las macrófagos peritoneales de ratón se extrajo utilizando el reactivo Tri Reagent, siguiendo el método proporcionado por la casa comercial que está basado en los procedimientos de extracción de RNA descritos por Chomczynski y Sacchi [214]. El uso de $800 \mu \mathrm{l}$ de Tri Reagent durante 5 minutos y a temperatura ambiente permite lisar las células por disociación de los complejos de nucleoproteínas. Tras el lisado, se añadieron $200 \mu \mathrm{l} \mathrm{de} \mathrm{CHCl}_{3}$, se agitó de forma enérgica durante 15 segundos $y$, tras una incubación durante 5 minutos a temperatura ambiente, se centrifugó a $13400 \mathrm{~g}$ (12000 rpm) durante 15 minutos a $4{ }^{\circ} \mathrm{C}$. La fase acuosa donde se encuentra el RNA se transfirió a otro tubo al que se añadieron $500 \mu \mathrm{l}$ de isopropanol y se incubó durante 10 minutos a temperatura ambiente con el fin de precipitar el RNA. Posteriormente, una centrifugación de $13400 \mathrm{~g}$ durante 10 minutos a $4{ }^{\circ} \mathrm{C}$ permite eliminar el sobrenadante, tras lo cual, el RNA se lavó con $1 \mathrm{ml}$ de etanol al 75\% (en $\mathrm{H}_{2} \mathrm{O}-\mathrm{DEPC}$ ) y se centrifugó a $10000 \mathrm{~g}$ durante 10 minutos. Una vez que el RNA se encontró totalmente seco, se disolvió en $20 \mu \mathrm{l}$ de $\mathrm{H}_{2} \mathrm{O}$-DEPC y se cuantificó a través de la medida de absorbancia a $260 \mathrm{~nm}$ en un espectrofotómetro UV/visible utilizando una cubeta TrayCell.

\section{C.2.13.2 Síntesis de cDNA}

A $2 \mu \mathrm{g}$ de RNA se les añadió $0,1 \mathrm{nmol}$ de cebadores aleatorios ( $2 \mu \mathrm{l}$ de la mezcla comercial) y $0,1 \mathrm{nmol}$ de oligo dT $\left(2 \mu \mathrm{l}\right.$ ) y $\mathrm{H}_{2} 0$-DEPC hasta completar un volumen de $15,6 \mu \mathrm{l}$, se mezcló y se calentó a $78{ }^{\circ} \mathrm{C}$ durante 3 minutos. Posteriormente, las muestras se colocaron en hielo y se añadieron $10 \mathrm{nmol}$ de cada dNTP $(0,4 \mu \mathrm{l}), 40 \mathrm{U}$ de inhibidor de RNasas $(2 \mu \mathrm{l}), 100 \mathrm{U}$ de transcriptasa reversa M-MLV $(1 \mu \mathrm{l})$ y $2 \mathrm{ml}$ de tampón de reacción (Tris $500 \mathrm{mM} \mathrm{pH} \mathrm{8,3,} \mathrm{KCl} 500$ $\mathrm{mM}$, DTT $50 \mathrm{mM}$ y $\mathrm{MgCl}_{2} 30 \mathrm{mM}$ ) hasta completar los $20 \mu \mathrm{l}$ de volumen final. La mezcla resultante se incubó primero a $43{ }^{\circ} \mathrm{C}$ durante 1 hora y, finalmente, a $92{ }^{\circ} \mathrm{C}$ durante 10 minutos.

\section{C.2.13.3 Cuantificación de mRNA mediante Q-PCR}

La técnica de PCR cuantitativa (Q-PCR) se utilizó para la cuantificación relativa de expresión de determinados genes de macrófagos peritoneales de ratón bajo diferentes condiciones. Todo ello utilizando genes de referencia (genes housekepping) cuyas expresiones se mantienen constantes en las muestras analizadas. Los genes de referencia usados fueron $\beta$-actina, Ciclofilina B, GADPH y Rn18s.

Para llevar a cabo la reacción se usaron 20 ng de cDNA a los que se añadió $5 \mu$ de una solución $2 X$ del reactivo Brilliant III Ultra-Fast SYBR ${ }^{\circledR}$ Green QPCR Master Mix, 0,5 $\mu$ le cada oligonucleótido de una disolución de $10 \mu \mathrm{M}$ y 0,15 $\mu$ l de una solución stock de $30 \mathrm{nM}$ de ROX. Los 
ciclos de amplificación se inician con 3 segundos a $95{ }^{\circ} \mathrm{C}$ para activar la polimerasa (Hot Start), continúa con 12 segundos a $95{ }^{\circ} \mathrm{C}$ (desnaturalización), 15 segundos a $60{ }^{\circ} \mathrm{C}$ (anneling) y 28 segundos a $72{ }^{\circ} \mathrm{C}$ (amplificación y detección de aumento de florescencia), repitiéndose hasta 40 ciclos. Se usaron dos réplicas biológicas independientes de las que se hacen dos réplicas técnicas de cada una.

Por último, el método utilizado para calcular la expresión génica está basado en el método comparativo $[215,216]$ donde se relativiza el número de ciclos necesarios para interceptar el valor umbral de fluorescencia $\left(C_{T}\right)$ de un gen problema frente al $C_{T}$ de un gen de referencia. El resultado $\left(\Delta C_{T}\right)$ determinado para un tratamiento concreto es referenciado, a su vez, frente al $\Delta C_{T}$ del mismo gen en la situación control. Asumiendo que la eficiencia de amplificación de ambos genes es igual a 1, se llega a la expresión:

\section{Expresión relativa $=2^{-\Delta \Delta C}$}

donde,

$\mathbf{C}_{\mathrm{T}}$ es número de ciclos necesarios para interceptar el valor umbral de fluorescencia o ciclo umbral

$\Delta \mathrm{C}_{\mathrm{T}}$ es $\mathrm{C}_{\mathrm{T}}$ de la muestra $-\mathrm{C}_{\mathrm{T}}$ del gen referencia

$\Delta \Delta \mathrm{C}_{\mathrm{T}}$ es $\Delta \mathrm{C}_{\mathrm{T}}$ de la muestra $-\Delta \mathrm{C}_{\mathrm{T}}$ de la muestra control 


\begin{tabular}{|c|c|}
\hline Oligo & Secuencia (5'-->3') \\
\hline mIL-10_Fw & GCTCTTACTGACTGGCATGAG \\
\hline mIL-10_Rv & CGCAGCTCTAGGAGCATGTG \\
\hline mCOX-2_Fw & TGAGCAACTATTCCAAACCAGC \\
\hline mCOX-2_Rv & GCACGTAGTCTTCGATCACTATC \\
\hline mTNFo_Fw & ACGGCATGGATCTCAAAGAC \\
\hline mTNF $\alpha \_R v$ & AGATAGCAAATCGGCTGACG \\
\hline $\mathrm{mCcl} 2$ Fw & AGGTCCCATGTCATGCTTCTGG \\
\hline $\mathrm{mCcl} 2 \_\mathrm{Rv}$ & CTGCTGCTGGTGATCCTCTTG \\
\hline mNos2_Fw & CCAAGCCCTCACCTACTTCC \\
\hline mNos2_Rv & CTCTGAGGGCTGACACAAGG \\
\hline mIL-6_Fw & TAGTCCTTCCTACCCCAATTTCC \\
\hline mIL-6_Rv & TTGGTCCTTAGCCACTCCTTC \\
\hline mRn18s_Fw & CCGAAGCGTTTACTTTGAAAAAA \\
\hline mRn18s_Rv & TTCCATTATTCCTAGCTGCGGTAT \\
\hline $\mathrm{m} \beta$-actina_Fw & GGCTGTATTCCCCTCCATCG \\
\hline $\mathrm{m} \beta$-actina_Rv & CCAGTTGGTAACAATGCCATGT \\
\hline mFizz1_Fw & CCAATCCAGCTAACTATCCCTCC \\
\hline mFizz1_Rv & ACCCAGTAGCAGTCATCCCA \\
\hline mYm1_Fw & CAGGTCTGGCAATTCTTCTGAA \\
\hline mYm1_Rv & GTCTTGCTCATGTGTGTAAGTGA \\
\hline mIL12 $\alpha \_F w$ & CTGTGCCTTGGTAGCATCTATG \\
\hline mIL12 $\alpha \_R v$ & GCAGAGTCTCGCCATTATGATTC \\
\hline mMrc1_Fw & CTCTGTTCAGCTATTGGACGC \\
\hline mMrc1_Rv & CGGAATTTCTGGGATTCAGCTTC \\
\hline mMrc2_Fw-2 & TACAGCTCCACGCTATGGATT \\
\hline mMrc2_Rv-2 & САCTCTCCCAGTTGAGGTACT \\
\hline mIL-12ß_Fw-2 & AGACATGGAGTCATAGGCTCTG \\
\hline mIL-12 $\beta \_R v-2$ & CCATTTTCCTTCTTGTGGAGCA \\
\hline mIL-23 $\alpha \_F w-2$ & AGCAACTTCACACCTCCCTAC \\
\hline mIL-23 $\alpha \_R v-2$ & ACTGCTGACTAGAACTCAGGC \\
\hline mArg-1_Fw-2 & TGGCTTGCGAGACGTAGAC \\
\hline mArg-1_Rv-2 & GCTCAGGTGAATCGGCCTTTTT \\
\hline mIL1ß_Fw & GCAACTGTTCCTGAACTCAACT \\
\hline mIL1 $\beta \_R v$ & ATCTTTTTGGGGTCCGTCAACT \\
\hline mTgf $\beta \_F w$ & CTCCCGTGGCTTCAGTGC \\
\hline $\mathrm{mTgf} \beta \_\mathrm{Rv}$ & GCCTTAGTTTGGACAGGATCTG \\
\hline
\end{tabular}

Tabla 11 Oligonucleótidos utilizados en los ensayos de Q-PCR.

Para cada gen, se utilizaron cebadotes directos (Fw) y cebadores inversos (Rv). El distintivo " $m$ " de cada oligonucleótido hace referencia a su pertenecía a ratón. Todos ellos fueron suministrados por MWG Biotech. 


\section{C.2.13.4 Análisis de datos}

Todos los experimentos se realizaron por duplicado o triplicado. Las figuras mostradas corresponden a un experimento representativo, y cada dato se muestra como la media \pm error estándar (SE). 
D.- RESULTADOS 


\section{D.1 Estimulación de macrófagos peritoneales de ratón mediante zimosán}

\section{D.1.1 Medida de la liberación de AA}

Se ha descrito exhaustivamente que la exposición a zimosán provoca un efecto en la liberación de AA y los consecuentes cambios producidos en los niveles de glicerofosfolípidos con contenido en AA en macrófagos peritoneales de ratón [78].

Con el fin de realizar el estudio del efecto de la estimulación de macrófagos peritoneales de ratones Swiss por zimosán, se comenzó realizando una dosimetría del zimosán con el fin de definir con precisión las concentraciones a la que este estímulo provoca los mayores niveles de liberación de AA. La estimulación de macrófagos peritoneales de ratón con diferentes concentraciones de zimosán durante una hora muestra que concentraciones de $1 \mathrm{mg} / 10^{6}$ células son suficientes para observar condiciones de saturación en la liberación de AA, llegándose a alcanzar valores máximos de movilización cercanos al $20 \%$ de total de AA celular. $€$

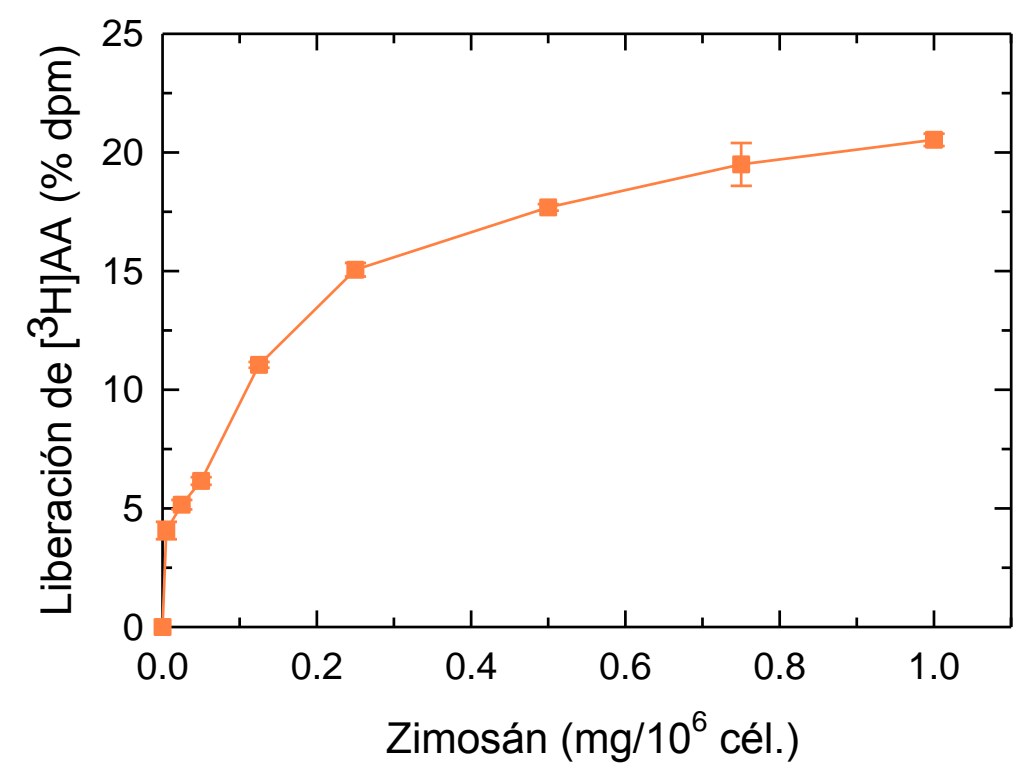

Figura 12. Medida de la liberación de [ $\left.{ }^{3} \mathrm{H}\right] \mathrm{AA}$ en una dosimetría de zimosán.

Medida de la liberación de $\left.{ }^{3} \mathrm{H}\right]$ de macrófagos peritoneales de ratón bajo condiciones de estimulación con zimosán a diferentes concentraciones $\left(\mathrm{mg} / 10^{6}\right.$ células). Para una mejor comprensión, se estimó una nula liberación neta de $\left[{ }^{3} \mathrm{H}\right] \mathrm{AA}$ a concentración 0 , para lo cual se restó el valor residual obtenido en ese punto a los demás puntos de estudio. 
Una vez establecidas las concentraciones saturantes de zimosán en la liberación de AA, se comprobó que el tiempo al que el zimosán libera la máxima cantidad de AA de los glicerofosfolípidos de las células es 1 hora, a partir de la cual, las células no son capaces de continuar liberando cantidades significativas de este ácido graso.

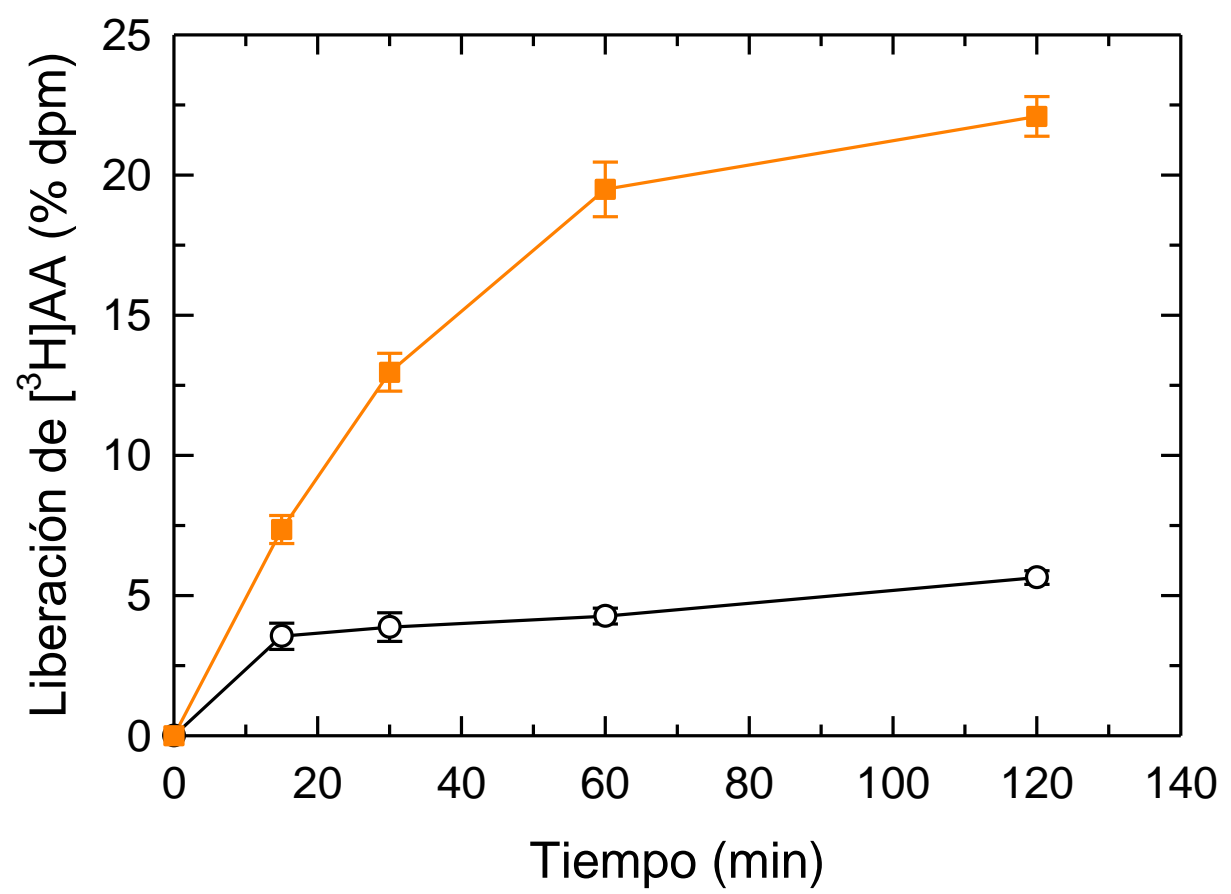

Figura 13. Medida de la liberación de[ $\left.{ }^{3} \mathrm{H}\right] \mathrm{AA}$ por la estimulacióncon zimosán a diferentes tiempos Medida de la liberación de[3H] de macrófagos peritoneales de ratón en condiciones basales (blanco) o bajo condiciones de estimulación con zimosán a una concentración de $1 \mathrm{mg} / 106$ células (naranja). Para una mejor comprensión, se estimó una nula liberación neta de [3H]AA a tiempo 0, para lo cual se restó el valor residual obtenido en ese punto a los demás puntos de estudio.

\section{D.1.2 Estudio de las especies de glicerofosfolípidos implicados en la liberación de AA}

Una vez establecidas la concentración y el tiempo a los cuales la estimulación con zimosán provoca los máximos niveles de liberación de AA en macrófagos peritoneales de ratón, se identificaron las especies de glicerofosfolípidos que contienen AA y que son capaces de liberar dicho ácido graso bajo estas determinadas condiciones de estimulación.

Como ya se ha descrito previamente, al contrario que el marcaje radiactivo, el análisis mediante HPLC/MS-ion trap permite una buena separación de las diferentes especies de glicerofosfolípidos y una óptima identificación gracias a los distintos ciclos de fragmentación que permite el analizador. 
Una vez identificadas más de 20 especies de glicerofosfolípidos con contenido en $A A$, mediante el uso de RP-HPLC-MS de trampa iónica, se compararon los niveles de fosfolípidos con AA que presentan los macrófagos peritoneales de ratón en estado basal y en condiciones de estimulación con zimosán.

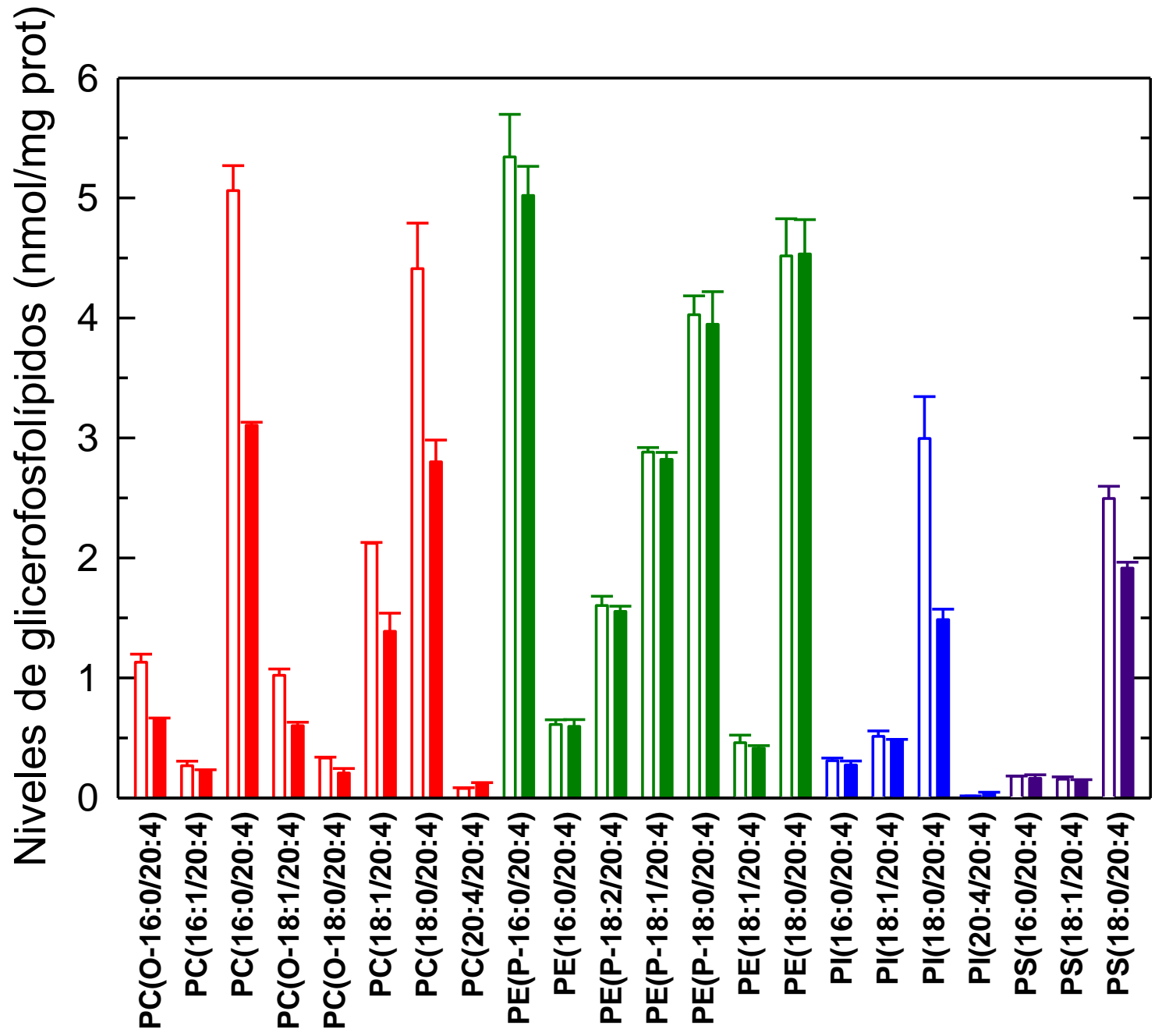

Figura 14. Análisis de los glicerofosfolípidos implicados en la liberación de AA por zmosán Análisis mediante HPLC-MS de los niveles de los glicerofosfolípidos con contenido en AA de macrófagos peritoneales de ratón en condiciones basales (blanco) y estimulados con zimosán a una concentración de 1mg/106 células (color). Tras la extracción lipídica se pudieron analizar en la misma carrera cromatográfica las diferentes especies de PC (rojo), PE (verde), PI (azul) y PS (morado) con AA.

Como se observa, las especies de PC liberan gran cantidad de AA, en especial las especies PC(16:0/20:4), PC(18:0/20:4), PC(18:1/20:4) y PC (0-16:0/20:4). Entre las especies de PI, la especie mayoritaria $\mathrm{PI}(18: 0 / 20: 4)$, que supone alrededor del $80 \%$ de todas las especies de PI con $\mathrm{AA}$, es la especie que libera prácticamente la totalidad de AA liberado de esta clase de fosfolípidos. Resultados similares aparecen en el análisis de las especies de PS que contienen AA, donde la especie mayoritaria PS(18:0/20:4) es la especie que libera casi la totalidad del AA. Respecto a las 
especies de PE, no se encontró una liberación neta de AA, ni en el total de especies de esta clase, ni en ninguna especie en concreto. Estos resultados, obviando pequeñas diferencias de los niveles en especies concretas de fosfolípidos, no difieren sustancialmente de los datos publicados por Astudillo et al. [78] y definen a las especies de PC como las principales fuentes de AA en la movilización provocada por la estimulación con zimosán (fig suma PL).

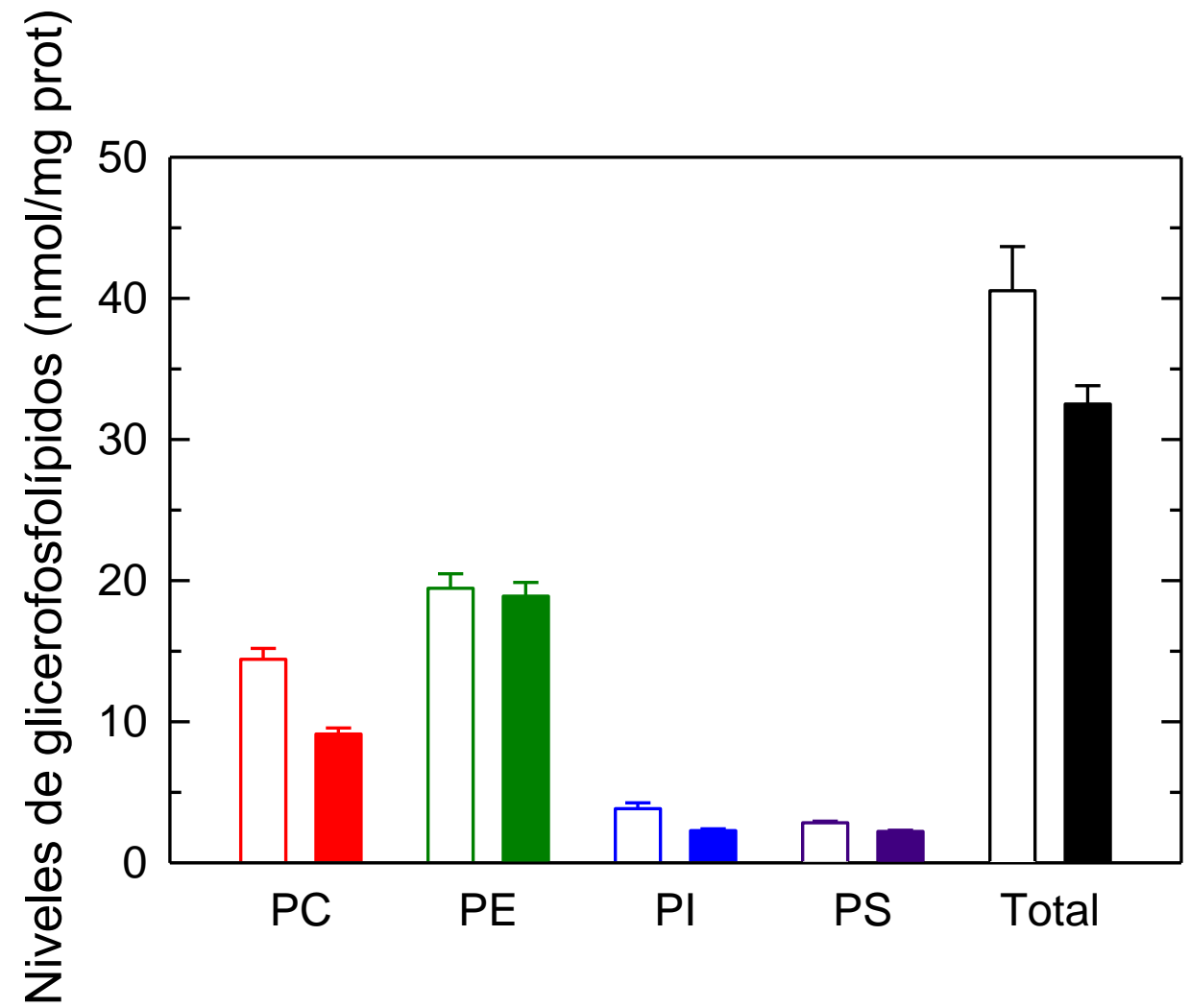

Figura 15. Análisis del total de glicerofosfolípidos implicados en la liberación de AA por zmosán Suma de las diferentes clases de glicerofosfolípidos con contenido en AA presentes en los macrófagos peritoneales de ratón en condiciones basales (blanco) y en condiciones de estimulación por zimosán (1mg/106 células) (color).

No todas las especies de glicerofosfolípidos con contenido en AA colaboran de igual modo en la liberación de dicho AA e incluso, ciertas especies como $\mathrm{PI}(16: 0 / 20: 4)$ o ( $\mathrm{PI}(18: 1 / 20: 4)$ no presentan prácticamente ningún descenso en sus niveles al estimular los macrófagos peritoneales de ratón con zimosán durante una hora y con una concentración de $1 \mathrm{mg} / 10^{6}$ células.

Además de estos efectos, bajo estas condiciones de estimulación concretas dos especies minoritarias homólogas, 1,2-diaraquidonoil-sn-glicero-3-fosfatidilinositol (PI(20:4/20:4)) y 1,2diaraquidonoil-sn-glicero-3-fosfatidilcolina ( $P C(20: 4 / 20: 4)$ ) aumentaron sus niveles en macrófagos peritoneales de ratón. Ambas especies, junto con la especie $P E(16: 1 / 20: 4)$, han sido ya descritas por aumentar sus niveles en condiciones de estimulación con zimosán en monocitos humanos [191]. 
La especie $\mathrm{PE}(16: 1 / 20: 4)$ es una especie muy minoritaria en monocitos humanos pero que, tanto en condiciones de estimulación como en condiciones basales, presenta niveles superiores al límite de detección que presenta la técnica empleada. Sin embargo, al contrario de lo observado en monocitos humanos, en los análisis de glicerofosfolípidos de los macrófagos peritoneales de ratón no se pudo identificar la especie $P E(16: 1 / 20: 4)$, pudiéndose únicamente identificar y cuantificar las especies $\mathrm{PI}(20: 4 / 20: 4)$ y $\mathrm{PC}$ (20:4/20:4) como las únicas especies de glicerofosfolípidos con contenido en AA que aumentan sus niveles en condiciones de estimulación con zimosán respecto a las condiciones basales.
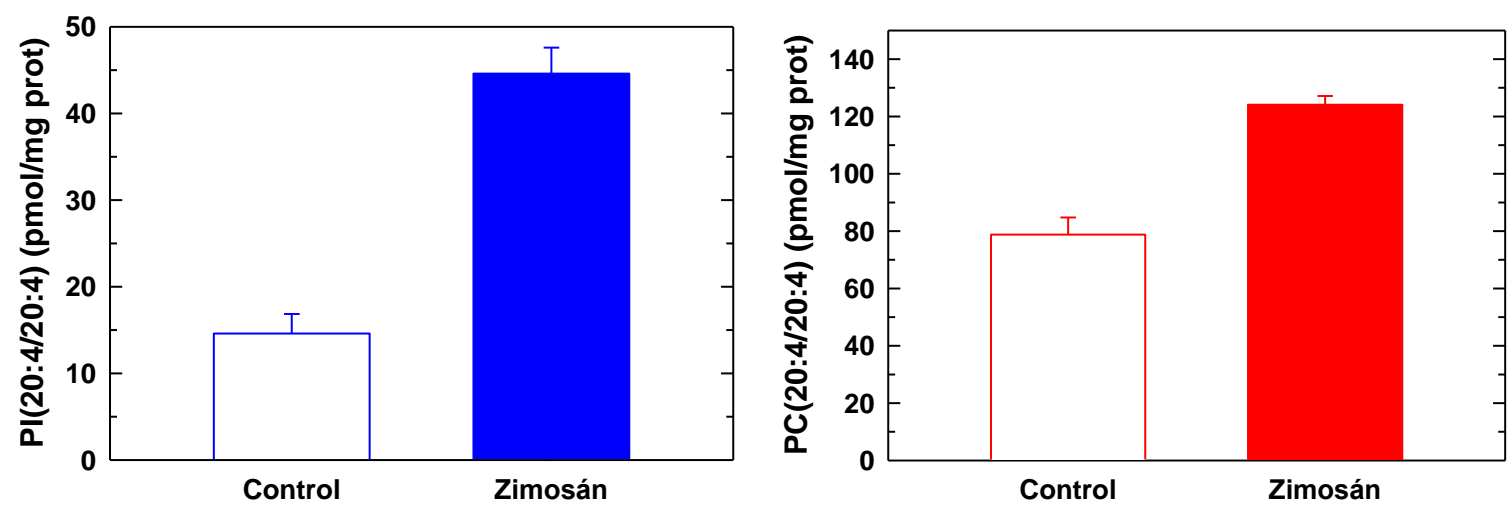

Figura 16. Análisis de $\mathrm{PI}(20: 4 / 20: 4)$ y PC(20:4/20:4) en la estimulación por zimosán Extracto de la figura 14. Análisis mediante HPLC-MS de los niveles de $\mathrm{PI}(20: 4 / 20: 4)$ y PC(20:4/20:4) en macrófagos peritoneales de ratón en estado basal (blanco), estimulados con zimosán (negro. Tras la extracción lipídica, mediante HPLC-MS se pudo identificar y cuantificar con ionización negativa la especie $\mathrm{PI}(20: 4 / 20: 4)$ con $\mathrm{m} / \mathrm{z}=905$ (azul), y mediante ionización positiva la especie PC(20:4/20:4) con $\mathrm{m} / \mathrm{z}=830$ (rojo).

\section{D.1.3 Implicación de la cPLA $2 \alpha$}

Para comprobar la implicación de las diferentes fosfolipasas en la liberación de AA bajo estímulación por zimosán se usaron distintos inhibidores específicos de posibles enzimas implicadas. Además de la utilización de la pirrofenona como inhibidor específico de la $\operatorname{cPLA}_{2} \alpha$, se comprobó el efecto de FKGK11 y FKGK18 que se han descrito recientemente [Kokotos, Dennis]

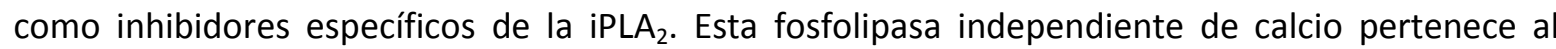
grupo VI de las $\mathrm{PLA}_{2}$ y muestra, además de una potente actividad fosfolipasa, actividad lisofosfolipasa y transacilasa [Dennis 2011]. Los aún escasos trabajos en los que se describen el uso de estos inhibidores utilizan concentraciones de FKGK11 de $10 \mu \mathrm{M}$ [Paliege 2012]. Sin embargo, la exposición de los macrófagos a esas concentraciones del inhibidor FKGK18 mostró indicios de pérdidad de viabilidad al observarse la liberación de importantes cantidades de AA sin que las células hubieran sido estimuladas. Para comprobar la eficacia de estos inhibidores y las concentraciones óptimas se realizó una dosimetría de FKGK18 y se comprobó su capacidad de 
inhibición de la iPLA $\mathrm{PL}_{2}$ midiendo el efecto en la generación de lisofosfolípidos en células RAW 264.7 Estudios previos han mostrado que la $\mathrm{iPLA}_{2}$ es responsable de mantener los niveles basales homeostáticos de lisofosfolípidos [217, 218]. FKGK18 a una concentración de 0,5 $\mu \mathrm{M}$ presenta un efecto similar al del inhibidor clásico de $\operatorname{iPLA}_{2} \operatorname{BEL}[217,218]$ en el descenso de los niveles celulares de lisoPI y es capaz de producir mayores efectos a una concentración de $1 \mu \mathrm{M}$ por lo que se uso esta última como concentración óptima en el uso de los compuestos FKGK11 y FKGK18 como inhibidores de la actividad de iPLA 2 .

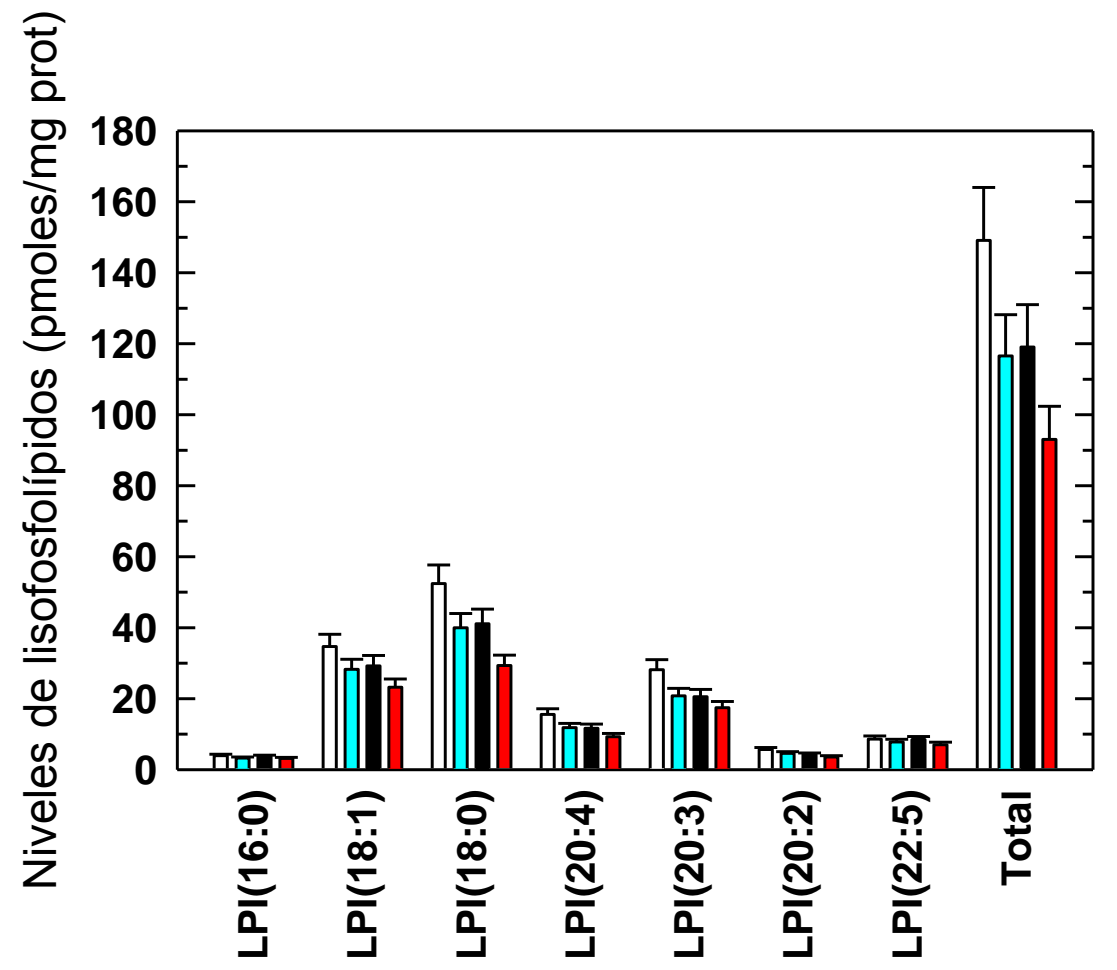

Figura 17 Análisis del efecto de inhibidores de $\mathrm{CPLA}_{2} \alpha$ en especies de lisoPI Análisis de diferentes inhibidores de la iPLA 2 -grupo VIA implicados en la formación de lisofosfoinositoles (lisoPI). Una vez extraídos los lípidos mediante HPLC-MS se analizaron los lisoPI presentes en macrófagos peritoneales en estado basal (blanco) y en tras 30 minutos de incubación con BEL a una concentración de $10 \mu \mathrm{M}$ (azul), FKGK18 a 0,5 $\mu \mathrm{M}$ (negro) y FKGK18 a $1 \mu \mathrm{M}$ (rojo).

Ha sido ampliamente descrita la implicación de la $\mathrm{CPLA}_{2} \alpha$ en la liberación de AA en células estimuladas [119, 126, 219]. Con el fin de comprobar dicha relación y de definir la implicación de la iPLA $A_{2}$ en la liberación de AA en macrófagos peritoneales de ratón, junto con FKGK11 y FKGK18 se estudió la implicación de BEL y la pirrofenona, descrita como un inhibidor específico de la cPLA ${ }_{2} \alpha$ [220]. Mientras que la inhibición de la cPLA $2 \alpha$ por pirrofenona es capaz de impedir la liberación de AA, la inhibición de la iPLA $A_{2}$ tanto por FKGK11 como por FKGK18 no produce un efecto similar en la movilización de AA. 


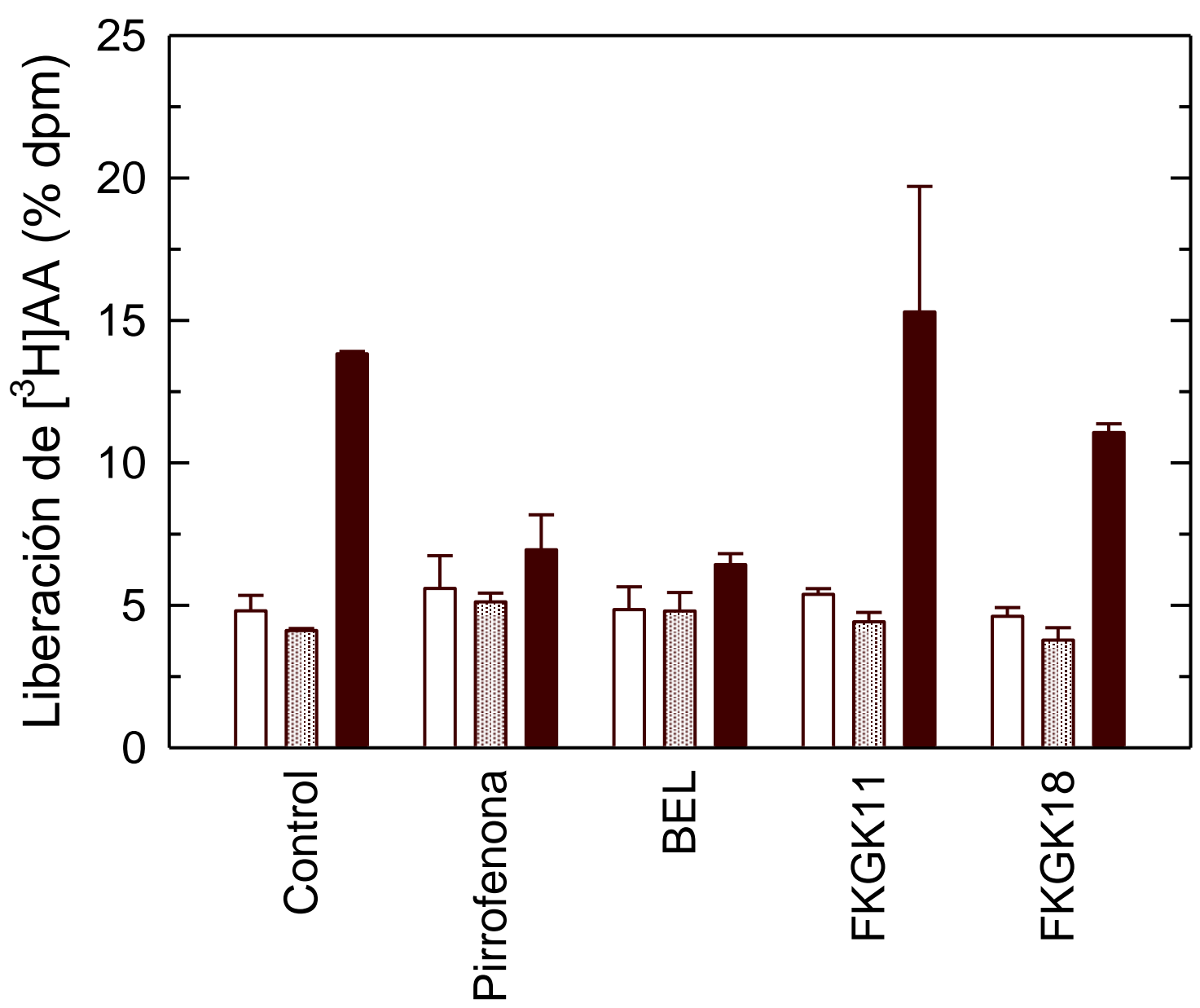

Basal Inıı⿰氵亡: Inhibidor Inhibidor + Zimosán

Figura 18. Análisis del efecto de diferentes inhibidores de $\mathrm{PLA}$ en la liberación de [ $\left.{ }^{3} \mathrm{H}\right] \mathrm{AA}$ por la estimulación por zimosán.

Liberación de [3H]AA en macrófagos peritoneales de ratón. Tanto para las células control (sin inhibidor) como para cada inhibidor (pirrofenona $1 \mu \mathrm{M})$, BEL $(10 \mu \mathrm{M})$, FKGK11 y FKGK18 $(1 \mu \mathrm{M})$ se muestra el $[3 \mathrm{H}]$ liberado de los macrófagos en condiciones basales (blanco), tras 30 minutos de exposición al respectivo inhibidor (negro) y al ser estimulados con zimosán (1mg/106 células) previa incubación durante 30 minutos con el respectivo inhibidor (rojo).

Sin embargo, BEL, al contrario que FKGK11 y FKGK18, sí impidó la liberación de AA en macrófagos peritoneales de ratón en condiciones de estimulación con zimosán, lo que sugeriría la implicación de la iPLA ${ }_{2}$ en dicha liberación de AA. Para corroborar este dato, contradictorio con la mayoría de resultados en bibliografía [205], se utilizaron células de animales modificados genéticamente que no expresan el gen que codifica para la iPLA $\mathrm{P}_{2}$. La estimulación con zimosán durante una hora a una concentración de $1 \mathrm{mg} / 1 \times 10^{6}$ de macrófagos peritoneales extraídos de ratones wild type $(\mathrm{Wt})$ y ratones knock-out $(\mathrm{KO})$ para la $\mathrm{iPLA}_{2}$ no mostró diferencias en la liberación de $\left[{ }^{3} \mathrm{H}\right] \mathrm{AA}$ (figura $\mathrm{X}$ ). Esto confirma los datos obtenidos mediante el uso de los inhibidores FKGK11 y 
FKGK18 y demuestra la inexistente implicación de la $\mathrm{iPLA}_{2}$ en la movilización de AA desde los glicerofosfolípidos bajo estimulaciones de zimosán. En este sentido, se ha demostrado que BEL es capaz de inhibir la actividad de PAP1, implicada en una posible movilización de AA a través de la acción de la fosfolipasa D (PLD) [221, 222] lo que podría explicar los datos obtenidos.

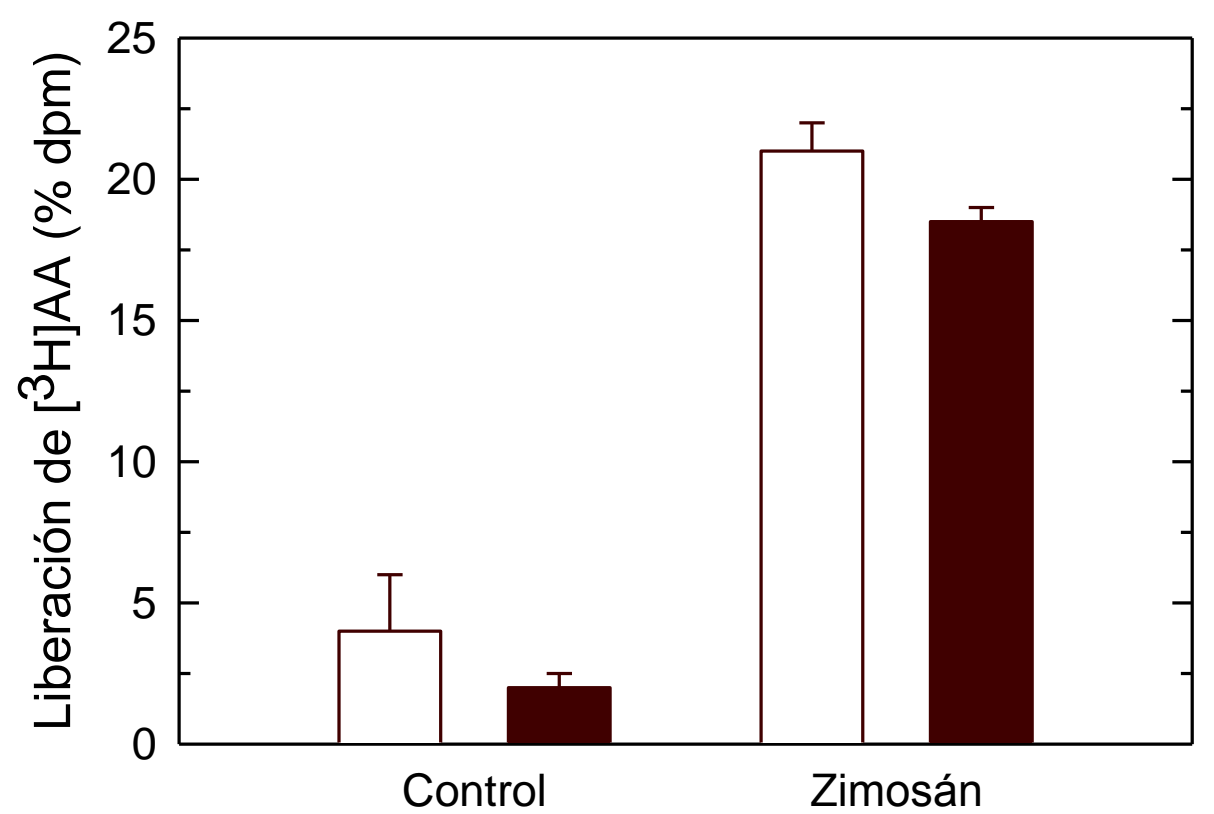

\begin{abstract}
Wt iPLA
Figura 19. Análisis de la liberación de $\left.{ }^{3} \mathrm{H}\right] \mathrm{AA}$ en ratones $\mathrm{KO}$ de la $\mathrm{CPLA} \mathrm{A}_{2} \alpha$ estimulados con zimosán. Comparativa de la liberación de [3H]AA en macrófagos peritoneales de ratón en condiciones basales (control) y estimulados con zimosán a una concentración de 1mg/106 células. Los macrófagos se extrajeron de dos ratones Wt (blanco) y dos ratones KO de la iPLA2-VIA (marrón).
\end{abstract}

Una vez de definido el papel de la cPLA2 $\alpha$ en la liberación de AA, con el fin de estudiar su implicación en la liberación de AA desde las diferentes especies de glicerofosfolípidos bajo condiciones de estimulación con zimosán, se utilizo pirrofenona (Pir) como inhibidor específico de esta fosfolipasa y se realizó el análisis mediante HPLC/MS de las especies de fosfolípidos que contienen y liberan AA. Como se muestra en la figura 20, la presencia de la pirrofenona impide el descenso de los niveles de todas las especies de fosfolípidos implicadas en la movilización de AA sin excepción. 

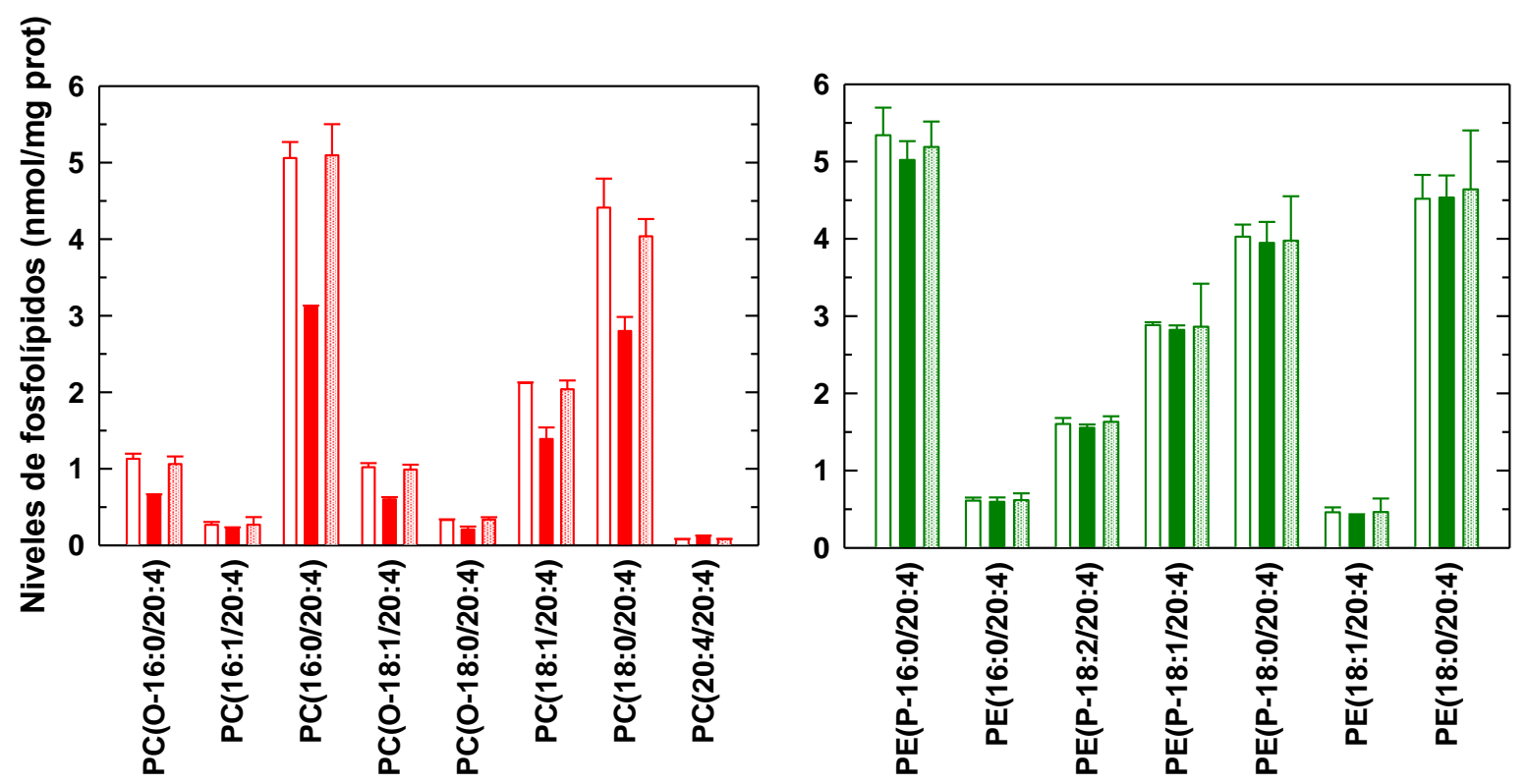

흘
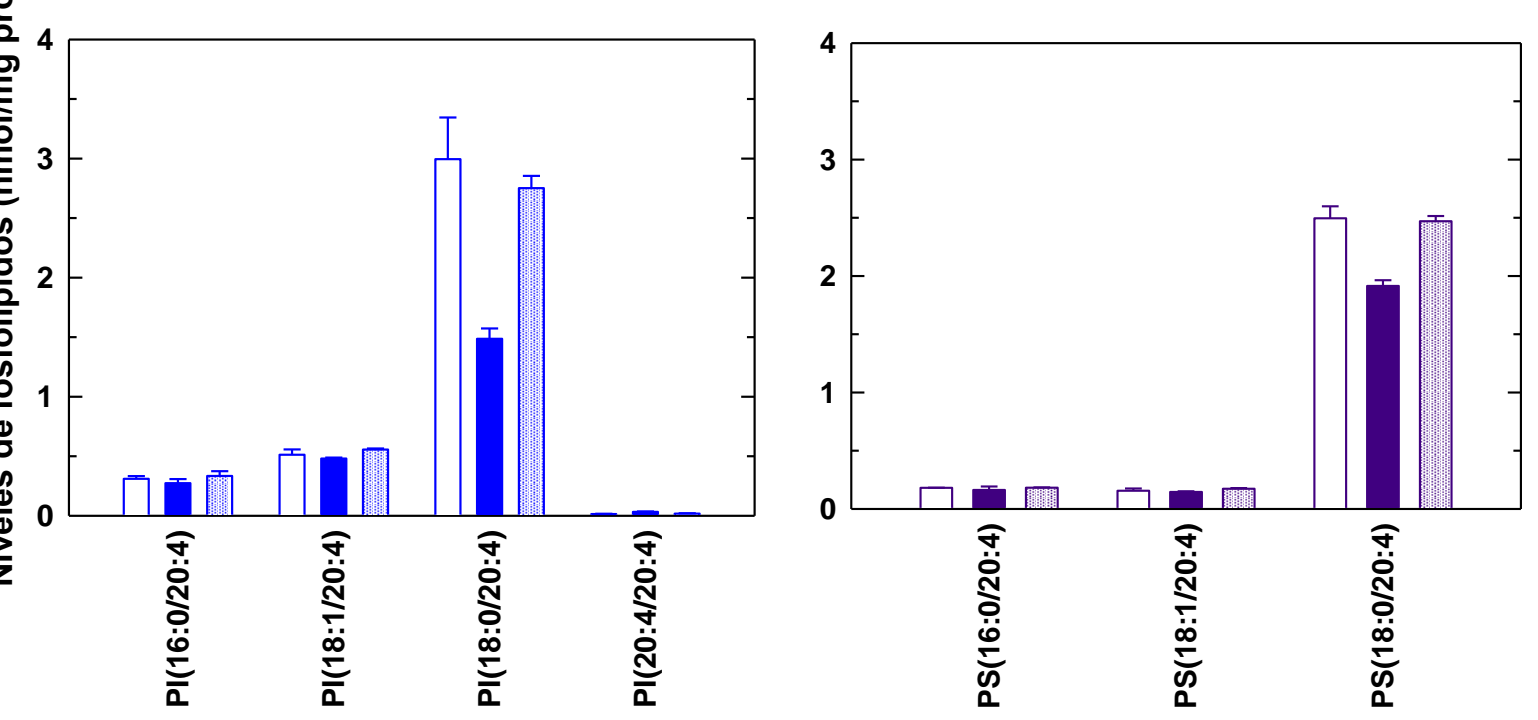

Basal

Zimosán

Pir + Zimosán

Figura 20. Análisis del efecto de la pirrofenona en la liberación de de AA desde los glicerofosfolípidos por la estimulación por zimosán.

Análisis mediante HPLC-MS de los niveles de los glicerofosfolípidos con contenido en AA de macrófagos peritoneales de ratón en condiciones basales (blanco), estimulados con zimosán (color) y estímulados con zimosán previa incubación con pirrofenona (Pir) a una concentración de $1 \mu \mathrm{M}$ durante 30 minutos (punteado). Tras la extracción lipídica se pudieron analizar en la misma carrera cromatográfica las diferentes especies de PC (rojo), PE (verde), PI (azul) y PS (morado) con AA. 
Los datos del total de los glicerofosfolípidos con AA muestran que la movilización de AA observado desde especies tanto de PC, PI como PS se ve impedido por el uso de pirrofenona, lo que demuestra la implicación de la $\mathrm{CPLA}_{2} \alpha$ en la liberación de AA en condiciones de estimulación por zimosán en macrófagos peritoneales de ratón.

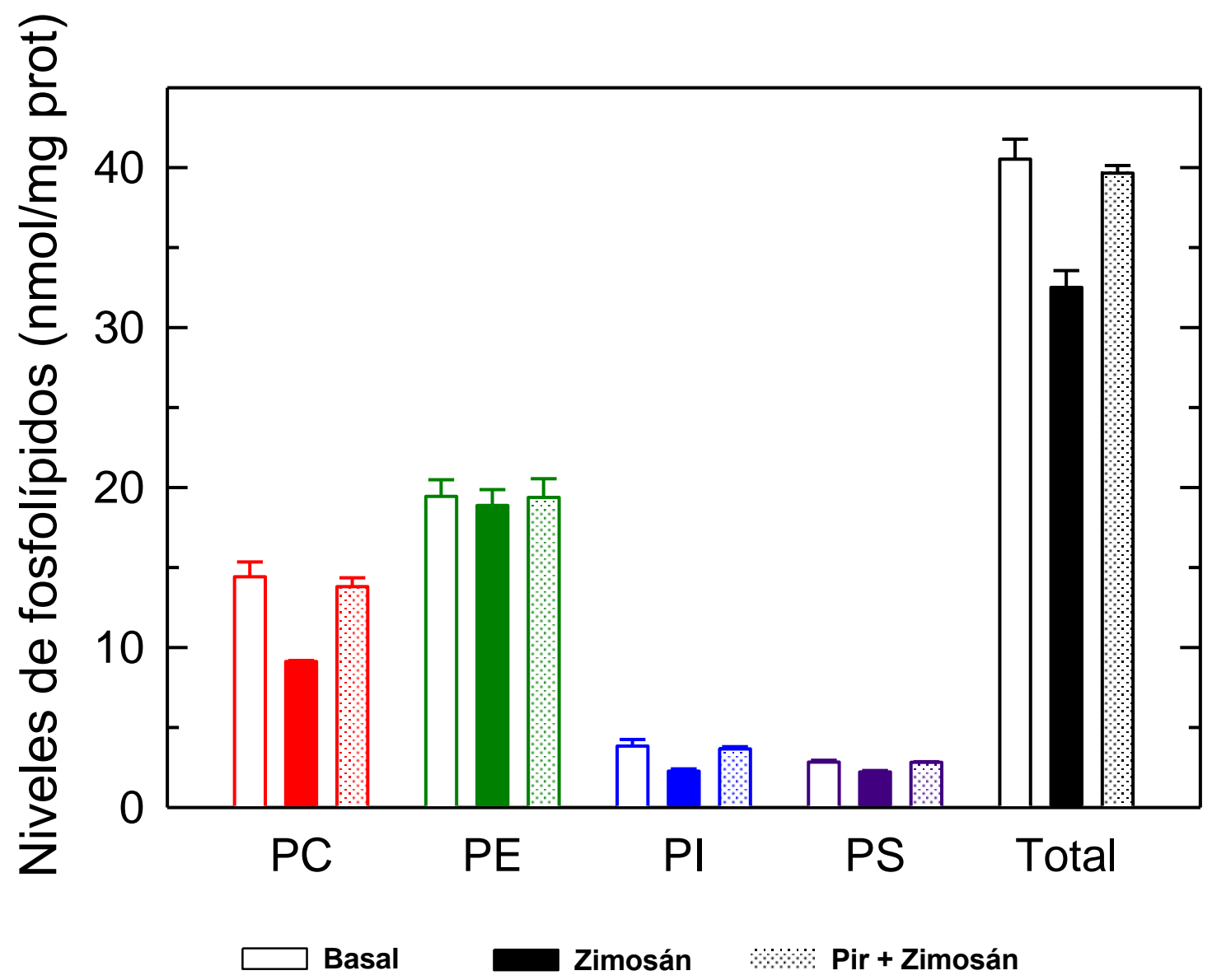

Figura 21. Análisis del efecto de la pirrofenona en la liberación de de AA desde total de glicerofosfolípidos por la estimulación por zimosán.

Suma de las diferentes clases de glicerofosfolípidos con contenido en AA presentes en los macrófagos peritoneales de ratón en condiciones basales (blanco) y en condiciones de estimulación por zimosán (color) y estimuladas con zimosán previa incubación con pirrofenona (Pir) a una concentración de $1 \mu \mathrm{M}$ durante 30 minutos (punteado). Se muestra la suma de especies de PC (rojo), PE (verde), PI (azul) y PS (morado) y la suma total de todas ellas (negro). 
Por su parte, la implicación de la cPLA 2 en la síntesis de $\mathrm{PI}(20: 4 / 20: 4)$ en monocitos humanos estimulados con zimosán fue demostrada por Balgoma et. al. mediante la utilización de pirrrofenona. El uso de este inhibidor impide el aumento de los niveles de esta especie en dichas condiciones de estimulación. En el caso de los macrófagos peritoneales se observa el mismo efecto inhibidor sobre esta especie fosfolipídica al utilizar la pirrofenona previamente al estímulo con zimosán. También en el caso de la especie $P C(20: 4 / 20: 4)$ se repite el efecto inhibidor de la pirrofenona en el aumento de sus niveles bajo condiciones de estimulación con zimosán.
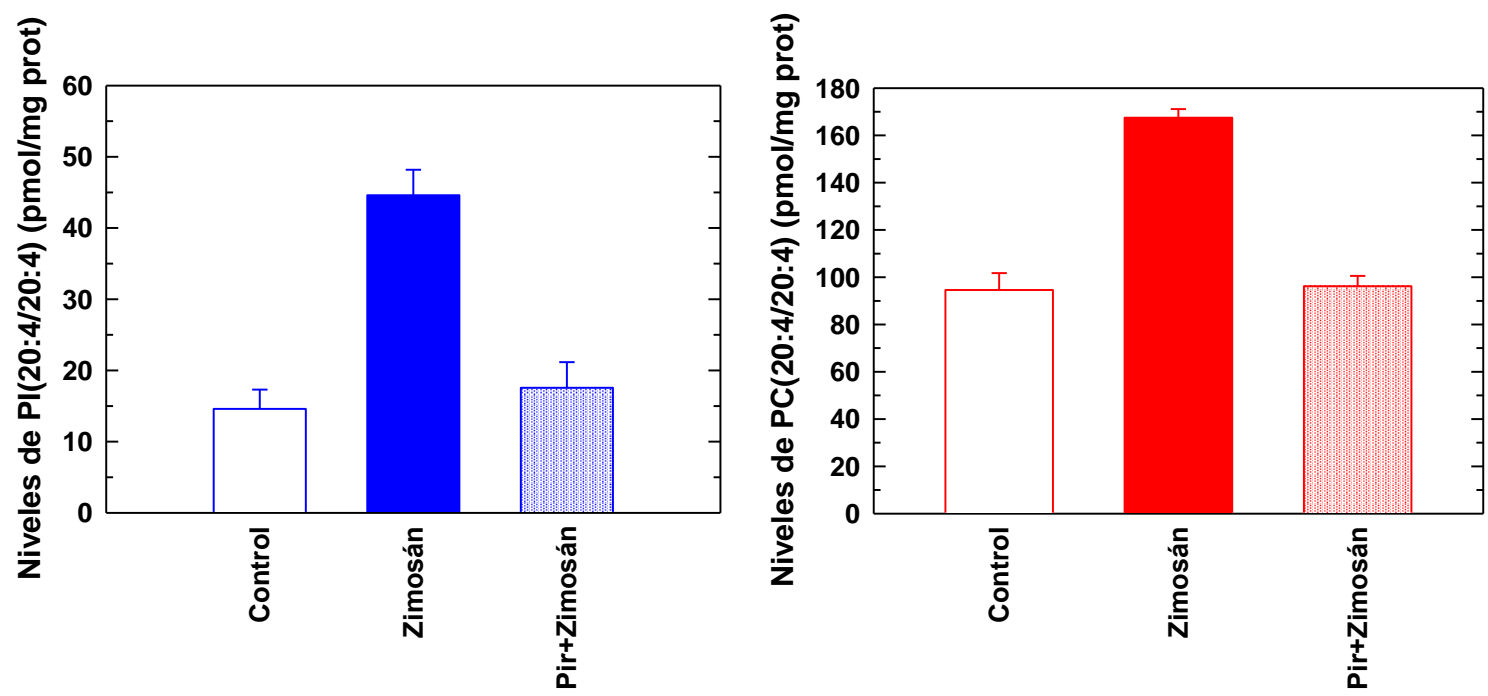

Figura 22. Análisis del efecto de la pirrofenona sobre los niveles de PI(20:4/20:4) y PC(20:4/20:4) ante la estimulación de zimosán.

Extracto de la figura 20. Análisis mediante HPLC-MS de los niveles de PI(20:4/20:4) y PC(20:4/20:4) en macrófagos peritoneales de ratón en estado basal (blanco), estimulados con zimosán (color) y estimulados con zimosán previa incubación durante 30 minutos con pirrofenona (Pir) a una concentración de $1 \mu \mathrm{M}$ (punteado). Tras la extracción lipídica, mediante HPLC-MS se pudo identificar y cuantificar con ionización negativa la especie $\mathrm{PI}(20: 4 / 20: 4)$ con $\mathrm{m} / \mathrm{z}=905$ (azul), y mediante ionización positiva la especie PC(20:4/20:4) con $\mathrm{m} / \mathrm{z}=830$ (rojo). 


\section{D.2 Efecto sinérgico de la estimulación mediante LPS y zimosán}

\section{D.2.1 Medida de la liberación de AA}

Como ya se ha mostrado previamente, la incubación de macrófagos peritoneales de ratón con zimosán durante una hora promueve la liberación de AA. Mientras que el zimosán es reconocido por diferentes receptores como TLR2 y receptores de manosa y, principalmente, dectina-1 [30], el LPS (lipopolisacárido), un componente esencial de las paredes celulares de las bacterias Gram negativas, es reconocido por otro miembro de los receptores Toll-like, TLR4.

EI LPS se ha descrito como un estímulo de la liberación de AA en macrófagos de ratón. Sin embargo, a diferencia del zimosán, este efecto no se observa durante las primeras dos horas de exposición al estímulo [44] y se ha descrito la necesidad de largos tiempos de incubación con LPS para la observación de liberación neta de AA [223]. Sin embargo, se ha demostrado que la preincubación con LPS durante $1 \mathrm{~h}$ antes de la estimulación de los macrófagos peritoneales de ratón con zimosán, es suficiente para provocar un aumentoo en la liberación de AA [224][Aderem 1986]. Este efecto potenciador del LPS sobre la respuesta del zimosán fue confirmado en los experimentos mostrados en la figura $\mathrm{X}$.

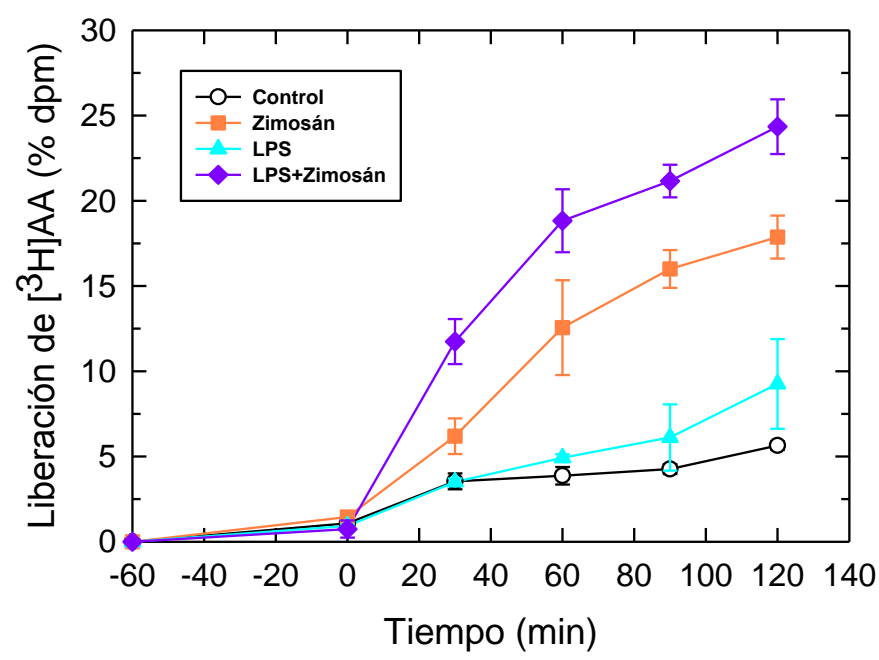

Figura 23. Medida de la liberación de [ $\left.{ }^{3} \mathrm{H}\right] \mathrm{AA}$ por la estimulación con LPS y zimosán. Liberación de [3H]AA de macrófagos peritoneales de ratón en condiciones basales (blanco), estimulados con $100 \mathrm{ng} / \mathrm{ml}$ de LPS (azul), con $1 \mathrm{mg} / 106$ células de zimosán (naranja) y con $1 \mathrm{mg} / 106$ células de zimosán previa estimulación durante una hora con 100ng/ml de LPS (violeta). Se consideró tiempo 0 al momento en el que las células son tratadas con zimosán. Para una mejor comprensión, se estimó una nula liberación neta de [3H]AA a tiempo -60, para lo cual se restó el valor residual obtenido en ese punto a los demás puntos de estudio. 
Ya que la cantidad de AA libre está controlado tanto por la acción de liberación llevada a cabo por las fosfolipasas como por la de incorporación desarrollada por las aciltransferasas, el objetivo fue determinar cuál de las dos acciones podrían explicaban una mayor cantidad de AA libre observado en estas condiciones de doble estimulación con LPS y zimosán. Mediante el uso de $\left[{ }^{3} \mathrm{H}\right] \mathrm{AA}$ se estudió la incorporación de este AA marcado radiactivamente en macrófagos peritoneales de ratón tanto en estado basal como tratados con la mismas condiciones de LPS. Como se muestra en la figura $X$, los macrófagos peritoneales de ratón no mostraron diferencias de incorporación de $\left[{ }^{3} \mathrm{H}\right] \mathrm{AA}$ en ambas condiciones $\mathrm{y}$, por lo tanto, el LPS no parece estar implicado en la incorporación de AA por modificación en la acción de las aciltransferasas implicadas.

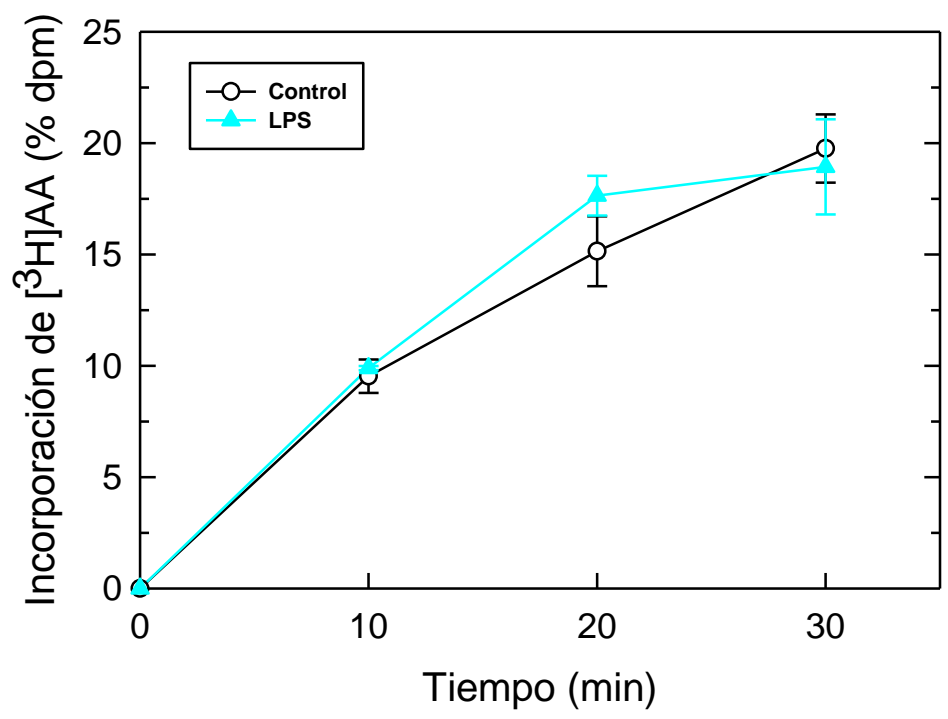

Figura 24 Análisis del efecto del LPS en la incorporación de [ $\left.{ }^{3} \mathrm{H}\right] \mathrm{AA}$.

Incorporación de [3H]AA en macrófagos peritoneales de ratón en condiciones basales (blanco) y incubadas con LPS a una concentración de $100 \mathrm{ng} / \mathrm{ml}$ (azul). A los macrófagos extraídos al día anterior, se les retira el [3H]AA que pueda quedar en exceso en el medio de cultivo y se dejan durante una hora en medio incompleto antes de añadir el LPS durante los tiempos indicados. Para una mejor comprensión, se estimó una nula liberación neta de [3H]AA a tiempo 0 , para lo cual se restó el valor residual obtenido en ese punto a los demás puntos de estudio. 


\section{D.2.2 Estudio de las especies de glicerofosfolípidos implicadas en la liberación de AA}

Como se ha descrito anteriormente, el análisis de las especies de glicerofosfolípidos en condiciones de estimulación con zimosán no produce una liberación homogénea de las diversas especies de fosfolípidos con contenido en $A A$, debido al doble control sobre el proceso de liberación de $A A$ en el que están implicadas la hidrólisis de los fosfolípidos a través de la $\operatorname{CPLA}_{2} \alpha$ y el intercambio de AA entre especies de PC y PE por transacilación. En primer lugar, antes del análisis del efecto sinérgico de LPS y zimosán, se llevó a cabo el estudio del efecto del LPS únicamente, ya que una liberación neta de AA puede no corresponderse con una inexistente modificación de los niveles de cada una de las especies de glicerofosfolípidos con contenido en $A A$, donde al descenso de los niveles de una especie fosfolipídica pueden verse compensados con el aumento de otro fosfolípido. Sin embargo, como era esperable, el análisis de todas las especies con AA mostró que ninguna de ellas presenta variaciones en sus niveles bajo la estimulación de LPS.

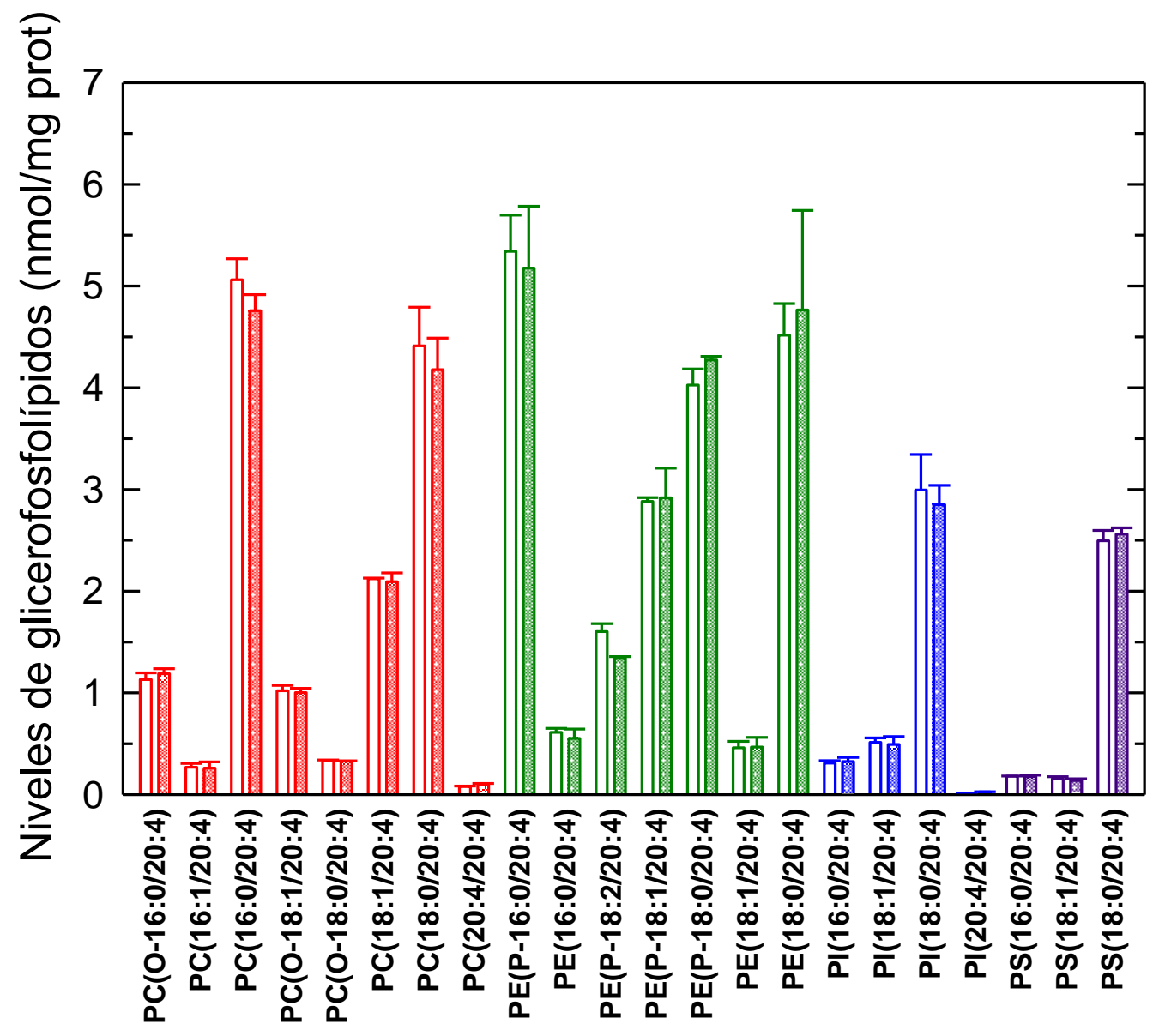

Figura 25 Análisis del efecto del LPS sobre los glicerofosfolípidos con AA. 
en la misma carrera cromatográfica las diferentes especies de PC (rojo), PE (verde), PI (azul) y PS (morado) con AA.

Una vez establecido el efecto del LPS sobre la liberación de AA en macrófagos peritoneales de ratón, se analizaron las especies de glicerofosfolípidos implicadas en el efecto sinérgico del LPS y el zimosán en dicha liberación de AA. Los análisis por espectrometría de masas acoplado a HPLC de las especies de fosfolípidos que contienen $A A$, mostraron un aumento de la liberación de $A A$ de las especie ya implicadas en la movilización de AA en condiciones de estimulación de zimosán. Así, las dos especies mayoritarias con cabeza polar de colina, $P C(16: 0 / 20: 4)$ y $P C(18: 0 / 20: 4)$ que ya suponen una gran parte de la liberación de AA promovido por zimosán, ven disminuidos sus niveles cuando los macrófagos peritoneales de ratón se preincuban durante una hora con LPS. El mismo efecto se observa en las especies $\mathrm{PI}(18: 0 / 20: 4)$ y PS(18:0/20:4), especies mayoritarias dentro de su clase y que representan la práctica totalidad de la liberación con zimosán y el aumento en la liberación en condiciones de preincubación con LPS. Por su parte, en especies de PE, donde no se observa una liberación neta de $A A$ en condiciones de estimulación con zimosán, sí parece observarse un descenso de sus niveles bajo el efecto sinérgico del LPS. Como se puede observar, dicha liberación procede de la especie mayoritaria de PE con contenido en AA, PE(P-16:0/20:4). 

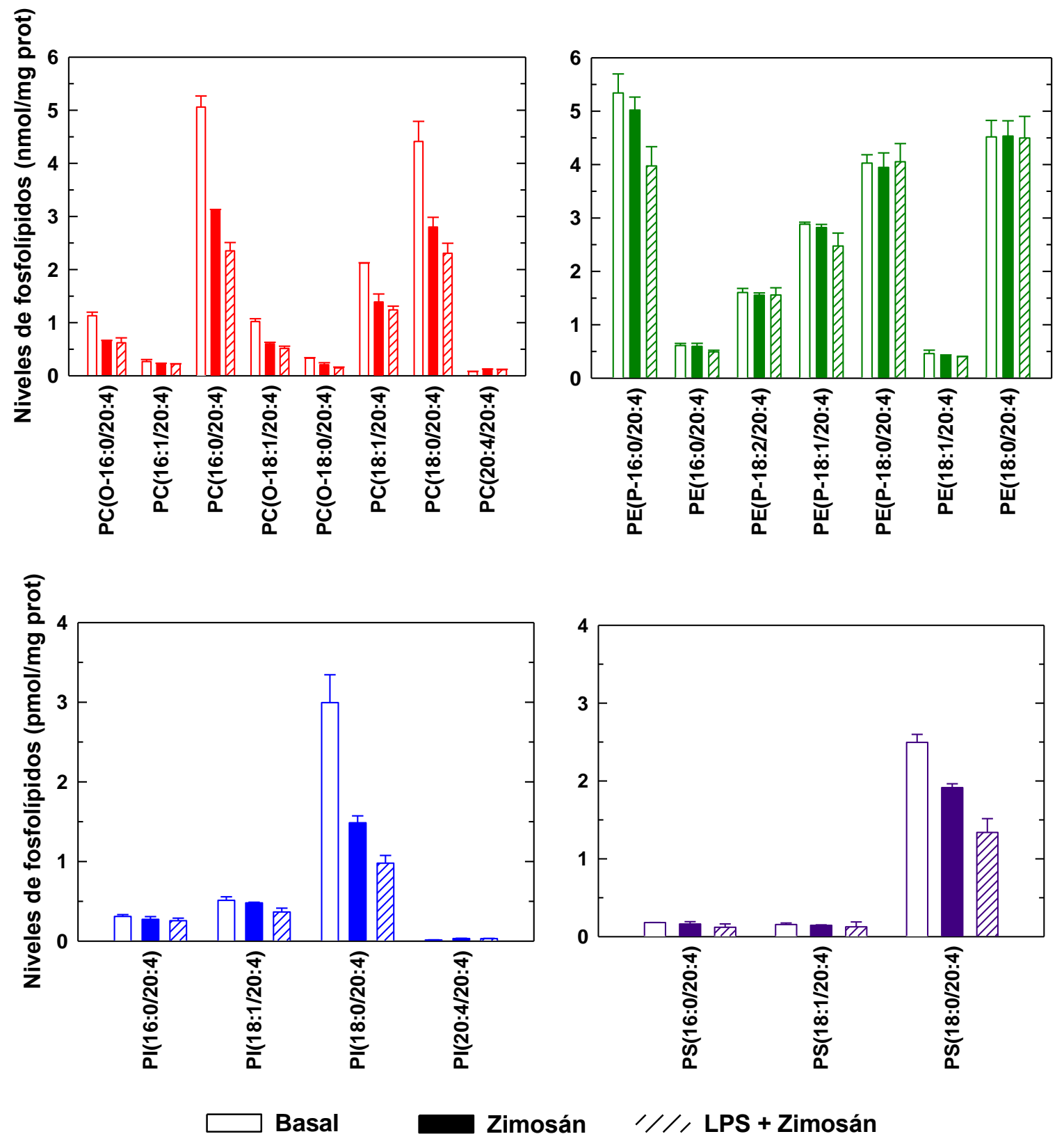

Figura 26. Análisis del efecto sinérgico del LPS y el zimosán sobre las especies de glicerofosfolípidos con AA Análisis mediante HPLC-MS de los niveles de los glicerofosfolípidos con contenido en AA de macrófagos peritoneales de ratón en condiciones basales (blanco), estimulados con zimosán (color) y estímulados con zimosán previa incubación durante una hora con LPS (rayado). Tras la extracción lipídica se pudieron analizar en la misma carrera cromatográfica las diferentes especies de PC (rojo), PE (verde), PI (azul) y PS (morado) con AA 
El total de fosfolípidos que contienen AA muestra el aumento de la liberación de AA entre las células estimuladas con zimosán si han sido previamente incubadas con LPS durante $1 \mathrm{~h}$. Dicho aumento en la liberación de AA parece no implicar de forma preferente a ninguna clase concreta de fosfolípidos. Por su parte, la suma de todos los fosfolípidos que contienen AA muestra una liberación de AA que se corresponde con lo observado en los experimentos de radiactividad.

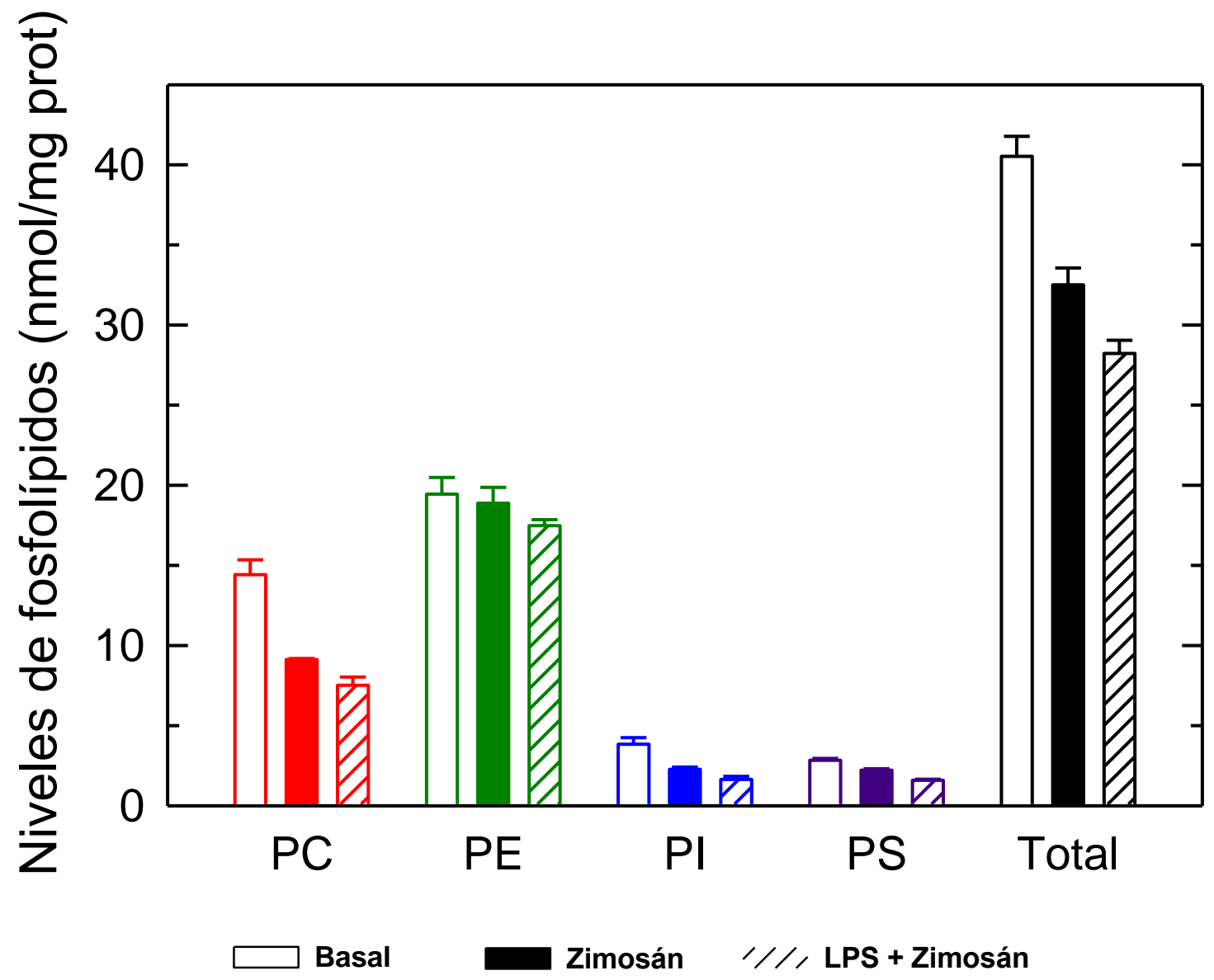

Figura 27. Análisis del efecto sinérgico del LPS y el zimosán sobre el total de glicerofosfolípidos con AA Suma de las diferentes clases de glicerofosfolípidos con contenido en AA presentes en los macrófagos peritoneales de ratón en condiciones basales (blanco), estimulados con zimosán (color) y estímulados con zimosán previa incubación durante una hora con LPS ( (rayado). Se muestra la suma de especies de PC (rojo), PE (verde), PI (azul) y PS (morado) y la suma total de todas ellas (negro). 
Por otra parte, respecto a las especies $\mathrm{PI}(20: 4 / 20: 4)$ y $\mathrm{PC}(20: 4 / 20: 4)$, la estimulación con LPS provoca un aumento en los niveles de estas especies. En el caso de la especie PI(20:4/20:4) dicho crecimiento es proporcionalmente más importante pero, en ambas especies, el efecto de la estimulación con LPS es inferior al observado cuando los macrófagos peritoneales de ratón se estimulan con zimosán. Sin embargo, aunque LPS parece aumentar los niveles tanto de la especie $\mathrm{PI}(20: 4 / 20: 4)$ como de $\mathrm{PC}(20: 4 / 20: 4)$, estas especies fosfolipídicas no parecen sufrir ninguna modificación cuando se preincuban durante 1 hora con LPS antes de estimular con zimosán los macrófagos peritoneales de ratón durante $1 \mathrm{~h}$ adicional.
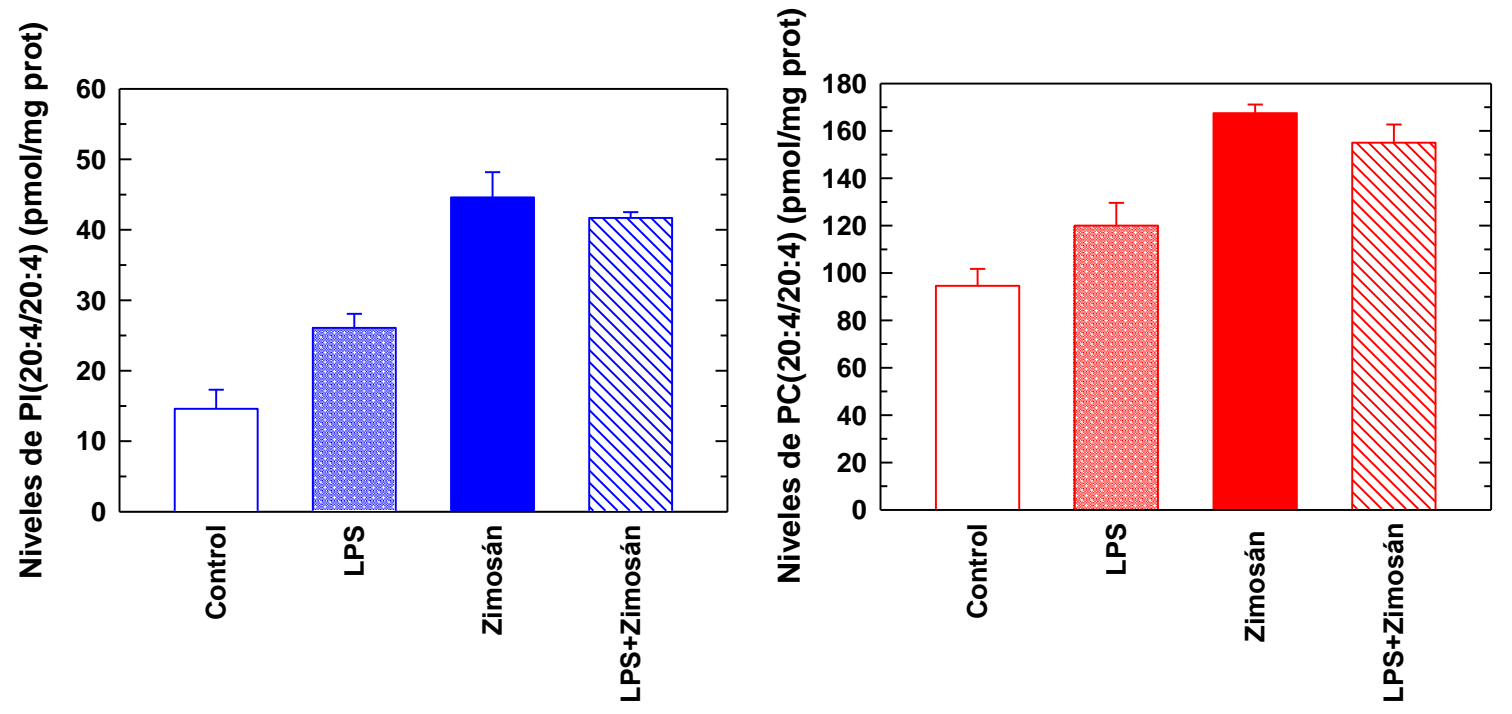

Figura 28. Análisis del efecto del LPS y zimosán sobre los niveles de las especies PI(20:4/20:4) y PC(20:4/20:4). Extracto de la figura 26. Análisis mediante HPLC-MS de los niveles de PI(20:4/20:4) y PC(20:4/20:4) en macrófagos peritoneales de ratón en estado basal (blanco), tratados con LPS (punteado), estimulados con zimosán (color) y estimulados con zimosán previa incubación durante una hora con LPS (rayado). Tras la extracción lipídica, mediante HPLCMS se pudo identificar y cuantificar con ionización negativa la especie $\mathrm{PI}(20: 4 / 20: 4)$ con $\mathrm{m} / \mathrm{z}=905$ (azul), y mediante ionización positiva la especie $\mathrm{PC}(20: 4 / 20: 4)$ con $\mathrm{m} / \mathrm{z}=830$ (rojo).

\section{D.2.3 Implicación de la cPLA $2 \alpha$}

Para comprobar la implicación de la cPLA2 $\alpha$ en el efecto sinérgico producido por la incubación previa durante una hora a la estimulación de los macrófagos peritoneales de ratón con zimosán se utilizó la pirrofenona.

En el diseño experimental se tuvo en cuenta la nula liberación neta de AA desde los glicerofosfolípidos bajo la estimulación de LPS durante 1 hora. Así, la utilización de pirrofenona fue posterior a la incubación con LPS pero previa a la estimulación por zimosán. Los resultados obtenidos, tanto de las diferentes especies como del total de fosfolípidos con contenido en AA muestran que la inhibición por pirrofenona de la activación de la $\mathrm{CPLA}_{2} \alpha$ provocado por el zimosán impide la liberación de AA en macrófagos peritoneales de ratón estimulados con LPS y zimosán. 

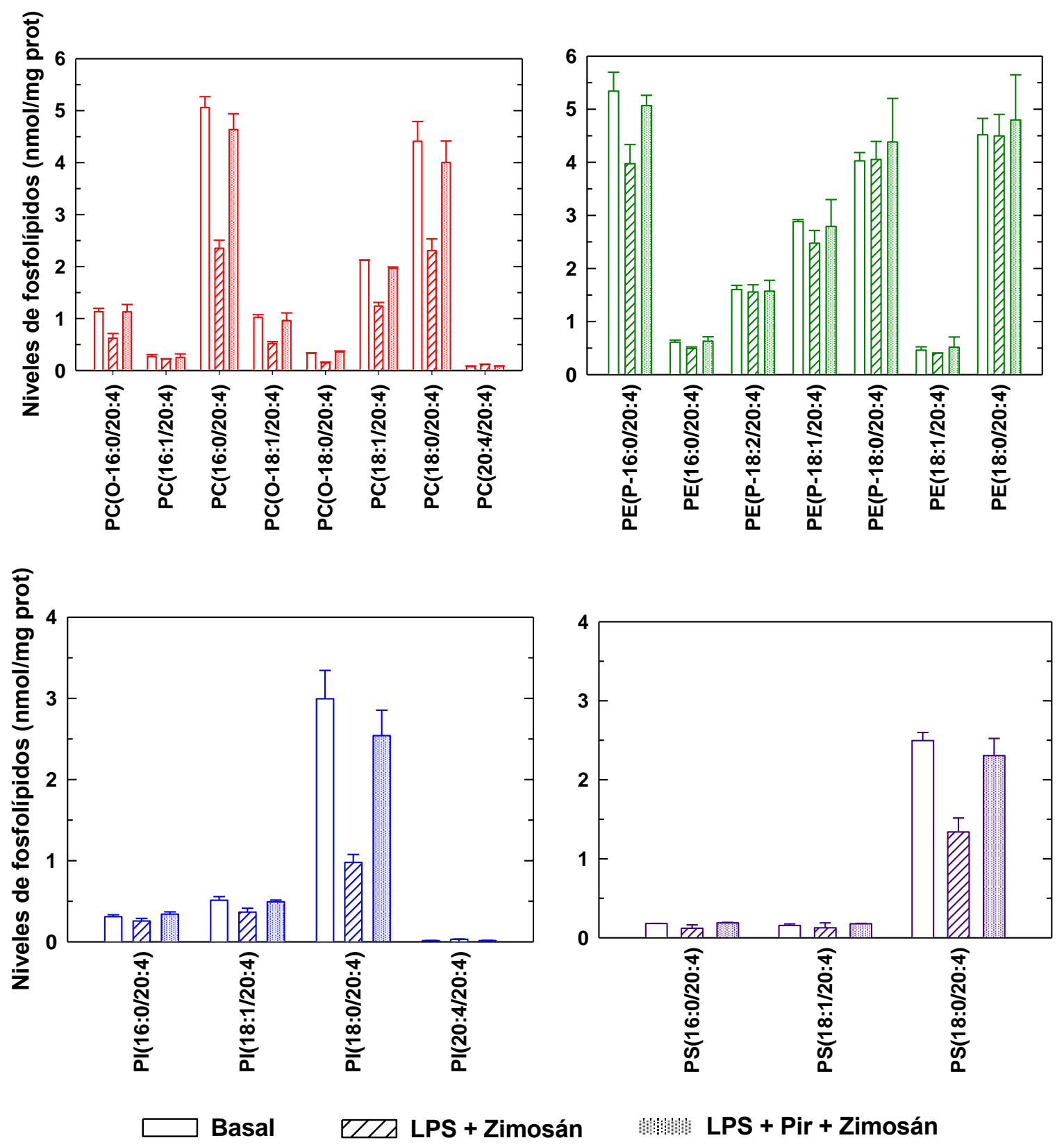

Figura 29. Análisis de la inhibición por pirrofenona en el efecto sinérgico del LPS y el zimosán sobre los glicerofosfolípidos con AA.

Análisis mediante HPLC-MS de los niveles de los glicerofosfolípidos con contenido en AA de macrófagos peritoneales de ratón en condiciones basales (blanco), estimulados con zimosán previa incubación con LPS (rayado) y macrófagos a los que se le añadió LPS y pirrofenona $(1 \mu \mathrm{M})$ una hora y 30 minutos respectivamente antes de ser estímulados con zimosán (punteado). Tras la extracción lipídica se pudieron analizar en la misma carrera cromatográfica las diferentes especies de PC (rojo), PE (verde), PI (azul) y PS (morado) con AA. 


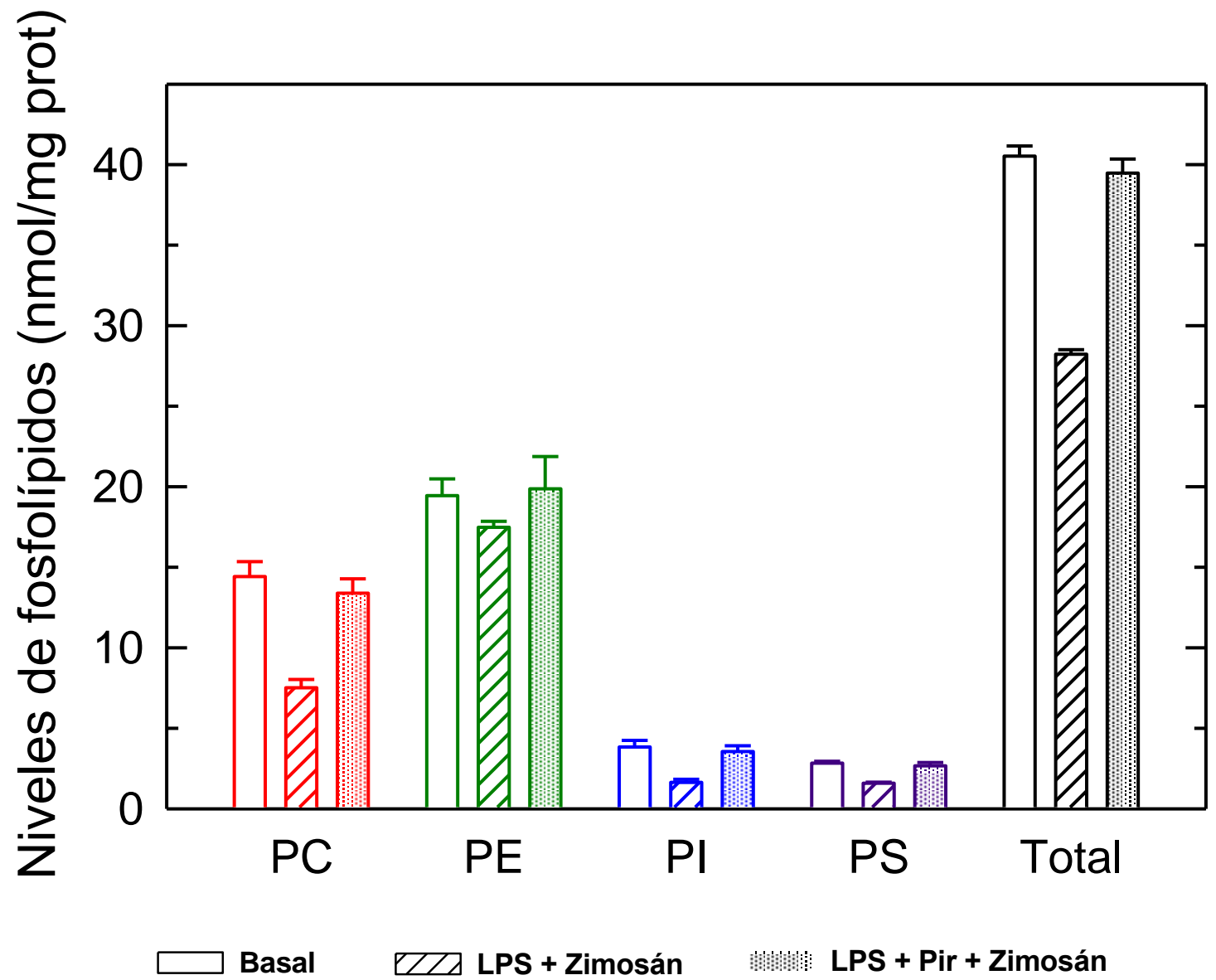

Figura 30. Análisis de la inhibición por pirrofenona en el efecto sinérgico del LPS y el zimosán sobre el total de los glicerofosfolípidos con AA.

Suma de las diferentes clases de glicerofosfolípidos con contenido en AA presentes en los macrófagos peritoneales de ratón en condiciones basales (blanco), estimulados con zimosán previa incubación con LPS (rayado) y macrófagos a los que se le añadió LPS y pirrofenona $(1 \mu \mathrm{M})$ una hora y 30 minutos respectivamente antes de ser estímulados con zimosán (punteado). Se muestra la suma de especies de PC (rojo), PE (verde), PI (azul) y PS (morado) y la suma total de todas ellas (negro). 


\section{D.3 Estimulación con zimosán opsonizado}

\section{D.3.1 Medida de la liberación de AA}

Debido a que tanto el zimosán como el zimosán opsonizado son reconocidos por receptores como dectina-1 y promueven la liberación de AA a través de la activación de la cPLA $A_{2}$, [Balsinde], los estudios de liberación de AA en macrófagos de ratón realizados hasta le fecha han usado indistintamente ambos estímulos. Sin embargo, el hecho de que otros receptores de membrana como FcR y CR3 se han demostrado implicados en el reconocimiento de las opsoninas que cubren el zimosán y que, por ejemplo, los receptores Fc se han descrito implicados en la liberación de AA [44], se consideró necesario realizar un estudio comparativo exhaustivo entre ambos estímulos en los macrófagos peritoneales de ratón.

Mediante el uso de $\left[{ }^{3} \mathrm{H}\right] \mathrm{AA}$ se observó que la estimulación con zimosán opsonizado durante $1 \mathrm{~h}$ de los macrófagos peritoneales de ratón a concentraciones saturantes de $1 \mathrm{mg} / 10^{6}$ células muestra un aumento en la liberación de AA respecto a la estimulación con la misma concentración de zimosán no opsonizado. Por otra parte, la dosimetría de zimosán opsonizado mostró que si bien concentraciones de $0,2 \mathrm{mg} / 10^{6}$ células son suficientes para alcanzar los máximos niveles de liberación de AA únicamente en macrófagos peritoneales de ratón estimulados con zimosán opsonizado, no se observan grandes diferencias en comparación al tratamiento con zimosán aparte de las observadas en condiciones de saturación.

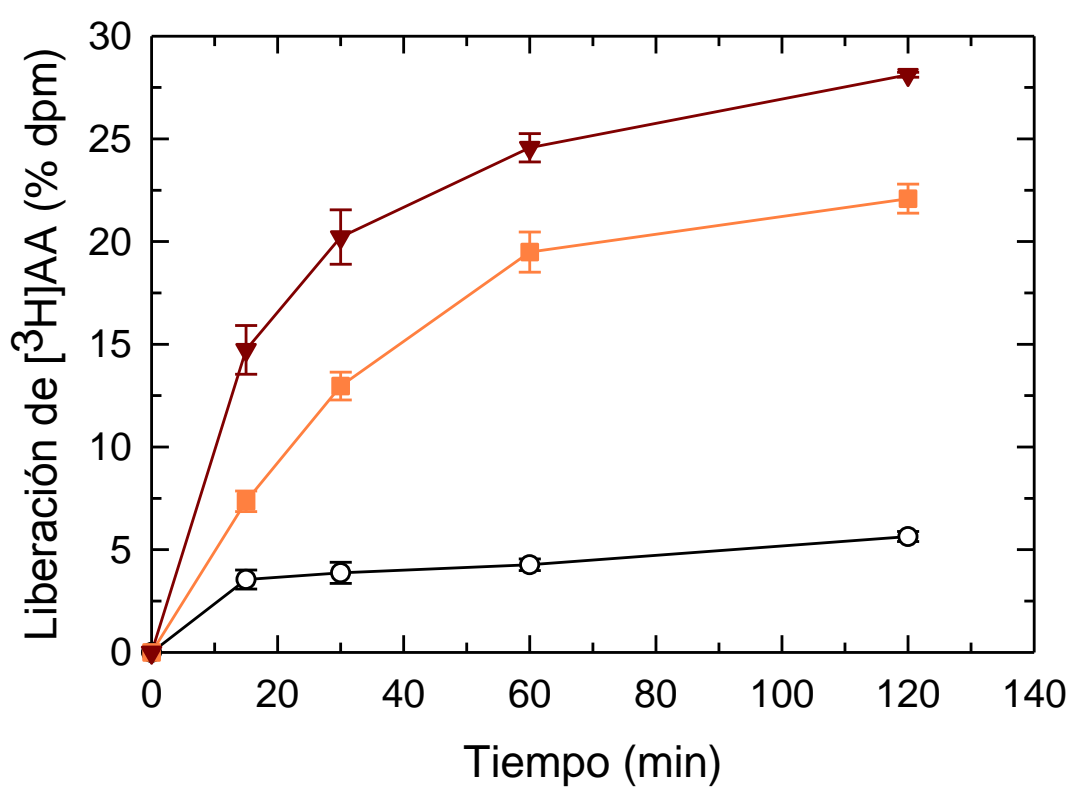

Figura 31. Liberación de [ $\left.{ }^{3} \mathrm{H}\right] \mathrm{AA}$ por estimulación con zimosán opsonizado Liberación de [3H]AA en macrófagos peritoneales de ratón en condiciones basales (blanco), estimulados con zimosán a una concentración de $1 \mathrm{mg} / 106$ células (naranja) y estimulados con zimosán opsonizado a una concentración de 1 mg/106 células (rojo). Para una mejor 
comprensión, se estimó una nula liberación neta de [3H]AA a tiempo 0, para lo cual se restó el valor residual obtenido en ese punto a los demás puntos de estudio.

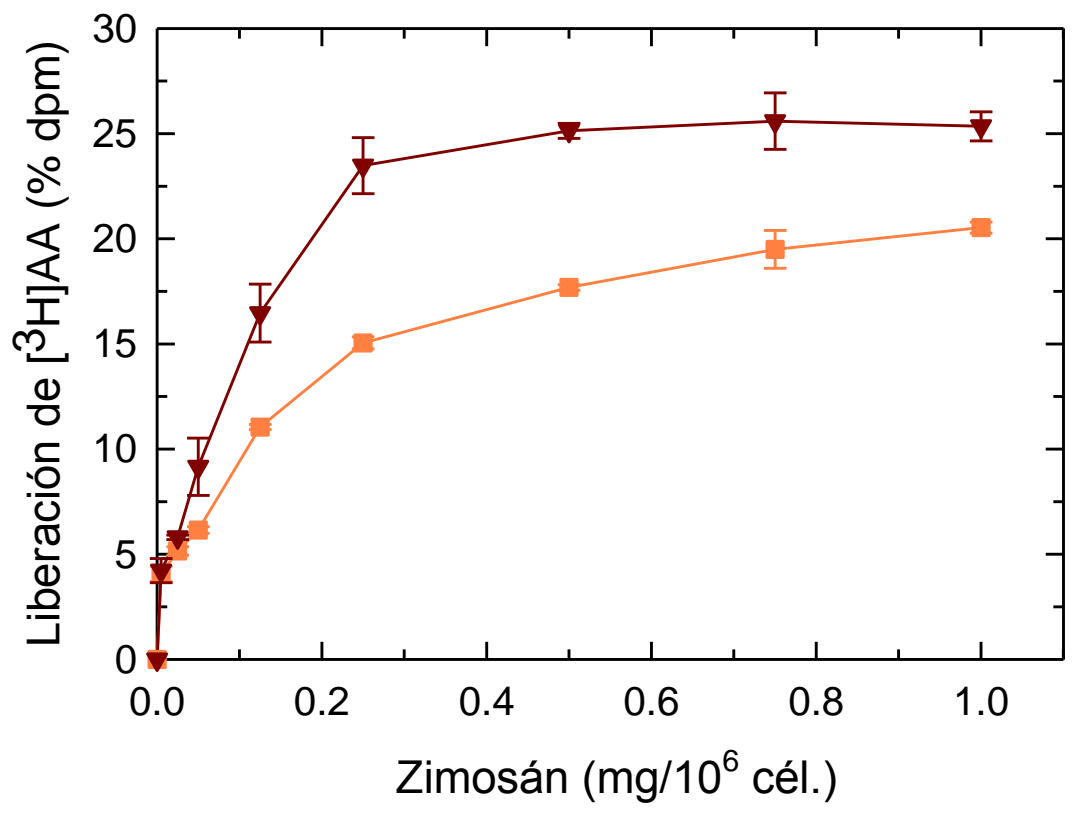

Figura 32. Dosimetría del zimosán opsonizado en relación con la liberación de [ $\left.{ }^{3} \mathrm{H}\right] \mathrm{AA}$. Medida de la liberación de[3H] de macrófagos peritoneales de ratón bajo condiciones de estimulación con zimosán (naranja) y zimosán opsonizado (rojo) a diferentes concentraciones (mg/106 células). Para una mejor comprensión, se estimó una nula liberación neta de [3H]AA a concentración 0 , para lo cual se restó el valor residual obtenido en ese punto a los demás puntos de estudio. 
Los macrófagos peritoneales de ratón que son estimulados durante 1 hora con concentraciones saturantes de zimosán de $1 \mathrm{mg} / 10^{6}$ células, muestran que mientras que una posterior incubación durante una hora con zimosán solo produce un moderado aumento de liberación, los macrófagos que son expuestos a zimosán opsonizado durante una hora muestran un aumento significativo en la liberación de AA. Sin embargo, cuando las células son previamente incubadas con zimosán opsonizado, la estimulación posterior con zimosán, opsonizado o no, no muestra una variación en la liberación de AA por parte de los macrófagos peritoneales de ratón. Esto pone en evidencia las diferencias existentes en la liberación de AA entre el zimosán y el zimosán cubierto por partículas, las cuales también pueden ser reconocidas por diferentes receptores de no patógenos distribuidos por toda la superficie macrofágica.

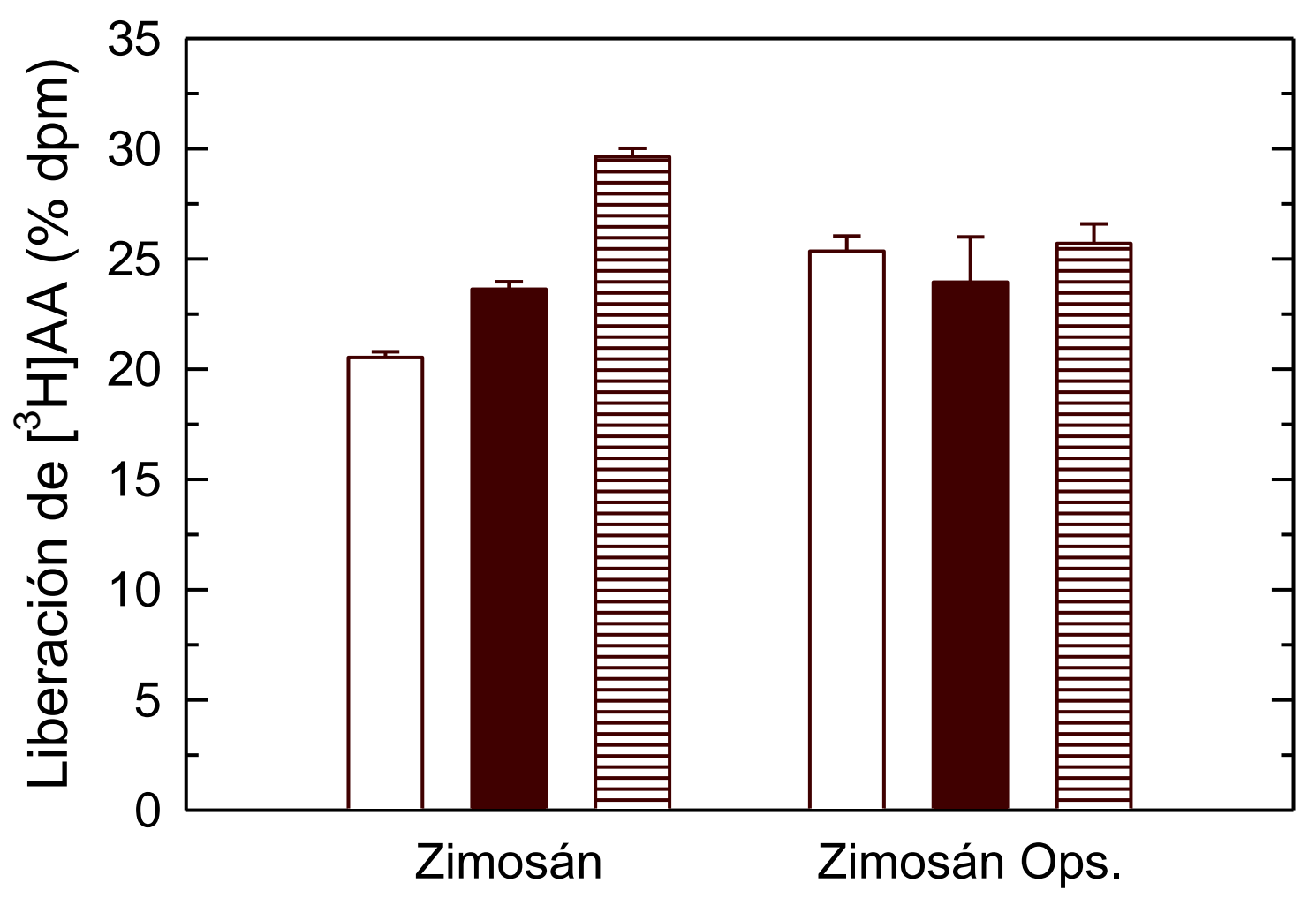

Figura 33. Liberación de [ $\left.{ }^{3}\right]$ AA tras una doble estimulación con zimosán y zimosán opsonizado. Liberación de [3H]AA en macrófagos peritoneales de ratón estimulados durante $1 \mathrm{~h}$ con zimosán y zimosán opsonizado respectivamente (blanco), estimulados por segunda vez durante una hora con zimosán (marrón) o con zimosán opsonizado (rayado). 


\section{D.3.2 Análisis de las especies de glicerofosfolípidos implicadas en la liberación de AA}

Como en el caso del efecto sinérgico del LPS y el zimosán, un cambio en la liberación de AA hace esencial un estudio completo de las especies de glicerofosfolípidos implicadas en dichas variaciones. En el análisis de las especies de glicerofosfolípidos con contenido en AA por HPLC/MS se observa que en macrófagos peritoneales de ratón estimulados con zimosán opsonizado se produce una liberación neta de una de $A A$ de las especies de $P E$, respuesta que no se observó cuando el estímulos corresponde a zimosán no opsonizado que, como ya se ha mostrado previamente, no provoca una liberación neta de AA de ninguna de las especies de PE. Dicha liberación no se produce por igual en todas las especies de PE, sino que es exclusiva de las especies plasmalógenas, es decir, las especies que contienen en su posición sn-1 un enlace tipo vinil éter, presentando en su posición sn-2 una molécula de AA. En concreto, con la estimulación con zimosán opsonizado se observa una liberación de un $20 \%$ del AA de las especies plasmenilos de PE.

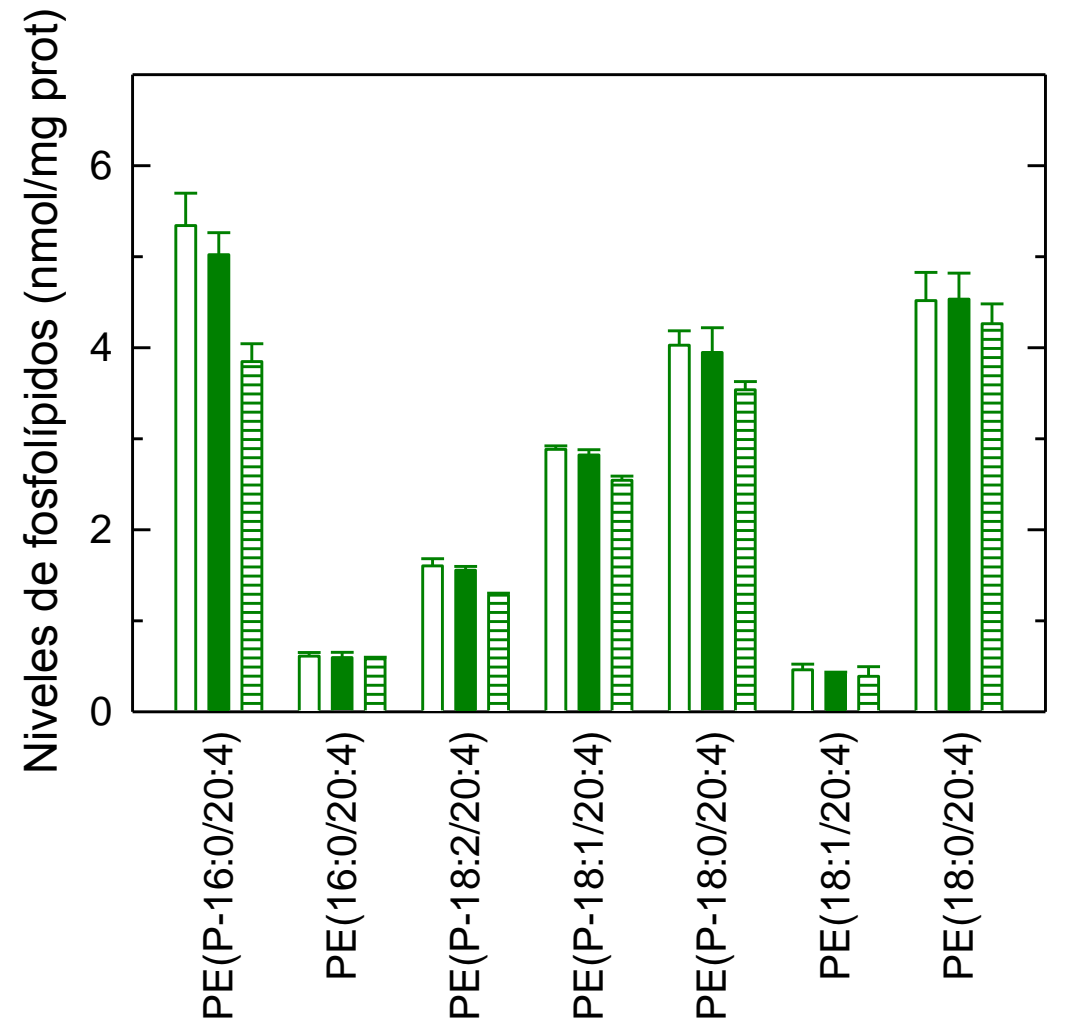

Figura 34. Análisis del efecto del zimsán opsonizado sobre las especies de PE con AA. Análisis mediante HPLC-MS de los niveles de las especies de PE con contenido en AA de macrófagos peritoneales de ratón en condiciones basales (blanco), estimulados con zimosán (verde) y estimulados con zimosán opsonizado (rayado). 
La mayor pérdida de AA desde as especies alquenil-PE esta en consonancia con los datos obtenidos en el análisis de las especies de alquenil-lisoPE, los cuales, como es esperable, debido a la hidrólisis del AA situado en posición sn-2 de los glicerofosfolípidos con enlace vinil éter, aumentan sus niveles bajo estimulación con zimosán opsonizado respecto tanto a las células basales como a las expuestas a zimosán. Sin embargo, se observó a su vez que especies de acil-lisoPE también presentan aumentos de sus niveles en respuesta a la estimulación con zimosán opsonizado. El crecimiento de estas especies no puede explicarse por la movilización de AA, por lo que puede que la hidrólisis de AA desde especies de plasmalógenas de PE vaya acompañada en paralelo de la movilización de otros ácidos grasos de especies otras especies de PE.

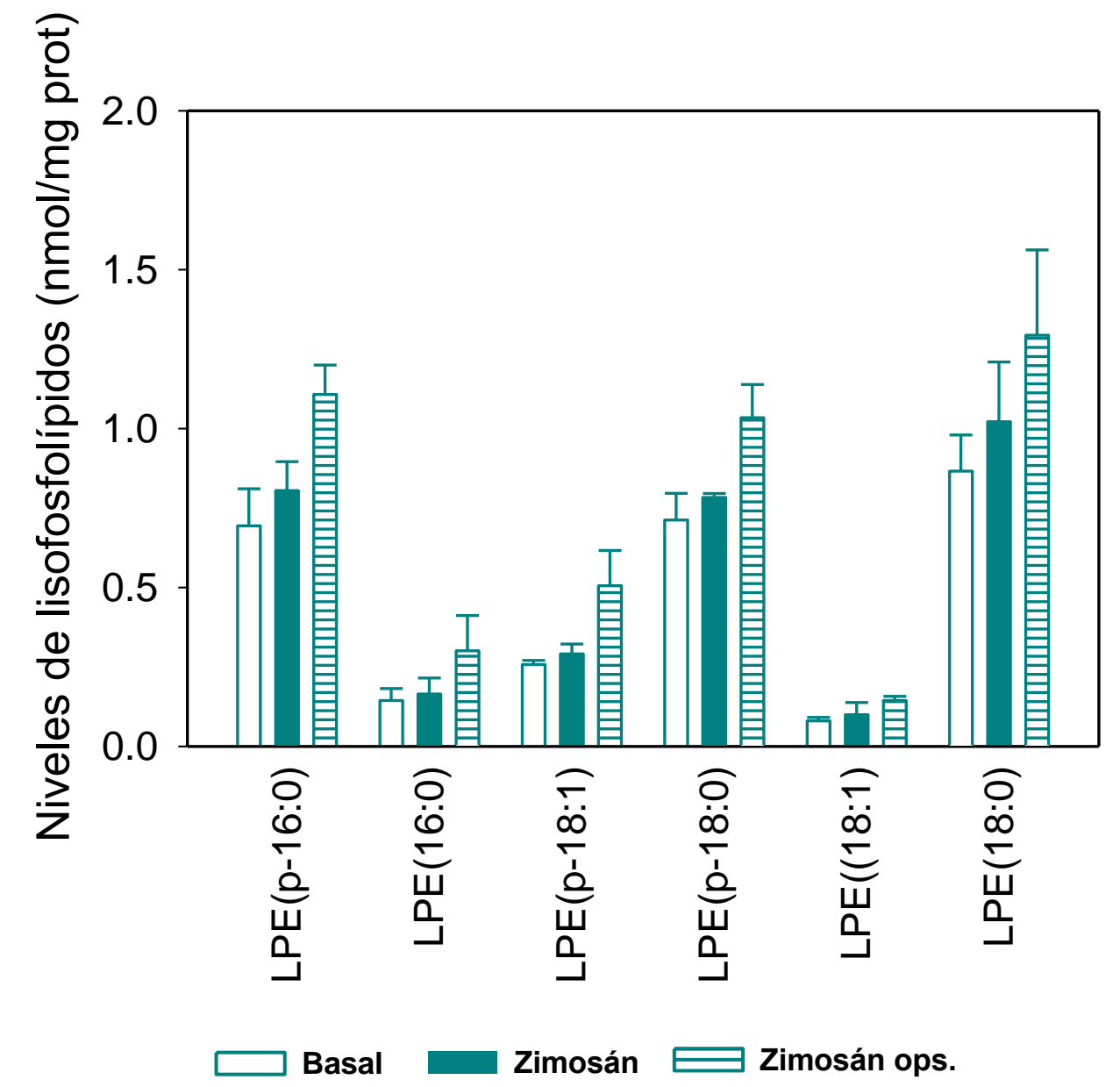

Figura 35. Análisis del efecto del zimsán opsonizado sobre las especies de lisoPE . Análisis mediante HPLC-MS de los niveles de las especies de lisoPE de macrófagos peritoneales de ratón en condiciones basales (blanco), estimulados con zimosán (negro) y estimulados con zimosán opsonizado (rojo). La extracción de los lisoPE se llevó a cabo sin acidificar el medio con $\mathrm{HCl}$ para no hidrolizar los enlaces vinil éter de alguna de las especies. 
Sin embargo, en contra de lo observado en las especies de PE, en otras especies de glicerofosfolípidos con conteniendo en AA, tanto especies de PC como de PI y PS, no se observó ninguna diferencia en la liberación de AA por el hecho de opsonizar previamente el zimosán antes de estimular los macrófagos peritoneales de ratón.

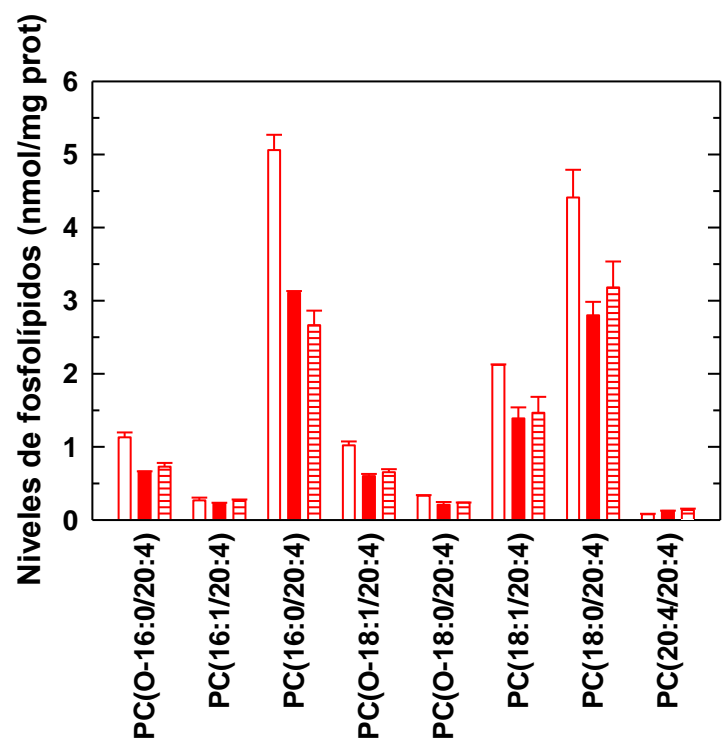

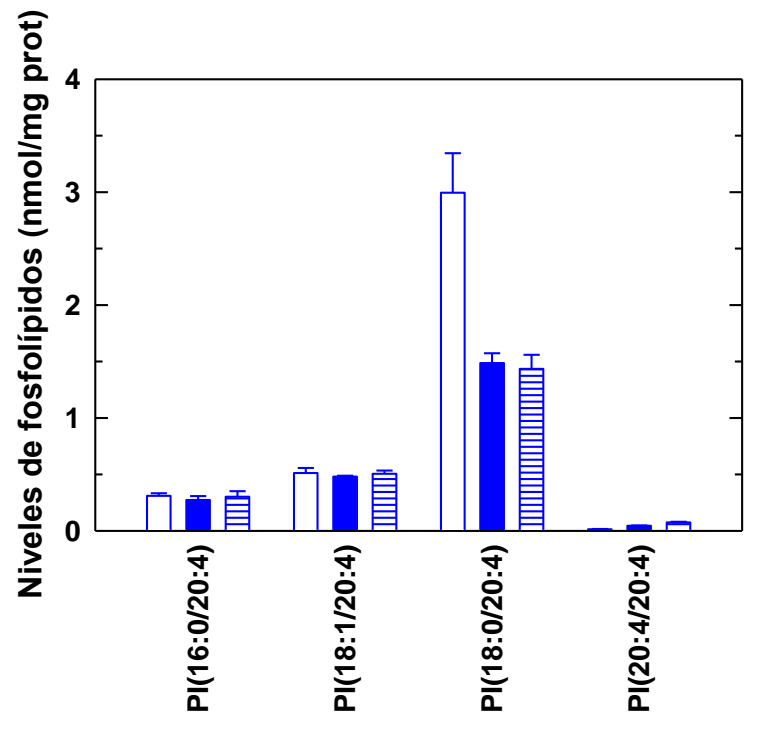

Basales

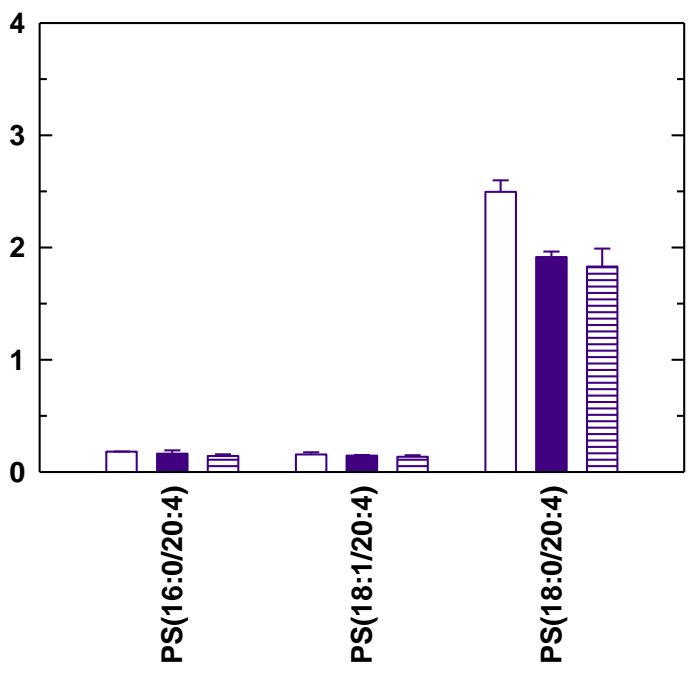

Zimosán opsonizado

Figura 36. Análisis del efecto del zimsán opsonizado sobre las especies de PC, PI y PS con AA. Análisis mediante HPLC-MS de los niveles de los glicerofosfolípidos con contenido en AA de macrófagos peritoneales de ratón en condiciones basales (blanco), estimulados con zimosán (negro) y estímulados con zimosán opsonizado (rojo). Tras la extracción lipídica se pudieron analizar en la misma carrera cromatográfica las diferentes especies de PC (rojo), PI (azul) y PS (morado) con AA. 
La suma de todos los glicerofosfolípidos con contenido en AA identificados muestra, que al igual que lo observado en los ensayos de liberación de AA por radiactividad, los macrófagos peritoneales de ratón estimulados con zimosán opsonizado durante $1 \mathrm{~h}$ y a una concentración de 1 $\mathrm{mg} / 10^{6}$ células, logran liberar mayor cantidad de AA que los macrófagos incubados con las mismas condiciones de zimosán. Esta diferencia en la liberación de AA no se observa ni en especies de PI, PC PS o especies acil o alquil de PE. Sólo las especies plásmalogenas de PE, que no muestran liberación neta de AA bajo las estimulación de zimosán, presentan una liberación de AA cuando los macrófagos peritoneales de ratón son incubados con zimosán. Son estas diferencias en la liberación en especies de PE con enlace vinil éter lo que provoca los distintos niveles de liberación total observados al comparar la estimulación en las mismas condiciones con zimosán o zimosán cubierto por opsoninas que pueden ser reconocidas por diversos receptores.

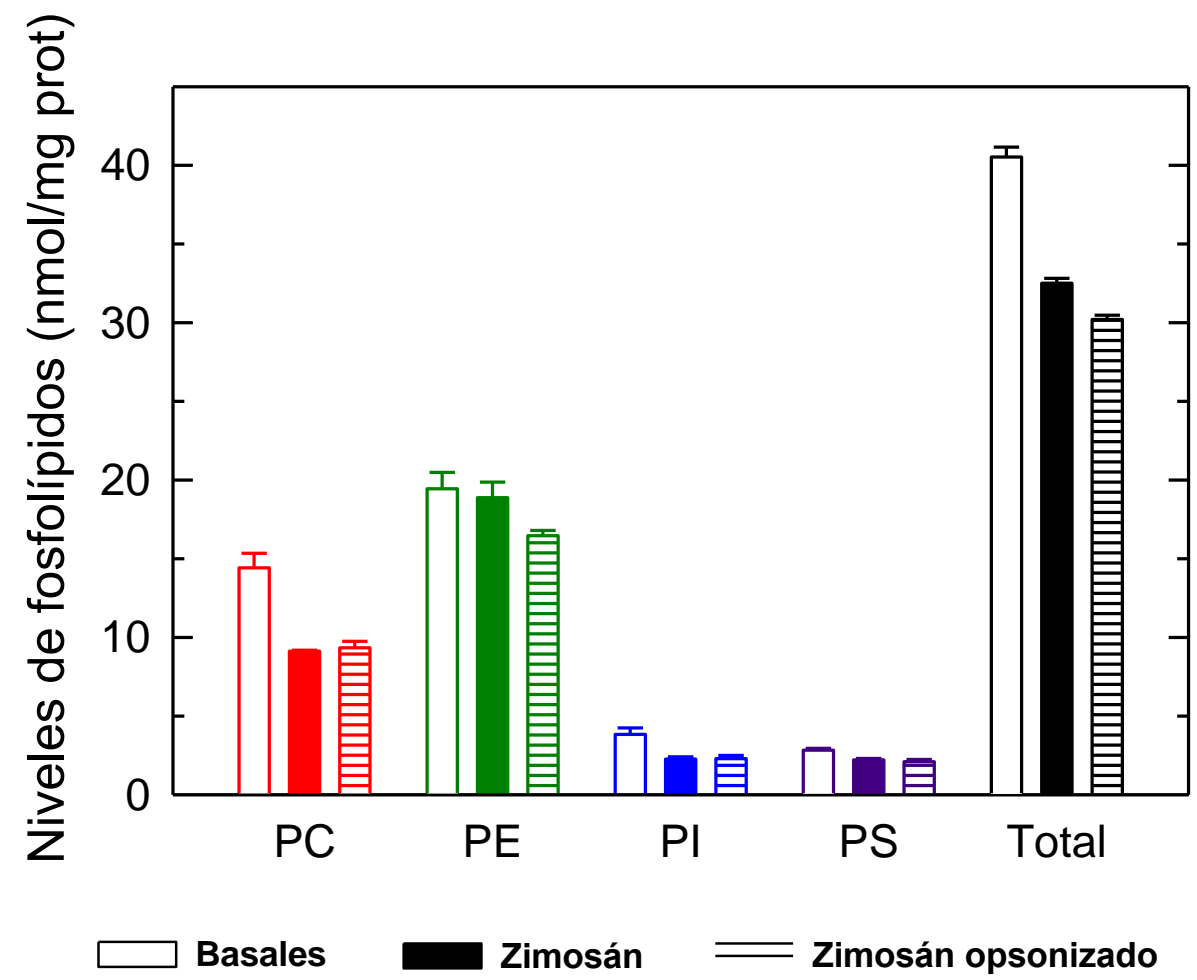

Figura 37. Análisis del efecto del zimsán opsonizado sobre el total de glicerofosfolípidos con AA. Suma de las diferentes clases de glicerofosfolípidos con contenido en AA presentes en los macrófagos peritoneales de ratón en condiciones basales (blanco), estimulados con zimosán (color) y estímulados con zimosán opsonizado (rayado). Se muestra la suma de especies de PC (rojo), PE (verde), PI (azul) y PS (morado) y la suma total de todas ellas (negro). 
Como ya se ha descrito anteriormente, la especie $\mathrm{PI}(20: 4 / 20: 4)$ junto con la especies $\mathrm{PC}(20: 4 / 20: 4)$ presentan aumentos de sus niveles cuando los macrófagos peritoneales de ratón son estimulados con zimosán no opsonizado a una concentración de $1 \mathrm{mg} / 10^{6}$ células y un tiempo de 1 hora. Este efecto, como se muestra en el la figura $X$, se ve incrementado cuando los macrófagos peritoneales de ratón son estimulados con zimosán opsonizado en las mismas condiciones de concentración de estímulo y tiempo de incubación.

Entre ambos especies, sobresale el aumento que experimenta la especie $\mathrm{PI}(20: 4 / 20: 4)$, que pasa de triplicar sus niveles con zimosán a quintuplicarlos cuando las células son expuestas a zimosán opsonizado. Estos cambios significativos pueden denotar un significado biológico importante de esta especia y por tanto parece necesario un estudio más exhaustivo, que se trata en un apartado posterior.
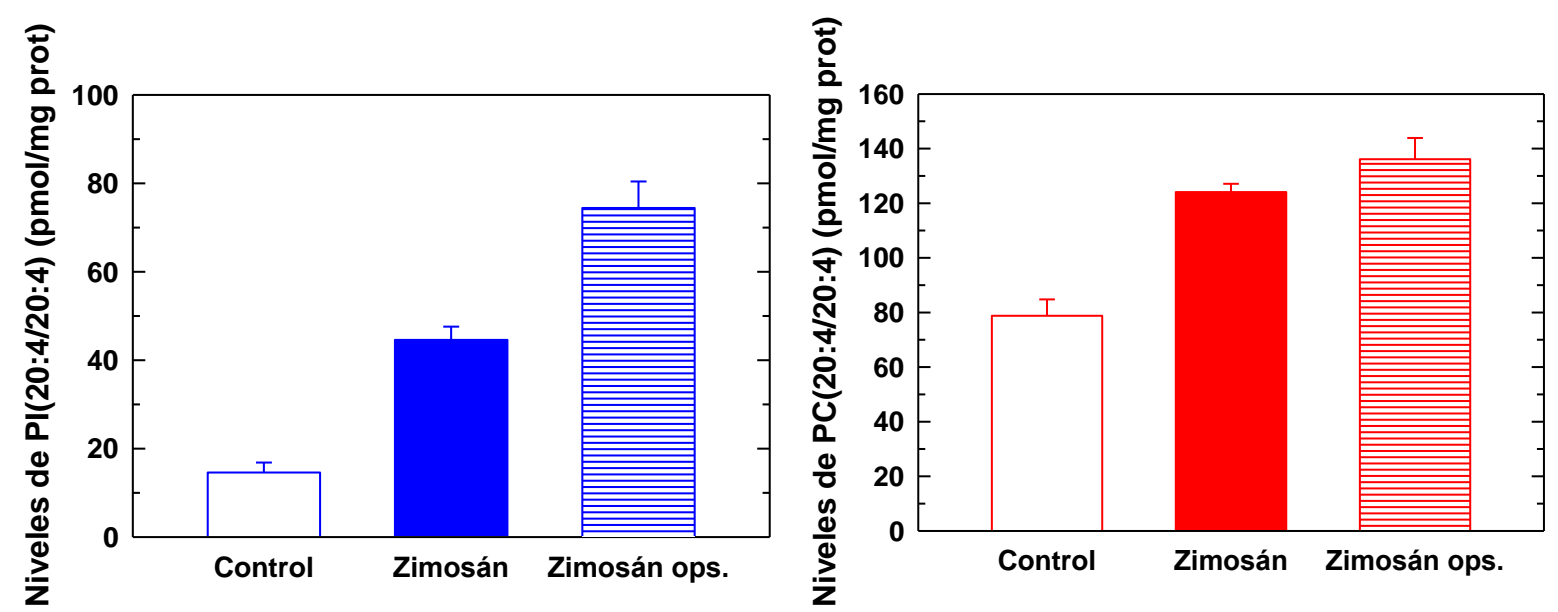

Figura 38. Análisis del efecto del zimsán opsonizado sobre las especies PI(20:4/20:4) y PC(20:4/20:4). Extracto de la figura 36. Análisis mediante HPLC-MS de los niveles de $\mathrm{PI}(20: 4 / 20: 4)$ y PC(20:4/20:4) en macrófagos peritoneales de ratón en estado basal (blanco), estimulados con zimosán (negro) y estimulados con zimosán opsonizado (rojo). Tras la extracción lipídica, mediante HPLC-MS se pudo identificar y cuantificar con ionización negativa la especie $\mathrm{PI}(20: 4 / 20: 4)$ con $\mathrm{m} / \mathrm{z}=905$ (azul), y mediante ionización positiva la especie $P C(20: 4 / 20: 4)$ con $\mathrm{m} / \mathrm{z}=830$ (rojo). 


\section{D.3.3 Implicación de la CPLA $2 \alpha$}

El uso de diferentes compuestos descritos como inhibidores específicos de la $\mathrm{CPLA}_{2} \alpha$ (pirrofenona) y de la iPLA 2 (FKGK11 y FKGK18) indicó que, al igual que con la estimulación con zimosán, la utilización de pirrofenona bloquea la liberación provocada por la estimulación por zimosán opsonizado de los macrófagos peritoneales de ratón, implicando de esta forma a la $\mathrm{CPLA}_{2} \alpha$, mientras que ni FKGK11 ni FKGK18 muestran efectos inhibitorios, excluyendo de esta forma a la iPLA 2 del proceso.

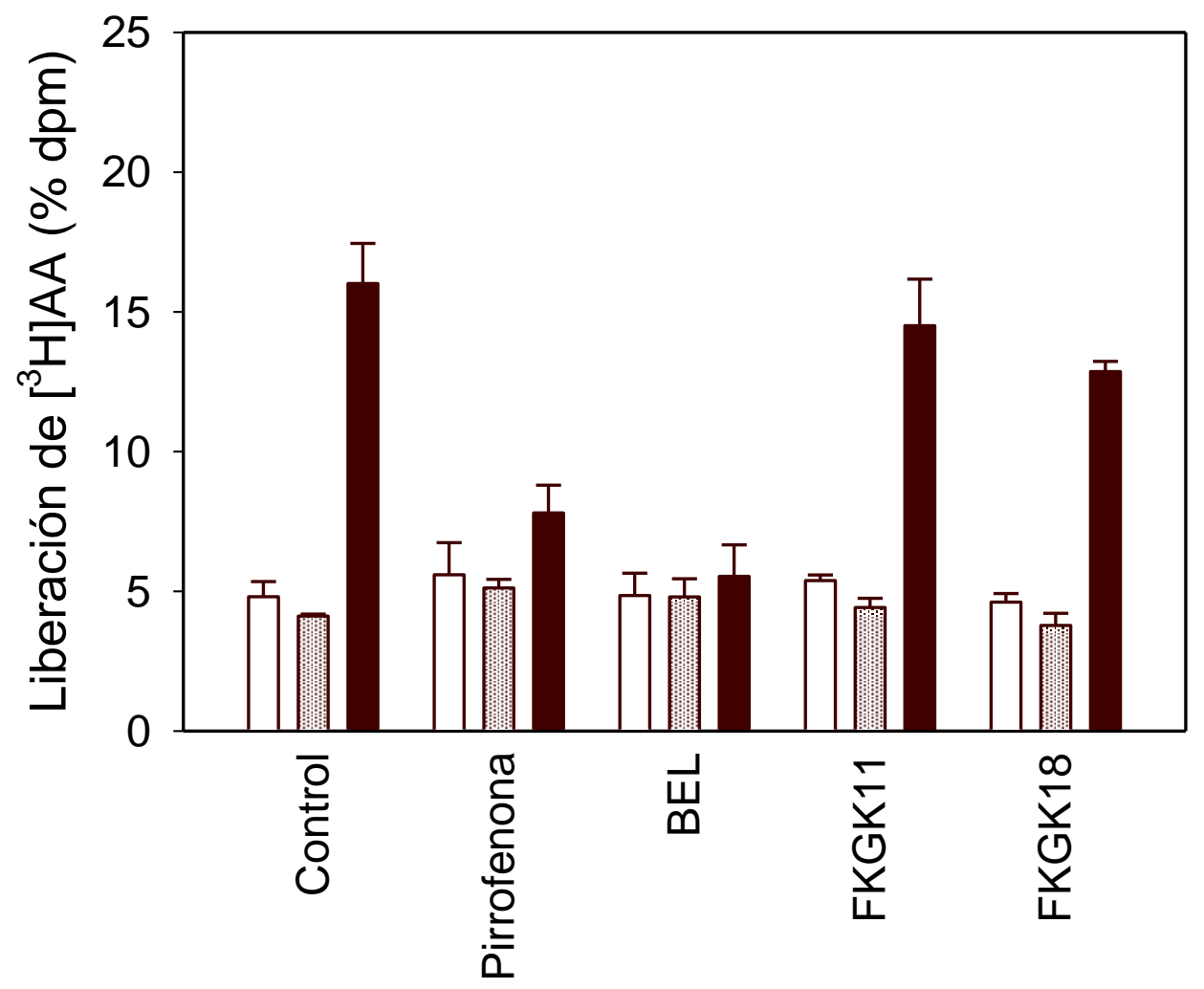

\section{Basal Inhibidor + Zimosán ops.}

Figura 39. Análisis del efecto de diferentes inhibidores de $\mathrm{PLA}$ en la liberación de [ $\left.{ }^{3} \mathrm{H}\right] \mathrm{AA}$ por la estimulación por zimosán.

Liberación de [3H]AA en macrófagos peritoneales de ratón. Tanto para las células control (sin inhibidor) como para cada inhibidor (pirrofenona $1 \mu \mathrm{M})$, BEL $(10 \mu \mathrm{M})$, FKGK11 y FKGK18 $(1 \mu \mathrm{M})$ se muestra el $[3 \mathrm{H}]$ liberado de los macrófagos en condiciones basales (blanco), tras 30 minutos de exposición al respectivo inhibidor (punteado) y al ser estimulados con zimosán opsonizado ( $1 \mathrm{mg} / 106$ células) previa incubación durante 30 minutos con el respectivo inhibidor (marrón). 
Sin embargo, al igual que en lo observado en la estimulación con zimosán, BEL impide la liberación de $A A$ en macrófagos peritoneales de ratón estimulados con zimosán opsonizado. La confirmación de que la iPLA $_{2}$ no está implicada en la movilización de AA desde los glicerofosfolípidos por acción del zimosán opsonizado se realizó utilizando ratones $K O$ de esta fosfolipasa. Así, en comparación con los ratones $W t$, los macrófagos peritoneales de ratones $K O$ presentan similares niveles de liberación de AA bajo condiciones de estimulación con zimosán opsonizado por lo que la iPLA ${ }_{2}$, al contrario que la $\mathrm{cPLA}_{2} \alpha$, no se muestra como una enzima clave en la movilización de AA desde los glicerofosfolípidos en macrófagos peritoneales de ratón en condiciones de estimulación con zimosán previamente opsonizado.

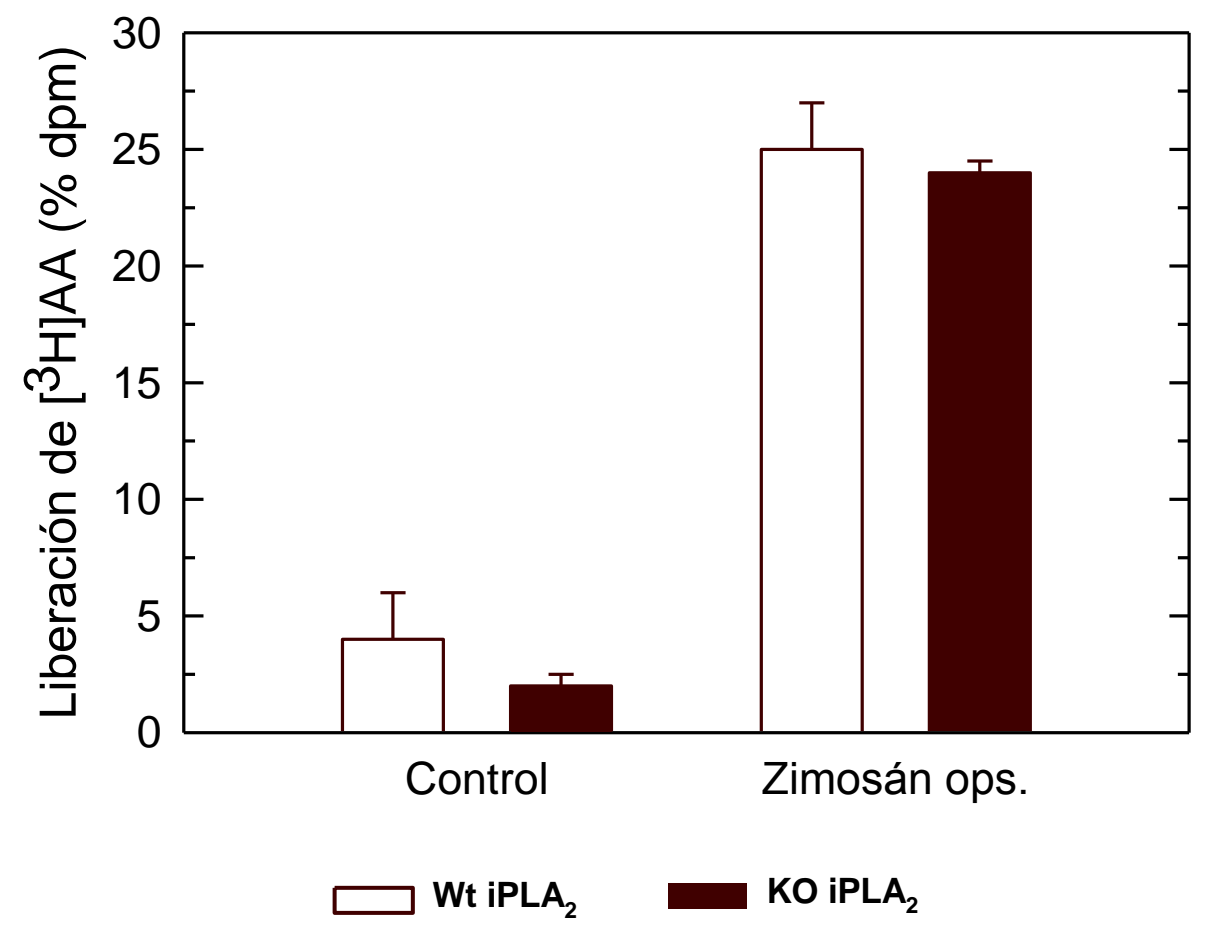

Figura 40. Análisis de la liberación de [ $\left.{ }^{3} \mathrm{H}\right] \mathrm{AA}$ en ratones KO de la cPLA $2 \alpha$ estimulados con zimosán opsonizado

Comparación de la liberación de [3H]AA en macrófagos peritoneales de ratón en condiciones basales (control) y estimulados con zimosán opsonizado a una concentración de $1 \mathrm{mg} / 106$ células. Los macrófagos se extrajeron de dos ratones Wt (blanco) y dos ratones KO de la iPLA2 (marrón). 
Respecto al estudio de los glicerofosfolípidos con contenido en AA, el tratamiento previo con pirrofenona muestra el bloqueo de la liberación de AA promovido por del zimosán opsonizado en todas las especies de glicerofosfolípidos incluidos las especies plasmalógenas de PE, lo que demuestra la implicación de la $\mathrm{CPLA}_{2} \alpha$ en este proceso y confirma los datos obtenidos mediante el ensayo de radiactividad.

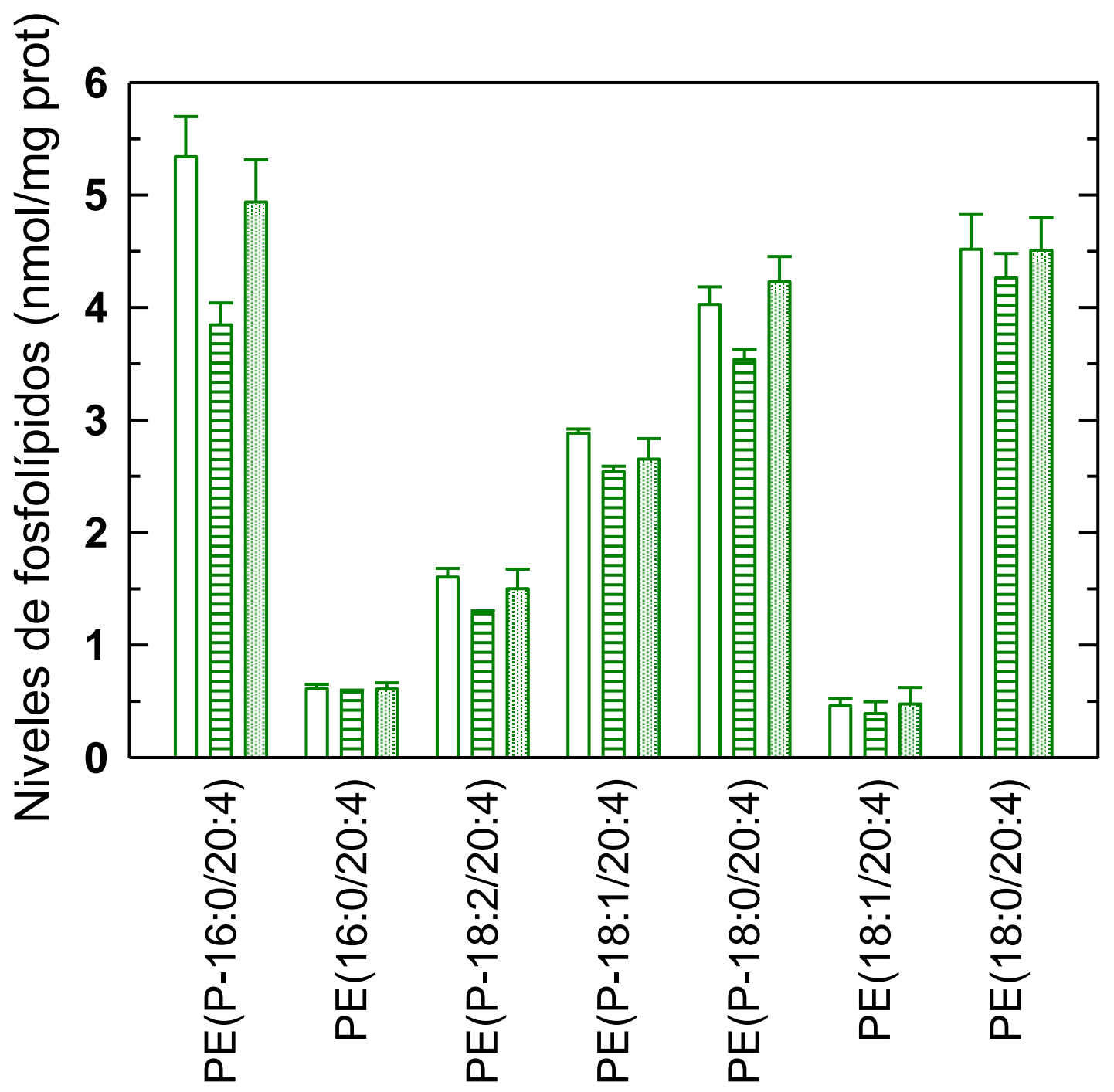

Figura 41. Análisis de la inhibición por pirrofenona del efecto del zimosán opsonizado sobre especies de PE con AA.

Análisis mediante HPLC-MS de los niveles de las especies de PE con contenido en AA de macrófagos peritoneales de ratón en condiciones basales (blanco), estimulados con zimosán opsonizado (rayado) y macrófagos a los que se le añadió pirrofenona $(1 \mu \mathrm{M}) 30$ minutos antes de ser estímulados con zimosán opsonizado (punteado). 
Además, el estudio de las especies de lisofosfolípidos mostró que la inhibición mediante pirrofenona de la $\mathrm{CPLA}_{2} \alpha$ impide el aumento de las especies plasmalógenas pero no se observa el mismo efecto en las especies de acil-lisoPE que también aumentan sus niveles en macrófagos peritoneales de ratón estimulados con zimosán opsonizado. Estos datos, junto con lo observado en el análisis de las especies fosfolipídicas, confirma la implicación de la $\operatorname{cPLA}_{2} \alpha$ en la liberación de AA desde las especies plasmalógenas de PE. Por otra parte, descartan la participación de la cPLA 2 en el aumento de los niveles de otras especies de lisoPE lo que indica que su formación no se deba a la movilización de AA desde los glicerofosfolípidos, actividad catalizada por la cPLA $\alpha$, sino a la liberación de otros ácidos grasos por la acción de otras fosfolipasas.

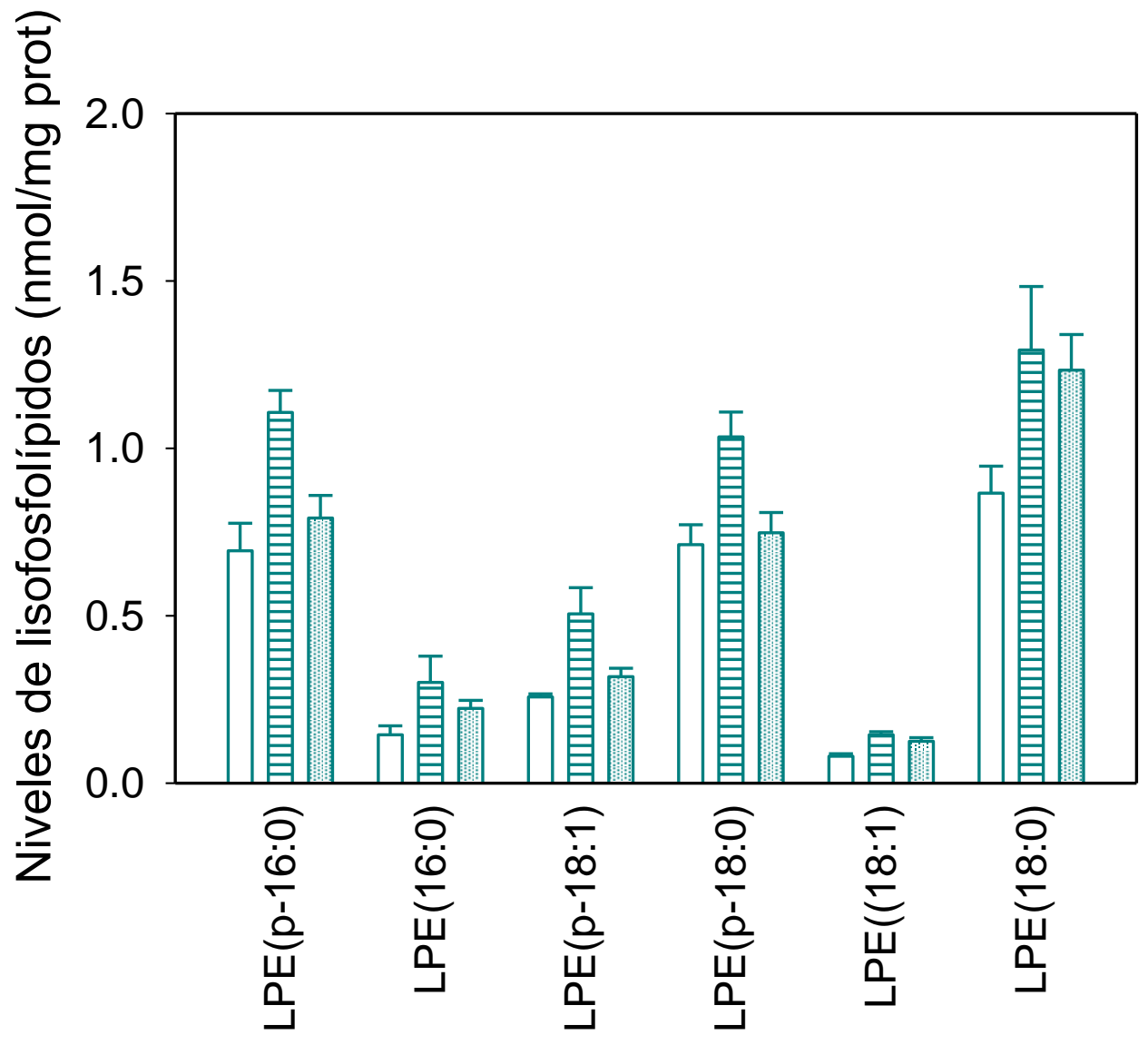

\section{Basal $=$ Zimosán ops.}

Figura 42. Análisis de la inhibición por pirrofenona del efecto del zimosán opsonizado especies de lisoPE. Análisis mediante HPLC-MS de los niveles de las especies de lisoPE de macrófagos peritoneales de ratón en condiciones basales (blanco), estimulados con zimosán opsonizado (rayado) y macrófagos a los que se le añadió pirrofenona $(1 \mu \mathrm{M}) 30$ minutos antes de ser estímulados con zimosán opsonizado (punteado). 
Respecto a las especies de PC, PI y PS, donde no se apreciaron diferencias en la liberación de AA entre la estimulación con zimosán y zimosán opsonizado, como en el caso del zimosán la inhibición de $\mathrm{CPLA}_{2} \alpha$ mediante el uso de pirrofenona bloquea la liberación de AA promovida por la estimulación de los macrófagos peritoneales de ratón con zimosán opsonizado.
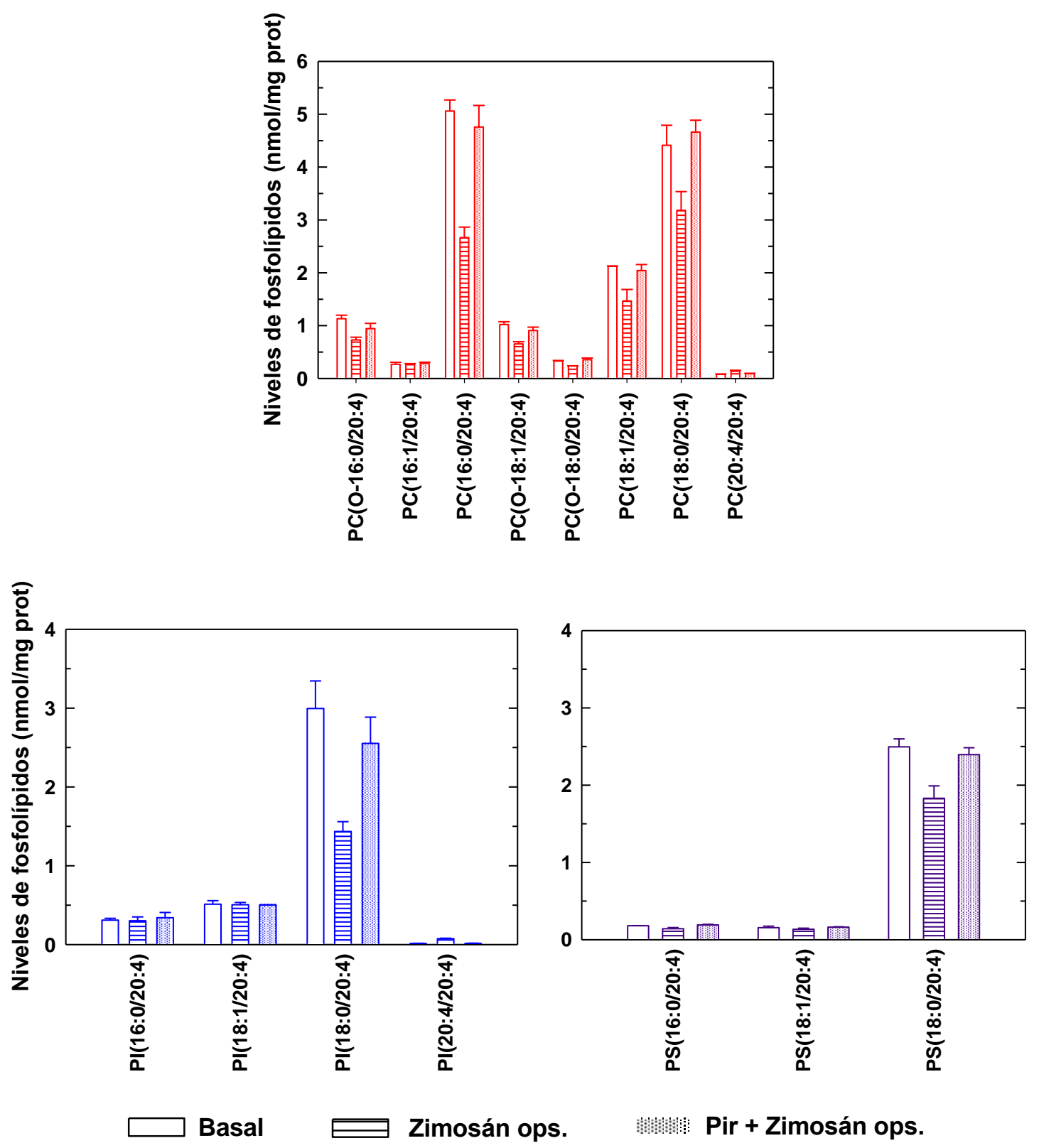

Figura 43. Análisis de la inhibición por pirrofenona del efecto del zimosán opsonizado sobre glicerofosfolípidos de PC, PI y PS con AA.

Análisis mediante HPLC-MS de los niveles de los glicerofosfolípidos con contenido en AA de macrófagos peritoneales de ratón en condiciones basales (blanco), estimulados con zimosán opsonizado (negro) y macrófagos a los que se le añadió pirrofenona ( $1 \mu \mathrm{M}) 30$ minutos antes de ser estímulados con zimosán opsonizado (rojo). Tras la extracción lipídica se pudieron analizar en la misma carrera cromatográfica las diferentes especies de PC (rojo), PI (azul) y PS (morado) con AA. 
En el total de glicerofosfolípidos se puede comprobar que, al igual que en el caso de la estimulación con zimosán, el uso de pirrofenona demuestra la implicación de la cPLA $\operatorname{co}_{2} \alpha$ en la liberación de AA desde los glicerofosfolípidos de macrófagos peritoneales de ratón estimulados con zimosán opsonizado.

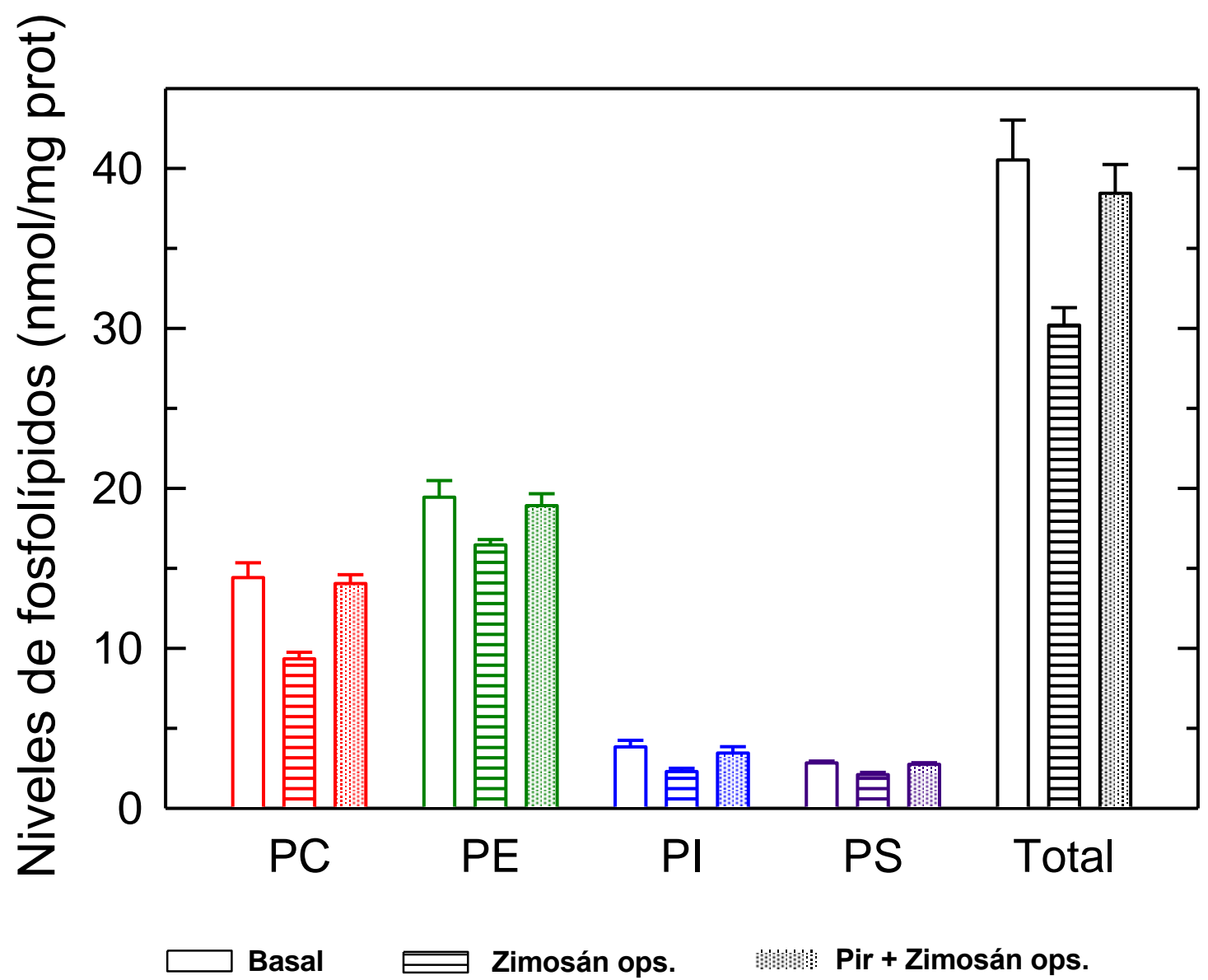

Figura 44. Análisis de la inhibición por pirrofenona del efecto del zimosán opsonizado sobre el total de glicerofosfolípidos con AA.

Suma de las diferentes clases de glicerofosfolípidos con contenido en AA presentes en los macrófagos peritoneales de ratón en condiciones basales (blanco), estimulados con zimosán opsonizado (rayado) y macrófagos a los que se le añadió pirrofenona $(1 \mu \mathrm{M}) 30$ minutos antes de ser estímulados con zimosán opsonizado (punteado). Se muestra la suma de especies de PC (rojo), PE (verde), PI (azul) y PS (morado) y la suma total de todas ellas (negro). 
Respecto a las especies con contenido en AA que aumentan sus niveles bajo la estimulación con zimosán opsonizado de macrófagos peritoneales de ratón, la inhibición por pirrofenona de la ${ }_{C P L A} \alpha$ impide observar dicho efecto tanto en la especie $\mathrm{PI}(20: 4 / 20: 4)$ como la especie $\mathrm{PC}(20: 4 / 20: 4)$.
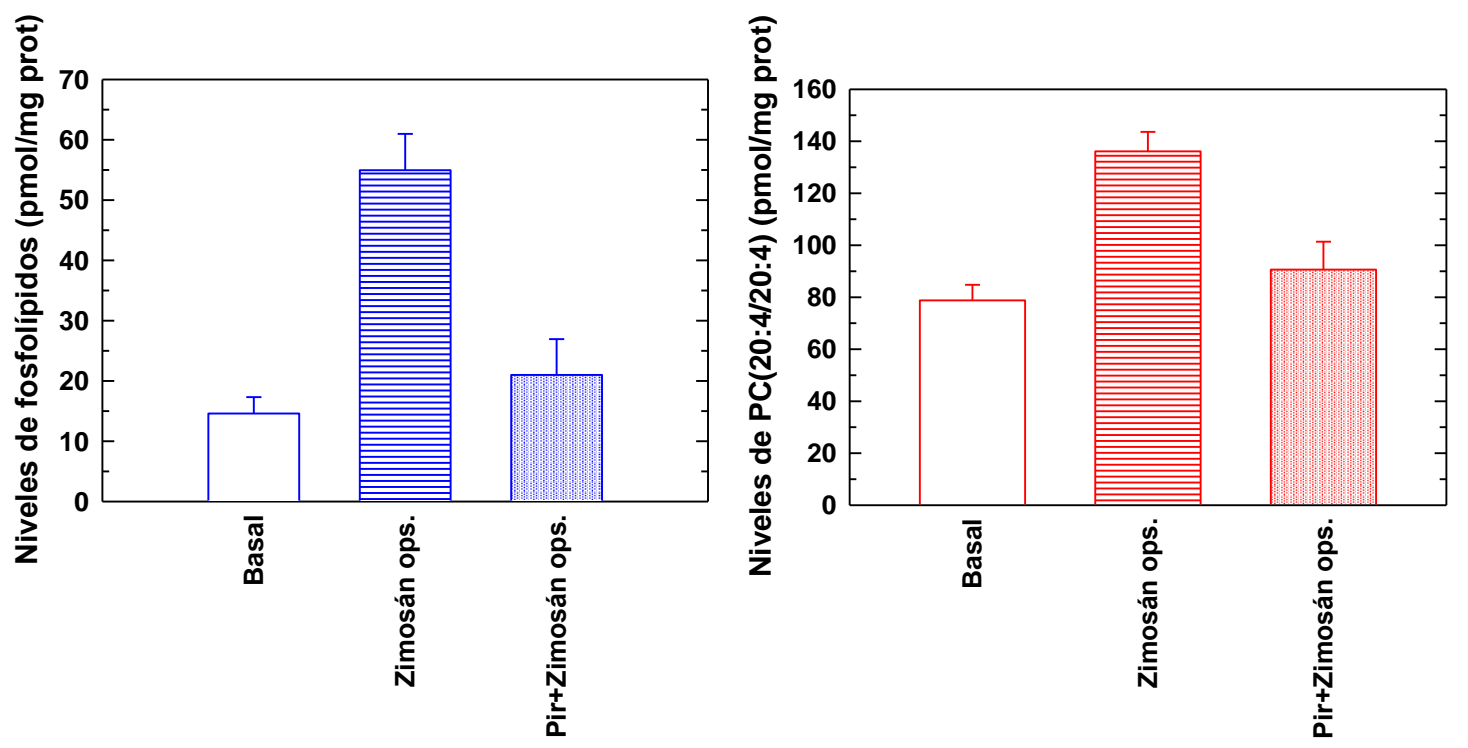

Figura 45. Análisis de la inhibición por pirrofenona del efecto de la estimulación con zimosán opsonizado sobre $\mathrm{PI}(20: 4 / 20: 4)$ y $\mathrm{PC}(20: 4 / 20: 4)$.

Extracto de la figura 43. Análisis mediante HPLC-MS de los niveles de $\mathrm{PI}(20: 4 / 20: 4)$ y PC(20:4/20:4) en macrófagos peritoneales de ratón en estado basal (blanco), estimulados con zimosán opsonizado (rayado) y estimulados con zimosán opsonizado previa incubación durante 30 minutos con pirrofenona (Pir) a una concentración de $1 \mu \mathrm{M}$ (punteado). Tras la extracción lipídica, mediante HPLC-MS se pudo identificar y cuantificar con ionización negativa la especie $\mathrm{PI}(20: 4 / 20: 4)$ con $\mathrm{m} / \mathrm{z}=905$ (azul), y mediante ionización positiva la especie $\mathrm{PC}(20: 4 / 20: 4)$ con $\mathrm{m} / \mathrm{z}=830$ (rojo). 


\section{D.4 1,2-Diaraquidonoil-glicero-sn-3-fosfatidilinositol}

Como se ha descrito, $\mathrm{PI}(20: 4 / 20: 4)$ y su homólogo $\mathrm{PC}(20: 4 / 20: 4)$ aumentan sus niveles cuando los macrófagos son estimulados con zimosán, respuesta que se ve incrementada si el zimosán se presenta cubierto por opsoninas. Sin embargo, mientras el incremento de $P C(20: 4 / 20: 4)$ debido a la activación celular se describió hace veinticinco años [225] y posteriormente se relacionó con la síntesis de anandamidas [226], el incremento en $\mathrm{PI}(20: 4 / 20: 4)$ después de la activación celular es un hallazgo nuevo y llamativo, lo cual llevó a caracterizarlo con detalle. El estudio de la producción de $\mathrm{PI}(20: 4 / 20: 4)$ a diferentes tiempos mostró que $\mathrm{PI}(20: 4 / 20: 4)$ aumentó linealmente sus niveles hasta una hora de estimulación con zimosán, decreciendo posteriormente pero manteniendo niveles más altos que el basal incluso dos horas después de la estimulación.

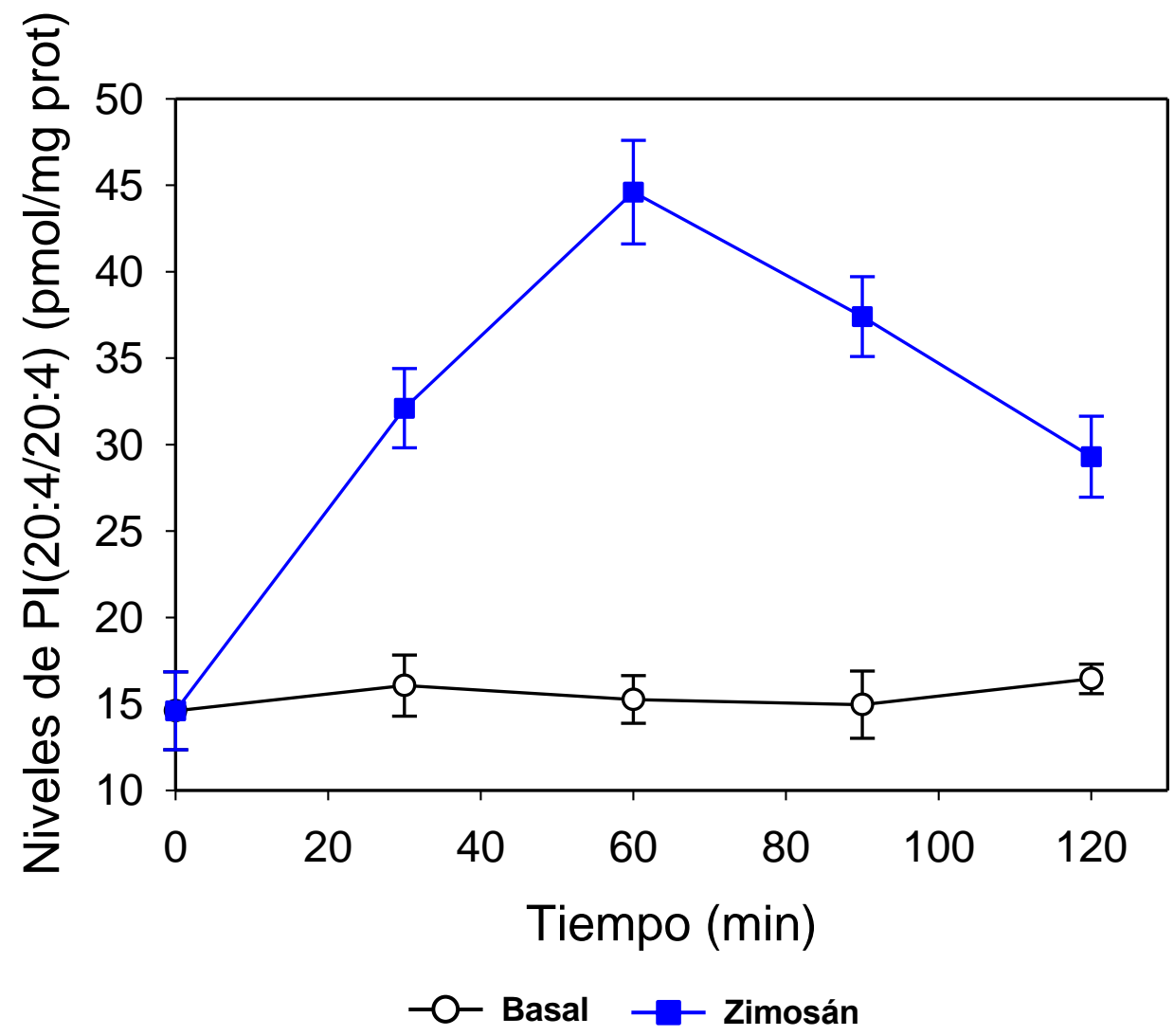

Figura 46. Niveles de PI(20:4/20:4) a diferentes tiempos de exposición a zimosán. Análisis mediante HPLC-MS de los niveles de la especie PI(20:4/20:4) en macrófagos peritoneales de ratón en condiciones basales (blanco) o bajo el estímulo de zimosán a una conectración de $1 \mathrm{mg} / 10^{6}$ células (azul). Dicha especie fue identificada en modo negativo con un $\mathrm{m} / \mathrm{z}$ de 905 . 


\section{D.4.1 Factores que regulan la producción de $\mathrm{PI}(20: 4 / 20: 4)$}

La fig X muestra que además del zimosán y el zimosán opsonizado, otro número amplio de estímulos usados en macrófagos producen también aumentos significativos de los niveles de $\mathrm{PI}(20: 4 / 20: 4)$. El ionóforo A23187 fue tan potente como el zimosán y el zimosán opsonizado induciendo la formación de PI(20:4/20:4) tras una hora de estimulación. Mientras, LPS, PAF y PMA se comportaron como inductores débiles de la síntesis de $\mathrm{PI}(20: 4 / 20: 4)$ y ATP no mostró ningún efecto. La exposición a LPS previa a la estimulación de las células con los agonistas antes mencionados no tuvo mayor efecto en la formación de $\mathrm{PI}(20: 4 / 20: 4)$ del que la presencia de LPS provoca por sí mismo.

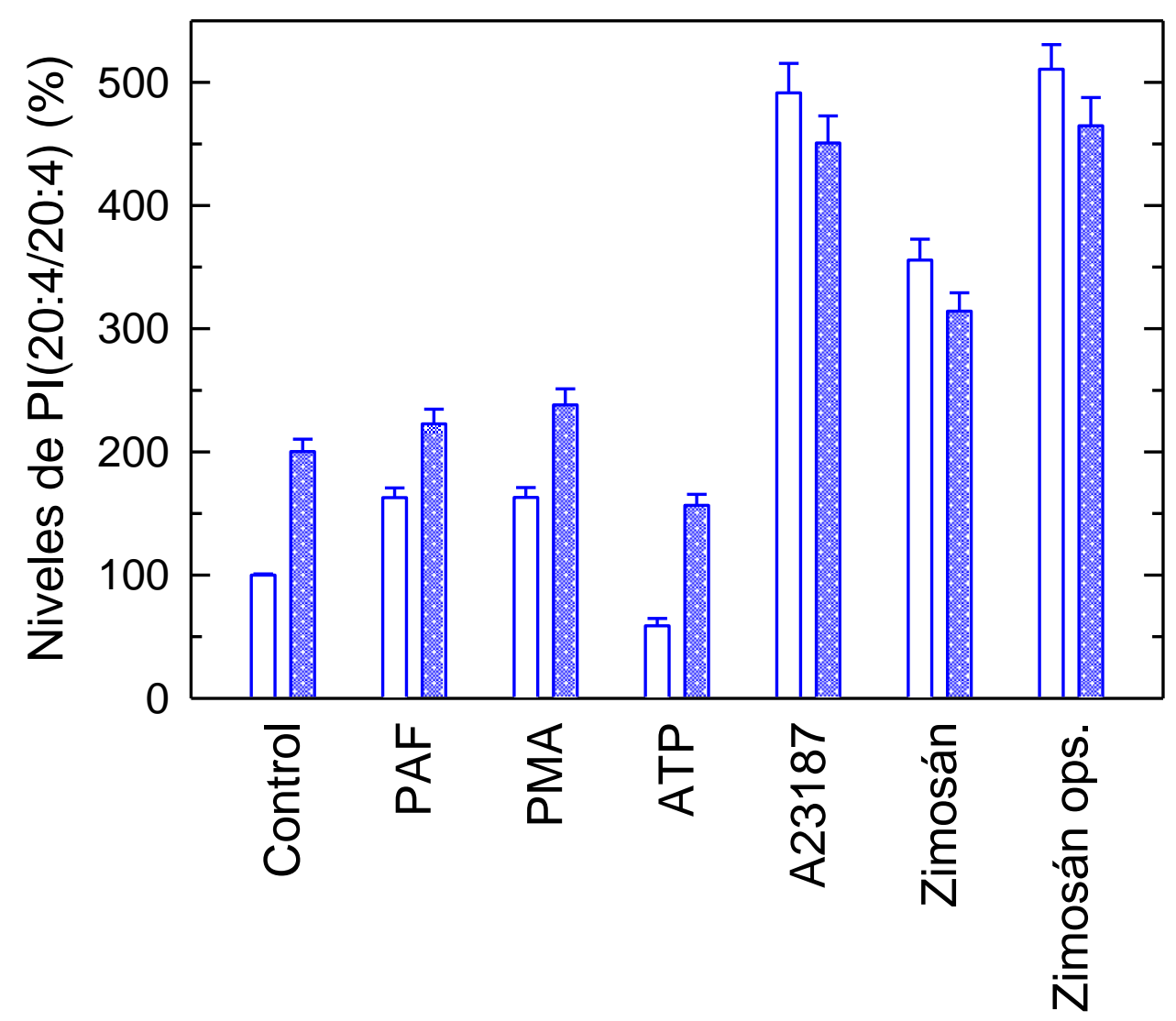

Figura 47. Niveles de PI(20:4/20:4) ante diferentes estímulos

Efecto de diferentes estímulos en la regulación de la síntesis de $\mathrm{PI}(20: 4 / 20: 4)$. Tras la extracción lipídica, se analizó mediante HPLC/MS los niveles de esta especie fosfolipídica en células etratadas con los diferentes estímulos (blanco) y expuestas con LPS durante una hora previamente a la estimulación (punteado), considerando control a las células sin estímulo. 


\section{D.4.2 Formación de $\mathrm{PI}(20: 4 / 20: 4)$ durante la peritonitis en ratón}

Para estudiar la generación in vivo de $\mathrm{PI}(20: 4 / 20: 4)$, se usó un modelo bien caracterizado de inducción de peritonitis por zimosán []. El zimosán se administró peritonealmente, las células peritoneales se extrajeron a diferentes tiempos y la formación de $\mathrm{PI}(20: 4 / 20: 4)$ se midió por HPLC/MS. Los niveles de $\mathrm{PI}(20: 4 / 20: 4)$ se incrementaron durante la primera hora de exposición a zimosán y descendieron de forma rápida posteriormente (figura 48). La curva que los niveles de $\mathrm{PI}(20: 4 / 20: 4)$ hace respecto al tiempo de exposición a zimosán es notablemente similar a lo observado cuando se utilizan macrófagos peritoneales aislados (figura 46). La fig X muestra también los niveles de la mayor especie de PI con contenido en $\mathrm{AA}, \mathrm{PI}(18: 0 / 20: 4)$, el cual decreció con el tiempo como consecuencia de la estimulación de la cPLA2 $\alpha$.

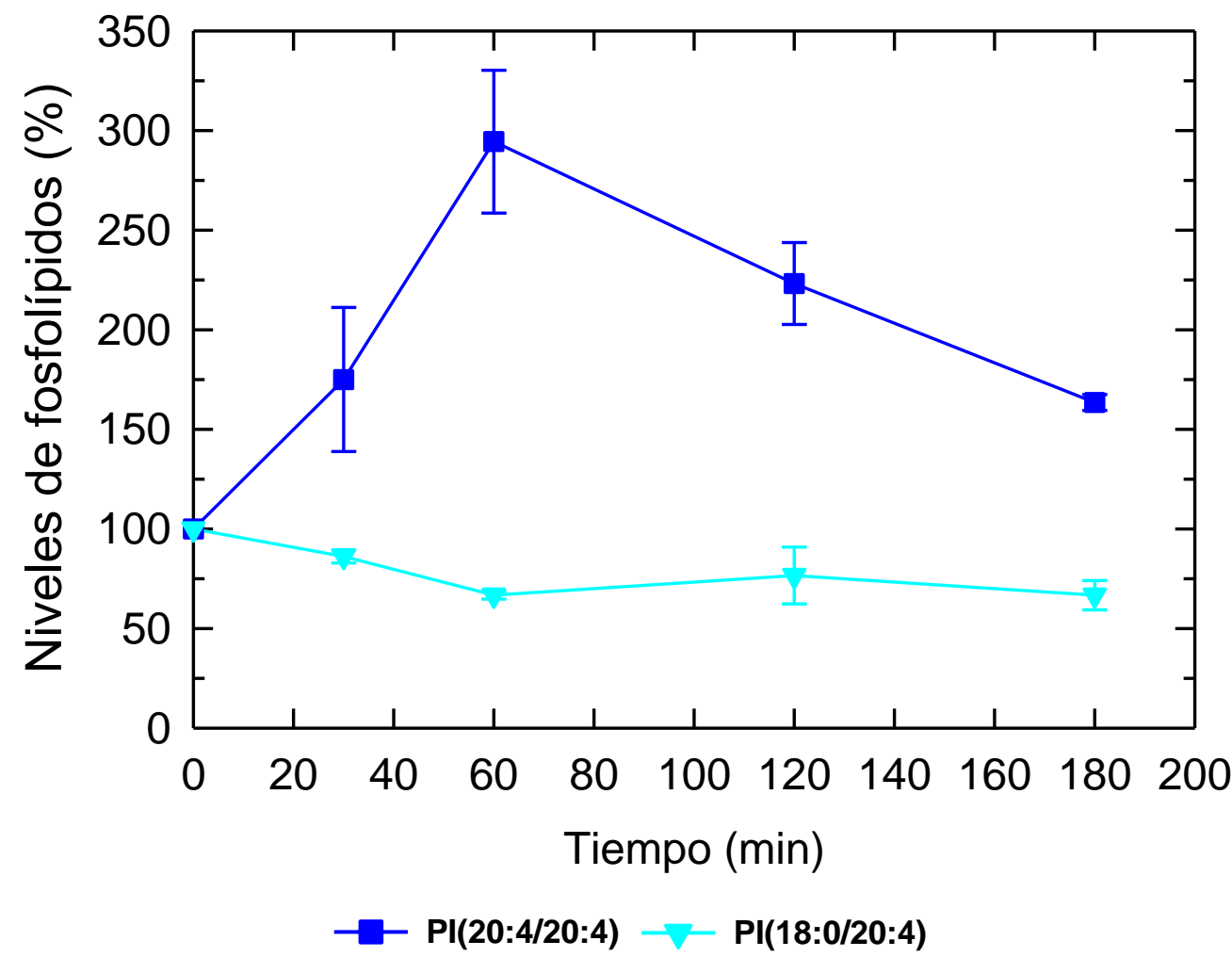

Figura 48. Niveles de $\mathrm{PI}(20: 4 / 20: 4)$ en peritinitis de ratón Análisis de los niveles de la especie $\mathrm{PI}(20: 4 / 20: 4)$ en ratones a los que se inyecto de forma intraperitoneal $1 \mathrm{mg}$ de zimosán. Tras los tiempos de incubación con el zimosán, se extrajeron los macrófagos peritoneales y seguidamente se congelaron para su posterior análisis por HPLC-MS. Además de la especie PI(20:4/20:4) con $\mathrm{m} / \mathrm{z}=905$, se identificó y cuantificó la especie $\mathrm{PI}(18: 0 / 20: 4)$ con $\mathrm{m} / \mathrm{z}=885$, ambas en modo negativo. 


\section{D.4.3 $\mathrm{PI}\left(\left[{ }^{2} \mathrm{H}\right] \mathrm{AA} /\left[{ }^{2} \mathrm{H}\right] \mathrm{AA}\right)$ como aceptor de AA exógeno en especies de $\mathbf{P I}$}

Mediante el uso de HPLC-ESI-MS, Balgoma et al. [90] describió $\left.\mathrm{PI}\left({ }^{2} \mathrm{H}\right] \mathrm{AA} /\left[^{2} \mathrm{H}\right] \mathrm{AA}\right)$ como el mayor aceptor de PI de AA exógeno en especies de PI en monocitos humanos cuando estos se exponen a concentraciones de $1 \mu \mathrm{M}$ de $A A$ marcado con ocho deuterios $\left.\left({ }^{2} \mathrm{H}\right] \mathrm{AA}\right)$. A pesar de que la especie endógena es una especie AA minoritaria, al ser expuesto a concentraciones de de $\left[{ }^{2} \mathrm{H}\right] \mathrm{AA}$, durante una hora, este AA exógeno se incorpora preferentemente a esta especie la cual tiene un corto periodo de vida respecto a otras especies aceptores de AA exógeno.

$\mathrm{PI}\left(\left[^{2} \mathrm{H}\right] \mathrm{AA} /\left[{ }^{2} \mathrm{H}\right] \mathrm{AA}\right)$ además de ser el mayor aceptor de AA exógeno en monocitos humanos, se comporta como el mayor aceptor en neutrófilos humanos extraídos de sangre periférica. La misma respuesta se ha observado en la línea celular HL-60 que corresponde a neutrófilos humanos. Sin embargo, en macrófagos peritoneales de ratón o en la línea celular RAW 264.7 de macrófagos de ratón la especies, $\mathrm{PI}\left(\left[^{2} \mathrm{H}\right] \mathrm{AA} /\left[{ }^{2} \mathrm{H}\right] \mathrm{AA}\right)$ no se comporta como el fosfolípido aceptor mayoritario de AA exógeno. En el caso de los macrófagos peritoneales de ratón, la especie mayoritaria de PI con $\left.{ }^{2} \mathrm{H}\right] \mathrm{AA}$ es $\left.\mathrm{PI}\left(18: 0 /{ }^{2} \mathrm{H}\right] \mathrm{AA}\right)$ que corresponde con la especie mayoritaria endógena con contenido en AA. Sin embargo, en células RAW 264.7 , la especie de PI que muestra mayor aceptación de $\left[{ }^{2} \mathrm{H}\right] \mathrm{AA}$ es la especie $\mathrm{PI}\left(18: 1 /\left[^{2} \mathrm{H}\right] \mathrm{AA}\right)$ a pesar de que no se trata de la especie endógena mayoritaria, que como en el caso de los macrófagos peritoneales de ratón, es $\mathrm{PI}(18: 0 / 20: 4)$. 

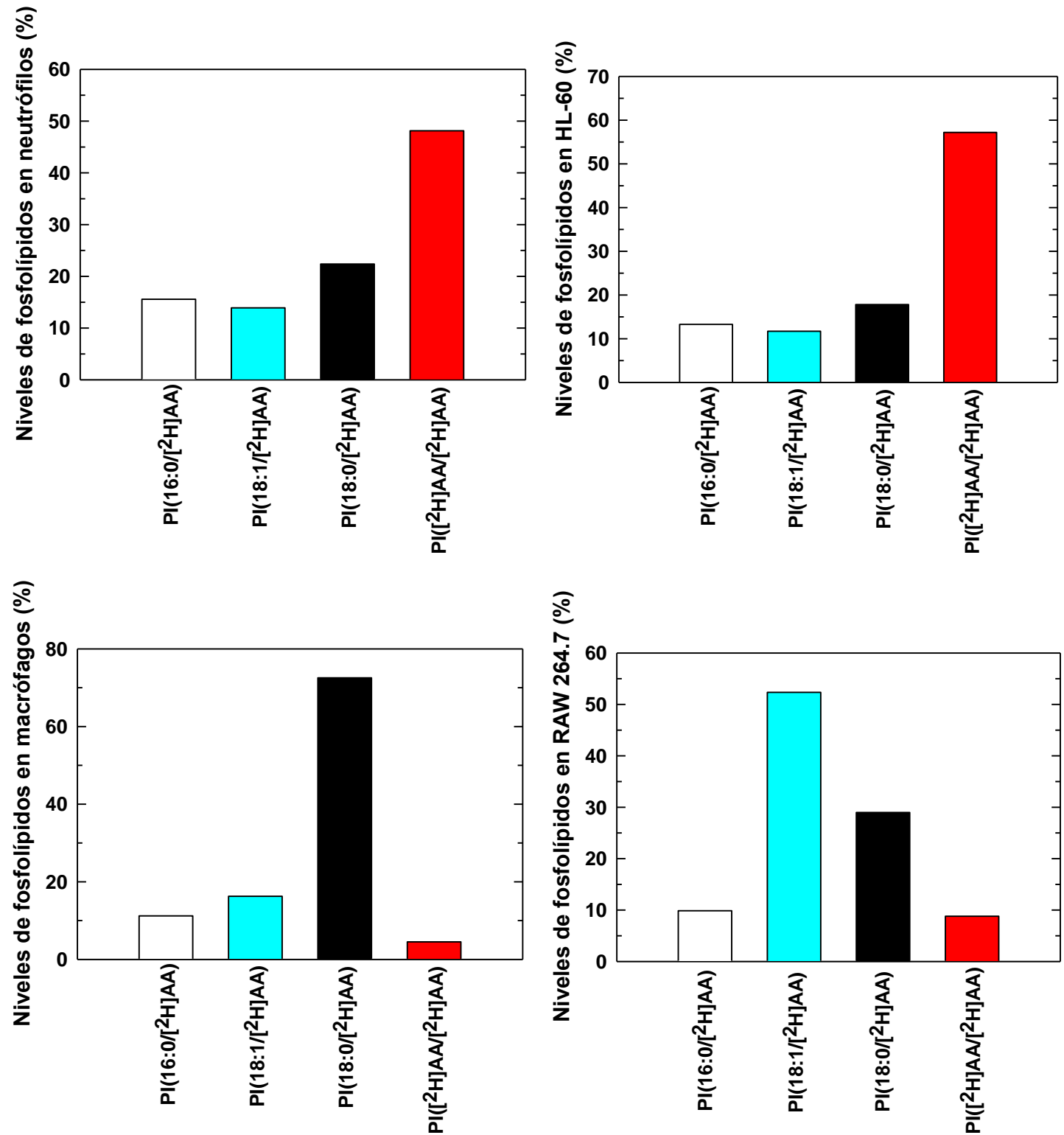

Figura 49. Especies de PI aceptores de $\left[{ }^{2} \mathrm{H}\right] \mathrm{AA}$.

Niveles de especies de PI que incorporan [2H]AA cuando los macrófagos peritoneales de ratón son expuestos durante 30 minutos con $[2 \mathrm{H}] \mathrm{AA}$ a una concentración de $1 \mu \mathrm{M}$. Tras la extracción de los lípidos, en el análisis por HPLC-MS se pudieron identificar cuatro especies de PI que eluían con las especies endógenas y que presentaban 8 unidades de $\mathrm{m} / \mathrm{z}$ más que las especies endógenas además de una forma acampanada en el espectro típica de los compuestos deuterados. 


\section{D.4.4 Introducción del $\mathrm{PI}(20: 4 / 20: 4)$ en las células y su seguimiento}

La cinética de la formación de $\mathrm{PI}(20: 4 / 20: 4)$, tanto in vitro como in vivo, mostrando un rápido incremento seguido por un pronunciado descenso, es consistente con la actuación de la molécula como un señalizador intracelular. Para estudiar esta posibilidad, se introdujo $\mathrm{PI}(20: 4 / 20: 4)$ en las células utilizando histona como carrier ya que es capaz de contrarrestar las cargas negativas que presenta el fosfolípidos y de hacer permeable la membrana celular [144, 227]. Mediante este procedimiento, encontramos que el $35 \pm 6 \%$ SE del fosfolípido añadido se incorpora dentro de las células durante 30 minutos de incubación. Es reseñable que las células metabolizan rápidamente el $\mathrm{PI}(20: 4 / 20: 4)$ incorporado, degradando aproximadamente el $70 \pm 10 \% \mathrm{SE}$ del fosfolípidos dentro de la primera hora. Esto es una observación importante, ya que la especie $\mathrm{PI}(20: 4 / 20: 4)$ añadida de manera exógena se comporta de la misma manera que la formada intracelularmente, lo que sugiere que la adición del $\mathrm{PI}(20: 4 / 20: 4)$ exógeno representa un modelo comparable a las condiciones fisiológicas.

Para estudiar el metabolismo de $\mathrm{PI}(20: 4 / 20: 4)$ en los macrófagos, se utilizaron lípidos con el AA marcado en posición sn-1, 1-[ $\left.{ }^{2} \mathrm{H}\right] \mathrm{AA}-2-\mathrm{AA}$-glicero-sn-3-glicerofosfatidilinositol, como la especie con el AA marcado en posición sn-2, 1-AA-2 $\left[{ }^{2} \mathrm{H}\right] \mathrm{AA}$-glicero-sn-3-glicerofosfatidilinositol. El análisis mediante HPLC/MS de ambos fosfolípidos a diferentes tiempos de exposición de las células, reveló que no se producía una incorporación de la marca a ninguna especie de gliecrofosfolípido, sugiriendo que $\mathrm{PI}(20: 4 / 20: 4)$ no es un intermediario en la formación o en el reemplazamiento de los fosfolípidos de membrana. Además, es de reseñar que ningún lisoPI con $\left[{ }^{2} \mathrm{H}\right] \mathrm{AA}$ se detectó en estudios realizados bajo las mismas condiciones, indicando que la pérdida de las dos moléculas de AA desde $\mathrm{PI}(20: 4 / 20: 4)$ ocurre, bien simultáneamente o bien secuencialmente pero de manera tan rápida que el lisoPI con contenido en $\left[{ }^{2} \mathrm{H}\right] \mathrm{AA}$ no tiene la capacidad de acumularse. En contraste a la falta de $\left[{ }^{2} \mathrm{H}\right] \mathrm{AA}$ encontrado en especies de glicerofosfolípidos, al incubar con ambos fosfolípidos, una marca abundante se detectó en lípidos neutros (triacilglicerol).

Por otra parte, resultados previos han mostrado que el fosfolípido de colina análogo a PI(20:4/20:4), PC (20:4/20:4), que es usado para la síntesis de anandamidas bajo ciertas condiciones [228]. Para investigar si $\mathrm{PI}(20: 4 / 20: 4)$ puede tener un papel similar, se usaron los dos fosfolípidos marcados. Después de la introducción del fosfolípido en las células, estas se estimularon con zimosán durante diferentes tiempos, y la síntesis de anandamida se determinó por HPLC/MS bajo las condiciones descritas por Dennis et al. [229]. No se pudo detectar anandamida marcada con deuterios en ninguna de las condiciones utilizadas, todas ellas superiores a las dos horas de incubación. De la misma manera, ningún eicosanoide con marcaje deuterado se pudo identificar por HPLC/MS. En conjunto, estos resultados indican que, a diferencia del PC(20:4/20:4), $\mathrm{PI}(20: 4 / 20: 4)$ no es una fuente de AA para la síntesis de anandamida u otros compuestos lipídicos bioactivos. 


\section{D.4.4.1 Relación de $\mathrm{PI}(20: 4 / 20: 4)$ con la expresión de diferentes genes implicados en inflamación}

Recientes estudios han sugerido que ciertas especies fosfolípidicas como $\mathrm{PC}(16: 0 / 18: 1)$ o PC(12:0/12:0) presentan la capacidad de regular la inducción de genes mediante la modulación de la actividad de factores de transcripción [230-232]. Para evaluar como $\mathrm{PI}(20: 4 / 20: 4)$ tiene una función similar en macrófagos, se estudió por qPCR los posibles efectos de este fosfolípidos en la inducción de un número importante de genes conocidos por su implicación en la inflamación que se muestran el la tabla 12.

\begin{tabular}{cccc}
\hline Arg1 & Ccl2 & COX-2 & Fizz1 \\
IL-1 $\beta$ & IL-6 & IL-10 & IL-12 $\alpha$ \\
IL-12 $\beta$ & IL-23 & Mrc-1 & Mrc2 \\
Nos2 & Tgf- $\beta$ & Tnf- $\alpha$ & Ym1
\end{tabular}

Tabla 12 Genes estudiados por la posible implicación de la especie PI(20:4/20:4) Genes estudiados por la posible implicación de la especie PI(20:4/20:4) en la regulación de sus niveles de expresión dentro de procesos inflamatorios producidos por la estimulación con zimosán de macrófagos peritoneales de ratón.

De todos ellos, se detectó claramente un importante aumento de la regulación de IL-10, COX-2, IL-23 y Tnf $\alpha$ bajo condiciones de estimulación con zimosán, lo cual está de acuerdo con lo estimado previamente [233-235]. La adición de $\mathrm{PI}(20: 4 / 20: 4)$ a las células no provocó ningún efecto y ni estimuló ni impidió la inducción de ninguno de los genes estudiados. La combinación del fosfolípidos con el zimosán tampoco produjo ningún efecto diferente a lo observado con el tratamiento con zimosán solo. 

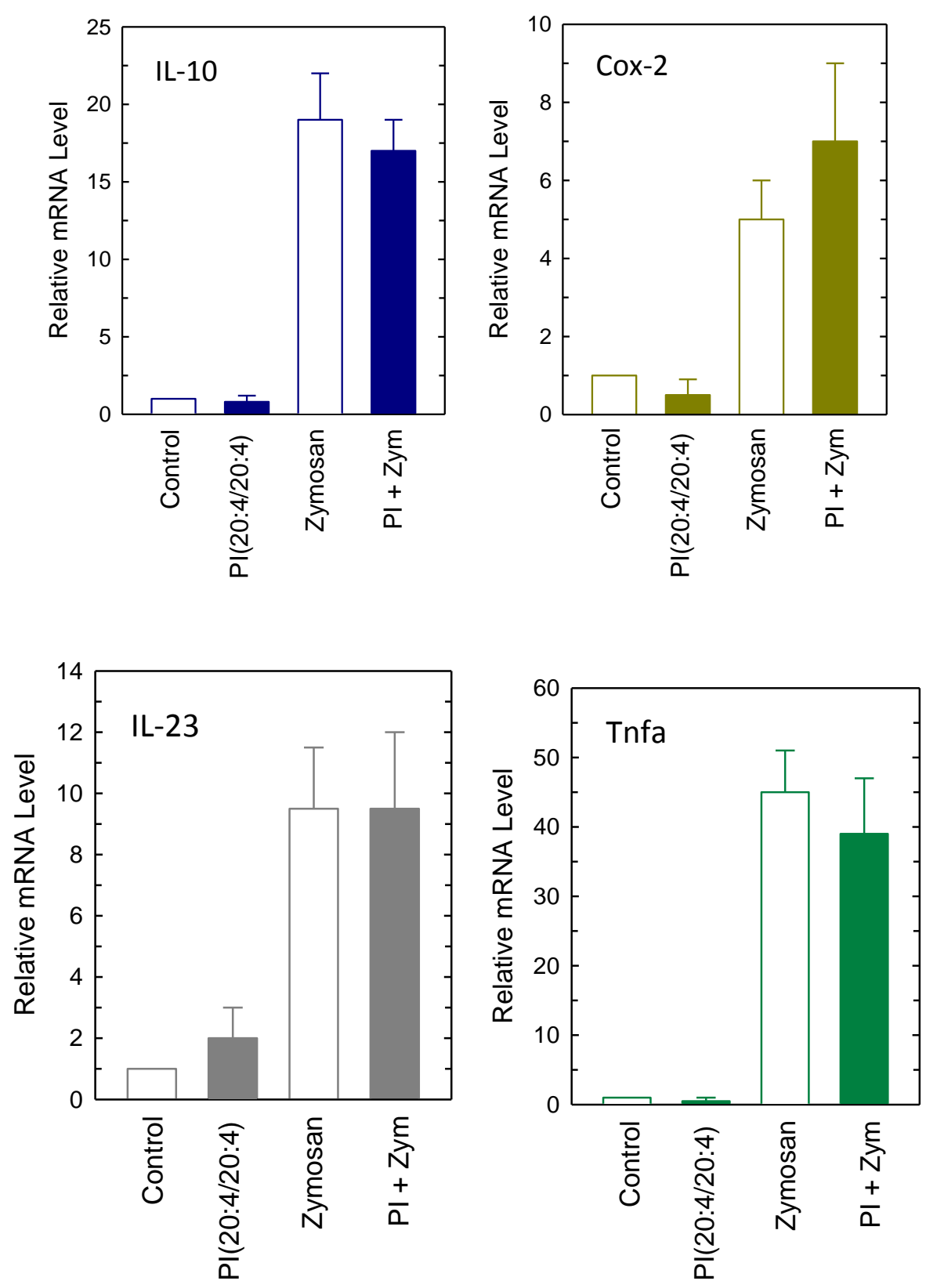

Figura 50. Expresión de genes implicados en inflamación en presencia de PI(20:4/20:4). Análisis mediante qPCR de la expresión de genes implicados en inflamación como IL-10, COX-1, IL-23, Tnfa, en macrófagos peritoneales de ratón en condiciones basales (control), con la presencia del carrier Histona H1, estimulados con zimosán y estimulados con zimosán en presencia de la especie $\mathrm{PI}(20: 4 / 20: 4)$ previamente introducida mediante la utilización de Histona $\mathrm{H} 1$ como carrier. 


\section{D.4.4.2 Relación del $\mathrm{PI}(20: 4 / 20: 4)$ con el aumento de los niveles de $\mathrm{O}_{2}{ }^{-}$ celular}

Tras la observada nula habilidad de $\mathrm{PI}(20: 4 / 20: 4)$ de regular respuestas largas en el tiempo como la transcripción de genes en macrófagos peritoneales de ratón, se propuso investigar los posibles efectos del fosfolípido en respuestas inmediatas. En este aspecto, la generación de especies de oxígeno reactivo como el anión superóxido o el peróxido de hidrógeno es una respuesta de los macrófagos para provocar la muerte de patógenos y el mantenimiento de una defensa eficiente por parte del hospedador [47]. El efecto del PI(20:4/20:4) en la producción de anión superóxido en macrófagos peritoneales de ratón se muestra en la figura 51 . Como se observa, existe una tendencia para inducir el anión superóxido cuando se añade $\mathrm{PI}(20: 4 / 20: 4)$ sólo a las células, pero no muestra una significancia estadística. Sin embargo, $\mathrm{PI}(20: 4 / 20: 4)$ aumentó significativamente la respuesta tanto a PMA como a zimosán. Como control de este experimento, se utilizó un PI procedente de extracto de hígado vacuno que, tras se analizado por MS, se puede afirmar que contiene principalmente $\mathrm{PI}(18: 0 / 20: 4), \mathrm{PI}(18: 0 / 20: 3), \mathrm{PI}(18: 1 / 18: 1)$ y $\mathrm{PI}(18: 0 / 18: 1)$ y no presenta $\mathrm{PI}(20: 4 / 20: 4)$. Bajo las mismas condiciones que se utilizaron para $\mathrm{PI}(20: 4 / 20: 4)$, el $\mathrm{PI}$ de extracto de hígado, no presentó efectos en la generación de anión superóxido bajo ninguna condición estudiada, subrayando de este modo, la especificidad de la acción de $\mathrm{PI}(20: 4 / 20: 4)$.

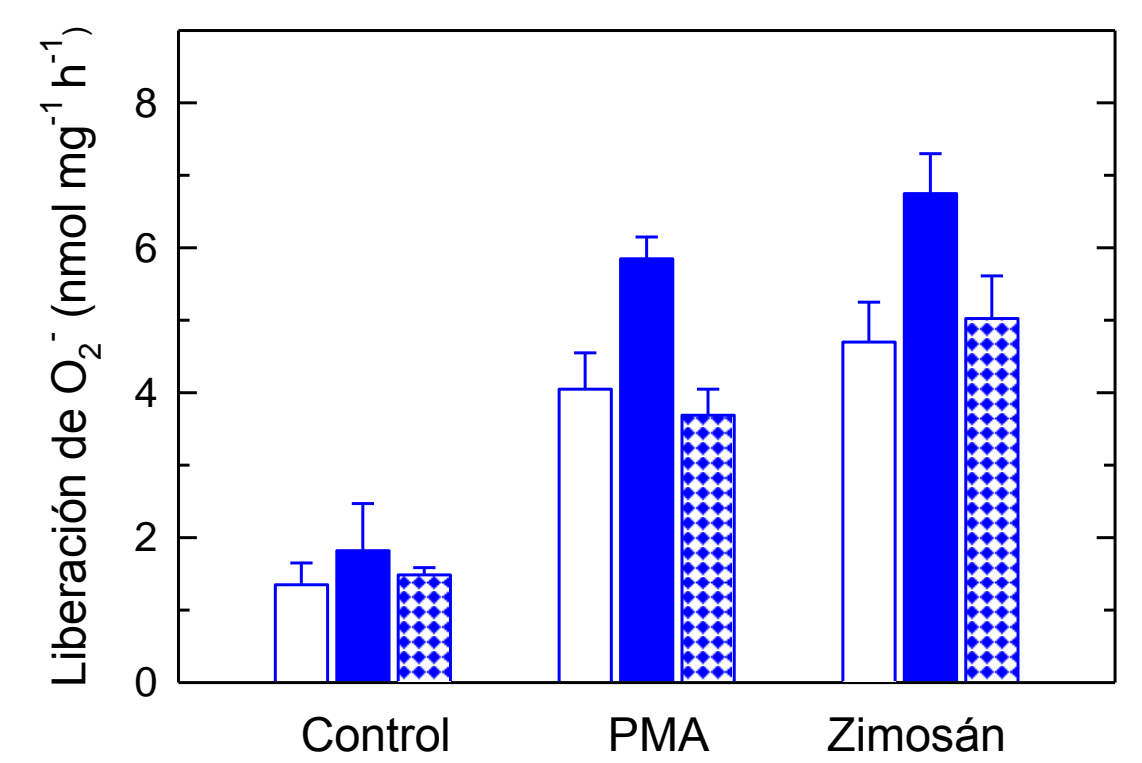

Control $\mathrm{PI}(20: 4 / 20: 4)$ **** PI de hígado vacuno

Figura 51. Media de anión superóxido y su relación con la presencia de PI(20:4/20:4) Análisis de la generación de anión superóxido mediante cuantificación de los nmol de citocromo $\mathrm{C}$ reducidos en macrófagos peritoneales de ratón en estado basal o en condiciones de estimulación con PMA (100 nM) o zimosán ( 1 mg/106 células). Mediante el uso de Histona se introdujo la especie PI(20:4/20:4) (azul), PI procedente de hígado vacuno (arlequinado) y se comparó con los macrófagos sin presencia de $\mathrm{PI}(20: 4 / 20: 4)$ pero incubados con la mismas cantidades de Histona (blanco). 
E.- DISCUSIÓN 


\section{E.1 Efecto sinérgico de la estimulación por LPS y zimosán en la liberación de AA}

Diferentes estudios previos realizados mediante el uso de $\left[{ }^{3} \mathrm{H}\right] \mathrm{AA}$ han indicado que PE actúa como la principal fuente de AA libre durante la activación celular [94]. Sin embargo, otros estudios han descrito la falta de cambios en los niveles de las especies de glicerofosfolípidos de PE con contenido en AA ante la estimulación con zimosán de monocitos humanos [Balgoma], lo cual es similar a los datos obtenidos en este trabajo en macrófagos peritoneales de ratón. Debido a que la movilización de AA esta regulada por dos reacciones contrapuestas de hidrólisis, mediada por la $\mathrm{CPLA}_{2} \alpha$, y la reacilación, el equilibrio observado en las especies de PE con AA en condiciones de activación de la $\mathrm{CPLA}_{2} \alpha$ por la estimulación con zimosán podría deberse a una alta reacilación de AA usando las especies de PC como donadoras a través de reacciones llevadas a cabo por la transacilasa independiente de CoA. De este modo, se entendería la nula liberación neta de AA desde especies de PE y la gran liberación de AA desde especies de PC observado.

Por otra parte, LPS también ha sido descrito como un estímulo de la liberación de AA. Sin embargo, se ha descrito que dicha liberación se debe a la activación directa de la $\operatorname{cPLA}_{2} \alpha$ sino por un incremento de los niveles de expresión de COX-2 que promueven la biosíntesis de PG [Rouzer 2004] en macrófagos peritoneales de ratón. Así, el LPS mediante la estimulación de la biosíntesis de PG provoca un aumento de la liberación de AA que, en consecuencia, produce un descenso de los niveles de glicerofosfolípidos con contenido en AA de un 9\% [236]. Dicha liberación de AA provocado por LPS se produce cuando los macrófagos peritoneales de ratón se incuban con este estímulo durante 5 horas [236]. Además, la preincubación de LPS durante 5 horas antes de la estimulación con zimosán, promueve un aumento de la movilización del AA desde las diferentes especies de glicerofosfolípidos [236]. En esta línea, se han publicado efectos de sinergismo por coactivación de TLR2 (zimosán) y TLR4 (LPS) [237-239]. Estos estudios han mostrado que la coactivación de TLR2 y TLR4 provoca mayor producción de TNF- $\alpha$, IL-6 y proteína inflamatoria de macrófago 1a (MIP-1a) tanto en macrófagos humanos como de ratón que cualquiera de los receptores por sí solo [23].

Ante estos datos, puede sugerirse que el efecto del LPS sobre la $\mathrm{CPLA}_{2} \alpha$ no se realiza sobre la actividad de esta enzima como lo hace el zimosán, sino que se lleva a cabo desplazando la reacción de biosínteis de eicosanoides hacía la producción de estos metabolitos mediante la mayor expresión de los genes que codifican para las proteínas implicadas en la síntesis de eicosanoides. Esto, además, requiere una mayor liberación de AA que sirva como sustrato para dicha síntesis de eicosanoides, implicando de esta forma la actividad de la $\operatorname{cPLA}_{2} \alpha$. Ese efecto del LPS puede explicar el aumento significativo de la liberación de AA desde los glicerofosfolípidos observado cuando tras 5 horas de incubación con LPS, los macrófagos peritoneales de ratón se estimulan con zimosán.

Sin embargo, este efecto en el incremento de la liberación también se ha descrito cuando los macrófagos peritoneales de ratón son preincubados únicamente durante una hora, tiempo en 
el cual el LPS no presenta por sí sólo liberación neta de AA respecto a las células basales [44]. La confirmación de este efecto sinérgico de la estimulación con LPS y zimosán en macrófagos peritoneales de ratón y el nulo efecto del LPS en la incorporación de AA indican que el mayor nivel de AA libre es consecuencia de una mayor liberación de AA. Además, el efecto observado por la pirrofenona impidiendo el descenso de los niveles los glicerofosfolípidos con contenido en $A A$, indica que, como es esperable, la cPLA $2 \alpha$ es la enzima encargada de esta movilización de AA.

Para su actividad, la cPLA $2 \alpha$ requiere de su traslocación a las membranas celulares donde se encuentran los glicerofosfolípidos que actúan como sustrato. El análsis mediante HPLC/MS de los glicerofosfolípidos implicados en la liberación de AA permite conocer con exactitud el acceso que presenta la $\mathrm{CPLA}_{2}$ a para catalizar la hidrólisis de cada uno de ellos. En este sentido, el análisis de los glicerofosfolípidos implicados en la liberación de AA por el efecto sinérgico del LPS y el zimosán no muestra la implicación de ningún otro fosfolípidos que no se vea involucrado en la movilización de AA por exposición de las células a zimosán. Esto indica que el efecto previo que pueda tener el LPS, no implica una traslocación de la $\mathrm{CPLA}_{2} \alpha$ a otros sumideros de la membrana donde especies concretas de fosfolípidos a los cuales no tiene acceso la cPLA ${ }_{2} \alpha$ cuando se activa por efecto del zimosán, si se puedan hidrolizar en presencia de LPS.

Estos datos están en consonancia con el nulo efecto del LPS sobre la regulación de los niveles de calcio intracelular [240], punto crítico en la traslocación de la cPLA2 $\alpha$. Sin embargo, la implicación del LPS en la fosforilación de la cPLA $2 \alpha$ [240] pueden definir al LPS como un estímulo de preactivación de la $\mathrm{CPLA}_{2} \mathrm{a}$, lo cual esta en consonancia con el efecto observado al exponer posteriormente las células a zimosán.

Los resultados aquí presentados confirman que, si bien el LPS no activa directamente a la ${ }_{C P L A} \alpha$ ni es capaz de modificar su translocación, sí que modifica la actividad de alguna enzima implicada en la ruta metabólica que comprende la liberación de AA y la posterior síntesis de eicosanoides. Aunque no esté determinado en este estudio, parece plausible ante estos datos, que la estimulación durante una hora con LPS, si bien no sea tiempo suficiente para producir cambios transcipcionales del gen que codifica para COX-2 u otras enzimas implicadas en la síntesis de eicosanoides, si pueda tener efecto sobre la actividad de estas enzimas, desplazando de este modo, el equilibrio metabólico hacia la biosíntesis de eicosanoides lo cual requiere un mayor aporte de AA libre como sustrato y en consecuencia, la implicación de la cPLA $\alpha$.

Aparte de describir un efecto sobre la $\mathrm{CPLA}_{2} \alpha$, este modelo de sinergismo de diferentes agonistas de la liberación de AA pone de relieve que la saturación del efecto del zimosán en la movilización de $A A$ no se debe a la completa actividad de la $\operatorname{cPLA}_{2} \alpha$, sino que podría reflejar una simple saturación de los receptores que reconocen zimosán, lo cual está en consonancia con el efecto observado en este trabajo en otras condiciones de estimulación.

En definitiva, el efecto observado por la exposición de los macrófagos a LPS y zimosán, sin ninguna diferencia lipídica distintiva respecto a la estimulación con zimosán, parece denotar la ausencia de una regulación específica en la respuesta. Esto puede deberse a que una infección 
doble con dos orígenes diferentes sea una situación puntual donde la maquinaria celular implicada en la regulación de la respuesta inflamatoria carezca de puntos de control específicos de tal manera que la respuesta sea, simplemente, consecuencia de una amplificación de la respuesta que presenta el zimosán por sí solo. 


\section{E.2 Liberación de AA desde las especies plasmalógenas de PE por la estimulación de zimosán opsonizado}

El hecho de que los macrófagos peritoneales de ratón sean capaces de reconocer el zimosán opsonizado por más receptores que los que reconocen el zimosán, entre ellos, principalmente CR3 y FCR, este último implicado en la liberación de AA ante partículas cubiertas por IgG [44] puede explicar los datos obtenidos en los que se demuestra una mayor liberación de AA cuando los macrófagos peritoneales de ratón son estimulados con zimosán opsonizado respecto a los estimulados con zimosán no cubierto por opsoninas. Estos resultados pueden explicarse por la ocupación de los receptores de no patógenos vía zimosán opsonizado, lo cual no se produce por la exposición a zimosán. Las partículas que cubren el zimosán opsonizado pueden ser reconocidos por estos receptores disponibles y promover la liberación de AA de los glicerofosfolípidos. El aumento de la liberación de AA por estimulación con zimosán opsonizado tras la exposición con zimosán y la ausencia de efecto al cambiar el orden de los estímulos parecen confirmar esta hipótesis. Además, aunque sin presentar una gran diferencia, la saturación a concentraciones más altas del zimosán respecto al zimosán opsonizado pueden también conducir a la implicar de los receptores de no patógenos en la liberación de AA.

Cuando se analizan mediante HPLC/MS las especies de glicerofosfolípidos, no se obtiene ninguna diferencia en los niveles de las especies de PC, PI y PS entre la estimulación con zimosán y zimosán cubierto con opsoninas. Sin embargo, especies de plasmenilos de PE muestran un descenso de sus niveles al opsonizar el zimosán antes de estimular a los macrófagos peritoneales de ratón. El hecho de que no exista diferencias en especies de PC, PI o PS ni en especies de acil-PE sugiere que la mayor liberación de AA debido a la opsonización del zimosán no es debido a un simple aumento de la actividad de la $\operatorname{cPLA}_{2} \alpha$.

En macrófagos peritoneales de ratón las clase de fosfolípidos con mayor cantidad de AA son los PE. Dentro de esta clase, las especies plasmalógenas con contenido en AA representan la subclase mayoritaria [94] Además, debido a su alta capacidad de movilización y reincorporación de $A A$, se trata de la subclase de glicerofosfolípidos más implicada en el intercambio de AA [241]. Aunque la $\mathrm{CPLA}_{2}$ a no presenta especificidad por ni por la clase ni por la subclase de fosfolípidos (enlace acil versus enlace éter en la posición $s n-1$ ) y se ha implicado a todas las subclases de PE en la liberación de AA, la tendencia del AA a estar asociado a las especies alquenil-PE [241] provoca una gran producción de especies de lisoPE de tipo alquenil. Esto concuerda con los datos obtenidos, que muestran, además del descenso de los niveles de alquenil-PE, un aumento consecuente de los niveles de alquenil-lisoPE. Además, en concordancia, la inhibición de la cPLA $\mathrm{A}_{2} \alpha$ por pirrofenona solo afecta al subgrupo de alquenil-lisoPE mientras que no afecta al aumento de los niveles de las especies de acil-lisoPE, sugiriendo de este modo que otras fosfolipasas pudieran estar implicadas movilizando otros ácidos grasos unidos a especies de acil-PE. 
El subgrupo de alquenil-lisoPE puede jugar un papel importante en la generación de compuestos implicados en la inflamación como PAF. Así, se han descrito en neutrófilos que estas especies concretas de alquenil-lisoPE pueden acumularse por activación celular y provocar, bien a través de la desacilción de especies 1-alquil-2-araquidonoil-PC o bien por competir con los alquillisoPC como aceptores de AA, la producción de lisoPAF y PAF en el sistema de membrana. El modelo propuesto implica que aunque la actividad $\mathrm{PLA}_{2}$ juega un papel importante en el modelo, la transacilasa independiente de CoA es la enzima responsable directa de la formación de lisoPAF en neutrófilos [94] y puede, por lo tanto, estar implicada en el metabolismo de alquenil-lisoPE en macrófagos estimulados por zimosán opsonizado.

Además de la formación de especies de alquenil-lisoPE, el descenso de los niveles de especies de alquenil-PE también pueden conllevar un significado biológico. Se ha descrito en este trabajo las numerosas funciones con las que se ha implicado a las especies plasmalógenas, que comprenden funciones antioxidantes, funciones relacionadas con la dinámica de la membrana o incluso de señalización celular. La rotura del equilibrio en los niveles de las especies alquenil-PE con contenido en AA por efecto exclusivo del zimosán opsonizado puede suponer cambios en dichas funciones aparejando un nuevo equilibrio metabólico en las células.

Una implicación específica de especies concretas de fosfolípidos y lisofosfolípidos, que debido al enlace vinil éter presentan unas características y funciones que las diferencia de otras sublclases, puede indicar una respuesta muy regulada y específica. Además, si bien las diferencias absolutas entre la respuesta de los macrófagos a zimosán y zimosán opsonizado no son radicales en referencia a la liberación de $A A$, esta pequeña divergencia puede significar la síntesis de eicosanoides que, como es sabido, no sólo tienen carácter proinflamatorio sino que también pueden presentan capacidad antiinflamatoria gracias a lo cual, ofrecen un servicio de regulación activa de la inflamación. En definitiva, la mayor presencia de alquenil-liso PE, el descenso de los niveles de alquenil-PE y la mayor abundancia de AA libre pueden representar un escenario más regulado de la inflamación, lo que puede evitar daños colaterales tanto celulares como tisulares a la vez que se mantiene la capacidad para afrontar y eliminar la invasión patogénica. 


\section{E.3 El PI(20:4/20:4) en la respuesta inmune innata}

Se han descrito en monocitos humanos que dos glicerofosfolípidos particulares con contenido en $\mathrm{AA}, \mathrm{PI}(20: 4 / 20: 4)$ y $\mathrm{PC}(20: 4 / 20: 4)$, este último, formado por la ruta de biosíntesis de novo ante altas concentraciones de AA vía una secuencial acilación del glicerol fosfato y del araquidonoil glicerol fosfato con AA [225], muestran también un aumento de sus niveles bajo la estimulación por diferentes agonistas como el zimosán. $\mathrm{PI}(20: 4 / 20: 4)$ no se produce por la ruta de novo sino que aumenta sus niveles vía reacilación directa de moléculas preexistentes de lisoPI cuando se exponen a las células a AA exógeno, llegando a suponer el mayor aceptor de AA exógeno en fosfolípidos de PI en monocitos humanos [90].

De forma similar a lo observado en monocitos humanos, y al igual que sucede con la especie PC(20:4/20:4), el incremento de los niveles de $\mathrm{PI}(20: 4 / 20: 4)$ está impedido por la inhibición de la CPLA2 $\alpha$ a través de la acción de la pirrofenona en macrófagos peritoneales de ratón bajo condiciones de estimulación con zimosán. Este hecho sugiere que la especie $\mathrm{PI}(20: 4 / 20: 4)$, está formado vía reacciones de reacilación dependientes de CoA, en los cuales, el AA proveniente de la hidrólisis de glicerofosfolípidos mediada la $\operatorname{cPLA}_{2} \alpha$, actúa como donador.

Por su parte, el comportamiento especial de $\mathrm{PI}(20: 4 / 20: 4)$ en presencia de zimosán, se repite por la exposición de las células a iónoforo A23187, pero es mucho menos significativa al utilizar otros estímulos de la liberación de AA como ATP, PMA o PAF. Este hecho, junto al efecto observado en presencia única de LPS, pueden indicar que la formación de $\mathrm{PI}(20: 4 / 20: 4)$ no es dependiente de un aumento considerable de los niveles de AA libre, lo cual está en consonancia con la biosíntesis de $\mathrm{PI}(20: 4 / 20: 4)$ vía ciclo de Lands a partir de reacilación de lisoPI observada en monocitos [191] y la formación de $\mathrm{PI}\left[{ }^{2} \mathrm{H}\right] \mathrm{AA} /\left[{ }^{2} \mathrm{H}\right] \mathrm{AA}$, cuando las células se exponen a bajas concentraciones de AA exógeno [90].

la formación de $\mathrm{PI}(20: 4 / 20: 4)$, que muestra un pico pronunciado tras una hora de exposición al agonista y un descenso tras ese tiempo, se repite en la inducción de peritonitis en ratón, otorgando a esta especie un valor fisiológico en condiciones de una invasión patogénica. Además, esta silueta característica que dibuja el PI(20:4/20:4) en células activadas parece implicar al PI(20:4/20:4) en respuestas rápidas celulares relacionadas con los procesos inflamatorios. Como se ha descrito, la presencia de $\mathrm{PI}(20: 4 / 20: 4)$ está relacionado con un aumento en la generación celular de anión superóxido en condiciones de estimulación ante patógenos, donde el macrófago requiere de este proceso para ejecutar los procesos de eliminación estos huéspedes.

En relación con esto, se ha descrito que la acción de la cPLA2 $\alpha$ conlleva la activación de la NADPH oxidasa [242]. La NADPH oxidasa se considera una enzima central en la generación de anión superóxido a través de la reducción del citocromo $C$, creando de esta manera una atmósfera intracelular oxigenada que facilita la síntesis de eicosanoides y supone un ambiente hostil para los patógenos huéspedes. Además, se ha descrito en ratones deficientes en CPLA2 $\alpha$ que la presencia de AA y no la de otro ácido graso puede restaurar la actividad NADPH oxidasa[243]. De esta forma, 
la cPLA2 $\alpha$ se convierte en un punto de conexión de la generación de anión superóxido y la formación de $\mathrm{PI}(20: 4 / 20: 4)$ y puede indicar que el AA libre y/o en forma de $\mathrm{PI}(20: 4 / 20: 4)$ regula la actividad de la NADPH oxidasa.

Hay que resaltar también, en concordancia con estos datos, como ha quedado demostrado en este trabajo, el incremento de los niveles de $\mathrm{PI}(20: 4 / 20: 4)$ se ven agudizados por zimosán opsonizado, el cual, se ha descrito que produce unos niveles de anión superóxido superiores a el efecto provocado por el zimosán. [47]. Estos datos, coincidentes con resultados previos propios, parecen definir de una manera concreta la relación del PI(20:4/20:4) con la generación de anión superóxido y, con ello, con la función de defensa antes posibles patógenos a través de trabajos de eliminación. 
F.- CONCLUSIONES 
Las conclusiones de esta tesis son:

1. El tratamiento durante una hora de LPS previa a la estimulación de macrófagos peritoneales de ratón con zimosán provoca una amplificación de la liberación de AA que resulta inespecífica respecto a las especies de glicerofosfolípidos implicadas. El nulo efecto del LPS en la incorporación y la demostrada relación de la cPLA2 $\alpha$ en el proceso parece asociar la mayor liberación de AA bien a una activación parcial de la cPLA2 $\alpha$ o bien a su activación indirecta asociada a un mayor metabolismo de AA.

2. El recubrimiento de zimosán por opsoninas permite un aumento de la liberación de AA en macrófagos peritoneales de ratón. La capacidad del zimosán opsonizado de incrementar los niveles de AA libre en condiciones de saturación de zimosán permiten postular la relación de receptores de no patógenos en la movilización de AA.

3. El análisis de las especies de glicerofosfolípidos con contenido en AA mediante HPLC/MS permite identificar la implicación exclusivia de las especies plasmalógenas de PE en el aumento de la liberación de AA. El aumento de especies alquenil-lisoPE confirma la hidrólisis de estas especies fosfolipídicas.

4. El efecto del zimosán opsonizado sobre las especies plasmalógenas de PE con contenido en AA implica la actividad de la CPLA2 $\alpha$. Además, la nula implicación de la CPLA2 $\alpha$ en el aumento de los niveles de acil-lisoPE demuestra la exclusiva implicación de las especies alquenil-PE en la movilización de AA.

5. La especie $\mathrm{PI}(20: 4 / 20: 4)$, al igual que en monocitos humanos, aumenta sus niveles en macrófagos peritoneales de ratón estimulados con zimosán. Este efecto se ve agudizado en presencia de zimosán opsonizado.

6. El similar comportamiento de $\mathrm{PI}(20: 4 / 20: 4)$ en modelos de peritonitis de ratón otorga a esta especie un carácter fisiopatológico.

7. La presencia de $\mathrm{PI}(20: 4 / 2=.4)$ es capaz de aumentar la generación de anión superóxido en células activadas, favoreciendo así las funciones de eliminación de patógenos de los macrófagos y otorgando a esta especie un significado biológico. 
G.- REFERENCIAS 


\section{RE FEREN CIAS}

1 Akira, S., Uematsu, S. and Takeuchi, O. (2006) Pathogen recognition and innate immunity. Cell. 124, 783-801

2 Geissmann, F., Manz, M. G., Jung, S., Sieweke, M. H., Merad, M. and Ley, K. (2010) Development of monocytes, macrophages, and dendritic cells. Science. 327, 656-661

3 Gordon, S. (2007) The macrophage: past, present and future. Eur J Immunol. 37 Suppl 1, S9-17

4 Bhargava, P. and Lee, C. H. (2012) Role and function of macrophages in the metabolic syndrome. Biochem J. 442, 253-262

5 Gordon, S. B. and Read, R. C. (2002) Macrophage defences against respiratory tract infections. Br Med Bull. 61, 45-61

6 Harizi, H. and Gualde, N. (2005) The impact of eicosanoids on the crosstalk between innate and adaptive immunity: the key roles of dendritic cells. Tissue Antigens. 65, 507-514

$7 \quad$ Nathan, C. (2002) Points of control in inflammation. Nature. 420, 846-852

8 Calder, P. C. (2006) n-3 polyunsaturated fatty acids, inflammation, and inflammatory diseases. Am J Clin Nutr. 83, 1505S-1519S

9 Calder, P. C. (2009) Fatty acids and inflammation: the cutting edge between food and pharma. Eur J Pharmacol. 668 Suppl 1, S50-58

10 Gantner, B. N., Simmons, R. M., Canavera, S. J., Akira, S. and Underhill, D. M. (2003) Collaborative induction of inflammatory responses by dectin-1 and Toll-like receptor 2. J Exp Med. 197, 1107-1117 Di Carlo, F. J. and Fiore, J. V. (1958) On the composition of zymosan. Science. 127, 756-757 Suram, S., Brown, G. D., Ghosh, M., Gordon, S., Loper, R., Taylor, P. R., Akira, S., Uematsu, S., Williams, D. L. and Leslie, C. C. (2006) Regulation of cytosolic phospholipase A2 activation and cyclooxygenase 2 expression in macrophages by the beta-glucan receptor. J Biol Chem. 281, 5506-5514

13 Kim, J. G., Moon, M. Y., Kim, H. J., Li, Y., Song, D. K., Kim, J. S., Lee, J. Y., Kim, J., Kim, S. C. and Park, J. B. Ras-related GTPases Rap1 and RhoA collectively induce the phagocytosis of serum-opsonized zymosan particles in macrophages. J Biol Chem. 287, 5145-5155

14 Xu, S., Huo, J., Gunawan, M., Su, I. H. and Lam, K. P. (2009) Activated dectin-1 localizes to lipid raft microdomains for signaling and activation of phagocytosis and cytokine production in dendritic cells. J Biol Chem. 284, 22005-22011

15 Hiller, G. and Sundler, R. (2002) Regulation of phospholipase C-gamma 2 via phosphatidylinositol 3-kinase in macrophages. Cell Signal. 14, 169-173

16 Dieter, P. and Fitzke, E. (1995) Differential regulation of phospholipase D and phospholipase C by protein kinase C-beta and -delta in liver macrophages. Cell Signal. 7, 687-694

17 Netea, M. G., van der Graaf, C., Van der Meer, J. W. and Kullberg, B. J. (2004) Toll-like receptors and the host defense against microbial pathogens: bringing specificity to the innate-immune system. J Leukoc Biol. 75, 749-755

Anderson, K. V., Bokla, L. and Nusslein-Volhard, C. (1985) Establishment of dorsal-ventral polarity in the Drosophila embryo: the induction of polarity by the Toll gene product. Cell. 42, 791-798 
Lemaitre, B., Nicolas, E., Michaut, L., Reichhart, J. M. and Hoffmann, J. A. (1996) The dorsoventral regulatory gene cassette spatzle/Toll/cactus controls the potent antifungal response in Drosophila adults. Cell. 86, 973-983

Kaisho, T. and Akira, S. (2001) Dendritic-cell function in Toll-like receptor- and MyD88knockout mice. Trends Immunol. 22, 78-83

Beutler, B., Jiang, Z., Georgel, P., Crozat, K., Croker, B., Rutschmann, S., Du, X. and Hoebe, K. (2006) Genetic analysis of host resistance: Toll-like receptor signaling and immunity at large. Annu Rev Immunol. 24, 353-389

Roach, J. C., Glusman, G., Rowen, L., Kaur, A., Purcell, M. K., Smith, K. D., Hood, L. E. and Aderem, A. (2005) The evolution of vertebrate Toll-like receptors. Proc Natl Acad Sci U S A. 102, 9577-9582

Underhill, D. M., Ozinsky, A., Hajjar, A. M., Stevens, A., Wilson, C. B., Bassetti, M. and Aderem, A. (1999) The Toll-like receptor 2 is recruited to macrophage phagosomes and discriminates between pathogens. Nature. 401, 811-815

Takeda, K., Takeuchi, O. and Akira, S. (2002) Recognition of lipopeptides by Toll-like receptors. J Endotoxin Res. 8, 459-463

Ozinsky, A., Underhill, D. M., Fontenot, J. D., Hajjar, A. M., Smith, K. D., Wilson, C. B., Schroeder, L. and Aderem, A. (2000) The repertoire for pattern recognition of pathogens by the innate immune system is defined by cooperation between toll-like receptors. Proc Natl Acad Sci U S A. 97, 13766-13771

Stahl, P. D., Rodman, J. S., Miller, M. J. and Schlesinger, P. H. (1978) Evidence for receptormediated binding of glycoproteins, glycoconjugates, and lysosomal glycosidases by alveolar macrophages. Proc Natl Acad Sci U S A. 75, 1399-1403

27 Taylor, P. R., Gordon, S. and Martinez-Pomares, L. (2005) The mannose receptor: linking homeostasis and immunity through sugar recognition. Trends Immunol. 26, 104-110

28 Stahl, P. D. and Ezekowitz, R. A. (1998) The mannose receptor is a pattern recognition receptor involved in host defense. Curr Opin Immunol. 10, 50-55

29 Taylor, P. R., Brown, G. D., Reid, D. M., Willment, J. A., Martinez-Pomares, L., Gordon, S. and Wong, S. Y. (2002) The beta-glucan receptor, dectin-1, is predominantly expressed on the surface of cells of the monocyte/macrophage and neutrophil lineages. J Immunol. 169, 3876-3882

Brown, G. D., Taylor, P. R., Reid, D. M., Willment, J. A., Williams, D. L., Martinez-Pomares, L., Wong, S. Y. and Gordon, S. (2002) Dectin-1 is a major beta-glucan receptor on macrophages. J Exp Med. 196, 407-412

Goodridge, H. S., Simmons, R. M. and Underhill, D. M. (2007) Dectin-1 stimulation by Candida albicans yeast or zymosan triggers NFAT activation in macrophages and dendritic cells. J Immunol. 178, 3107-3115

Gantner, B. N., Simmons, R. M. and Underhill, D. M. (2005) Dectin-1 mediates macrophage recognition of Candida albicans yeast but not filaments. EMBO J. 24, 1277-1286

Saijo, S., Fujikado, N., Furuta, T., Chung, S. H., Kotaki, H., Seki, K., Sudo, K., Akira, S., Adachi, Y., Ohno, N., Kinjo, T., Nakamura, K., Kawakami, K. and Iwakura, Y. (2007) Dectin-1 is required for host defense against Pneumocystis carinii but not against Candida albicans. Nat Immunol. 8, 39-46

Taylor, P. R., Tsoni, S. V., Willment, J. A., Dennehy, K. M., Rosas, M., Findon, H., Haynes, K., Steele, C., Botto, M., Gordon, S. and Brown, G. D. (2007) Dectin-1 is required for betaglucan recognition and control of fungal infection. Nat Immunol. 8, 31-38

Underhill, D. M., Rossnagle, E., Lowell, C. A. and Simmons, R. M. (2005) Dectin-1 activates Syk tyrosine kinase in a dynamic subset of macrophages for reactive oxygen production. Blood. 106, 2543-2550 
Le Cabec, V., Carreno, S., Moisand, A., Bordier, C. and Maridonneau-Parini, I. (2002) Complement receptor 3 (CD11b/CD18) mediates type I and type II phagocytosis during nonopsonic and opsonic phagocytosis, respectively. J Immunol. 169, 2003-2009

37 Daeron, M. (1997) Fc receptor biology. Annu Rev Immunol. 15, 203-234

38 Rudders, R. A. and Andersen, J. (1982) IgD-Fc receptors on normal and neoplastic human B lymphocytes. Clin Exp Immunol. 50, 579-586

39 Ravetch, J. V. and Bolland, S. (2001) IgG Fc receptors. Annu Rev Immunol. 19, 275-290

40 Nimmerjahn, F. and Ravetch, J. V. (2007) Fc-receptors as regulators of immunity. Adv Immunol. 96, 179-204

41 Qiao, H., Andrade, M. V., Lisboa, F. A., Morgan, K. and Beaven, M. A. (2006) FcepsilonR1 and toll-like receptors mediate synergistic signals to markedly augment production of inflammatory cytokines in murine mast cells. Blood. 107, 610-618

42 Monteiro, R. C. and Van De Winkel, J. G. (2003) IgA Fc receptors. Annu Rev Immunol. 21, 177-204

43 Shibuya, A., Sakamoto, N., Shimizu, Y., Shibuya, K., Osawa, M., Hiroyama, T., Eyre, H. J., Sutherland, G. R., Endo, Y., Fujita, T., Miyabayashi, T., Sakano, S., Tsuji, T., Nakayama, E., Phillips, J. H., Lanier, L. L. and Nakauchi, H. (2000) Fc alpha/mu receptor mediates endocytosis of IgM-coated microbes. Nat Immunol. 1, 441-446

44 Aderem, A. A., Wright, S. D., Silverstein, S. C. and Cohn, Z. A. (1985) Ligated complement receptors do not activate the arachidonic acid cascade in resident peritoneal macrophages. J Exp Med. 161, 617-622

45 Muto, S., Vetvicka, V. and Ross, G. D. (1993) CR3 (CD11b/CD18) expressed by cytotoxic T cells and natural killer cells is upregulated in a manner similar to neutrophil CR3 following stimulation with various activating agents. J Clin Immunol. 13, 175-184

46 Le Cabec, V., Cols, C. and Maridonneau-Parini, I. (2000) Nonopsonic phagocytosis of zymosan and Mycobacterium kansasii by CR3 (CD11b/CD18) involves distinct molecular determinants and is or is not coupled with NADPH oxidase activation. Infect Immun. 68, 4736-4745

47 Elsori, D. H., Yakubenko, V. P., Roome, T., Thiagarajan, P. S., Bhattacharjee, A., Yadav, S. P. and Cathcart, M. K. (2011) Protein kinase Cdelta is a critical component of Dectin-1 signaling in primary human monocytes. J Leukoc Biol. 90, 599-611

48 Funk, C. D. (2001) Prostaglandins and leukotrienes: advances in eicosanoid biology. Science. 294, 1871-1875

49 Phillis, J. W., Horrocks, L. A. and Farooqui, A. A. (2006) Cyclooxygenases, lipoxygenases, and epoxygenases in CNS: their role and involvement in neurological disorders. Brain Res Rev. 52, 201-243

50 Folco, G. and Murphy, R. C. (2006) Eicosanoid transcellular biosynthesis: from cell-cell interactions to in vivo tissue responses. Pharmacol Rev. 58, 375-388

51 Soberman, R. J. and Christmas, P. (2003) The organization and consequences of eicosanoid signaling. J Clin Invest. 111, 1107-1113

52 Zhou, L. and Nilsson, A. (2001) Sources of eicosanoid precursor fatty acid pools in tissues. J Lipid Res. 42, 1521-1542

53 Minich, D. M., Vonk, R. J. and Verkade, H. J. (1997) Intestinal absorption of essential fatty acids under physiological and essential fatty acid-deficient conditions. J Lipid Res. 38, 17091721

54 Fisher, G. J., Talwar, H. S., Ryder, N. S. and Voorhees, J. J. (1989) Differential activation of human skin cells by platelet activating factor: stimulation of phosphoinositide turnover and arachidonic acid mobilization in keratinocytes but not in fibroblasts. Biochem Biophys Res Commun. 163, 1344-1350 
Brindley, D. N., McCann, B. S., Niaura, R., Stoney, C. M. and Suarez, E. C. (1993) Stress and lipoprotein metabolism: modulators and mechanisms. Metabolism. 42, 3-15

Horrobin, D. F., Huang, Y. S., Cunnane, S. C. and Manku, M. S. (1984) Essential fatty acids in plasma, red blood cells and liver phospholipids in common laboratory animals as compared to humans. Lipids. 19, 806-811

57 Cao, Y., Pearman, A. T., Zimmerman, G. A., McIntyre, T. M. and Prescott, S. M. (2000) Intracellular unesterified arachidonic acid signals apoptosis. Proc Natl Acad Sci U S A. 97, 11280-11285

Balsinde, J. and Dennis, E. A. (1996) Distinct roles in signal transduction for each of the phospholipase A2 enzymes present in P388D1 macrophages. J Biol Chem. 271, 6758-6765 Serini, S., Piccioni, E., Merendino, N. and Calviello, G. (2009) Dietary polyunsaturated fatty acids as inducers of apoptosis: implications for cancer. Apoptosis. 14, 135-152

Guijas, C., Astudillo, A. M., Gil-de-Gomez, L., Rubio, J. M., Balboa, M. A. and Balsinde, J. (2012) Phospholipid sources for adrenic acid mobilization in RAW 264.7 macrophages. Comparison with arachidonic acid. Biochim Biophys Acta. 1821, 1386-1393

Sprecher, H., VanRollins, M., Sun, F., Wyche, A. and Needleman, P. (1982) Dihomoprostaglandins and -thromboxane. A prostaglandin family from adrenic acid that may be preferentially synthesized in the kidney. J Biol Chem. 257, 3912-3918

VanRollins, M., Horrocks, L. and Sprecher, H. (1985) Metabolism of 7,10,13,16docosatetraenoic acid to dihomo-thromboxane, 14-hydroxy-7,10,12-nonadecatrienoic acid and hydroxy fatty acids by human platelets. Biochim Biophys Acta. 833, 272-280

Kopf, P. G., Zhang, D. X., Gauthier, K. M., Nithipatikom, K., Yi, X. Y., Falck, J. R. and Campbell, W. B. (2010) Adrenic acid metabolites as endogenous endothelium-derived and zona glomerulosa-derived hyperpolarizing factors. Hypertension. 55, 547-554

Harkewicz, R., Fahy, E., Andreyev, A. and Dennis, E. A. (2007) Arachidonate-derived dihomoprostaglandin production observed in endotoxin-stimulated macrophage-like cells. J Biol Chem. 282, 2899-2910

65 Dackor, R. T., Cheng, J., Voltz, J. W., Card, J. W., Ferguson, C. D., Garrett, R. C., Bradbury, J. A., DeGraff, L. M., Lih, F. B., Tomer, K. B., Flake, G. P., Travlos, G. S., Ramsey, R. W., Jr., Edin, M. L., Morgan, D. L. and Zeldin, D. C. (2011) Prostaglandin E(2) protects murine lungs from bleomycin-induced pulmonary fibrosis and lung dysfunction. Am J Physiol Lung Cell Mol Physiol. 301, L645-655

Farooqui, A. A. (2011) Lipid mediators and their metabolism in the nucleous: implications for Alzheimer's disease. J Alzheimers Dis. 30 Suppl 2, S163-178

67 Burnett, B. P. and Levy, R. M. (2012) 5-Lipoxygenase metabolic contributions to NSAIDinduced organ toxicity. Adv Ther. 29, 79-98

68 Zhu, D. and Ran, Y. (2012) Role of 15-lipoxygenase/15-hydroxyeicosatetraenoic acid in hypoxia-induced pulmonary hypertension. J Physiol Sci. 62, 163-172

69 Irvine, R. F. (1982) How is the level of free arachidonic acid controlled in mammalian cells? Biochem J. 204, 3-16

70 Flesch, I., Schonhardt, T. and Ferber, E. (1989) Phospholipases and acyltransferases in macrophages. Klin Wochenschr. 67, 119-122

71 Chilton, F. H. and Murphy, R. C. (1986) Remodeling of arachidonate-containing phosphoglycerides within the human neutrophil. J Biol Chem. 261, 7771-7777

Angle, M. J., Paltauf, F. and Johnston, J. M. (1988) Selective hydrolysis of ether-containing glycerophospholipids by phospholipase A2 in rabbit lung. Biochim Biophys Acta. 962, 234240

73 Mancini, A., Del Rosso, F., Roberti, R., Orvietani, P., Coletti, L. and Binaglia, L. (1999) Purification of ethanolaminephosphotransferase from bovine liver microsomes. Biochim Biophys Acta. 1437, 80-92 
74 Brites, P., Waterham, H. R. and Wanders, R. J. (2004) Functions and biosynthesis of plasmalogens in health and disease. Biochim Biophys Acta. 1636, 219-231

75 Lee, T. C., Qian, C. G. and Snyder, F. (1991) Biosynthesis of choline plasmalogens in neonatal rat myocytes. Arch Biochem Biophys. 286, 498-503

76 da Silva, T. F., Sousa, V. F., Malheiro, A. R. and Brites, P. (2012) The importance of etherphospholipids: A view from the perspective of mouse models. Biochim Biophys Acta. 1822, 1501-1508

Leslie, C. C. (2004) Regulation of arachidonic acid availability for eicosanoid production. Biochem Cell Biol. 82, 1-17

Astudillo, A. M., Balgoma, D., Balboa, M. A. and Balsinde, J. (2012) Dynamics of arachidonic acid mobilization by inflammatory cells. Biochim Biophys Acta. 1821, 249-256

Chilton, F. H., Fonteh, A. N., Surette, M. E., Triggiani, M. and Winkler, J. D. (1996) Control of arachidonate levels within inflammatory cells. Biochim Biophys Acta. 1299, 1-15

Perez-Chacon, G., Astudillo, A. M., Ruiperez, V., Balboa, M. A. and Balsinde, J. (2009) Signaling role for lysophosphatidylcholine acyltransferase 3 in receptor-regulated arachidonic acid reacylation reactions in human monocytes. J Immunol. 184, 1071-1078

Kang, D., Takeshige, K. and Minakami, S. (1987) [The role of Ca2+ in metabolisms and functions of neutrophils]. Ryumachi. 27, 47-57

Cao, Y., Traer, E., Zimmerman, G. A., McIntyre, T. M. and Prescott, S. M. (1998) Cloning, expression, and chromosomal localization of human long-chain fatty acid-CoA ligase 4 (FACL4). Genomics. 49, 327-330

83 Shindou, H., Eto, M., Morimoto, R. and Shimizu, T. (2009) Identification of membrane Oacyltransferase family motifs. Biochem Biophys Res Commun. 383, 320-325

84 Shindou, H. and Shimizu, T. (2009) Acyl-CoA:lysophospholipid acyltransferases. J Biol Chem. 284, 1-5

85 Zhao, Y., Chen, Y. Q., Bonacci, T. M., Bredt, D. S., Li, S., Bensch, W. R., Moller, D. E., Kowala, M., Konrad, R. J. and Cao, G. (2008) Identification and characterization of a major liver lysophosphatidylcholine acyltransferase. J Biol Chem. 283, 8258-8265

Gijon, M. A., Riekhof, W. R., Zarini, S., Murphy, R. C. and Voelker, D. R. (2008) Lysophospholipid acyltransferases and arachidonate recycling in human neutrophils. J Biol Chem. 283, 30235-30245

Lee, H. C., Inoue, T., Imae, R., Kono, N., Shirae, S., Matsuda, S., Gengyo-Ando, K., Mitani, S. and Arai, H. (2008) Caenorhabditis elegans mboa-7, a member of the MBOAT family, is required for selective incorporation of polyunsaturated fatty acids into phosphatidylinositol. Mol Biol Cell. 19, 1174-1184

88 Yuki, K., Shindou, H., Hishikawa, D. and Shimizu, T. (2009) Characterization of mouse Iysophosphatidic acid acyltransferase 3: an enzyme with dual functions in the testis. J Lipid Res. 50, 860-869

89 Kennedy, E. P. and Weiss, S. B. (1956) The function of cytidine coenzymes in the biosynthesis of phospholipides. J Biol Chem. 222, 193-214

90 Balgoma, D., Montero, O., Balboa, M. A. and Balsinde, J. (2008) Calcium-independent phospholipase A2-mediated formation of 1,2-diarachidonoyl-glycerophosphoinositol in monocytes. FEBS J. 275, 6180-6191

91 Weeks, R., Dowhan, W., Shen, H., Balantac, N., Meengs, B., Nudelman, E. and Leung, D. W. (1997) Isolation and expression of an isoform of human CDP-diacylglycerol synthase cDNA. DNA Cell Biol. 16, 281-289

92 Lands, W. E. (1958) Metabolism of glycerolipides; a comparison of lecithin and triglyceride synthesis. J Biol Chem. 231, 883-888 
Balsinde, J. (2002) Roles of various phospholipases A2 in providing lysophospholipid acceptors for fatty acid phospholipid incorporation and remodelling. Biochem J. 364, 695702

94 Nieto, M. L., Venable, M. E., Bauldry, S. A., Greene, D. G., Kennedy, M., Bass, D. A. and Wykle, R. L. (1991) Evidence that hydrolysis of ethanolamine plasmalogens triggers synthesis of platelet-activating factor via a transacylation reaction. J Biol Chem. 266, 1869918706

95 Astudillo, A. M., Perez-Chacon, G., Balgoma, D., Gil-de-Gomez, L., Ruiperez, V., Guijas, C., Balboa, M. A. and Balsinde, J. (2011) Influence of cellular arachidonic acid levels on phospholipid remodeling and CoA-independent transacylase activity in human monocytes and $U 937$ cells. Biochim Biophys Acta. 1811, 97-103

96 Winkler, J. D., Bolognese, B. J., Roshak, A. K., Sung, C. M. and Marshall, L. A. (1997) Evidence that $85 \mathrm{kDa}$ phospholipase A2 is not linked to CoA-independent transacylasemediated production of platelet-activating factor in human monocytes. Biochim Biophys Acta. 1346, 173-184

97 Bonventre, J. V., Huang, Z., Taheri, M. R., O'Leary, E., Li, E., Moskowitz, M. A. and Sapirstein, A. (1997) Reduced fertility and postischaemic brain injury in mice deficient in cytosolic phospholipase A2. Nature. 390, 622-625

Kramer, R. M., Stephenson, D. T., Roberts, E. F. and Clemens, J. A. (1996) Cytosolic phospholipase A2 (CPLA2) and lipid mediator release in the brain. J Lipid Mediat Cell Signal. 14, 3-7

99 Balsinde, J., Balboa, M. A. and Dennis, E. A. (1998) Functional coupling between secretory phospholipase A2 and cyclooxygenase-2 and its regulation by cytosolic group IV phospholipase A2. Proc Natl Acad Sci U S A. 95, 7951-7956

100 Balsinde, J., Winstead, M. V. and Dennis, E. A. (2002) Phospholipase A(2) regulation of arachidonic acid mobilization. FEBS Lett. 531, 2-6

101 Balsinde, J., Fernandez, B. and Solis-Herruzo, J. A. (1994) Increased incorporation of arachidonic acid into phospholipids in zymosan-stimulated mouse peritoneal macrophages. Eur J Biochem. 221, 1013-1018

102 Perez-Chacon, G., Astudillo, A. M., Ruiperez, V., Balboa, M. A. and Balsinde, J. (2010) Signaling role for lysophosphatidylcholine acyltransferase 3 in receptor-regulated arachidonic acid reacylation reactions in human monocytes. J Immunol. 184, 1071-1078

103 Balsinde, J., Fernandez, B., Solis-Herruzo, J. A. and Diez, E. (1992) Pathways for arachidonic acid mobilization in zymosan-stimulated mouse peritoneal macrophages. Biochim Biophys Acta. 1136, 75-82

104 Six, D. A. and Dennis, E. A. (2000) The expanding superfamily of phospholipase $A(2)$ enzymes: classification and characterization. Biochim Biophys Acta. 1488, 1-19

105 Kudo, I. and Murakami, M. (2002) Phospholipase A2 enzymes. Prostaglandins Other Lipid Mediat. 68-69, 3-58

106 Schaloske, R. H. and Dennis, E. A. (2006) The phospholipase A2 superfamily and its group numbering system. Biochim Biophys Acta. 1761, 1246-1259

107 Burke, J. E. and Dennis, E. A. (2009) Phospholipase A2 structure/function, mechanism, and signaling. J Lipid Res. 50 Suppl, S237-242

108 Marone, G., Fimiani, B., Torella, G., Poto, S., Bianco, P. and Condorelli, M. (1983) Possible role of arachidonic acid and of phospholipase A2 in the control of lysosomal enzyme release from human polymorphonuclear leukocytes. J Clin Lab Immunol. 12, 111-116

109 Qiu, Z. H., de Carvalho, M. S. and Leslie, C. C. (1993) Regulation of phospholipase A2 activation by phosphorylation in mouse peritoneal macrophages. J Biol Chem. 268, 2450624513 
110 Satake, Y., Diaz, B. L., Balestrieri, B., Lam, B. K., Kanaoka, Y., Grusby, M. J. and Arm, J. P. (2004) Role of group $V$ phospholipase A2 in zymosan-induced eicosanoid generation and vascular permeability revealed by targeted gene disruption. J Biol Chem. 279, 16488-16494

111 Balestrieri, B., Hsu, V. W., Gilbert, H., Leslie, C. C., Han, W. K., Bonventre, J. V. and Arm, J. P. (2006) Group V secretory phospholipase A2 translocates to the phagosome after zymosan stimulation of mouse peritoneal macrophages and regulates phagocytosis. J Biol Chem. 281, 6691-6698

112 Diaz, B. L., Satake, Y., Kikawada, E., Balestrieri, B. and Arm, J. P. (2006) Group V secretory phospholipase A2 amplifies the induction of cyclooxygenase 2 and delayed prostaglandin D2 generation in mouse bone marrow culture-derived mast cells in a strain-dependent manner. Biochim Biophys Acta. 1761, 1489-1497

113 Kramer, R. M., Checani, G. C., Deykin, A., Pritzker, C. R. and Deykin, D. (1986) Solubilization and properties of $\mathrm{Ca} 2+-$ dependent human platelet phospholipase A2. Biochim Biophys Acta. 878, 394-403

114 Alonso, F., Henson, P. M. and Leslie, C. C. (1986) A cytosolic phospholipase in human neutrophils that hydrolyzes arachidonoyl-containing phosphatidylcholine. Biochim Biophys Acta. 878, 273-280

115 Clark, J. D., Lin, L. L., Kriz, R. W., Ramesha, C. S., Sultzman, L. A., Lin, A. Y., Milona, N. and Knopf, J. L. (1991) A novel arachidonic acid-selective cytosolic PLA2 contains a Ca(2+)dependent translocation domain with homology to PKC and GAP. Cell. 65, 1043-1051

116 Kramer, R. M., Roberts, E. F., Manetta, J. and Putnam, J. E. (1991) The Ca2(+)-sensitive cytosolic phospholipase A2 is a 100-kDa protein in human monoblast U937 cells. J Biol Chem. 266, 5268-5272

117 Tay, A., Simon, J. S., Squire, J., Hamel, K., Jacob, H. J. and Skorecki, K. (1995) Cytosolic phospholipase $\mathrm{A} 2$ gene in human and rat: chromosomal localization and polymorphic markers. Genomics. 26, 138-141

118 Ghosh, M., Tucker, D. E., Burchett, S. A. and Leslie, C. C. (2006) Properties of the Group IV phospholipase A2 family. Prog Lipid Res. 45, 487-510

119 Gijon, M. A., Spencer, D. M., Siddiqi, A. R., Bonventre, J. V. and Leslie, C. C. (2000) Cytosolic phospholipase $A 2$ is required for macrophage arachidonic acid release by agonists that Do and Do not mobilize calcium. Novel role of mitogen-activated protein kinase pathways in cytosolic phospholipase A2 regulation. J Biol Chem. 275, 20146-20156

120 Leslie, C. C., Voelker, D. R., Channon, J. Y., Wall, M. M. and Zelarney, P. T. (1988) Properties and purification of an arachidonoyl-hydrolyzing phospholipase A2 from a macrophage cell line, RAW 264.7. Biochim Biophys Acta. 963, 476-492

121 Gijon, M. A., Spencer, D. M., Kaiser, A. L. and Leslie, C. C. (1999) Role of phosphorylation sites and the C2 domain in regulation of cytosolic phospholipase A2. J Cell Biol. 145, 12191232

122 Qiu, Z. H., Gijon, M. A., de Carvalho, M. S., Spencer, D. M. and Leslie, C. C. (1998) The role of calcium and phosphorylation of cytosolic phospholipase $\mathrm{A} 2$ in regulating arachidonic acid release in macrophages. J Biol Chem. 273, 8203-8211

123 Lin, W. W. and Chen, B. C. (1998) Distinct PKC isoforms mediate the activation of CPLA2 and adenylyl cyclase by phorbol ester in RAW264.7 macrophages. Br J Pharmacol. 125, 16011609

124 Del Bufalo, A., Bernad, J., Dardenne, C., Verda, D., Meunier, J. R., Rousset, F., MartinozziTeissier, S. and Pipy, B. Contact sensitizers modulate the arachidonic acid metabolism of PMA-differentiated U-937 monocytic cells activated by LPS. Toxicol Appl Pharmacol. 256, 35-43

125 Balsinde, J. (1993) Mechanism of arachidonic acid liberation in ethanol-treated mouse peritoneal macrophages. Biochim Biophys Acta. 1169, 54-58 
126 Balsinde, J., Balboa, M. A., Li, W. H., Llopis, J. and Dennis, E. A. (2000) Cellular regulation of cytosolic group IV phospholipase A2 by phosphatidylinositol bisphosphate levels. J Immunol. 164, 5398-5402

127 Reynolds, L. J., Hughes, L. L., Louis, A. I., Kramer, R. M. and Dennis, E. A. (1993) Metal ion and salt effects on the phospholipase A2, lysophospholipase, and transacylase activities of human cytosolic phospholipase A2. Biochim Biophys Acta. 1167, 272-280

128 Perisic, O., Fong, S., Lynch, D. E., Bycroft, M. and Williams, R. L. (1998) Crystal structure of a calcium-phospholipid binding domain from cytosolic phospholipase A2. J Biol Chem. 273, 1596-1604

129 Channon, J. Y. and Leslie, C. C. (1990) A calcium-dependent mechanism for associating a soluble arachidonoyl-hydrolyzing phospholipase $\mathrm{A} 2$ with membrane in the macrophage cell line RAW 264.7. J Biol Chem. 265, 5409-5413

130 Nalefski, E. A., Sultzman, L. A., Martin, D. M., Kriz, R. W., Towler, P. S., Knopf, J. L. and Clark, J. D. (1994) Delineation of two functionally distinct domains of cytosolic phospholipase A2, a regulatory $\mathrm{Ca}(2+)$-dependent lipid-binding domain and a $\mathrm{Ca}(2+)$-independent catalytic domain. J Biol Chem. 269, 18239-18249

131 Glover, S., de Carvalho, M. S., Bayburt, T., Jonas, M., Chi, E., Leslie, C. C. and Gelb, M. H. (1995) Translocation of the 85-kDa phospholipase A2 from cytosol to the nuclear envelope in rat basophilic leukemia cells stimulated with calcium ionophore or IgE/antigen. J Biol Chem. 270, 15359-15367

132 Schievella, A. R., Regier, M. K., Smith, W. L. and Lin, L. L. (1995) Calcium-mediated translocation of cytosolic phospholipase $A 2$ to the nuclear envelope and endoplasmic reticulum. J Biol Chem. 270, 30749-30754

133 Sierra-Honigmann, M. R., Bradley, J. R. and Pober, J. S. (1996) "Cytosolic" phospholipase A2 is in the nucleus of subconfluent endothelial cells but confined to the cytoplasm of confluent endothelial cells and redistributes to the nuclear envelope and cell junctions upon histamine stimulation. Lab Invest. 74, 684-695

134 Nakatani, Y., Tanioka, T., Sunaga, S., Murakami, M. and Kudo, I. (2000) Identification of a cellular protein that functionally interacts with the C2 domain of cytosolic phospholipase A(2)alpha. J Biol Chem. 275, 1161-1168

135 Dessen, A., Tang, J., Schmidt, H., Stahl, M., Clark, J. D., Seehra, J. and Somers, W. S. (1999) Crystal structure of human cytosolic phospholipase A2 reveals a novel topology and catalytic mechanism. Cell. 97, 349-360

136 Burke, J. E., Hsu, Y. H., Deems, R. A., Li, S., Woods, V. L., Jr. and Dennis, E. A. (2008) A phospholipid substrate molecule residing in the membrane surface mediates opening of the lid region in group IVA cytosolic phospholipase A2. J Biol Chem. 283, 31227-31236

137 Lin, L. L., Wartmann, M., Lin, A. Y., Knopf, J. L., Seth, A. and Davis, R. J. (1993) CPLA2 is phosphorylated and activated by MAP kinase. Cell. 72, 269-278

138 Girotti, M., Evans, J. H., Burke, D. and Leslie, C. C. (2004) Cytosolic phospholipase A2 translocates to forming phagosomes during phagocytosis of zymosan in macrophages. J Biol Chem. 279, 19113-19121

139 Casas, J., Meana, C., Esquinas, E., Valdearcos, M., Pindado, J., Balsinde, J. and Balboa, M. A. (2009) Requirement of JNK-mediated phosphorylation for translocation of group IVA phospholipase A2 to phagosomes in human macrophages. J Immunol. 183, 2767-2774

140 Kramer, R. M., Roberts, E. F., Um, S. L., Borsch-Haubold, A. G., Watson, S. P., Fisher, M. J. and Jakubowski, J. A. (1996) p38 mitogen-activated protein kinase phosphorylates cytosolic phospholipase A2 (CPLA2) in thrombin-stimulated platelets. Evidence that proline-directed phosphorylation is not required for mobilization of arachidonic acid by CPLA2. J Biol Chem. 271, 27723-27729 
141 Nakamura, H., Hirabayashi, T., Shimizu, M. and Murayama, T. (2006) Ceramide-1phosphate activates cytosolic phospholipase A2alpha directly and by PKC pathway. Biochem Pharmacol. 71, 850-857

142 Lamour, N. F., Subramanian, P., Wijesinghe, D. S., Stahelin, R. V., Bonventre, J. V. and Chalfant, C. E. (2009) Ceramide 1-phosphate is required for the translocation of group IVA cytosolic phospholipase A2 and prostaglandin synthesis. J Biol Chem. 284, 26897-26907

143 Leslie, C. C. and Channon, J. Y. (1990) Anionic phospholipids stimulate an arachidonoylhydrolyzing phospholipase $A 2$ from macrophages and reduce the calcium requirement for activity. Biochim Biophys Acta. 1045, 261-270

144 Casas, J., Gijon, M. A., Vigo, A. G., Crespo, M. S., Balsinde, J. and Balboa, M. A. (2006) Phosphatidylinositol 4,5-bisphosphate anchors cytosolic group IVA phospholipase A2 to perinuclear membranes and decreases its calcium requirement for translocation in live cells. Mol Biol Cell. 17, 155-162

145 Das, S. and Cho, W. (2002) Roles of catalytic domain residues in interfacial binding and activation of group IV cytosolic phospholipase A2. J Biol Chem. 277, 23838-23846

146 Casas, J., Valdearcos, M., Pindado, J., Balsinde, J. and Balboa, M. A. (2010) The cationic cluster of group IVA phospholipase A2 (Lys488/Lys541/Lys543/Lys544) is involved in translocation of the enzyme to phagosomes in human macrophages. J Lipid Res. 51, 388399

147 Hirabayashi, T., Murayama, T. and Shimizu, T. (2004) Regulatory mechanism and physiological role of cytosolic phospholipase A2. Biol Pharm Bull. 27, 1168-1173

148 Kwon, J. H., Lee, J. H., Kim, K. S., Chung, Y. W. and Kim, I. Y. (2012) Regulation of cytosolic phospholipase A2 phosphorylation by proteolytic cleavage of annexin A1 in activated mast cells. J Immunol. 188, 5665-5673

149 Chakraborti, S., Roy, S., Mandal, A., Dey, K., Chowdhury, A., Shaikh, S. and Chakraborti, T. (2012) Role of PKCalpha-p(38)MAPK-G(i)alpha axis in NADPH oxidase derived O(2)(.-)mediated activation of CPLA(2) under U46619 stimulation in pulmonary artery smooth muscle cells. Arch Biochem Biophys. 523, 169-180

150 Clark, J. D., Schievella, A. R., Nalefski, E. A. and Lin, L. L. (1995) Cytosolic phospholipase A2. J Lipid Mediat Cell Signal. 12, 83-117

151 Leslie, C. C. (1997) Properties and regulation of cytosolic phospholipase A2. J Biol Chem. 272, 16709-16712

152 Lin, L. L., Lin, A. Y. and DeWitt, D. L. (1992) Interleukin-1 alpha induces the accumulation of cytosolic phospholipase A2 and the release of prostaglandin E2 in human fibroblasts. J Biol Chem. 267, 23451-23454

153 Buczynski, M. W., Dumlao, D. S. and Dennis, E. A. (2009) Thematic Review Series: Proteomics. An integrated omics analysis of eicosanoid biology. J Lipid Res. 50, 1015-1038

154 Samuelsson, B., Dahlen, S. E., Lindgren, J. A., Rouzer, C. A. and Serhan, C. N. (1987) Leukotrienes and lipoxins: structures, biosynthesis, and biological effects. Science. 237, 1171-1176

155 Feltenmark, S., Gautam, N., Brunnstrom, A., Griffiths, W., Backman, L., Edenius, C., Lindbom, L., Bjorkholm, M. and Claesson, H. E. (2008) Eoxins are proinflammatory arachidonic acid metabolites produced via the 15-lipoxygenase-1 pathway in human eosinophils and mast cells. Proc Natl Acad Sci U S A. 105, 680-685

156 Fredman, G. and Serhan, C. N. (2011) Specialized proresolving mediator targets for RvE1 and RvD1 in peripheral blood and mechanisms of resolution. Biochem J. 437, 185-197

157 Janakiram, N. B., Mohammed, A. and Rao, C. V. (2011) Role of lipoxins, resolvins, and other bioactive lipids in colon and pancreatic cancer. Cancer Metastasis Rev. 30, 507-523

158 Schwab, J. M. and Serhan, C. N. (2006) Lipoxins and new lipid mediators in the resolution of inflammation. Curr Opin Pharmacol. 6, 414-420 
159 Sacerdoti, D., Gatta, A. and McGiff, J. C. (2003) Role of cytochrome P450-dependent arachidonic acid metabolites in liver physiology and pathophysiology. Prostaglandins Other Lipid Mediat. 72, 51-71

160 Fang, X., Kaduce, T. L., Weintraub, N. L., Harmon, S., Teesch, L. M., Morisseau, C., Thompson, D. A., Hammock, B. D. and Spector, A. A. (2001) Pathways of epoxyeicosatrienoic acid metabolism in endothelial cells. Implications for the vascular effects of soluble epoxide hydrolase inhibition. J Biol Chem. 276, 14867-14874

161 Vanella, L., Kim, D. H., Sodhi, K., Barbagallo, I., Burgess, A. P., Falck, J. R., Schwartzman, M. L. and Abraham, N. G. (2011) Crosstalk between EET and HO-1 downregulates Bach1 and adipogenic marker expression in mesenchymal stem cell derived adipocytes. Prostaglandins Other Lipid Mediat. 96, 54-62

162 Jahn, U., Galano, J. M. and Durand, T. (2008) Beyond prostaglandins--chemistry and biology of cyclic oxygenated metabolites formed by free-radical pathways from polyunsaturated fatty acids. Angew Chem Int Ed Engl. 47, 5894-5955

163 Calder, P. C. (2009) Fatty acids and immune function: relevance to inflammatory bowel diseases. Int Rev Immunol. 28, 506-534

164 Harizi, H., Corcuff, J. B. and Gualde, N. (2008) Arachidonic-acid-derived eicosanoids: roles in biology and immunopathology. Trends Mol Med. 14, 461-469

165 Fonteh, A. N. and Chilton, F. H. (1992) Rapid remodeling of arachidonate from phosphatidylcholine to phosphatidylethanolamine pools during mast cell activation. J Immunol. 148, 1784-1791

166 Brugger, B., Erben, G., Sandhoff, R., Wieland, F. T. and Lehmann, W. D. (1997) Quantitative analysis of biological membrane lipids at the low picomole level by nano-electrospray ionization tandem mass spectrometry. Proc Natl Acad Sci U S A. 94, 2339-2344

167 Haroldsen, P. E. and Murphy, R. C. (1987) Analysis of phospholipid molecular species in rat lung as dinitrobenzoate diglycerides by electron capture negative chemical ionization mass spectrometry. Biomed Environ Mass Spectrom. 14, 573-578

168 Byrdwell, W. C. (2001) Atmospheric pressure chemical ionization mass spectrometry for analysis of lipids. Lipids. 36, 327-346

169 Petkovic, M., Schiller, J., Muller, M., Benard, S., Reichl, S., Arnold, K. and Arnhold, J. (2001) Detection of individual phospholipids in lipid mixtures by matrix-assisted laser desorption/ionization time-of-flight mass spectrometry: phosphatidylcholine prevents the detection of further species. Anal Biochem. 289, 202-216

170 Cole, M. J. and Enke, C. G. (1991) Direct determination of phospholipid structures in microorganisms by fast atom bombardment triple quadrupole mass spectrometry. Anal Chem. 63, 1032-1038

171 Uran, S., Larsen, A., Jacobsen, P. B. and Skotland, T. (2001) Analysis of phospholipid species in human blood using normal-phase liquid chromatography coupled with electrospray ionization ion-trap tandem mass spectrometry. J Chromatogr B Biomed Sci Appl. 758, 265275

172 Zhao, S., Jia, L., Gao, P., Li, Q., Lu, X., Li, J. and Xu, G. (2008) Study on the effect of eicosapentaenoic acid on phospholipids composition in membrane microdomains of tight junctions of epithelial cells by liquid chromatography/electrospray mass spectrometry. J Pharm Biomed Anal. 47, 343-350

173 Ivanova, P. T., Cerda, B. A., Horn, D. M., Cohen, J. S., McLafferty, F. W. and Brown, H. A. (2001) Electrospray ionization mass spectrometry analysis of changes in phospholipids in RBL-2H3 mastocytoma cells during degranulation. Proc Natl Acad Sci U S A. 98, 7152-7157

174 Koulman, A., Woffendin, G., Narayana, V. K., Welchman, H., Crone, C. and Volmer, D. A. (2009) High-resolution extracted ion chromatography, a new tool for metabolomics and 
lipidomics using a second-generation orbitrap mass spectrometer. Rapid Commun Mass Spectrom. 23, 1411-1418

175 Ejsing, C. S., Sampaio, J. L., Surendranath, V., Duchoslav, E., Ekroos, K., Klemm, R. W., Simons, K. and Shevchenko, A. (2009) Global analysis of the yeast lipidome by quantitative shotgun mass spectrometry. Proc Natl Acad Sci U S A. 106, 2136-2141

176 Griffiths, W. J., Jonsson, A. P., Liu, S., Rai, D. K. and Wang, Y. (2001) Electrospray and tandem mass spectrometry in biochemistry. Biochem J. 355, 545-561

177 Cui, Z. and Thomas, M. J. (2009) Phospholipid profiling by tandem mass spectrometry. J Chromatogr B Analyt Technol Biomed Life Sci. 877, 2709-2715

178 Larsen, A., Uran, S., Jacobsen, P. B. and Skotland, T. (2001) Collision-induced dissociation of glycero phospholipids using electrospray ion-trap mass spectrometry. Rapid Commun Mass Spectrom. 15, 2393-2398

179 Ekroos, K., Ejsing, C. S., Bahr, U., Karas, M., Simons, K. and Shevchenko, A. (2003) Charting molecular composition of phosphatidylcholines by fatty acid scanning and ion trap MS3 fragmentation. J Lipid Res. 44, 2181-2192

180 Jungalwala, F. B., Turel, R. J., Evans, J. E. and McCluer, R. H. (1975) Sensitive analysis of ethanolamine- and serine-containing phosphoglycerides by high-performance liquid chromatography. Biochem J. 145, 517-526

181 Kim, H. Y., Wang, T. C. and Ma, Y. C. (1994) Liquid chromatography/mass spectrometry of phospholipids using electrospray ionization. Anal Chem. 66, 3977-3982

182 Peterson, B. L. and Cummings, B. S. (2006) A review of chromatographic methods for the assessment of phospholipids in biological samples. Biomed Chromatogr. 20, 227-243

183 Fang, N., Yu, S. and Badger, T. M. (2003) LC-MS/MS analysis of lysophospholipids associated with soy protein isolate. J Agric Food Chem. 51, 6676-6682

184 Barroso, B. and Bischoff, R. (2005) LC-MS analysis of phospholipids and lysophospholipids in human bronchoalveolar lavage fluid. J Chromatogr B Analyt Technol Biomed Life Sci. 814, 21-28

185 Pacetti, D., Malavolta, M., Bocci, F., Boselli, E. and Frega, N. G. (2004) High-performance liquid chromatography/electrospray ionization ion-trap tandem mass spectrometric analysis and quantification of phosphatidylcholine molecular species in the serum of cystic fibrosis subjects supplemented with docosahexaenoic acid. Rapid Commun Mass Spectrom. 18, 2395-2400

186 Lesnefsky, E. J., Stoll, M. S., Minkler, P. E. and Hoppel, C. L. (2000) Separation and quantitation of phospholipids and lysophospholipids by high-performance liquid chromatography. Anal Biochem. 285, 246-254

187 Igbavboa, U., Hamilton, J., Kim, H. Y., Sun, G. Y. and Wood, W. G. (2002) A new role for apolipoprotein E: modulating transport of polyunsaturated phospholipid molecular species in synaptic plasma membranes. J Neurochem. 80, 255-261

188 Ogiso, H., Suzuki, T. and Taguchi, R. (2008) Development of a reverse-phase liquid chromatography electrospray ionization mass spectrometry method for lipidomics, improving detection of phosphatidic acid and phosphatidylserine. Anal Biochem. 375, 124131

189 Han, X., Yang, K. and Gross, R. W. (2012) Multi-dimensional mass spectrometry-based shotgun lipidomics and novel strategies for lipidomic analyses. Mass Spectrom Rev. 31, 134-178

190 Taguchi, R., Houjou, T., Nakanishi, H., Yamazaki, T., Ishida, M., Imagawa, M. and Shimizu, T. (2005) Focused lipidomics by tandem mass spectrometry. J Chromatogr B Analyt Technol Biomed Life Sci. 823, 26-36 
191 Balgoma, D., Astudillo, A. M., Perez-Chacon, G., Montero, O., Balboa, M. A. and Balsinde, J. (2011) Markers of monocyte activation revealed by lipidomic profiling of arachidonic acidcontaining phospholipids. J Immunol. 184, 3857-3865

192 Valdearcos, M., Esquinas, E., Meana, C., Gil-de-Gomez, L., Guijas, C., Balsinde, J. and Balboa, M. A. (2011) Subcellular localization and role of lipin-1 in human macrophages. J Immunol. 186, 6004-6013

193 Ivanova, P. T., Milne, S. B. and Brown, H. A. (2010) Identification of atypical ether-linked glycerophospholipid species in macrophages by mass spectrometry. J Lipid Res. 51, 15811590

194 Yang, J., Yang, S., Gao, X. and Yuan, Y. J. (2011) Integrative investigation of lipidome and signal pathways in human endothelial cells under oxidative stress. Mol Biosyst. 7, 24282440

195 Dennis, E. A., Deems, R. A., Harkewicz, R., Quehenberger, O., Brown, H. A., Milne, S. B., Myers, D. S., Glass, C. K., Hardiman, G., Reichart, D., Merrill, A. H., Jr., Sullards, M. C., Wang, E., Murphy, R. C., Raetz, C. R., Garrett, T. A., Guan, Z., Ryan, A. C., Russell, D. W., McDonald, J. G., Thompson, B. M., Shaw, W. A., Sud, M., Zhao, Y., Gupta, S., Maurya, M. R., Fahy, E. and Subramaniam, S. (2010) A mouse macrophage lipidome. J Biol Chem. 285, 3997639985

196 Norris, P. C., Reichart, D., Dumlao, D. S., Glass, C. K. and Dennis, E. A. (2011) Specificity of eicosanoid production depends on the TLR-4-stimulated macrophage phenotype. J Leukoc Biol. 90, 563-574

197 Andreyev, A. Y., Shen, Z., Guan, Z., Ryan, A., Fahy, E., Subramaniam, S., Raetz, C. R., Briggs, S. and Dennis, E. A. (2010) Application of proteomic marker ensembles to subcellular organelle identification. Mol Cell Proteomics. 9, 388-402

198 Cohn, Z. A. and Benson, B. (1965) THE DIFFERENTIATION OF MONONUCLEAR PHAGOCYTES. MORPHOLOGY, CYTOCHEMISTRY, AND BIOCHEMISTRY. J Exp Med. 121, 153-170

199 Bannenberg, G. L., Chiang, N., Ariel, A., Arita, M., Tjonahen, E., Gotlinger, K. H., Hong, S. and Serhan, C. N. (2005) Molecular circuits of resolution: formation and actions of resolvins and protectins. J Immunol. 174, 4345-4355

200 Leslie, C. C. and Detty, D. M. (1986) Arachidonic acid turnover in response to lipopolysaccharide and opsonized zymosan in human monocyte-derived macrophages. Biochem J. 236, 251-259

201 Bonney, R. J., Wightman, P. D., Davies, P., Sadowski, S. J., Kuehl, F. A., Jr. and Humes, J. L. (1978) Regulation of prostaglandin synthesis and of the selective release of lysosomal hydrolases by mouse peritoneal macrophages. Biochem J. 176, 433-442

202 Dennis, E. A., Cao, J., Hsu, Y. H., Magrioti, V. and Kokotos, G. (2011) Phospholipase A2 enzymes: physical structure, biological function, disease implication, chemical inhibition, and therapeutic intervention. Chem Rev. 111, 6130-6185

203 Kokotos, G., Hsu, Y. H., Burke, J. E., Baskakis, C., Kokotos, C. G., Magrioti, V. and Dennis, E. A. (2010) Potent and selective fluoroketone inhibitors of group VIA calcium-independent phospholipase A2. J Med Chem. 53, 3602-3610

204 Ghomashchi, F., Stewart, A., Hefner, Y., Ramanadham, S., Turk, J., Leslie, C. C. and Gelb, M. H. (2001) A pyrrolidine-based specific inhibitor of cytosolic phospholipase A(2)alpha blocks arachidonic acid release in a variety of mammalian cells. Biochim Biophys Acta. 1513, 160166

205 Balboa, M. A. and Balsinde, J. (2002) Involvement of calcium-independent phospholipase A2 in hydrogen peroxide-induced accumulation of free fatty acids in human U937 cells. J Biol Chem. 277, 40384-40389

206 Hazen, S. L., Zupan, L. A., Weiss, R. H., Getman, D. P. and Gross, R. W. (1991) Suicide inhibition of canine myocardial cytosolic calcium-independent phospholipase A2. 
Mechanism-based discrimination between calcium-dependent and -independent phospholipases A2. J Biol Chem. 266, 7227-7232

207 Balsinde, J. and Dennis, E. A. (1996) Bromoenol lactone inhibits magnesium-dependent phosphatidate phosphohydrolase and blocks triacylglycerol biosynthesis in mouse P388D1 macrophages. J Biol Chem. 271, 31937-31941

208 Bligh, E. G. and Dyer, W. J. (1959) A rapid method of total lipid extraction and purification. Can J Biochem Physiol. 37, 911-917

209 Thurnhofer, S. and Vetter, W. (2006) Application of ethyl esters and d3-methyl esters as internal standards for the gas chromatographic quantification of transesterified fatty acid methyl esters in food. J Agric Food Chem. 54, 3209-3214

210 Diez, E., Balsinde, J., Aracil, M. and Schuller, A. (1987) Ethanol induces release of arachidonic acid but not synthesis of eicosanoids in mouse peritoneal macrophages. Biochim Biophys Acta. 921, 82-89

211 Smith, M. T. and Evans, C. G. (1984) Inhibitory effect of superoxide-generating quinones on superoxide dismutase. Biochem Pharmacol. 33, 3109-3110

212 Suzuki, M., Kato, M., Hanaka, H., Izumi, T. and Morikawa, A. (2003) Actin assembly is a crucial factor for superoxide anion generation from adherent human eosinophils. J Allergy Clin Immunol. 112, 126-133

213 Mukherjee, G., Quinn, M. T., Linner, J. G. and Jesaitis, A. J. (1994) Remodeling of the plasma membrane after stimulation of neutrophils with $\mathrm{f}$-Met-Leu-Phe and dihydrocytochalasin $\mathrm{B}$ : identification of membrane subdomains containing NADPH oxidase activity. J Leukoc Biol. 55, 685-694

214 Chomczynski, P. and Sacchi, N. (1987) Single-step method of RNA isolation by acid guanidinium thiocyanate-phenol-chloroform extraction. Anal Biochem. 162, 156-159

215 Livak, K. J. and Schmittgen, T. D. (2001) Analysis of relative gene expression data using realtime quantitative PCR and the 2(-Delta Delta C(T)) Method. Methods. 25, 402-408

216 Pfaffl, M. W. (2001) A new mathematical model for relative quantification in real-time RTPCR. Nucleic Acids Res. 29, e45

217 Winstead, M. V., Balsinde, J. and Dennis, E. A. (2000) Calcium-independent phospholipase $A(2)$ : structure and function. Biochim Biophys Acta. 1488, 28-39

218 Balsinde, J., Perez, R. and Balboa, M. A. (2006) Calcium-independent phospholipase A2 and apoptosis. Biochim Biophys Acta. 1761, 1344-1350

219 Ambs, P., Baccarini, M., Fitzke, E. and Dieter, P. (1995) Role of cytosolic phospholipase A2 in arachidonic acid release of rat-liver macrophages: regulation by $\mathrm{Ca} 2+$ and phosphorylation. Biochem J. 311 ( Pt 1), 189-195

220 Ono, T., Yamada, K., Chikazawa, Y., Ueno, M., Nakamoto, S., Okuno, T. and Seno, K. (2002) Characterization of a novel inhibitor of cytosolic phospholipase A2alpha, pyrrophenone. Biochem J. 363, 727-735

221 Balsinde, J. and Dennis, E. A. (1997) Function and inhibition of intracellular calciumindependent phospholipase A2. J Biol Chem. 272, 16069-16072

222 Balboa, M. A. and Insel, P. A. (1998) Stimulation of phospholipase D via alpha1-adrenergic receptors in Madin-Darby canine kidney cells is independent of PKCalpha and -epsilon activation. Mol Pharmacol. 53, 221-227

223 Rouzer, C. A. and Marnett, L. J. (2005) Glycerylprostaglandin synthesis by resident peritoneal macrophages in response to a zymosan stimulus. J Biol Chem. 280, 26690-26700

224 Aderem, A. A., Cohen, D. S., Wright, S. D. and Cohn, Z. A. (1986) Bacterial lipopolysaccharides prime macrophages for enhanced release of arachidonic acid metabolites. J Exp Med. 164, 165-179 
225 Chilton, F. H. and Murphy, R. C. (1987) Stimulated production and natural occurrence of 1,2-diarachidonoylglycerophosphocholine in human neutrophils. Biochem Biophys Res Commun. 145, 1126-1133

226 Di Marzo, V., De Petrocellis, L., Sugiura, T. and Waku, K. (1996) Potential biosynthetic connections between the two cannabimimetic eicosanoids, anandamide and 2arachidonoyl-glycerol, in mouse neuroblastoma cells. Biochem Biophys Res Commun. 227, 281-288

227 Ozaki, S., DeWald, D. B., Shope, J. C., Chen, J. and Prestwich, G. D. (2000) Intracellular delivery of phosphoinositides and inositol phosphates using polyamine carriers. Proc Natl Acad Sci U S A. 97, 11286-11291

228 Sugimoto, H. and Yamashita, S. (1999) Characterization of the transacylase activity of rat liver 60-kDa lysophospholipase-transacylase. Acyl transfer from the sn-2 to the sn-1 position. Biochim Biophys Acta. 1438, 264-272

229 Buczynski, M. W., Svensson, C. I., Dumlao, D. S., Fitzsimmons, B. L., Shim, J. H., Scherbart, T. J., Jacobsen, F. E., Hua, X. Y., Yaksh, T. L. and Dennis, E. A. (2010) Inflammatory hyperalgesia induces essential bioactive lipid production in the spinal cord. J Neurochem. 114, 981-993

230 Lamaziere, A. and Wolf, C. (2010) Phosphatidylcholine and PPARalpha: a relevant connection in liver disease? Gastroenterol Clin Biol. 34, 250-251

231 Chakravarthy, M. V., Lodhi, I. J., Yin, L., Malapaka, R. R., Xu, H. E., Turk, J. and Semenkovich, C. F. (2009) Identification of a physiologically relevant endogenous ligand for PPARalpha in liver. Cell. 138, 476-488

232 Barroso, E., Rodriguez-Calvo, R., Serrano-Marco, L., Astudillo, A. M., Balsinde, J., Palomer, X. and Vazquez-Carrera, M. (2011) The PPARbeta/delta activator GW501516 prevents the down-regulation of AMPK caused by a high-fat diet in liver and amplifies the PGC-1alphaLipin 1-PPARalpha pathway leading to increased fatty acid oxidation. Endocrinology. 152, 1848-1859

233 Fournier, T., Fadok, V. and Henson, P. M. (1997) Tumor necrosis factor-alpha inversely regulates prostaglandin D2 and prostaglandin E2 production in murine macrophages. Synergistic action of cyclic AMP on cyclooxygenase-2 expression and prostaglandin E2 synthesis. J Biol Chem. 272, 31065-31072

234 Shinomiya, S., Naraba, H., Ueno, A., Utsunomiya, I., Maruyama, T., Ohuchida, S., Ushikubi, F., Yuki, K., Narumiya, S., Sugimoto, Y., Ichikawa, A. and Oh-ishi, S. (2001) Regulation of TNFalpha and interleukin-10 production by prostaglandins $\mathrm{I}(2)$ and $E(2)$ : studies with prostaglandin receptor-deficient mice and prostaglandin E-receptor subtype-selective synthetic agonists. Biochem Pharmacol. 61, 1153-1160

235 Gerosa, F., Baldani-Guerra, B., Lyakh, L. A., Batoni, G., Esin, S., Winkler-Pickett, R. T., Consolaro, M. R., De Marchi, M., Giachino, D., Robbiano, A., Astegiano, M., Sambataro, A., Kastelein, R. A., Carra, G. and Trinchieri, G. (2008) Differential regulation of interleukin 12 and interleukin 23 production in human dendritic cells. J Exp Med. 205, 1447-1461

236 Rouzer, C. A., Ivanova, P. T., Byrne, M. O., Brown, H. A. and Marnett, L. J. (2007) Lipid profiling reveals glycerophospholipid remodeling in zymosan-stimulated macrophages. Biochemistry. 46, 6026-6042

237 Sato, S., Nomura, F., Kawai, T., Takeuchi, O., Muhlradt, P. F., Takeda, K. and Akira, S. (2000) Synergy and cross-tolerance between toll-like receptor (TLR) 2- and TLR4-mediated signaling pathways. J Immunol. 165, 7096-7101

238 Paul-Clark, M. J., McMaster, S. K., Belcher, E., Sorrentino, R., Anandarajah, J., Fleet, M., Sriskandan, S. and Mitchell, J. A. (2006) Differential effects of Gram-positive versus Gramnegative bacteria on NOSII and TNFalpha in macrophages: role of TLRs in synergy between the two. Br J Pharmacol. 148, 1067-1075 
239 Bagchi, A., Herrup, E. A., Warren, H. S., Trigilio, J., Shin, H. S., Valentine, C. and Hellman, J. (2007) MyD88-dependent and MyD88-independent pathways in synergy, priming, and tolerance between TLR agonists. J Immunol. 178, 1164-1171

240 Doerfler, M. E., Weiss, J., Clark, J. D. and Elsbach, P. (1994) Bacterial lipopolysaccharide primes human neutrophils for enhanced release of arachidonic acid and causes phosphorylation of an 85-kD cytosolic phospholipase A2. J Clin Invest. 93, 1583-1591

241 Tessner, T. G., Greene, D. G. and Wykle, R. L. (1990) Selective deacylation of arachidonatecontaining ethanolamine-linked phosphoglycerides in stimulated human neutrophils. J Biol Chem. 265, 21032-21038

242 Levy, R. (2006) The role of cytosolic phospholipase A2-alfa in regulation of phagocytic functions. Biochim Biophys Acta. 1761, 1323-1334

243 Rubinek, T. and Levy, R. (1993) Arachidonic acid increases the activity of the assembled NADPH oxidase in cytoplasmic membranes and endosomes. Biochim Biophys Acta. 1176, 51-58 